\title{
DYNAMIC ANALYSIS OF A BIOFILTER TREATING ATAD OFF GASES AND DYNAMIC MODEL DEVELOPMENT
}

\author{
by \\ Balasubramaniam Shanchayan \\ M. Eng. (NUS), B.Sc. Eng. (Peradeniya)
}

A thesis submitted to the Faculty of Graduate Studies and Research

In partial fulfillment of the requirements for the Degree of

Doctor of Philosophy
Department of Civil and Environmental Engineering Carleton University
Ottawa, Ontario

C Copyright 2006

B. Shanchayan

The Doctor of Philosophy in Environmental Engineering Program is a joint program with the University of Ottawa, administered by the Ottawa-Carleton Institute for Environmental Engineering 


$\begin{array}{ll}\begin{array}{l}\text { Library and } \\ \text { Archives Canada }\end{array} & \begin{array}{l}\text { Bibliothèque et } \\ \text { Archives Canada }\end{array} \\ \begin{array}{l}\text { Published Heritage } \\ \text { Branch }\end{array} & \begin{array}{l}\text { Direction du } \\ \text { Patrimoine de l'édition }\end{array} \\ \begin{array}{l}\text { 395 Wellington Street } \\ \text { Ottawa ON K1A 0N4 }\end{array} & \begin{array}{l}\text { 395, rue Wellington } \\ \text { Ottana ON K1A ON4 } \\ \text { Canada Oa }\end{array}\end{array}$

Your file Votre référence ISBN: 978-0-494-16677-2 Ourfile Notre référence ISBN: 978-0-494-16677-2

NOTICE:

The author has granted a nonexclusive license allowing Library and Archives Canada to reproduce, publish, archive, preserve, conserve, communicate to the public by telecommunication or on the Internet, loan, distribute and sell theses worldwide, for commercial or noncommercial purposes, in microform, paper, electronic and/or any other formats.

The author retains copyright ownership and moral rights in this thesis. Neither the thesis nor substantial extracts from it may be printed or otherwise reproduced without the author's permission.
AVIS:

L'auteur a accordé une licence non exclusive permettant à la Bibliothèque et Archives Canada de reproduire, publier, archiver, sauvegarder, conserver, transmettre au public par télécommunication ou par l'Internet, prêter, distribuer et vendre des thèses partout dans le monde, à des fins commerciales ou autres, sur support microforme, papier, électronique et/ou autres formats.

L'auteur conserve la propriété du droit d'auteur et des droits moraux qui protège cette thèse. $\mathrm{Ni}$ la thèse ni des extraits substantiels de celle-ci ne doivent être imprimés ou autrement reproduits sans son autorisation.
In compliance with the Canadian

Privacy Act some supporting forms may have been removed from this thesis.

While these forms may be included in the document page count, their removal does not represent any loss of content from the thesis.
Conformément à la loi canadienne sur la protection de la vie privée, quelques formulaires secondaires ont été enlevés de cette thèse.

Bien que ces formulaires aient inclus dans la pagination, il n'y aura aucun contenu manquant. 


\title{
DYNAMIC ANALYSIS OF A BIOFILTER TREATING ATAD OFF GASES AND DYNAMIC MODEL DEVELOPMENT
}

\author{
B. Shanchayan \\ Department of Civil and Environmental Engineering \\ Carleton University, Ottawa, ON
}

\begin{abstract}
Autothermal thermophilic aerobic digestion (ATAD) is a sludge treatment process that can produce high quality biosolids. However, the ATAD process has been found to generate odours that can cause complaints from people living downwind of a wastewater treatment facility. The ATAD process emits relatively high quantities of ammonia $\left(\mathrm{NH}_{3}\right)$ and reduced sulfur compounds (RSC). Therefore, further treatment of the off gases is required prior to venting. Biofiltration has become a preferred treatment option because of its low operating costs. There is little information to describe how a biofilter responds biologically and chemically to the dynamic loading of complex mixtures of odorous contaminants that are present in ATAD off gases.
\end{abstract}

The treatment of ATAD off gases in biofilters was evaluated under controlled conditions. The full scale study was conducted at the wastewater treatment plant, McMinnville, Oregon. The pilot scale studies employed an ATAD/biofilter pilot plant that was located at the Robert O. Pickard Environmental Centre (ROPEC), Ottawa, Ontario. Temperature was observed to have a substantial impact on nitrification in the biofilter but had little impact on the removal of RSC's. The source of post-humidification water (potable vs. plant) did not appear to influence the performance of the biofilter. Increasing the leachate $\mathrm{pH}$ in the biofilter did not appear to affect either the rate of nitrification or the 
rate of oxidation of RSC. The elimination capacity of $\mathrm{RSC}$ and $\mathrm{NH}_{3}$ did not appear to be exceeded over the range of loadings examined in this study. However, the high $\mathrm{NH}_{3}$ loading changed the removal mechanism. The results indicate that the biofilter bed temperature enhanced the nitrification, whereas more contact time was needed to accommodate the nitrification process.

A dynamic model was developed to establish a mathematical description of processes (physical, chemical and biological) important in dynamic biofiltration. This is the first attempt to develop a dynamic biofilter model for a mixture of two distinct chemical compounds $\left(\mathrm{NH}_{3}\right.$ and $\left.\mathrm{RSC}\right)$. The dynamic biofilter model, which was incorporated into the AQUASIM program, was calibrated with pilot biofilter data. The model simulation agreed well with the experimental data. 


\section{ACKNOWLEDGEMENT}

Sincere gratitude is expressed to my thesis supervisor, Associate Professor Wayne Parker, Department of Civil Engineering, University of Waterloo, for giving me the opportunity to conduct this study, and for his valuable guidance in completing this thesis. The NSERC (Natural Sciences and Engineering Research Council of Canada) is gratefully acknowledged for their funding for this study. I would like to register my sincere appreciation of Ambio Biofiltration Inc. and Thermo Process Inc. for their supply of pilot plant reactors. I would also like to thank Dr. Calvin Pride, Ambio Biofiltration Inc., for his frequent feedback regarding the biofilter.

My deep appreciation is expressed to the staff at the Robert O. Pickard Environmental Centre (ROPEC), Ottawa, especially Mr. Benoit Labeau and the Process Technologists for their kind help while I was running the pilot rectors at ROPEC. I would also like to thank the staff at the McMinnville water reclamation facility, Oregon, for allowing us to study the full scale ATAD and biofilter systems. I would particularly like to thank Mr. P. Logeswaran and Mr. L. Shingie for their assistance in helping me with 24-hours sampling events. I would like to thank Associate Professor Robert Burk, Department of Chemistry, Carleton University, who made valuable suggestions for the GC analysis. I would also like to thank Laboratory Technologists at the Civil and Environmental Engineering Laboratories, Carleton University.

At this time, I would also like to acknowledge the support of my parents and teachers. Finally but not least, my deepest gratitude is expressed to all my friends in Ottawa for their unlimited love, understanding and support. 


\author{
ABSTRACT \\ ACKNOWLEDGENENT \\ TABLE OF CONTENTS \\ NOMENCLATURE \\ LIST OF FIGURES \\ LIST OF TABLES
}

$\frac{\text { Page }}{\text { ii }}$
iv
v
viii
ix
xi

\section{Chapter One Introduction}

1.1 Motivation

1.2 Objectives of this study

1.3 Outline of dissertation

Chapter Two Literature Review

2.1 ATAD process and application 5

2.1.1 Introduction $\quad 5$

2.1.2 ATAD process $\quad 7$

2.1.2.1 Biological reactions in a ATAD system 10

$\begin{array}{ll}\text { 2.1.2.2 Off gases from a ATAD system } & 14\end{array}$

$\begin{array}{llr}2.2 & \text { Biofiltration Process } & 18\end{array}$

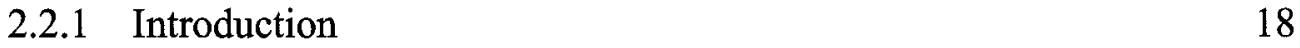

$\begin{array}{ll}\text { 2.2.2 Biofiltration for mixed gases } & 20\end{array}$

$\begin{array}{ll}\text { 2.2.2.1 Removal of reduced sulfur compounds } & 21\end{array}$

$\begin{array}{ll}\text { 2.2.2.2 Removal of ammonia } & 24\end{array}$

2.2.2.3 Treatment of mixtures of $\mathrm{RSC}$ and $\mathrm{NH}_{3} \quad 27$

$\begin{array}{lll}2.3 & \text { Biotreatment mechanisms } & 30\end{array}$

$\begin{array}{ll}\text { 2.3.1 Ammonia treatment mechanisms } & 30\end{array}$

2.3.2 Reduced sulfur compounds treatment mechanisms

$\begin{array}{lll}2.4 & \text { Factors affecting biofilter performance } & 40\end{array}$

$\begin{array}{lll}2.4 .1 & \text { Biofulter media } & 40\end{array}$

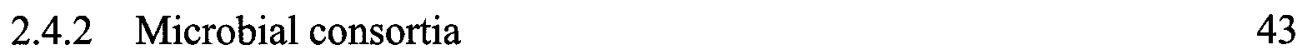

2.4.3 Essential environmental conditions $\quad 44$

$\begin{array}{lll}2.5 & \text { Models } & 47\end{array}$

Chapter Three Preliminary Full-scale Study

$\begin{array}{llr}3.1 & \text { Introduction } & 59\end{array}$

$\begin{array}{ll}3.2 & \text { Materials and methods }\end{array}$ 
$\begin{array}{ll}3.2 .1 & \text { Existing system setup }\end{array}$

$\begin{array}{ll}\text { 3.2.2 Gas sampling and analysis } & 62\end{array}$

$\begin{array}{ll}\text { 3.2.3 Liquid sampling and analysis } & 65\end{array}$

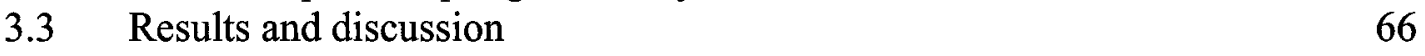

$\begin{array}{lll}\text { 3.3.1 Gas phase analysis } & 66\end{array}$

$\begin{array}{lll}\text { 3.3.2 Liquid phase analysis } & 73\end{array}$

$\begin{array}{ll}\text { 3.3.3 Nitrogen and sulfur mass balances } & 76\end{array}$

$\begin{array}{lll}3.4 & \text { Conclusions } & 78\end{array}$

\section{Chapter Four The Pilot Scale Study: Materials and Methodology}

$\begin{array}{lll}4.1 & \text { Introduction } & 81\end{array}$

4.2 Experimental approach $\quad 81$

4.2.1 Pilot scale studies on ATAD and biofilter system 82

4.2.2 Experimental plan for the pilot study $\quad 84$

$\begin{array}{ll}\text { 4.2.3 Gas sampling and analysis } & 85\end{array}$

4.2.4 Liquid sampling and analysis $\quad 88$

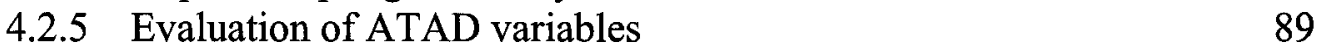

4.2.6 Evaluation of biofilter variables $\quad 91$

$\begin{array}{lll}4.2 .7 & \text { Biofilter media analysis } & 93\end{array}$

$\begin{array}{lll}4.3 & \text { Standard preparation and calibration } & 94\end{array}$

$\begin{array}{lll}\text { 4.3.1 Gas phase standard preparation and calibration } & 94\end{array}$

$\begin{array}{ll}\text { 4.3.2 Liquid phase standard preparation and calibration } & 96\end{array}$

4.3.3 Air flow measurement corrections $\quad 97$

4.4 Quality control 98

Chapter Five The Pilot Scale Study: Results and Discussions

$\begin{array}{lll}5.1 & \text { Introduction } & 100\end{array}$

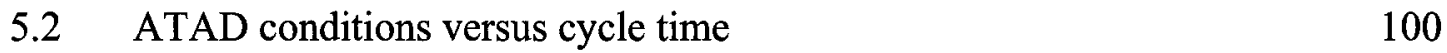

$\begin{array}{lll}5.3 & \text { Gas phase analysis } & 109\end{array}$

5.3.1 ATAD off gas analysis at the scrubber inlet 109

5.3.1.1 ATAD operating conditions versus gas production $\quad 110$

$\begin{array}{ll}\text { 5.3.1.2 Scrubber removal } & 115\end{array}$

$\begin{array}{ll}\text { 5.3.2 Dynamic gas loading on the biofilter } & 119\end{array}$

5.3.3 Peak concentrations and cumulative mass variations with
air flow rates

5.3.4 Off gas variation along the biofilter 129

5.3.5 N containing compounds other than $\mathrm{NH}_{3}$ gas 133

$\begin{array}{lll}5.4 & \text { Leachate analysis } & 134\end{array}$

5.5 S and N mass balance within the biofilter 141

$\begin{array}{lll}5.6 & \text { The effects on N compounds variations } & 144\end{array}$

5.6.1 The effects on nitrification process 144

5.6.2 The effects of $\mathrm{N}$ compound variations in the leachate 146 
5.6.2.1 Cooling down of water saturated off gases 147

5.6.2.2 Production of other $\mathrm{N}$ containing compounds 152

5.6.2.3 Effect of $\mathrm{NH}_{3}$ solubility in the presence of $\mathrm{CO}_{2} \quad 155$

5.6.3 Accumulation of $\mathrm{N}$ compound on the packing 159

$\begin{array}{lll}5.7 & \text { Effects of biofilter operating conditions on performance } & 160\end{array}$

$\begin{array}{lll}5.7 .1 & \text { Biofilter bed temperature } & 160\end{array}$

$\begin{array}{ll}\text { 5.7.2 Post humidification water } & 164\end{array}$

$\begin{array}{lll}\text { 5.7.3 Biofilter bed } \mathrm{pH} & 168\end{array}$

$\begin{array}{ll}\text { 5.7.4 Biofilter pollutant loading rate } & 172\end{array}$

Chapter Six Biofilter Model Development

$\begin{array}{lll}6.1 & \text { Introduction } & 176\end{array}$

$\begin{array}{lll}6.2 & \text { Model development } & 177\end{array}$

$\begin{array}{lll}\text { 6.2.1 } & \text { Model concept } & 177\end{array}$

6.2.2 Basic assumptions for a structured model development $\quad 180$

$\begin{array}{ll}\text { 6.2.3 Contaminants analysis: governing equations } & 181\end{array}$

$\begin{array}{ll}\text { 6.2.4 Contaminants degradation } & 182\end{array}$

6.3 The dynamic model calibration and sensitivity analysis 188

$\begin{array}{ll}\text { 6.3.1 Sensitivity analysis } & 188\end{array}$

$\begin{array}{ll}\text { 6.3.2 Dynamic model calibration } & 191\end{array}$

$\begin{array}{lll}6.4 & \text { Results and discussion } & 201\end{array}$

$\begin{array}{ll}6.5 & \text { Conclusions } \\ \end{array}$

Chapter Seven Overall Conclusions and Recommendations

$\begin{array}{lll}7.1 & \text { Conclusions } & 207\end{array}$

$\begin{array}{ll}7.2 & \text { Recommendations } \\ & 210\end{array}$

$\begin{array}{lr}\text { REFERENCES } & 212\end{array}$

$\begin{array}{lll}\text { Appendix A Experimental schedule and operating conditions } & 227\end{array}$

$\begin{array}{lll}\text { Appendix B } & \text { ATAD off gas characterization } & 230\end{array}$

$\begin{array}{lll}\text { Appendix C Gas phase RSCs calibration data } & 237\end{array}$

$\begin{array}{lll}\text { Appendix D } & \text { Aqueous sample calibration data } & 238\end{array}$

Appendix E Estimation of reactor dimensions in the model development $\quad 239$

Appendix F The sampling events data (included on a CD-Rom) 


\section{NOMENCLATURE}

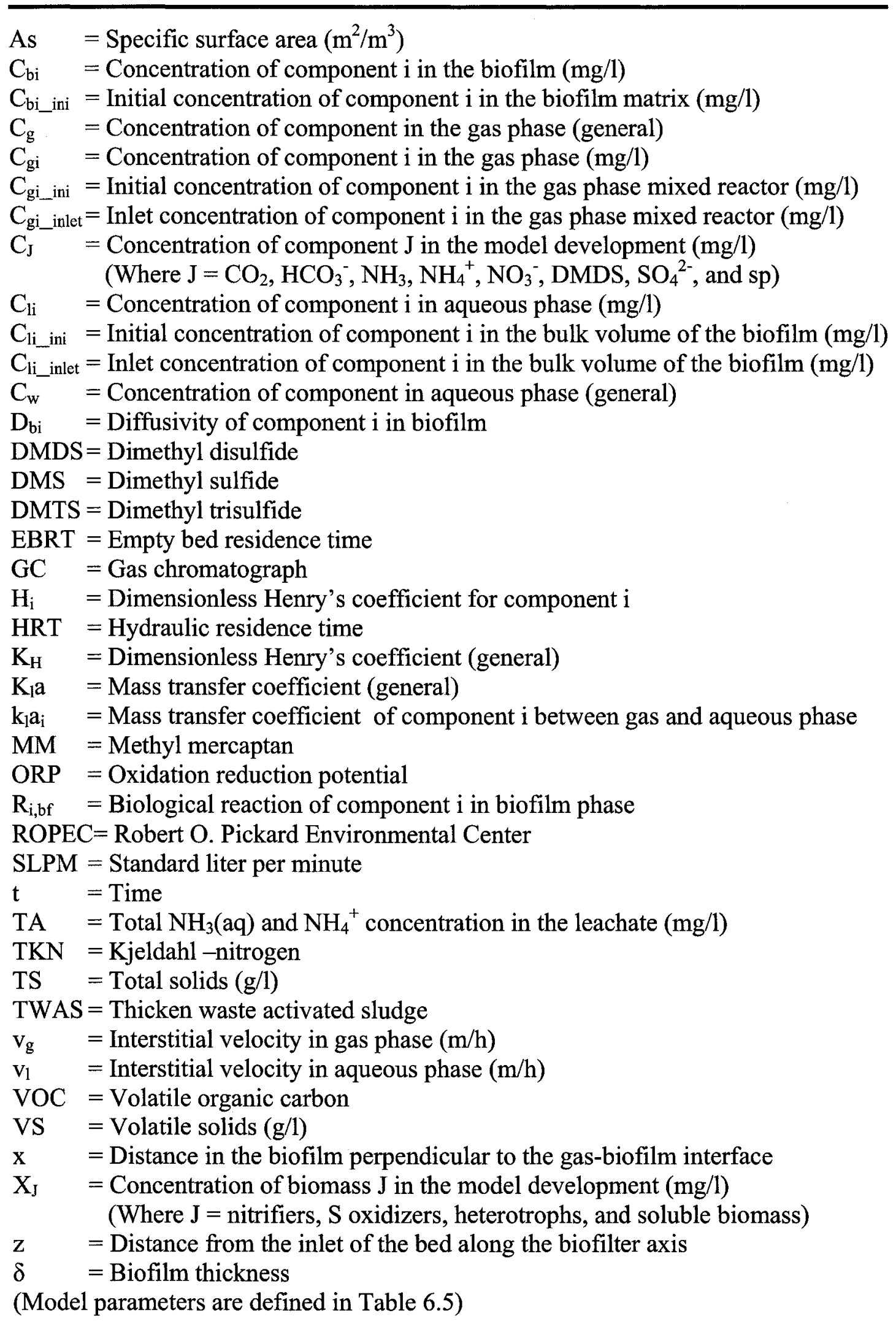




\section{List of Figures}

Figure

Description

Page

$\begin{array}{lll}2.1 & \text { Schematic diagram of ATAD } & 7\end{array}$

$\begin{array}{ll}2.2 & \text { Biological reactions in ATAD system } \\ 2.3 & 13\end{array}$

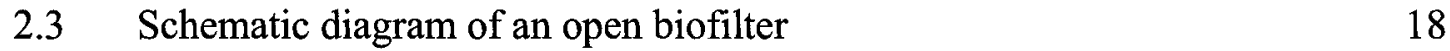

$2.4 \quad$ Biofilter setup used by Sun et al. (2000) 28

2.5 Microbiological nitrogen transformations and oxidation states 33

2.6 Assumed mechanism for oxidation of DMDS 36

$\begin{array}{lll}2.7 & \text { Assumed mechanism for oxidation of DMS } & 37\end{array}$

2.8 The biophysical model for the biological filter bed 50

2.9 Structure considered for finite differencing in the biofilter model 53

2.10 Biofilm model representation by Alonso et al. (1998) 55

2.11 Biofilm model representation by Li et al. (2002) 56

3.1 Schematic overview of the ATAD digesters feeding pathways 60

$\begin{array}{lll}3.2 & \text { Plan view of the biofilter } & 61\end{array}$

3.3 Gas phase concentrations of $\mathrm{NH}_{3}$ and $\mathrm{H}_{2} \mathrm{~S}$ at the scrubber inlet 67

3.4 Gas phase concentrations of $\mathrm{NH}_{3}$ and $\mathrm{H}_{2} \mathrm{~S}$ at the biofilter inlet 67

3.5 Gas phase concentrations of MM, DMS and DMDS at the biofilter inlet 68

3.6 Gas phase concentrations of $\mathrm{NH}_{3}$ and $\mathrm{H}_{2} \mathrm{~S}$ at the headspace of the $\begin{array}{ll}\text { ATAD reactors } & 69\end{array}$

3.7 The digester temperature variation during one cycle 70

3.8 Removal efficiencies variations along the cycle in the biofilter 72

Concentrations of $\mathrm{SO}_{4}{ }^{2-}, \mathrm{NH}_{3}-\mathrm{N}, \mathrm{NO}_{3}{ }^{-}-\mathrm{N}$ and $\mathrm{NO}_{2}{ }^{-}-\mathrm{N}$ in leachate
samples

3.10 Biofilter leachate $\mathrm{pH}$ vs. cycle time $\quad 75$

4.1 Schematic diagram of proposed pilot scale ATAD and biofilter system $\quad 82$

4.2 The pilot scale ATAD and biofilter system at the ROPEC 83

5.2.1 ORP value variations along the cycle within the ATAD 101

5.2.2 The digester temperature variation during one cycle 103

5.2.3 ATAD temperature, airflow rate and sludge loading rate variations $\quad 104$

5.2.4 ATAD temperature Vs. (a) airflow rates and (b) sludge loading rate 106

5.2.5 Total and volatile solids destruction in the ATAD 108

$\begin{array}{lll}\text { 5.3.1 ATAD off gas variation at the scrubber inlet } & 109\end{array}$

5.3.2 Production of ATAD off gases related to ORP, airflow, sludge loading, and ATAD temperature

5.3.3 The scrubber removal efficiency vs. gas retention time 116

$\begin{array}{lll}\text { 5.3.4 Schematic diagram of a scrubber } & 116\end{array}$

5.3.5 Odorant concentrations at biofilter inlet (a)DMDS, (b)DMS, (c)MM, (d)DMTS, (e) $\mathrm{NH}_{3}$

$\begin{array}{lll}\text { 5.3.6 } & \mathrm{CO} 2 \text { gas concentration variation } & 123\end{array}$ 
5.3.7 Maximum concentrations of RSCs at (a) scrubber inlet (b) biofilter inlet (c) biofilter outlet

5.3.8 Cumulative mass of RSCs at (a) scrubber inlet, (b) biofilter inlet, (c) biofilter outlet

5.3.9 Maximum concentrations and cumulative mass of $\mathrm{NH}_{3}$ at three sampling ports

5.3.10 Off gas concentrations along the biofilter in Case 1

5.4.1 Scrubber leachate variations versus time with corresponding gas phase pollutant loading

5.4.2 Case 1: Concentrations of $\mathrm{SO}_{4}{ }^{2-}, \mathrm{NH}_{4}{ }^{+}, \mathrm{NO}_{3}{ }^{-}, \mathrm{NO}_{2}{ }^{-}$in the biofilter leachate and corresponding gas phase concentrations

5.4.3 Case 2: Concentrations of $\mathrm{SO}_{4}{ }^{2-}, \mathrm{NH}_{4}{ }^{+}, \mathrm{NO}_{3}{ }^{-}, \mathrm{NO}_{2}{ }^{-}$in the biofilter leachate and corresponding gas phase concentrations

5.4.4 The variation of $\mathrm{pH}$ in the biofilter leachate (a) case 1 (b) case $2 \quad 139$

5.4.5 Concentration of $\mathrm{NH}_{4}{ }^{+}$and TKN along the cycle

5.6.1 The effects of temperature and EBRT on the nitrification

5.6.2 The predicted $\mathrm{NH}_{4}{ }^{+}$concentrations versus time after adding condensed $\mathrm{NH}_{3}$ mass into the scrubber feed water

5.6.3 The predicted $\mathrm{NH}_{4}{ }^{+}$concentrations versus time after adding condensed $\mathrm{NH}_{3}$ mass into the biofilter feed water

152

5.6.4 Conceptual model diagram for $\mathrm{NH}_{3}-\mathrm{CO}_{2}-\mathrm{H}_{2} \mathrm{O}$ system 157

5.7.1 Concentrations of (a) $\mathrm{NH}_{4}^{+}$(b) $\mathrm{NO}_{3}{ }^{-}$(c) net $\mathrm{SO}_{4}{ }^{2-}$ (d) $\mathrm{pH}$ at the biofilter leachate for the warm versus cold bed

5.7.2 Effect of bed temperature on biofilter performance 163

5.7.3 Feed water and biofilter leachate $\mathrm{pH}$ with (a) plant water and (b) potable water

5.7.4 Biofilter leachate concentrations of (a) $\mathrm{NH}_{4}{ }^{+}$(b) net $\mathrm{NO}_{3}{ }^{-}$

(c) net $\mathrm{SO}_{4}{ }^{2-}$ for potable and plant water

5.7.5 Source of post humidification effects on different biofilter operating Conditions

5.7.6 Biofilter leachate $\mathrm{pH}$ values for different packing conditions $\quad 170$

5.7.7 Leachate mass flows of (a) $\mathrm{NO}_{3}^{-}$(b) net $\mathrm{SO}_{4}{ }^{2-}$ for different packing conditions

5.7.8 The packing conditions effects on different biofilter operating conditions 172

$\begin{array}{lll}\text { 5.7.9 Biofilter pollutant loading effects for different operating conditions } & 174\end{array}$

6.1 Schematic representations of model concepts 178

6.2 Schematic representations of model for one layer 179

6.3 Gas phase results: experimental data vs. model prediction 201

6.4 Leachate results: experimental data vs. model prediction 203

6.5 Leachate $\mathrm{pH}$ : experimental data vs. model prediction 205 


\section{List of Tables}

\section{Table}

2.1 Odour substances in the ATAD off gas stream 15

2.2 Henry's law coefficients for the off gas compounds 16

2.3 Maximum concentrations of odorous compounds from ATAD system 17

2.4 Removal rate constants for RSC in a peat biofilter 22

2.5 Reduced sulfur compound studies in the literature 23

2.6 Biofilter $\mathrm{NH}_{3}$ removal studies in the literature 25

2.7 Long term $\mathrm{NH}_{3}$ treatment in a pilot plant 27

2.8 Combined $\mathrm{NH}_{3}$ and $\mathrm{RSC}$ removal studies $\quad 29$

2.9 Summery of biofilter model studies in literature and their main features $\quad 48$

$\begin{array}{lll}3.1 & \text { Gas sampling summery } & 62\end{array}$

$\begin{array}{lll}3.2 & \text { GC conditions } & 64\end{array}$

3.3 Gas phase detection limits for each compound 64

$\begin{array}{lll}3.4 & \text { Mean removal efficiency of the systems } & 72\end{array}$

$\begin{array}{ll}3.5 & \text { Literature comparison of removal rates }\end{array}$

$\begin{array}{lll}3.6 & \text { Nitrogen mass balance within the biofilter } & 77\end{array}$

$\begin{array}{lll}3.7 & \text { Sulfur mass balance within the biofilter } & 77\end{array}$

$\begin{array}{lll}\text { 4.2.1 Experimental variable } & 84\end{array}$

4.2.2 Experimental conditions for the biofilter 85

4.2.3 Biofilter experimental variable combination 85

$\begin{array}{lll}\text { 4.2.4 GC conditions } & 88\end{array}$

4.2.5 Gas phase detection limits for each compound 88

4.3.1 Characteristics of permeation tubes for target compounds 95

$\begin{array}{lll}\text { 4.3.2 IC standard stock solution } & 97\end{array}$

4.3.3 Rotameter vs. anemometer readings 98

5.3.1 ATAD gas production versus sludge loading $\quad 114$

$\begin{array}{ll}\text { 5.3.2 Removal efficiencies in the scrubber } & 119\end{array}$

5.3.3 Case 1: total mass of S and N removal along the biofilter 130

5.3.4 Case 2: total mass of S and N removal along the biofilter 130

5.4.1 The ATAD and the biofilter conditions for the leachate analysis 136

$\begin{array}{ll}\text { 5.5.1 S mass balance within the biofilter } & 142\end{array}$

5.5.2 N mass balance within the biofilter 143

$\begin{array}{ll}\text { 5.6.1 Henry's law coefficient variation for scrubber condition } & 149\end{array}$

5.6.2 Condensed vapour water vs. temperature for the scrubber condition $\quad 149$

5.6.3 $\mathrm{NH}_{4}^{+}$concentration after the off gas condensed in to the potable
feed water of the scrubber

5.6.4 $\mathrm{NH}_{4}{ }^{+}$concentration after the off gas condensed in to the plant feed $\begin{array}{ll}\text { water of the scrubber } & 149\end{array}$

$\begin{array}{ll}\text { 5.6.5 Henry's law coefficient variation for biofilter condition } & 150\end{array}$

5.6.6 Condensed vapour water vs. temperature for the biofilter condition $\quad 150$ 
5.6.7 $\mathrm{NH}_{4}{ }^{+}$concentration after the off gas condensed in to the potable feed water of the biofilter

5.6.8 $\mathrm{NH}_{4}{ }^{+}$concentration after the off gas condensed in to the plant feed water of the biofilter

5.7.1 Selected biofilter conditions for the bed temperature study

5.7.2 Selected biofilter conditions for the source of post humidification study

5.7.3 Selected biofilter conditions for the packing effects study

5.7.4 Selected biofilter conditions for the pollutant loading study

6.1 A summary of processes and rate equations used in the model 185

6.2 The model process and stoichiometric matrix

6.3 Sensitivity results and corresponding significant parameters

6.4 Biofilter loading for the model calibration

6.5 Suggested parameter values for the dynamic biofilter model

6.6 Biofilter inlet conditions

6.7 Mass balance details

Al Pilot study sampling events and corresponding operating conditions 


\section{Chapter \\ One}

\section{Introduction}

\subsection{Motivation}

As a result of population growth and new legislation to control water pollution, sludge production is increasing worldwide. At the same time, there are increasing concerns with sludge disposal and land application. There are many sludge treatment processes currently used in the world. A recently developed technology is the autothermal thermophilic aerobic digestion (ATAD) process. Since the ATAD process is relatively new, there are limited plants currently using this technology in North America. The ATAD process has many advantages including high disinfection potential, low space and volume requirements, significant loss of organic matter, and the treated sludge can be applied to land with minimal or no management restrictions for pathogen control (McFarland, 2001). However, the ATAD process itself generates odours and has the potential for complaints from people living downwind of a wastewater treatment facility (Pride, 2002). Due to ATAD processes, relatively high amounts of ammonia $\left(\mathrm{NH}_{3}\right)$ and reduced sulfur compounds (RSC) such as hydrogen sulfide $\left(\mathrm{H}_{2} \mathrm{~S}\right)$, methyl mercaptan (MM), dimethyl sulfide (DMS), carbon disulfide $\left(\mathrm{CS}_{2}\right)$, dimethyl disulfide (DMDS) dimethyl trisulfide (DMTS) are released (Hepner et al., 2002). Therefore, further treatment is required prior to venting. 
Technologies that have been employed to treat offgases from wastewater treatment facilities include acid/base scrubbers, incineration, bioscrubbers and biofilters. Among these options, biofiltration is a relatively new technology and can effectively treat ATAD offgases. Biofiltration has become a preferred option because of its low operating costs. The ATAD operations generate odor nuisance, subsequently the biofilter treatment of these offgases eliminate the odor effectively.

It has been a century since biofiltration was first utilized for air pollution abatement. However, until the early 1980 's, its underlying fundamental principles of operation were not well-understood. The first notable attempt to illustrate and quantify the biofiltration process was made by Ottengraf and Oever (1983). Since then, there have been a number of studies that have concentrated on biofilter performance, operating kinetics and model development. Most traditional biofilter models assume that the biofilter reaches steady state (Devinny et al., 1999). Changes in biofilter performance with time due to variations in the amount of biomass present in the system have been developed more recently. Most recently, dynamic models that describe the mass transport and attenuation of odor causing air emissions in a biofiltration unit have been reported by Li et al., (2002).

Most biofilter studies have involved single pollutants. For example, there have been a number of studies on $\mathrm{NH}_{3}$ and reduced sulfur compounds separately. However, relatively few studies have reported on biofiltration of mixed gases such as ATAD offgases. In addition, these biofilter studies have involved either steady state or transient conditions, where the inlet gas composition and concentration are almost stable with time. However 
ATAD offgases vary in composition with time on a repeating interval (Staton et al., 2002). The combination of an ATAD system and a biofiltration system has had mixed success in recent years (Pride, 2002). There is little information to describe the behavior of biofilters treating an air stream that varies in composition on a regularly repeating basis.

Most of the studies on biofiltration have concentrated on medium choice, retention time, control of operating parameters and capital costs (Devinny et al., 1999). Few studies have reported on chemical accumulation of substances and chemical and biological byproducts in the biofilter media. Some mathematical models were developed to describe the activity of particular chemicals based on their pollutants in the biofilter (Devinny et al., 1999).

In summary, even though a number of studies have been performed on biofiltration, there are limited studies on mixed gas pollutants such as ATAD off gases. Also there is little information to describe the behavior of biofilters treating an air stream that varies in composition on a regularly repeating basis.

\subsection{Objective of this study}

Based on above motivations, the main objective of this research is to identify the dynamic variations in a biofilter which is treating ATAD offgases and their removal mechanisms. The specific tasks leading to the above objective are to: 
- Perform a full-scale field study to characterize ATAD offgases and understand the treatment mechanisms that are responsible for biofilter performance. This preliminary study is to evaluate the effectiveness of the biofilter for the treatment of ATAD offgases.

- Characterize the dynamic variations of ATAD offgases in and out of a pilot scale biofilter. Based on experiences from the full scale study, the pilot scale ATAD and biofilter studies were organized.

- Analyze the chemical accumulations of substances and mass balances of sulfur (S) and nitrogen $(\mathrm{N})$ within the biofilter.

- Develop a dynamic model to describe the biofilter performance and use the model to conduct parameter sensitivity studies and to check their validity through experimental results.

\subsection{Outline of dissertation}

This dissertation provides an overview of the ATAD and biofiltration technologies. This background information as well as a review of past studies on both systems is summarized in Chapter Two. Chapter Three discusses a preliminary study that was conducted at the McMinnville water reclamation facility. Chapter Four describes the materials and methodology that were used in the pilot scale study. Chapter Five describes and discusses the results of the pilot scale study. Chapter Six describes the development of a dynamic model of a biofilter system. Chapter Six also describes sensitivity analysis for the dynamic model and simulation results. Finally, Chapter Seven describes the general conclusions and future research recommendations. 


\section{Chapter}

\section{Two}

\section{Literature Review}

\subsection{ATAD Process and Application}

\subsubsection{Introduction}

Digested sewage sludge (biosolids) has a value for its fertilizer and soil conditioning qualities. For this reason and because of its relatively low cost, the most widely used method for disposal of biosolids in Ontario is through land application. However increasing urbanization is making this less attractive especially for major cities. Also, there is increasing concern about the presence of pathogenic organisms in the biosolids that are generated in municipal wastewater treatment processes. This concern has lead to the development of a variety of alternative stabilization processes that can generate biosolids with reduced pathogen content.

Autothermal Thermophilic Aerobic Digestion (ATAD) is one of the processes that has been found to generate a very high quality biosolids. As stated in USEPA (1990), ATAD technology meets the current federal (U.S.) pathogen control requirements for land application of biosolids. In an ATAD system, the process operates under thermophilic temperature conditions without supplemental heat and relies on the heat released during digestion to attain and sustain the desired operating temperatures (LaPara and Alleman, 1998). Sludge at approximately $6 \%$ solids content is transferred to digesters, and then it is mixed and aerated in the digesters raising the temperature to over $60^{\circ} \mathrm{C}$ by biological energy. 
ATAD has been studied since 1960s and it was significantly developed since the mid 1970s (USEPA, 1990). By the 1980's many full-scale plants were operating in Europe and it is currently, widely and successfully implemented in Europe (Germany, Great Britain, Switzerland, Norway, France and Italy). Until the early 1990's no full-scale plants were reported operating in North America. The first North American ATAD reactor was built at the Salmon Arm Water Pollution Control Center (British Columbia, Canada) to stabilize municipal sludge (Kelly, 1990).

There are quite different design approaches used by the major ATAD system designers in North America. The ATAD systems that were developed in the early 90 s and mid 90 s are described as $1^{\text {st }}$ generation systems. These $1^{\text {st }}$ generation systems were built with multiple tanks in series (i.e., 2 or more), equipped with mechanical aerators that operated at a constant speed. Due to the lack of aeration and mixing substantial quantities of odorants were generated in these systems. In addition, these processes were not well received in North America because of relatively low volatile solids reduction and high dewatering costs. However, starting in the late $90 \mathrm{~s}$, there has been a number of new features introduced in ATAD designs. By providing high efficiency aeration and mixing systems, $2^{\text {nd }}$ generation ATAD systems were introduced. These ATAD units were designed with less complex reactors to improve the short comings which were observed in the $1^{\text {st }}$ generation ATAD systems (Scisson J.P., 2003; Staton et al., 2001). 


\subsubsection{ATAD process}

McFarland (2001) indicated that ATAD processes should have an adequately thickened sludge feed, suitably insulated digestion tanks, good mixing and an efficient aeration device that minimizes latent heat loss. As long as the system is well mixed and sufficient oxygen is provided, the temperature in the reactor will rise until a balance between heat generation and heat loss occurs.

In terms of operation, the system is usually either a batch or a semi-batch system. These systems ensure that the sludge has been retained in the reactor for long enough at the correct temperature to produce high quality biosolids. Figure 2.1 shows the configuration of an ATAD system. The ATAD reactors usually are cylindrical in shape and insulated to minimize the heat loss. Typical features include an aerator, mixer and foam breaker.

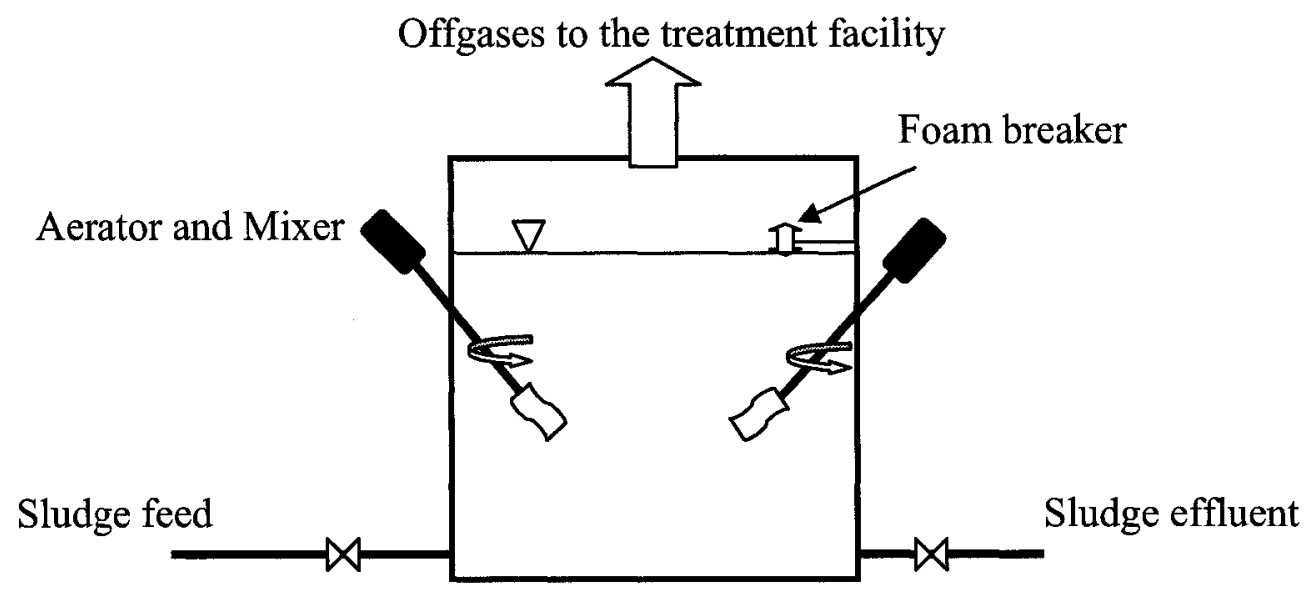

Figure 2.1 Schematic diagram of ATAD

Aeration and mixing are probably the two most important factors to consider when designing an ATAD system. A highly efficient aeration system is needed to supply 
sufficient oxygen to meet the high oxygen demand and minimize the latent heat loss that occurs when process air is exhausted (McFarland, 2001). Several types of aeration/mixing devices have been used with ATAD systems, including; aspirating aerators, combination recirculation pump/venturi arrangement and turbines and diffused air (WEF, 1995). The most common aeration system used in $1^{\text {st }}$ generation ATAD systems consisted of two or more aspirating aerators that were located around the digester. However this was modified to jet aeration with a recirculation pump in the $2^{\text {nd }}$ generation ATAD systems. The use of jet aeration with recirculation of sludge eliminated the mechanical mixer within the ATAD. The aeration rates in the ATAD were controlled to establish better environment to the microbial activities. At the same time optimum air flow rates reduce energy requirements and eliminate the cooling effects associated with excess aeration (Fothergill and Mavinic, 2000).

One of the key indicators of the effectiveness of aeration is to measure the dissolved oxygen (DO) concentration. It is generally accepted that the oxidation-reduction potential (ORP) value is an indirect measure of DO at concentrations that cannot be measured directly with oxygen probes. The ATAD sludge DO concentrations are relatively low or not measurable by general DO meters because of the high temperature. Therefore, the ORP is often monitored to evaluate the effectiveness of aeration in ATADs (Kelly, 1990).

Most of the ATAD systems $\left(1^{\text {st }}\right.$ generation ATADs) in wastewater treatment facilities consist of two or more ATAD reactors in series. Generally the first reactor raises the sludge temperature from the feed temperature to nearly the thermophilic range. 
Subsequently the second or following reactors keep the sludge in the thermophilic range for the required time period (Kelly, 1990). According to USEPA (1990) biosolids regulations (40 CFR 503), before discharging the sludge, the final effluent in the ATAD should be in complete thermophilic temperature for a required time period to meet the regulatory standards (Class A biosolids). For example, according to USEPA regulations, if reactor temperature is $60{ }^{\circ} \mathrm{C}$, the required solids retention time is around 4 hours to produce Class A biosolids, while, if the reactor temperature is around $50{ }^{\circ} \mathrm{C}$, the solids retention time should be around 100 hours. However the $2^{\text {nd }}$ generation ATAD systems are designed accordingly to ensure the quality of ATAD effluent (Scisson, 2003).

The feed characteristics to the ATAD are critical to achieve successful operation. A minimum feed solids concentration of $3 \%$ with a range of 3 to $6 \%$ is recommended (Staton et al., 2001). Feed solids concentrations of less than 3\% may not achieve auto thermal conditions, while the solids concentrations greater than $6 \%$ become difficult to mix and aerate effectively. Hence anaerobic pockets (or dead zones) may occur within the reactor. This may subsequently lead to produce more odorous compounds in the ATAD (USEPA, 1990). 


\subsubsection{Biological reactions in a ATAD system}

Although chemical reactions may occur in ATADs, biochemical reactions are assumed to be predominant in ATAD digesters. The biochemical reactions are promoted by enzymes, which are affected by $\mathrm{pH}$ and temperature. Rittmann and McCarty (2001) reported that specific enzymes such as amylase (responsible for starch conversion to sugar) increase in activity in response to temperature increases. By extension, bacterial growth and consequential sludge degradation rates also respond to $\mathrm{pH}$ and temperature. For aerobic processes, activity is assumed to double for each $10{ }^{\circ} \mathrm{C}$ rise of temperature.

Generally microbiologists have classified microbes on the basis of their optimum temperatures for growth, thereby introducing the concept of psychrophiles (below $10^{\circ} \mathrm{C}$ ), mesophiles (between 20 and $45^{\circ} \mathrm{C}$ ), thermophiles $\left(45\right.$ to $65^{\circ} \mathrm{C}$ ) and hyper-thermophiles (above $65^{\circ} \mathrm{C}$ ) as distinctly separate groups of microbes. In an ATAD process, the temperature range is around $60^{\circ} \mathrm{C}$ in the second or final digester. Usually the first digester temperature fluctuates during the loading and unloading periods and are typically around 40 to $55^{\circ} \mathrm{C}$ (Kelly, 1990). Generally, digester $\mathrm{pH}$ does not have to be controlled in ATAD systems. With a feed sludge $\mathrm{pH}$ of around 6.5 , the $\mathrm{pH}$ value in the first ATAD reactor is typically 7.2, and may be as high as 8.0 in the second reactor (McFarland, 2001).

Generally the biological reactions can be described as shown in Figure 2.2 (Booth and Tramontini, 1984). It can also be described by the following stoichiometric Equation 2.1.1 (WEF, 1995). 
$\mathrm{C}_{5} \mathrm{H}_{7} \mathrm{NO}_{2}+5 \mathrm{O}_{2} \longrightarrow 5 \mathrm{CO}_{2}+2 \mathrm{H}_{2} \mathrm{O}+\mathrm{NH}_{3}+$ Energy

$\mathrm{C}_{5} \mathrm{H}_{7} \mathrm{NO}_{2}=$ the cell mass of a microorganism

In aerobic digestion, $\mathrm{NH}_{3}$ is liberated by hydrolysis of amino acids in protein. $\mathrm{The}^{\mathrm{NH}} \mathrm{N}_{3}$ is released into water and equilibrates with $\mathrm{NH}_{4}{ }^{+}$as shown in Equation 2.1.2. This process increases the $\mathrm{pH}$ in the reactor.

$$
\mathrm{NH}_{3}+\mathrm{H}_{2} \mathrm{O} \longleftrightarrow \mathrm{NH}_{4}^{+}+\mathrm{OH}^{-}
$$

The equilibrium chemistry of the $\mathrm{NH}_{4}{ }^{+}-\mathrm{NH}_{3}$ couple changes with increased temperatures, at which point partitioning of ammonia to the gas phase is favored. Removal of $\mathrm{NH}_{3}$ results in the release of $\mathrm{H}^{+}$ions in the liquid phase. Therefore, a decrease in $\mathrm{pH}$ will result. However continuous release of $\mathrm{NH}_{3}$ from hydrolysis of amino acids increases the $\mathrm{pH}$ of the liquid solution in ATAD reactors.

When a batch of fresh sludge is introduced into the ATAD, it exerts a very high oxygen demand in the process and hence as shown in Equation 2.1.1, relatively high concentrations of $\mathrm{CO}_{2}$ are released due to the biological reactions in the reactor. Since the system is in thermophilic conditions, $\mathrm{CO}_{2}$ stripping from the liquid to the air is favored at high temperatures; therefore $\mathrm{CO}_{2}$ is also released from ATAD (Kelly, 1990).

The heat produced by the biomass during the destruction of the sludge organics results from the fermentation and oxidation of organics to produce lower energy compounds such as $\mathrm{CO}_{2}, \mathrm{H}_{2} \mathrm{O}, \mathrm{NH}_{3}$ and inorganic salts. The energy available depends on the oxidative state of the waste constituents. The energy produced also depends on the ability 
of the biomass to degrade the wastes. The waste biodegradability, reaction rates and time available for conversions become important parameters in controlling the temperature rise within the digester.

As shown in Figure 2.2, complex substrate is broken down into soluble matter by hydrolysis reactions. The soluble matter is then degraded biologically. When biodegradable matter is aerobically degraded by microbes, a fraction of the biodegradable matter is converted into $\mathrm{CO}_{2}$ and the energy released is used by the microbes performing the oxidation to fix a further fraction of the substrate carbon to form additional microbial biomass. The oxidation of organic matter to $\mathrm{CO}_{2}$ and water during respiration yields energy, some of which is stored in ATP, but microorganisms are not $100 \%$ efficient and a portion is released as heat energy. In addition, as the microorganisms decay, the cell matter is solubilized through endogenous respiration and used for cryptic growth thereby producing more heat. At higher temperatures the decay rates are faster so there is more cryptic growth where microorganisms grow on the products of decay (Booth and Tramontini, 1984). 


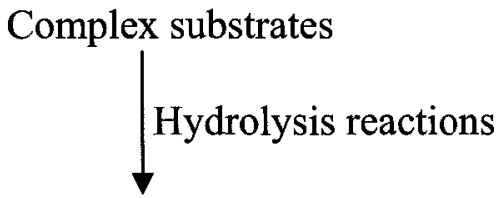

Soluble organics<smiles>[CH2]C(C)(C)O[O+2]</smiles>

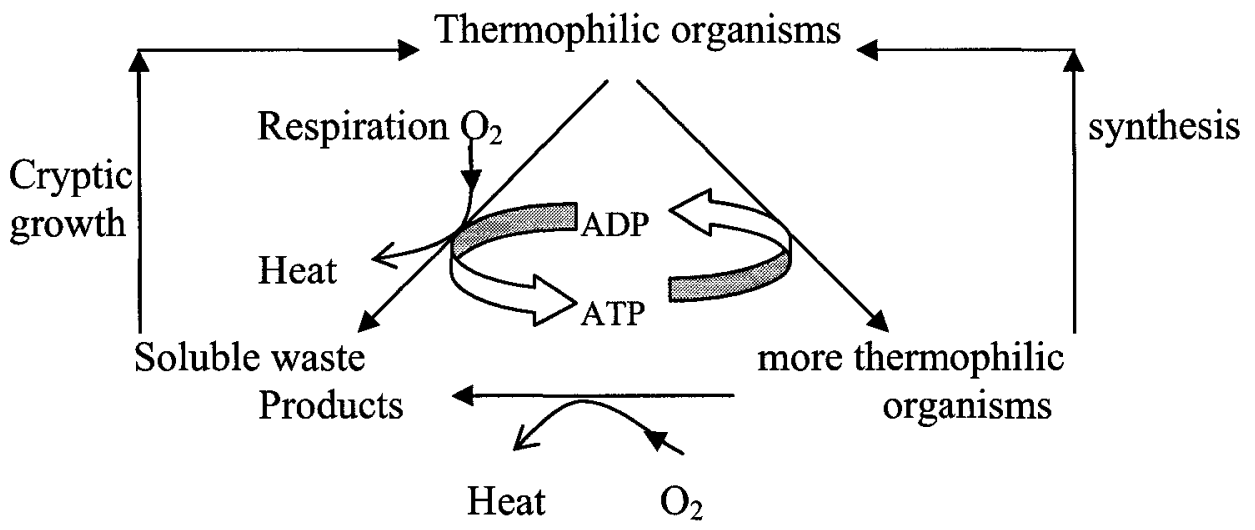

Figure 2.2 Biological reactions in ATAD system (after Booth and Tramontini, 1984)

In $\mathrm{ATAD}$ systems, operating temperatures of more than $40^{\circ} \mathrm{C}$ inhibit nitrification (WEF, 1995). Therefore as stated in Equation 2.1.1, the biomass $\mathrm{N}$ components release to the system as $\mathrm{NH}_{3}(\mathrm{aq})$ rather than $\mathrm{NO}_{3}{ }^{-}$in the liquid phase. Equation 2.1.1 indicates that approximately $1.5 \mathrm{~kg}$ of $\mathrm{O}_{2}$ is required per $\mathrm{kg}$ of volatile solids destroyed (WEF, 1995). Approximately $21,000 \mathrm{~kJ}$ of energy is released per $\mathrm{kg}$ of volatile solids destroyed.

In order to achieve autothermal operation in the ATAD process, the heat production must be maximized. The heat balance in such processes is a critical factor for both economic and effective process operation. Therefore an effective ATAD process depends on insulation of the digester, maintenance of appropriate reaction rates that generate sufficient heat and heat exchange between the process feed and effluent streams (Hamer, 
1989). The ATAD systems are designed to have short solids retention times within insulated reactors. As long as the system is well mixed and sufficient oxygen is provided, the temperature in the reactor will rise until a balance occurs (heat loss equals heat input from exothermic reaction).

\subsubsection{Offgases from ATAD systems}

One characteristic of the ATAD process that has limited the application of this technology is the significant odor content of the offgases (Pride, 2001; Staton et al., 2001). Since the ATAD process is relatively new, and there are limited plants currently using this technology in the North America, very little information about the type and amount of odor generated from the ATAD is available. Due to ATAD processes relatively high amounts of $\mathrm{NH}_{3}$ and some reduced sulfur compounds (RSCs) such as $\mathrm{H}_{2} \mathrm{~S}$, MM, DMS, DMDS are released (Hepner et al., 2002; Staton et al., 2001). The ATAD offgases vary in composition with time on a repeating interval. The duration of the interval will depend upon the operating characteristics of the digester and the feed cycle of fresh sludge (Staton et al., 2001).

The reduced sulfur compounds are formed during the biodegradation of organic sulfur compounds, biological methylation of sulfide and biochemical oxidation of other reduced sulfur compounds. Taylor (1989) found that MM and DMS were the principal byproducts of protein decomposition. Proteins are degraded to MM and DMS by aerobic, anaerobic or facultative micro-organisms. Carbon disulfide $\left(\mathrm{CS}_{2}\right)$ was also found to result from aerobic protein degradation. MM is further aerobically degraded to DMS, DMDS 
and DMTS by biochemical oxidation. If the conditions in the environment become anaerobic it is expected that DMS and $\mathrm{CS}_{2}$ are degraded to $\mathrm{MM}$ and $\mathrm{H}_{2} \mathrm{~S}$ (Taylor and Kiene, 1989; Taylor, 1989). Higgins et al. (2003) reported that the degradation of sulfur containing amino acids, specifically cysteine and methionine can produce $\mathrm{H}_{2} \mathrm{~S}$ and $\mathrm{MM}$ under anaerobic conditions.

$\mathrm{NH}_{3}$ is a product of decomposition under aerobic and anaerobic conditions. $\mathrm{NH}_{3}$ originates from protein deamination (Hentz, 1997). Under both aerobic and anaerobic conditions, bacteria breakdown amino acids and $\mathrm{NH}_{3}$ is a by-product. In addition to the compounds mentioned earlier, several volatile organic compounds (trimethyl amine, acetone, toluene, etc.) were also detected in ATAD offgases (Hepner et al., 2002).

Table 2.1 Odor substances in the ATAD offgas stream

\begin{tabular}{|c|c|c|c|c|c|}
\hline $\begin{array}{c}\text { Odor } \\
\text { substance }\end{array}$ & $\begin{array}{c}\text { Notation in } \\
\text { this } \\
\text { dissertation }\end{array}$ & $\begin{array}{c}\text { Chemical } \\
\text { formula }\end{array}$ & $\mathrm{MW}$ & $\begin{array}{c}\text { Odor } \\
\text { recognition } \\
\text { threshold } \mathrm{ppb}_{\mathrm{v}}\end{array}$ & Description of gas \\
\hline Ammonia & $\mathrm{NH}_{3}$ & $\mathrm{NH}_{3}$ & 17 & $37000^{*}$ & $\begin{array}{c}\text { Color less, irritant } \\
\text { and pungent smell }\end{array}$ \\
\hline $\begin{array}{c}\text { Hydrogen } \\
\text { sulfide }\end{array}$ & $\mathrm{H}_{2} \mathrm{~S}$ & $\mathrm{H}_{2} \mathrm{~S}$ & 34 & $4.7^{*}$ & $\begin{array}{c}\text { Corrosive, } \\
\text { extremely toxic and } \\
\text { rotten eggs smell }\end{array}$ \\
\hline $\begin{array}{c}\text { Methyl } \\
\text { mercaptan }\end{array}$ & $\mathrm{MM}$ & $\mathrm{CH}_{3} \mathrm{SH}$ & 48 & $1.0^{*}$ & $\begin{array}{c}\text { Rotten cabbage } \\
\text { smell }\end{array}$ \\
\hline $\begin{array}{c}\text { Dimethyl } \\
\text { sulfide }\end{array}$ & $\mathrm{DMS}$ & $\left(\mathrm{CH}_{3}\right)_{2} \mathrm{~S}$ & 62 & $1.0^{*}$ & $\begin{array}{c}\text { Decayed cabbage } \\
\text { smell }\end{array}$ \\
\hline $\begin{array}{c}\text { Dimethyl } \\
\text { disulfide }\end{array}$ & $\mathrm{DMDS}$ & $\left(\mathrm{CH}_{3}\right)_{2} \mathrm{~S}_{2}$ & 94 & $0.1-3.6^{* *}$ & $\begin{array}{c}\text { Decayed cabbage } \\
\text { smell }\end{array}$ \\
\hline
\end{tabular}

("Lopez et al., 2000; ${ }^{* *}$ Smet et al., 1996a)

Some common odorous substances, which have been characterized in ATAD offgases and their odor recognition threshold values, are presented in Table 2.1. Reduced sulfur 
compounds tend to be the most odorous as indicated by their relatively low threshold concentrations. Small concentrations of these compounds may be significant contributors to odor nuisance. The molecular weights (MW) of these substances generally range from 17 to 94 . Typically, lower molecular weight compounds have higher vapor pressures and hence a greater potential for emission to the atmosphere. Substances of high molecular weight are normally less volatile and thus normally have less potential for causing odor complaints (WEF, 1995). Dimensionless Henry's law coefficients are given in Table 2.2 (Sander, 2004). Low $\mathrm{K}_{\mathrm{H}}$ represents high solubility in water. As shown in Table 2.2, among the RSCs DMDS has relatively high solubility in water while $\mathrm{CS}_{2}$ has less solubility.

Table 2.2 Henry's law coefficients for the offgas compounds

\begin{tabular}{|c|c|}
\hline Compound & $\begin{array}{c}\mathrm{K}_{\mathrm{H}}(\text { dimensionless }) \text { at } 20^{\circ} \mathrm{C} \\
\left(\mathrm{K}_{\mathrm{H}}=\mathrm{C}_{\mathrm{g}} / \mathrm{C}_{\mathrm{L}}\right)\end{array}$ \\
\hline $\mathrm{NH}_{3}$ & 0.00055 \\
\hline $\mathrm{CO}_{2}$ & 1.015 \\
\hline $\mathrm{H}_{2} \mathrm{~S}$ & 0.370 \\
\hline $\mathrm{MM}$ & 0.176 \\
\hline $\mathrm{DMS}$ & 0.072 \\
\hline $\mathrm{CS}_{2}$ & 0.641 \\
\hline $\mathrm{DMDS}$ & 0.034 \\
\hline $\mathrm{NO}$ & 20.16 \\
\hline $\mathrm{NO}_{2}$ & 2.987 \\
\hline $\mathrm{N}_{2} \mathrm{O}$ & 1.427 \\
\hline
\end{tabular}

(Sander, 2004)

Pride (2002) reported that the odorous compounds generated by an ATAD were present in relatively high concentrations including: MM ( 1 to $150 \mathrm{ppm}), \mathrm{DMS}$ and DMDS (0.5 to $40 \mathrm{ppm}$ ) and $\mathrm{NH}_{3}$ (greater than $1400 \mathrm{ppm}$ ). The maximum concentrations of odorous compounds from three different full-scale ATAD systems are shown in Table 2.3 (Pride, 2002). 
Table 2.3 Maximum concentrations of odorous compounds from ATAD system (Pride, 2002)

\begin{tabular}{|l|c|c|c|}
\hline $\begin{array}{l}\text { Odor compound } \\
\text { (ppm) }\end{array}$ & $\begin{array}{c}\text { McMinnville, } \\
\text { Oregon }\end{array}$ & $\begin{array}{c}\text { Franklin, } \\
\text { Indiana }\end{array}$ & $\begin{array}{c}\text { Princeton, } \\
\text { Indiana }\end{array}$ \\
\hline MM & 128 & 80 & 10 \\
\hline DMS & 14.8 & n.a. & n.a. \\
\hline DMDS & 9.6 & n.a. & n.a. \\
\hline $\mathrm{NH}_{3}$ & 1400 & 1200 & 400 \\
\hline
\end{tabular}

Note: n.a. $=$ not analyzed

In aerobic digestion, $\mathrm{NH}_{3}$ is liberated by hydrolysis of the amino acids in protein. This generation is somewhat cyclical since time is required after the digester is filled with fresh sludge before the hydrolysis processes become highly active. Effects of temperature and $\mathrm{pH}$ on $\mathrm{NH}_{3}$ equilibrium is given in Equations 2.1.3 and 2.1.4 (Emerson et al., 1975).

$p K_{a}=0.09018+\frac{2729.92}{T}$

$f=\frac{1}{\left(10^{p K a-p H}+1\right)}$

$p K_{a}=$ the acid dissociation constant of the $\mathrm{NH}_{4}{ }^{+}$ion

$T=$ temperature in ${ }^{\circ} \mathrm{K}$

$f=$ fraction of free $\mathrm{NH}_{3}$ in total ammonia (free $\mathrm{NH}_{3}$ and $\mathrm{NH}_{4}{ }^{+}$)

As shown in Equation 2.1.3 and Equation 2.1.4, the concentration of $\mathrm{NH}_{3}$ increases with increasing $\mathrm{pH}$ and with increasing temperature. The equilibrium chemistry of the $\mathrm{NH}_{4}{ }^{+}-$ $\mathrm{NH}_{3}$ couple changes with increased temperatures, at which point partitioning of $\mathrm{NH}_{3}$ to the gas phase is favored. Depending on the $\mathrm{pH}$ of the reactor, $\mathrm{NH}_{3}$ can be stripped in to the exhaust. The pH levels typically observed in ATAD systems tend to be slightly basic (around 8), which enhances the stripping potential for $\mathrm{NH}_{3}$ (USEPA, 1990). 


\subsection{Biofiltration Process}

\subsubsection{Introduction}

Biological abatement technologies have become increasingly popular because of low costs, operational simplicity and because they are intrinsically clean technologies. There are minimal requirements for energy and raw materials and minimal waste production. In particular, biofiltration has become an accepted and mature technique for air pollution control with substantial industrial confidence (Johan et al., 1993). This is demonstrated by the exponentially increasing capacity of biofilters around the world.

Biofiltration is essentially a packed bed of particles in which microorganisms are immobilized on top of the packing particles called support medium. The contaminated air stream is humidified and passed through the bed. Figure 2.3 shows a schematic diagram of an open biofilter. Often a post humidification system is needed to keep the packing materials at the required moisture content for optimum microbial activity. The post humidification water can be potable water or treated effluent from a wastewater treatment system. As shown in the Figure 2.3, leachate is collected at the bottom of the bed for further treatment.

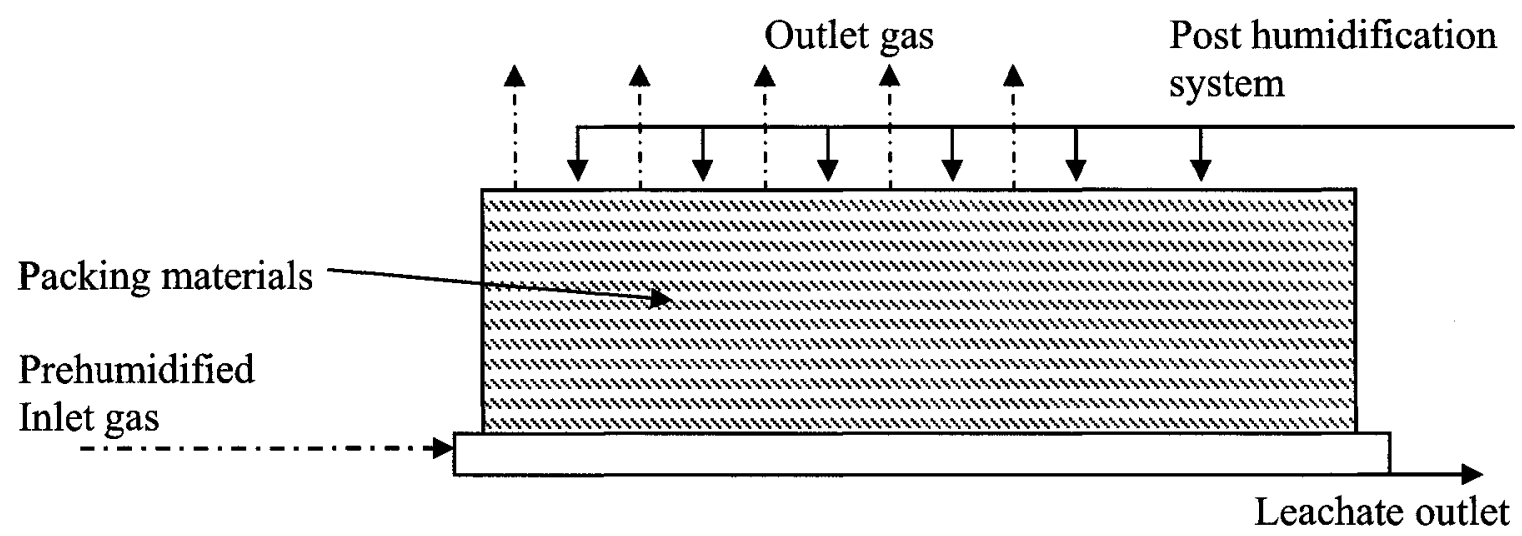

Figure 2.3 Schematic diagram of an open biofilter 
In the biofilter, contaminants (odorous compounds) are transferred to the interface of the gas and biofilm that is attached to the bed packing material, where they may be absorbed into the biofilm. The contaminants dissolve in the liquid phase and, in the biofilm may be degraded biologically. Within the biofilm, contaminants may be used as carbon and/or energy sources by the microorganisms. The "uptake" of contaminants by microorganisms creates a concentration gradient within the biofilm, which promotes molecular diffusion of substrate molecules from the gas-biofilm interface toward the biofilm-solid interface (Corsi and Seed, 1995). Microorganisms convert the pollutants to $\mathrm{CO}_{2}$, water and other end products. Depending on the choice of the support media, there could be other means of pollutant removal such as adsorption in the packing media (e.g. GAC) and absorption by the humidification water. In general more than one mechanism is involved in the removal of pollutants in a biofilter.

It has been a century since biofiltration technology for air pollution abatement was first utilized. In 1923, the biological elimination of $\mathrm{H}_{2} \mathrm{~S}$ emissions from wastewater treatment plants was first studied. Probably one of the earliest patents in this field was granted in 1934 (Ottengraf and Diks, 1991). Early applications of biological treatment of odorous gases included a soil bed system built in Nuernberg, West Germany in 1959 and biofilters were built in Geneva, Switzerland, and Mercer Island, Washington, to remove odors from wastewater treatment and compost manufacturing (Bohn and Bohn, 1988; Bohn, 1997). As stated by Ottengraf (1986), one example in North America was a soil biofilter system, which was employed around 1953, for the treatment of odorous sewer gases in Long Beach, California. From the late 1970s, most of the development of biological off-gas 
treatment has been carried out in Germany and The Netherlands, in response to increasingly stringent national regulatory requirements (Leson and Winer, 1991). However, until the early eighties, the underlying fundamental principles of operation were not well understood. The first notable attempt to illustrate and quantity the biofiltration process was made by Ottengraf and Oever (1983).

\subsubsection{Biofiltration for mixed gases}

Most controlled biofilter studies have involved single pollutants (inorganic or organic) under either steady state or transient conditions, while only few researchers have studied a combination of a few pollutants. These include mixtures of different organic substances including VOCs and BTEX (Swanson and Loehr, 1997; Deschusse, 1997; Corsi and Seed, 1995; Leson and Winer, 1991), organic and inorganic substances (Kim et al., 2002; Morales et al., 1998; Cho et al., 1991a; Cho et al., 1991b) and inorganic substances (Chung et al., 2000; Sun et al., 2000). These latter studies tend to have been performed under either steady state conditions with respect to contaminant concentration in the air stream or under conditions of limited transience. For example, single steps in concentration that were then followed by an extended period of constant concentration where the system was allowed to approach steady state (Deschusses, 1997; Tang and Hwang, 1996; Shareefdon and Baltzis, 1994a; Shareefdon and Baltzis, 1994b). 


\subsubsection{Removal of reduced sulfur compounds}

There have been a number of studies on removal of pure RSCs in the literature. Some studies have concentrated on the removal of single RSC in biofilters. Yang and Allen (1994a) performed extensive studies on $\mathrm{H}_{2} \mathrm{~S}$ in a compost biofilter. Using a mixed culture of microorganisms in compost, they obtained a maximum elimination capacity of $130 \mathrm{~g}$ $\mathrm{S} / \mathrm{m}^{3} / \mathrm{hr}$ for $\mathrm{H}_{2} \mathrm{~S}$ removal. Gibson and Otten, (1997) studied the dynamic response of a compost biofilter with laboratory scale studies of DMDS. The system responded well to both step and cyclic dynamic loading. A removal rate of $3.48 \mathrm{~g}-\mathrm{S} / \mathrm{m}^{3} / \mathrm{hr}$ was obtained for a relatively low air flow rate (superficial velocity around $0.6 \mathrm{~m} / \mathrm{min}$ ) in their studies. Budwill and Coleman (2000) investigated the biofiltration of DMS vapor using two peatbased biofilter systems. One had perlite mixed into the peat and was inoculated with a Hyphomicrobium sp. culture. The other biofilter had vermiculite mixed into the peat and was inoculated with Thiobacillus thioparus ATCC 8185. Both biofilters performed similarly in terms of removal efficiencies and elimination capacities.

Some studies have been conducted on mixtures of RSCs in biofilters. Cho et al. (1991a) performed an extensive study on a peat biofilter to treat RSCs. Table 2.4 shows the Monod kinetic constants for $\mathrm{H}_{2} \mathrm{~S}, \mathrm{MM}$, DMS and DMDS in a peat biofilter. As shown in Table 2.4, the maximum removal rate varied from $0.5 \mathrm{~g}-\mathrm{S} \mathrm{kg}^{-1}$ (dry peat) $\mathrm{d}^{-1}$ for DMS to

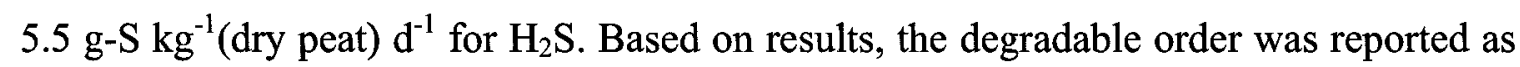
follows, $\mathrm{H}_{2} \mathrm{~S}>\mathrm{MM}>\mathrm{DMDS}>\mathrm{DMS}$ 
Cho et al. (1991a) also reported that, when a mixture of RSC was simultaneously degraded, the removal rate of DMS decreased as compared to the single DMS gas removal. Cho et al. (1991a) isolated Thiobacillus species HA43, which proved to be an adequate candidate for the improvement of treatment efficiency in biodeodorization systems treating air from aerobically digested sludge.

Table 2.4 Removal rate constants for RSC in a peat biofilter (Cho et al., 1991a)

\begin{tabular}{|c|c|c|}
\hline Compound & $\begin{array}{c}\text { Maximum removal rate } \\
\mathrm{V}_{\mathrm{m}}\left(\mathrm{g}_{-} \mathrm{S} \mathrm{kg}^{-1}(\mathrm{dry} \text { peat }) \mathrm{d}^{-1}\right)\end{array}$ & $\begin{array}{c}\text { Saturation constant } \\
\mathrm{K}_{\mathrm{s}}(\mathrm{ppm})\end{array}$ \\
\hline $\mathrm{H}_{2} \mathrm{~S}$ & 5.52 & 84.7 \\
\hline $\mathrm{MM}$ & 1.16 & 17.7 \\
\hline $\mathrm{DMS}$ & 0.50 & 4.8 \\
\hline DMDS & 1.02 & 7.1 \\
\hline
\end{tabular}

Many of the biofilter studies on RSC have concentrated on finding suitable microorganisms and packing materials (Kanagawa and Mikami, 1989; Cho et al., 1991a; Phae and Shoda, 1991). Table 2.5 summarizes the RSCs removal studies in biofilters. As shown in Table 2.5, a variety of media and microorganisms have been used in these studies and the RSC removal rates or removal efficiencies have been reported. Kangawa and Mikami (1989) reported that RSCs were successfully removed by Thiobacillus thioparus in a synthetic media. Hirai et al. (1990) studied odorous sulfur compounds such as $\mathrm{H}_{2} \mathrm{~S}, \mathrm{MM}$, and DMS in a peat biofilter. They studied each gas alone and then combinations of these gases. Using a model that incorporated Monod kinetics, the maximum removal efficiency and saturation constants were calculated. Hirai et al. (1990) reported that the maximum removal rate of $\mathrm{H}_{2} \mathrm{~S}$ in its acclimated peat was one order larger than those in MM and DMS acclimated peat. The removal of DMS decreased when $\mathrm{MM}$ and $\mathrm{H}_{2} \mathrm{~S}$ were present in the air stream. Based on their results, Hirai et al. 
(1990) suggested that two stage column biofilter to treat the mixture of RSC, hence $\mathrm{H}_{2} \mathrm{~S}$ and $\mathrm{MM}$ can be removed in the first column, while the second column exclusively for DMS removal. Phae and Shoda (1991) reported the degradation rates of RSCs for fungi, which were isolated from soil. They observed that fungi removal rates were far larger than those reported in previous studies, which used Thiobacillus sp. (Kanagawa and Mikami, 1989; Cho et al., 1991a).

Table 2.5 Reduced sulfur compound studies in the literature

\begin{tabular}{|c|c|c|c|c|}
\hline Authors, year & Support media & Pollutants & Microbial type & Remarks \\
\hline $\begin{array}{l}\text { Kanagawa and } \\
\text { Mikami, } 1989\end{array}$ & ${ }^{\mathrm{S} 1}$ Basal medium & $\begin{array}{l}\mathrm{H}_{2} \mathrm{~S}, \mathrm{MM} \\
\text { DMS\& } \\
\text { DMDS }^{\mathrm{P1}^{*}}\end{array}$ & $\begin{array}{l}\text { Thiobacillus } \\
\text { thioparus TK-m }\end{array}$ & $\begin{array}{l}\text { Cell yield: } \mathrm{H}_{2} \mathrm{~S}-9.2 \mathrm{~g} / \mathrm{mol} \\
\mathrm{MM}-20 \mathrm{~g} / \mathrm{mol} ; \mathrm{DMS}- \\
21 \mathrm{~g} / \mathrm{mol} ; \mathrm{DMDS}-33 \\
\mathrm{~g} / \mathrm{mol}\end{array}$ \\
\hline $\begin{array}{l}\text { Hirai et al., } \\
1990\end{array}$ & Peat & $\begin{array}{l}\mathrm{H}_{2} \mathrm{~S}, \mathrm{MM}^{\mathrm{M}} \\
\& \mathrm{DMS}^{\mathrm{P} 1^{*}}\end{array}$ & n.a. & MR1 \\
\hline $\begin{array}{l}\text { Cho et al., } \\
\text { 1991a }\end{array}$ & $\begin{array}{l}\text { S2Modified } \\
\text { Waksman medium } \\
\text { and peat }\end{array}$ & $\begin{array}{l}\mathrm{H}_{2} \mathrm{~S}, \mathrm{MM} \\
\text { DMS\& } \\
\text { DMDS }\end{array}$ & $\begin{array}{l}\text { Thiobacillus sp. } \\
\text { HA43 }\end{array}$ & $\begin{array}{l}\mathrm{H}_{2} \mathrm{~S} \& \mathrm{MM} \text { degraded } \\
\text { well, but DMS\& DMDS } \\
\text { are relatively lower than } \\
\text { other two. }\end{array}$ \\
\hline $\begin{array}{l}\text { Phae and Shoda, } \\
1991\end{array}$ & $\begin{array}{l}\text { Potato dextrose agar } \\
\text { medium }\end{array}$ & $\begin{array}{l}\mathrm{H}_{2} \mathrm{~S}, \mathrm{MM} \\
\text { DMS\& } \\
\text { DMDS }\end{array}$ & Fungus from soil & $\begin{array}{l}\mathrm{H}_{2} \mathrm{~S}-2250 \mathrm{U} 1 ; \mathrm{MM}-112 \\
\text { U1 DMS- } \\
\text { DMDS- }\end{array}$ \\
\hline $\begin{array}{l}\text { Cho et al., } \\
1991 \mathrm{~b}\end{array}$ & Peat & DMDS & $\begin{array}{l}\text { Night soil sludge } \\
\text { microorganisms }\end{array}$ & $\mathrm{R}=76.8 \mathrm{~g} \mathrm{~S} / \mathrm{m}^{3} /$ day \\
\hline $\begin{array}{l}\text { Yang and Allen, } \\
\text { 1994a }\end{array}$ & Yard waste compost & $\mathrm{H}_{2} \mathrm{~S}$ & $\begin{array}{l}\text { General compost } \\
\text { microorganisms }\end{array}$ & $\mathrm{ER} 1=130 \mathrm{~g} \mathrm{~S} / \mathrm{m}^{3} / \mathrm{hr}$ \\
\hline $\begin{array}{l}\text { Gibson and } \\
\text { Otten, } 1997\end{array}$ & $\begin{array}{l}\text { Compost +industrial } \\
\text { paper products }\end{array}$ & DMDS & $\begin{array}{l}\text { Thiobacillus } \\
\text { thioparus }\end{array}$ & $\mathrm{R}=83.0 \mathrm{~g} \mathrm{~S} / \mathrm{m}^{3} /$ day \\
\hline $\begin{array}{l}\text { Kong and Allen, } \\
1997\end{array}$ & $\begin{array}{l}\text { Compost/pine bark } \\
\text { nugget }\end{array}$ & DMS & $\begin{array}{l}\text { compost was seeded } \\
\text { with activated sludge }\end{array}$ & ER2 $\approx 68.0 \mathrm{~g} \mathrm{~S} / \mathrm{m}^{3} /$ day \\
\hline $\begin{array}{l}\text { Chitwood et al., } \\
1999\end{array}$ & $\begin{array}{l}\text { Lava rock (porous } \\
\text { stones) and wood } \\
\text { chips }\end{array}$ & $\begin{array}{l}\mathrm{H}_{2} \mathrm{~S} \text { (mixed } \\
\text { VOCs) }\end{array}$ & $\begin{array}{l}\text { Thiobacillus } \\
\text { thiooxidans }\end{array}$ & $\begin{array}{l}99.6 \% \text { removal } \\
\text { efficiency }\end{array}$ \\
\hline $\begin{array}{l}\text { Budwill and } \\
\text { Coleman, } 2000\end{array}$ & $\begin{array}{l}\text { (1) perlite \& peat } \\
\text { (2) vermiculite \& } \\
\text { peat }\end{array}$ & DMS & $\begin{array}{l}\text { Hyphomicrobium sp. } \\
\text { Thiobacillus } \\
\text { thioparus }\end{array}$ & $\begin{array}{l}\mathrm{R}=381.5 \mathrm{~g} \mathrm{~S} / \mathrm{m}^{3} / \text { day } \\
\mathrm{R}=346.8 \mathrm{~g} \mathrm{~S} / \mathrm{m}^{3} / \text { day }\end{array}$ \\
\hline
\end{tabular}

Note:

P1: Studied each gas alone and mixed gases

MR1: By kinetic analysis (using Michaelis-Menton type equation), maximum removal rate $\left(\mathrm{V}_{\mathrm{m}}\right.$, in $\mathrm{g}-\mathrm{S} / \mathrm{d}$ kg-dry peat) was reported for single and mixed gases combinations. $\mathrm{R}$ : removal rate

S1 \& S2: synthetic medium with required nutrient

$\mathrm{U1}: \mathrm{ppm} / \mathrm{g}$ dry cell mass $/ \mathrm{hr}$ 
$\mathrm{ER} 1=$ maximum elimination capacity of compost is $130 \mathrm{~g} \mathrm{~S} / \mathrm{m}^{3} / \mathrm{hr}$

$\mathrm{ER} 2=$ maximum elimination capacity of compost is $5.5 \mathrm{~g}-\mathrm{DMS} / \mathrm{m}^{3} / \mathrm{hr} \approx 68.0 \mathrm{~g} \mathrm{~S} /$ $\mathrm{m}^{3} /$ day

n.a. $=\operatorname{did}$ not report

\subsubsection{Removal of ammonia}

$\mathrm{NH}_{3}$ can be removed in a biofilter by biological oxidation, adsorption on the media and absorption into the water phase. Table 2.6 summarizes the $\mathrm{NH}_{3}$ removal studies that have been reported in the literature. Biological activity in biofilters is sensitive to media conditions such as $\mathrm{pH}$, ionic strength, available nutrients and the presence of inhibitors. $\mathrm{NH}_{3}$ impacts all of these, thus the biological performance of a biofilter in treating all contaminants, including $\mathrm{NH}_{3}$, can be affected by the ammonia loading. Excess $\mathrm{NH}_{3}$ loading may inhibit the biofilter operation due to the accumulation of nitrite $\left(\mathrm{NO}_{2}{ }^{-}\right)$and free $\mathrm{NH}_{3}$ (Kim et al., 2000b; Liberty and Taraba, 2002). A maximum ammonia loading of $1.8 \mathrm{~g} \mathrm{NH}_{3} / \mathrm{m}^{3}$ peat/hour into a biofilter was reported by Hartikainen et al. (1996). When the $\mathrm{NH}_{3}$ concentration increased above $45 \mathrm{mg} \mathrm{NH} / \mathrm{m}^{3}$ (around $65 \mathrm{ppm}$ ), it caused an accumulation of free $\mathrm{NH}_{3}$ and $\mathrm{NO}_{2}^{-}$, which inhibited nitrification and the biological activity of microorganisms. Chung and Huang (1998) also confirmed that excess concentrations of $\mathrm{NH}_{3}$ would lower the removal efficiency. They reported that the maximum inlet concentration could not exceed $75 \mathrm{ppm}$. In contrast, Liang et al. (2000) reported that the maximum inlet ammonia concentration was $200 \mathrm{ppm}$ in compost with activated carbon added biofilter to get less than $1.0 \mathrm{mg} / \mathrm{m}^{3}$ outlet concentration. This result showed that the relatively higher concentration $(200 \mathrm{ppm})$ of $\mathrm{NH}_{3}$ gas can be treated in a biofilter. More recently, Liberty and Taraba (2002) reported that microbial activity was reduced at around $135 \mathrm{ppm}$ of $\mathrm{NH}_{3}$, because of high dissolved $\mathrm{NO}_{3}{ }^{-}$and 
$\mathrm{NH}_{4}{ }^{+}$ion concentrations. They used oven-dried compost in a laboratory-scale biofilter to study the dynamics of $\mathrm{NH}_{3}$ biotransformation.

Table 2.6 Biofilter $\mathrm{NH}_{3}$ removal studies in the literature

\begin{tabular}{|c|c|c|c|c|c|}
\hline $\begin{array}{c}\text { Authors \& } \\
\text { Year }\end{array}$ & $\begin{array}{l}\text { Support } \\
\text { media }\end{array}$ & Microbial type & $\begin{array}{c}\text { Max. } \\
\text { removal } \\
\text { rate: \#1 }\end{array}$ & $\begin{array}{l}\text { Max.inlet } \\
\text { conc. }\end{array}$ & Remarks \\
\hline $\begin{array}{l}\text { Hartikinen et } \\
\text { al., } 1996\end{array}$ & peat & $\begin{array}{l}\text { Nitrifying bacteria } \\
\text { from activated sludge }\end{array}$ & $<\mathrm{Cl}$ & - & Rl \\
\hline $\begin{array}{l}\text { Chung and } \\
\text { Huang, } 1998\end{array}$ & $\begin{array}{l}\text { Cell-laden } \\
\text { Ca-alginate } \\
\text { beads }\end{array}$ & $\begin{array}{l}\text { Nitrosomonas } \\
\text { europaea }\end{array}$ & 1.11 & $<75 \mathrm{ppm}$ & $\begin{array}{l}\text { To reach emission } \\
\text { limit ( } 1 \mathrm{ppm})\end{array}$ \\
\hline $\begin{array}{l}\text { Liang et al., } \\
2000\end{array}$ & $\begin{array}{l}\text { Compost }+ \\
\text { GAC }\end{array}$ & $\begin{array}{l}\text { bacteria from } \\
\text { activated sludge }\end{array}$ & - & $<200 \mathrm{ppm}$ & $\begin{array}{l}\text { To reach emission } \\
\text { std of China } \\
(1 \mathrm{mg} / \mathrm{m} 3)\end{array}$ \\
\hline $\begin{array}{l}\text { Chung et al., } \\
2000\end{array}$ & $\begin{array}{l}\text { Cell-laden } \\
\text { Ca-alginate } \\
\text { beads }\end{array}$ & $\begin{array}{l}\text { Nitrosomonas } \\
\text { europaea }\end{array}$ & - & $<164 \mathrm{ppm}$ & $\begin{array}{l}\text { To reach air std. } \\
\text { Used mixed air with } \\
\mathrm{H}_{2} \mathrm{~S}\end{array}$ \\
\hline $\begin{array}{l}\text { Kim et al., } \\
2000 \mathrm{a}\end{array}$ & $\begin{array}{l}\text { Peat } \\
\text { Rock wool } \\
\text { Fuyolite } \\
\text { Ceramics }\end{array}$ & Nitrifying bacteria & $\begin{array}{l}16.7 \\
8.3 \\
6.3 \\
5.0\end{array}$ & - & $\begin{array}{l}\text { Organic media was } \\
\text { better than inorganic } \\
\text { media }\end{array}$ \\
\hline $\begin{array}{l}\text { Kim et al., } \\
2000 \text { b }\end{array}$ & $\begin{array}{l}{ }^{\mathrm{S} 1} \text { Basal } \\
\text { medium }\end{array}$ & $\begin{array}{l}\text { Marine bacterium } \\
\text { Vibrio alginolyticus }\end{array}$ & 22.8 & - & High load of $\mathrm{NH}_{3}$ \\
\hline $\begin{array}{l}\text { Liberty and } \\
\text { Taraba, } 2002\end{array}$ & $\begin{array}{l}\text { Yard-waste } \\
\text { Compost }\end{array}$ & $\begin{array}{l}\text { (1) WWAS } \\
\text { (2) NB }\end{array}$ & $\begin{array}{c}\mathrm{Rmax}= \\
0.679\end{array}$ & $<135 \mathrm{ppm}$ & $\begin{array}{l}\text { To keep microbial } \\
\text { activity high }\end{array}$ \\
\hline
\end{tabular}

Note :

1\# : $\quad$ g-N / kg-dry material/day

Cl: $\quad 1.8 \mathrm{~g} \mathrm{NH}_{3} / \mathrm{m}^{3}$ peat/hour

NB: NitroBac synthetic microbial medium, which is having nitrifying seed culture

R1: no accumulation of $\mathrm{NH}_{4}{ }^{+}$or $\mathrm{NO}_{2}{ }^{-}$was found in experiment with low $\mathrm{NH}_{3}$ load, i.e. complete nitrification occurred

$\mathrm{R}_{\max }$ : maximum microbial activity rate

S1: $\quad$ synthetic medium with required nutrient

WWAS: wastewater activated sludge

Since ATAD process releases high concentration of $\mathrm{NH}_{3}$ (more than $300 \mathrm{ppm}$ ) in the offgas, it is necessary to reduce the $\mathrm{NH}_{3}$ concentration. Therefore a wet scrubber is often introduced between the ATAD offgas outlet and biofilter inlet (Pride, 2002). To reduce 
$\mathrm{NH}_{3}$ inhibition in a biofilter, most of the $\mathrm{NH}_{3}$ can be removed in the wet scrubber prior to entry into the biofilter.

The removal of $\mathrm{NH}_{3}$ through nitrification is an acid forming process, but most of the studies show that the $\mathrm{pH}$ did not drop significantly due to the neutralizing effect of absorbing $\mathrm{NH}_{3}$, which reacts in the liquid phase to form $\mathrm{NH}_{4}{ }^{+}$. Smet et al. (2000) reported that only $50 \%$ of the $\mathrm{NH}_{3}$ input to a biofilter was nitrified; the remaining $50 \%$ remained in the filter as $\mathrm{NH}_{3}(\mathrm{aq})$. Hartikainen et al. (1996) reported that approximately $80 \%$ of the $\mathrm{NH}_{3}-\mathrm{N}$ was oxidized to $\mathrm{NO}_{3}-\mathrm{N}$ in a peat biofilter.

Liang et al. (2000) operated a pilot biofilter treating $\mathrm{NH}_{3}$-contaminated air for a period of eight months and the treatment results are shown in Table 2.7. They used a mixture of compost and GAC as a filter media and a mixed culture of microorganisms, which were taken from an activated sludge process. The removed ammonia was mainly converted to nitrate. In order to meet the Chinese standard for ammonia emissions $\left(1.0 \mathrm{mg} \mathrm{NH}_{3} / \mathrm{m}^{3}\right)$, it was concluded that the ammonia load should be lower than $0.157 \mathrm{~kg} \mathrm{NH}_{3} / \mathrm{kg}$ media/d (around $200 \mathrm{ppm}$ of $\mathrm{NH}_{3}$ ). They also reported that the combination of two principal processes (biofiltration and adsorption) offers a complete solution for the removal of ammonia. During normal treatment the capacity of the biological ammonia removal was sufficient. However, at shock loadings the activity of the micro-organisms might not be able to adapt fast enough to ensure the required treatment efficiency. The activated carbon then adsorbed the ammonia temporarily and thereby equalized the shock loading. 
Table 2.7 Long term $\mathrm{NH}_{3}$ treatment in a pilot plant (Liang et al., 2000)

\begin{tabular}{|c|c|c|c|}
\hline $\begin{array}{c}\text { Influent } \mathrm{NH}_{3} \\
(\mathrm{ppm})\end{array}$ & $\begin{array}{c}\text { Applied loading } \\
\left(\mathrm{g} \mathrm{NH}_{3} / \mathrm{kg} \text { media/d) }\right.\end{array}$ & $\begin{array}{c}\text { Removed loading } \\
\left(\mathrm{g} \mathrm{NH}_{3} / \mathrm{kg} \text { media/d) }\right.\end{array}$ & $\begin{array}{c}\text { Removal } \\
\text { efficiency (\%) }\end{array}$ \\
\hline 100 & 0.079 & 0.078 & 98.7 \\
\hline 200 & 0.157 & 0.156 & 99.4 \\
\hline 300 & 0.236 & 0.234 & 99.2 \\
\hline 500 & 0.393 & 0.376 & 95.7 \\
\hline
\end{tabular}

\subsubsection{Treatment of mixtures of $\mathrm{RSC}$ and $\mathrm{NH}_{3}$}

As shown in Table 2.8, few studies have been conducted on mixtures of $\mathrm{NH}_{3}$ and $\mathrm{RSCs}$. Malhautier et al. (2003) studied a mixture of $\mathrm{NH}_{3}$ and $\mathrm{H}_{2} \mathrm{~S}$ in two different granulated sludge packing materials. They showed that $\mathrm{NH}_{3}$ oxidation had no negative effect on $\mathrm{H}_{2} \mathrm{~S}$ removal. They also presented the results of a mass balance and the degradation product proportions in the biofilter process. For the nitrogen mass balance, gaseous $\mathrm{NH}_{3}$, nitrate, nitrite and dissolved nitrogen were considered while for the sulfur balance $\mathrm{H}_{2} \mathrm{~S}$, elemental sulfur and sulfate were considered. The error in the mass balance for sulfur was low as compared to the nitrogen mass balance. They suggested that it was probable that $\mathrm{NH}_{3}$ supplying the biofilters was converted into species other than nitrite and nitrate such as organic nitrogen and gaseous nitrogen.

Jones et al. (2004) studied the kinetic evaluation of $\mathrm{H}_{2} \mathrm{~S}$ and $\mathrm{NH}_{3}$ biofiltration for wastewater lift station emissions. They reported that the $\mathrm{NH}_{3}$ gas concentration up to 80 ppm did not affect the $\mathrm{H}_{2} \mathrm{~S}$ removal efficiency. The impact of operating parameters such as moisture content and gas retention time on biofiltration of $\mathrm{H}_{2} \mathrm{~S}$ and $\mathrm{NH}_{3}$ gases was studied by Sun et al. (2000). They also reported the results of sulfur (S) and nitrogen (N) mass balances within the biofilter and chemical accumulation of $\mathrm{S}$ and $\mathrm{N}$ in the biofilter 
media. Sun et al. (2000) studied a laboratory scale biofilter with filter media of yard waste compost and wood chips (Figure 2.4). The biofilter packing height was $0.2 \mathrm{~m}$ and internal diameter of the column was $0.3 \mathrm{~m}$. The media bottom layer as shown in Figure 2.4 accumulated more $\mathrm{S}$ and $\mathrm{N}$ in various forms than the upper layers. Sun et al. (2000) concluded that higher $\mathrm{SO}_{4}-\mathrm{S}$ and $\mathrm{NO}_{3}-\mathrm{N}$ concentrations in the bottom of the filter bed could be the result of receiving more oxygen in the feed gas in these up-flow biofilter. In terms of the $\mathrm{S}$ and $\mathrm{N}$ balances, they indicated that differences between calculated and measured values were not significant for $\mathrm{S}$, but were significant for $\mathrm{N}$. They suggested that possible reasons for these discrepancies may have been the error in gas flow measurements and the loss of gaseous forms of $\mathrm{S}$ and $\mathrm{N}$ that were not measured.

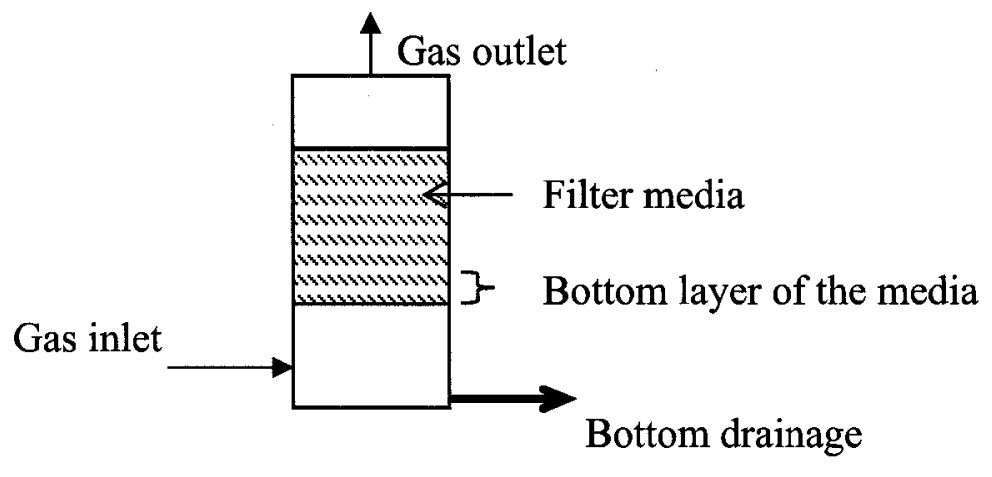

Figure 2.4 Biofilter setup used by Sun et al. (2000)

Chung et al. (2001) performed extensive studies on $\mathrm{H}_{2} \mathrm{~S}$ and $\mathrm{NH}_{3}$ gas mixtures using a biofilter and focused on removal characteristics, removal efficiency, and removal kinetics of this gas mixture. $\mathrm{H}_{2} \mathrm{~S}$ and $\mathrm{NH}_{3}$ at high concentrations were observed to be inhibitory substrates for $\mathrm{H}_{2} \mathrm{~S}$ removal. They found that the biofilter successfully handled a gas mixture of $\mathrm{H}_{2} \mathrm{~S}$ and $\mathrm{NH}_{3}$ within the 5-65 ppm range showing removal efficiencies greater than $96 \%$. However, $\mathrm{Kim}$ et al. (2002) reported that $\mathrm{NH}_{3}$ removal rates were reduced for 
high $\mathrm{H}_{2} \mathrm{~S}$ loading (over $200 \mathrm{ppm}$ ) while sulfur oxidizing bacteria did not show inhibition at $\mathrm{NH}_{3}$ concentrations under $150 \mathrm{ppm}$.

Table 2.8 Combined $\mathrm{NH}_{3}$ and $\mathrm{RSC}$ removal studies

\begin{tabular}{|c|c|c|c|c|}
\hline $\begin{array}{l}\text { Authors } \\
\text { \& Year }\end{array}$ & $\begin{array}{c}\text { Support } \\
\text { media }\end{array}$ & Pollutants & Microbial type & Remarks \\
\hline $\begin{array}{l}\text { Jones et } \\
\text { al., } 2004\end{array}$ & $\begin{array}{l}\text { Compost } \\
\text { and } \\
\text { woodchips }\end{array}$ & $\begin{array}{l}\mathrm{H}_{2} \mathrm{~S}(100 \mathrm{ppm}) \\
\mathrm{NH}_{3}(80 \mathrm{ppm})\end{array}$ & Mixed culture & $\begin{array}{l}\text { Kinetic evaluation of } \\
\mathrm{H}_{2} \mathrm{~S} \text { and } \mathrm{NH}_{3} \\
\text { biofiltration }\end{array}$ \\
\hline $\begin{array}{l}\text { Malhauti } \\
\text { er et al., } \\
2003\end{array}$ & $\begin{array}{l}\text { Granulated } \\
\text { sludge }\end{array}$ & $\begin{array}{l}\mathrm{H}_{2} \mathrm{~S}\left(140 \mathrm{mg} / \mathrm{m}^{3}\right) \\
\mathrm{NH}_{3}\left(70 \mathrm{mg} / \mathrm{m}^{3}\right)\end{array}$ & Mixed culture & $\begin{array}{l}\text { Study to investigate } \\
\text { the potential of } \\
\text { granulated sludge }\end{array}$ \\
\hline $\begin{array}{l}\text { Chung et } \\
\text { al., } 2000\end{array}$ & $\begin{array}{l}\text { Cell-laden } \\
\text { Ca-alginate } \\
\text { beads }\end{array}$ & $\begin{array}{l}\mathrm{H}_{2} \mathrm{~S}(0-120 \mathrm{ppm}) \\
\mathrm{NH}_{3}(0-120 \mathrm{ppm})\end{array}$ & $\begin{array}{l}\text { Thiobacillus } \\
\text { thioparus } \\
\text { Nitrosomonas } \\
\text { europaea }\end{array}$ & $\begin{array}{l}\text { Study on removal } \\
\text { efficiency, removal } \\
\text { kinetics and pressure } \\
\text { drop }\end{array}$ \\
\hline $\begin{array}{l}\text { Sun et al., } \\
2000\end{array}$ & $\begin{array}{l}\text { Yard waste } \\
\text { compost and } \\
\text { wood chips }\end{array}$ & $\begin{array}{l}\mathrm{H}_{2} \mathrm{~S}(1.7-2.3 \mathrm{ppm}) \\
\mathrm{NH}_{3}(17.9-20.1 \\
\mathrm{ppm})\end{array}$ & Mixed culture & $\begin{array}{l}\text { Study on } \mathrm{S} \& \mathrm{~N} \\
\text { balance within the } \\
\text { system }\end{array}$ \\
\hline $\begin{array}{l}\text { Kikuchi, } \\
2000\end{array}$ & Soil & Malodorous air ${ }^{\# 1}$ & $\begin{array}{l}\text { Top soil } \\
\text { microorganisms }\end{array}$ & $\begin{array}{l}\text { Inlet odorous } \\
\text { compounds were } \\
\text { relatively high } \\
\text { concentration. }\end{array}$ \\
\hline $\begin{array}{l}\text { Kim et } \\
\text { al., } 2002\end{array}$ & $\begin{array}{l}\text { Wood chips } \\
\text { and GAC }\end{array}$ & $\begin{array}{l}\mathrm{H}_{2} \mathrm{~S}(35-440 \mathrm{ppm}) \\
\mathrm{NH}_{3}(20-200 \mathrm{ppm})\end{array}$ & ${ }^{\sharp 2}$ Mixed culture & $\begin{array}{l}{ }^{\# 3} \text { At high } \mathrm{H}_{2} \mathrm{~S} \\
\text { loading, } \mathrm{NH}_{3} \\
\text { removal rate reduced }\end{array}$ \\
\hline
\end{tabular}

Note:

\#1: Malodorous air emitted from a composter of municipal solid waste (containing $\mathrm{H}_{2} \mathrm{~S}$, MM, DMS, DMDS, $\mathrm{NH}_{3}$, trimethyl amine, acetaldehyde, and styrene \#2: Activated sludge and Thiobacillus thioparus \#3 : The activity of nitrifying bacteria was inhibited by high $\mathrm{H}_{2} \mathrm{~S}(>200 \mathrm{ppm})$ but recovered gradually after $\mathrm{H}_{2} \mathrm{~S}$ addition was ceased.

Kikuchi (2000) performed pilot-scale tests of a soil biofilter for treatment of malodorous gas. He reported that air containing $\mathrm{NH}_{3}, \mathrm{MM}$, DMS, DMDS, trimethyl amine and acetaldehyde could be treated with a soil filter with $99 \%$ deodorizing efficiency. The concentrations of these malodorous gases $\left(\mathrm{NH}_{3}-128 \mathrm{mg} / \mathrm{l} ; \mathrm{MM}-0.2 \mathrm{mg} / \mathrm{l} ; \mathrm{DMS}-0.11\right.$ $\mathrm{mg} / 1 ; \mathrm{DMDS}-0.011 \mathrm{mg} / \mathrm{l})$ were relatively higher than in ATAD offgases. The EBRT 
was around 100 seconds. Most of the odorous compounds such as $\mathrm{NH}_{3}, \mathrm{MM}$, and $\mathrm{DMS}$ were removed by the soil filter with high efficiency (over 92\%), but the removal efficiency for DMDS was comparatively low (27\%). However, Kikuchi (2000) did not demonstrate the possible reason for the low DMDS removal efficiency.

\subsection{Biotreatment Mechanisms}

The treatment of air streams containing a mixture of inorganic and organic substances is made complex by the fact that there are a number of interacting chemical and microbial mechanisms that may be active. In addition, reactor design and operating conditions will impact performance. Mechanisms that are primarily physical or chemical in nature include gas-liquid mass transfer, adsorption to media and dissociation of ionic species. For some compounds (i.e., ammonia) these mechanisms are $\mathrm{pH}$ sensitive. However, the $\mathrm{pH}$ of a biofilter is influenced by microbial processes that generate inorganic acids (i.e., nitrification and oxidation of RSC), dissolution of $\mathrm{CO}_{2}$ gas as well as addition of buffer due to dissolution of weak bases such as ammonia.

\subsubsection{Ammonia treatment mechanisms}

The incoming gaseous $\mathrm{NH}_{3}$ can be directly absorbed into the leachate as $\mathrm{NH}_{3}(\mathrm{aq})$ or can be oxidized to nitrite and then to nitrate through nitrification (microbial activities). Some $\mathrm{N}$ sources may be transformed into organic forms in the microbial cells. The first two phenomena are presented in the following equations (Tchobanoglous et al., 2003).

Direct absorption into the water phase:

$$
\mathrm{NH}_{3(\mathrm{~g})} \longrightarrow \mathrm{NH}_{3 \text { (aq) }}
$$


Hydrolysis equilibrium reaction:

$$
\mathrm{NH}_{3(\mathrm{aq})}+\mathrm{H}_{2} \mathrm{O} \longleftrightarrow \mathrm{NH}_{4}^{+}+\mathrm{OH}^{-}
$$

Biological nitrification:

$$
\begin{aligned}
& 2 \mathrm{NH}_{4}^{+}+3 \mathrm{O}_{2} \longrightarrow 2 \mathrm{NO}_{2}^{-}+4 \mathrm{H}^{+}+2 \mathrm{H}_{2} \mathrm{O} \\
& 2 \mathrm{NO}_{2}^{-}+\mathrm{O}_{2} \longrightarrow 2 \mathrm{NO}_{3}^{-}
\end{aligned}
$$

The ammonia entering the biofilter in the gas phase will transfer into the liquid phase within the biofilter as shown in Equation 2.3.1. The maximum liquid phase concentration will be defined by the Henry's Law coefficient for $\mathrm{NH}_{3}$, however liquid phase concentrations may be less than equilibrium values due to the effects of gas-liquid mass transfer limitations, protonation of the ammonia and potential biotransformation in the liquid phase. Due to the hydrolysis reaction, the absorbed $\mathrm{NH}_{3}$ will exist as either $\mathrm{NH}_{3(\mathrm{aq})}$ or $\mathrm{NH}_{4}^{+}$. Hence the addition of $\mathrm{NH}_{3}$ to the liquid phase will tend to elevate the $\mathrm{pH}$ of the liquid if it is below the $\mathrm{pKa}$ value for the reaction defined in Equation 2.3.2 (Sawyer, 1978). $\mathrm{NH}_{4}{ }^{+}$can be converted to $\mathrm{NO}_{2}^{-}$and subsequently $\mathrm{NO}_{3}^{-}$through the microbially mediated process known as nitrification. The nitrification results in the release of protons and hence can result in a decrease in the liquid $\mathrm{pH}$. The most important factors affecting the nitrification process are (1) temperature that affects the growth of nitrifiers (2) $\mathrm{pH}$ since formation of acidic products decrease the buffering capacity of the waste within the system (3) retention time of the $\mathrm{NH}_{3}$ gas and $\mathrm{NH}_{3}(\mathrm{aq})$ in the biofilter and (4) inhibitors that increase with the production of free $\mathrm{NH}_{3}, \mathrm{NO}_{2}^{-}$(Tchobanoglous et al., 2003; Rittmann and McCarty, 2001). 
Generally nitrification is a two-step process. In the first step, $\mathrm{NH}_{4}{ }^{+}$is oxidized to $\mathrm{NO}_{2}{ }^{-}$ according to Equation 2.3.3. The most commonly recognized genus of bacteria that carries out the first step is Nitrosomonas. The second stage of the nitrification reaction is the oxidation of $\mathrm{NO}_{2}{ }^{-}$to $\mathrm{NO}_{3}{ }^{-}$(Equation 2.3.4). Nitrobacter is the recognized genus of the $\mathrm{NO}_{2}{ }^{-}$oxidizers (Rittmann and McCarty, 2001). Nitrosomonas and Nitrobacter are both aerobic and chemoautotrophic bacteria. Heterotrophic nitrification has generally been viewed as less significant than autotrophic nitrification, due to the significantly higher activity rates of the autotrophs (Rittmann and McCarty, 2001). The use of common heterotrophic bacteria to remove $\mathrm{NH}_{3}$ is inefficient because the demand for a nitrogen source in these bacteria is one-tenth of the demand for a carbon source, indicating that a continuous supply of carbon source is essential. Hence the composition of the microbial population will depend upon the nature of the offgas composition (Gibson, 2001).

Figure 2.5 illustrates the various pathways and intermediates for microbial ammonia transformations in a biofilter (du Plessis et al., 1997). Even though most of the wastewater treatment related-reports have shown that $\mathrm{NH}_{4}{ }^{+}$is involved in the nitrification process, Wood (1986) reported that ammonia $\left(\mathrm{NH}_{3}\right)$ is the substrate for ammonia oxidizers not ammonium $\left(\mathrm{NH}_{4}{ }^{+}\right)$. Wood (1986) reported that the direct oxidation of $\mathrm{NH}_{4}{ }^{+}$ to hydroxylamine $\left(\mathrm{NH}_{2} \mathrm{OH}\right)$ is an energetically unfavorable process. $\mathrm{NH}_{3}$ oxidation involves uncharged $\mathrm{NH}_{3}$ and molecular $\mathrm{O}_{2}$, and yields $\mathrm{NH}_{2} \mathrm{OH}$ as the product (Equation 2.3.5).

$$
\mathrm{NH}_{3}+\mathrm{O}_{2}+2 \mathrm{H}^{+} \longrightarrow \mathrm{NH}_{2} \mathrm{OH}+\mathrm{H}_{2} \mathrm{O}
$$


The enzyme responsible is known as ammonia monooxygenase. There have been no reports of $\mathrm{NH}_{2} \mathrm{OH}$ being detected or trapped during normal $\mathrm{NH}_{3}$ oxidation, implying that the free concentration is very low (Wood, 1986).

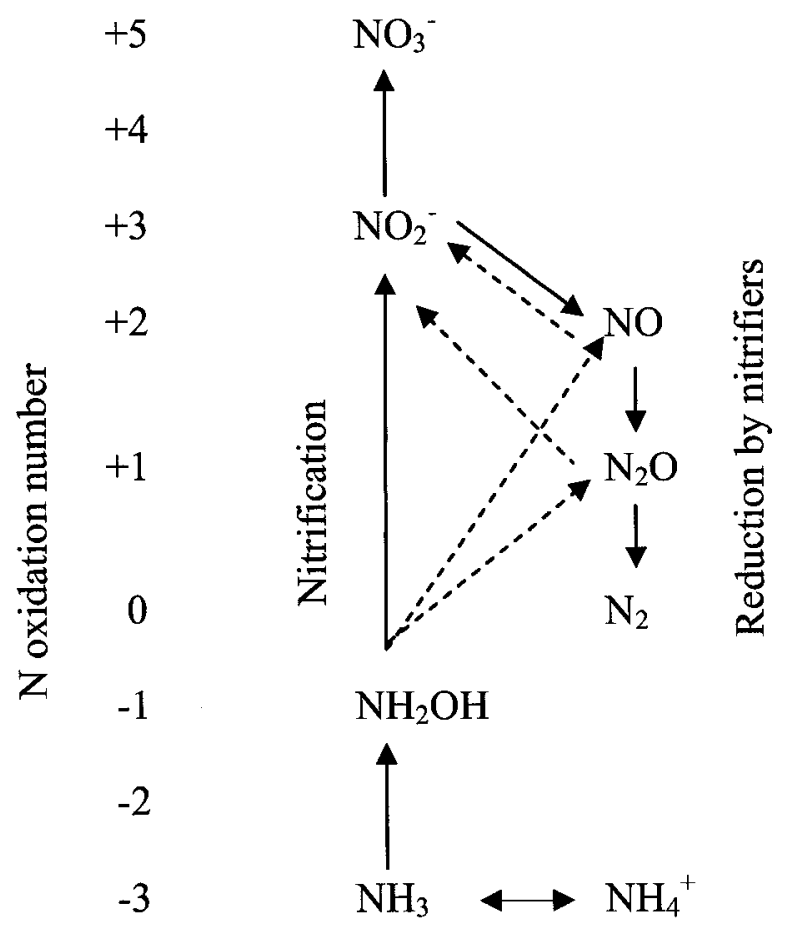

Figure 2.5 Microbiological nitrogen transformations and oxidation states (du Plessis et al., 1997)

As shown in Figure 2.5, the biological oxidation of $\mathrm{NH}_{2} \mathrm{OH}$ is to nitrite by Nitrosomonas sp. then further oxidation of nitrite to nitrate by Nitrobacter sp. The $\mathrm{NH}_{3}$ oxidizing bacteria may produce small amounts of some intermediates like $\mathrm{NO}$ and $\mathrm{N}_{2} \mathrm{O}$ under aerobic conditions (Wood, 1986; du Plessis et al., 1997). Du Plessis et al. (1997) reported that oxidation of ammonium by mostly autotrophic bacteria is often implicated as the major source of $\mathrm{N}_{2} \mathrm{O}$ and $\mathrm{NO}_{\mathrm{X}}$ in soils. Although $\mathrm{N}_{2} \mathrm{O}$ and $\mathrm{NO}_{\mathrm{x}}$ reduction by nitrifiers is 
similar to that which is found by denitrifying organisms, the kinetics of $\mathrm{N}_{2} \mathrm{O}$ and $\mathrm{NO}_{\mathrm{x}}$ reduction is significantly slower for nitrifiers than denitrifiers.

Although there have been reports of denitrification in trickle bed biofilters for waste water treatment, denitrification rarely has been observed in gas phase biofilters. This is in part because there is greater external resistance for oxygen transfer in waste water biofilm systems than in gas phase systems. However, Zhu et al. (2004), Clemens and Cuhls (2003) and de Plessis et al. (1997) have reported the reduction of nitrate into some nitrogen gases in gas phase biofilters.

Denitrification is the reduction of nitrate to nitrogen gas utilizing facultative bacteria and an organic food source. The transformation process can be illustrated by the following sequence:

$2 \mathrm{NO}_{3}^{-} \longrightarrow 2 \mathrm{NO}_{2}^{-} \longrightarrow 2 \mathrm{NO} \longrightarrow \mathrm{N}_{2} \mathrm{O} \longrightarrow \mathrm{N}_{2}$

Denitrification requires relatively low oxygen concentrations which are contrary to the aerobic condition of nitrification. Denitrification can remove nitrate over a $\mathrm{pH}$ range of 5 -10 , being most effective in the range of $\mathrm{pH} 7-8.5$. This process can occur even at temperature range of $5-10^{\circ} \mathrm{C}$, but the rates are slow (Rittmann and McCarty, 2001).

Zhu et al. (2004) reported that in a gas phase aerobic biofilter, the nutrient $\mathrm{NO}_{3}{ }^{-}$can serve both as a growth controlling nutrient and as an electron acceptor in a biofilm. The microbial communities within the biofilters provided a more complete picture of 
denitrification on biofilter performance. Zhu et al. (2004) identified denitrifiers (microbial communities) in the packing by microbial analysis and confirmed that the denitrification process was active in the biofilter.

Clemens and Cuhls (2003) reported that when $\mathrm{NH}_{3}$ gas was treated in an aerobic biofilter, $\mathrm{N}_{2} \mathrm{O}$ and $\mathrm{NO}$ were released from the biofilter. The $\mathrm{N}_{2} \mathrm{O}$ and $\mathrm{NO}$ production in the biofilter were correlated with the $\mathrm{NH}_{3}$ retention and loading to the biofilter. It was also stated that high loads of $\mathrm{NH}_{3}$ might have inhibited complete nitrification by an increased concentration of free $\mathrm{NH}_{3}$ or alternatively a high nitrification rate may have resulted in nitrite accumulation and drop in $\mathrm{pH}$. Both processes might lead to nitrite accumulation that can enhance the formation of gaseous $\mathrm{N}_{2} \mathrm{O}$ and $\mathrm{NO}_{\mathrm{x}}$ by either biogenic or abiogenic processes (Clemens and Cuhls, 2003).

\subsubsection{Reduced sulfur compound treatment mechanisms}

RSC have low water solubility and relatively high vapor pressures. So these compounds have relatively high Henry's law coefficient which is a negative factor for efficient mass transfer from air to aqueous systems, then low removal efficiencies would be expected for RSC in a biofilter. However, as indicated in Section 2.2, many successful biofilter systems have been observed to treat the RSC with very high removal efficiency. Therefore it was believed that biological mediated reactions were dominant on the removal of RSC. 
The biological oxidation of DMDS and DMS is presented in Figures 2.6 and 2.7 respectively. Smith and Kelly (1988b) proposed a mechanism for the oxidation of DMDS by T.thioparus strain E6 (Figure 2.6).

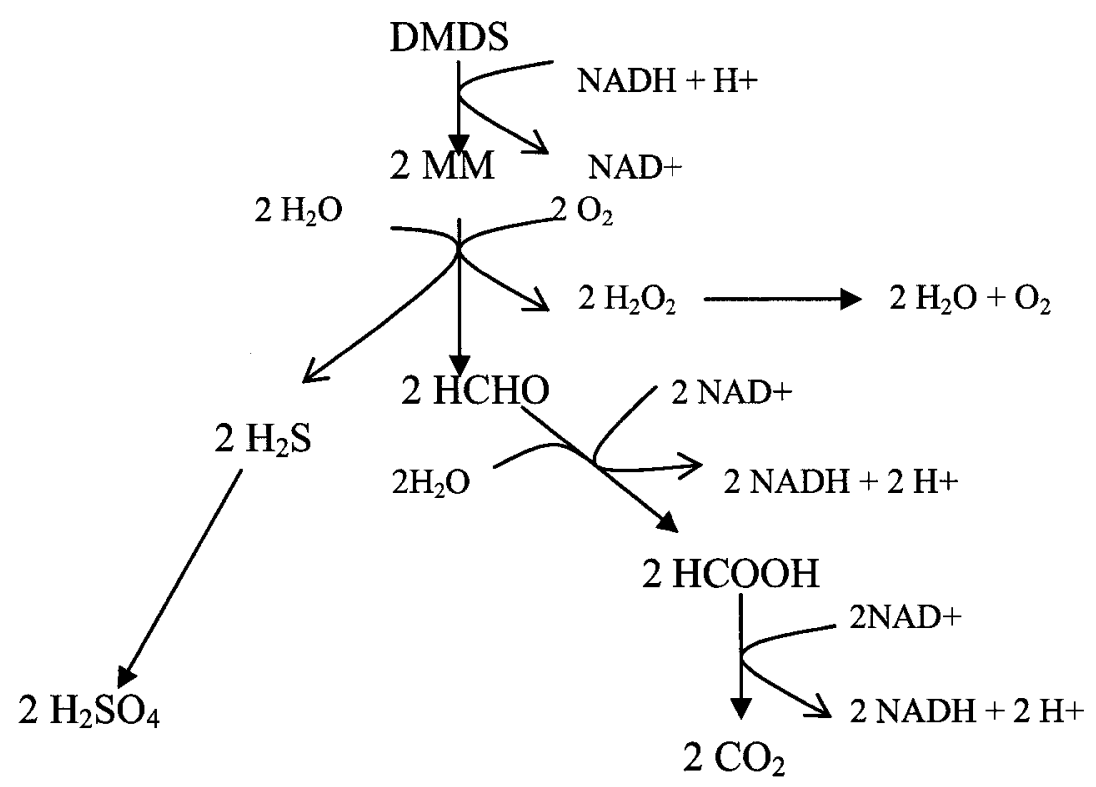

Figure 2.6 Assumed mechanism for oxidation of DMDS

(Smith and Kelly, 1988b)

As shown in Figure 2.6, one molecule of DMDS produces two molecules of MM and the reaction is independent of oxygen. The 'DMDS reductase' enzyme uses NADH as a reductant when transforming DMDS to $\mathrm{MM}$. The $\mathrm{MM}$ is believed to be oxidized via formaldehyde $(\mathrm{HCHO})$ and formate $(\mathrm{HCOOH})$ to $\mathrm{CO}_{2}$ and sulfate (Smith and Kelly, 1988a). The oxidation of $\mathrm{MM}$ by ' $\mathrm{MM}$ oxidase' produces $\mathrm{H}_{2} \mathrm{~S}$ as an intermediate, but under aerobic conditions there would be rapid biochemical oxidation of $\mathrm{H}_{2} \mathrm{~S}$ to sulfate.

De Bont et al. (1981) proposed a mechanism for the oxidation of DMS by Hyphomicrobium S. As shown in Figure 2.7, the oxidation of DMS produces MM and HCHO by the 'mono-oxygenase' enzyme for which again, NADH is the preferred 
electron donor. The reaction is strictly dependent on the presence of oxygen (De Bont et al., 1981). The rest of the pathway is the same as that of DMDS.

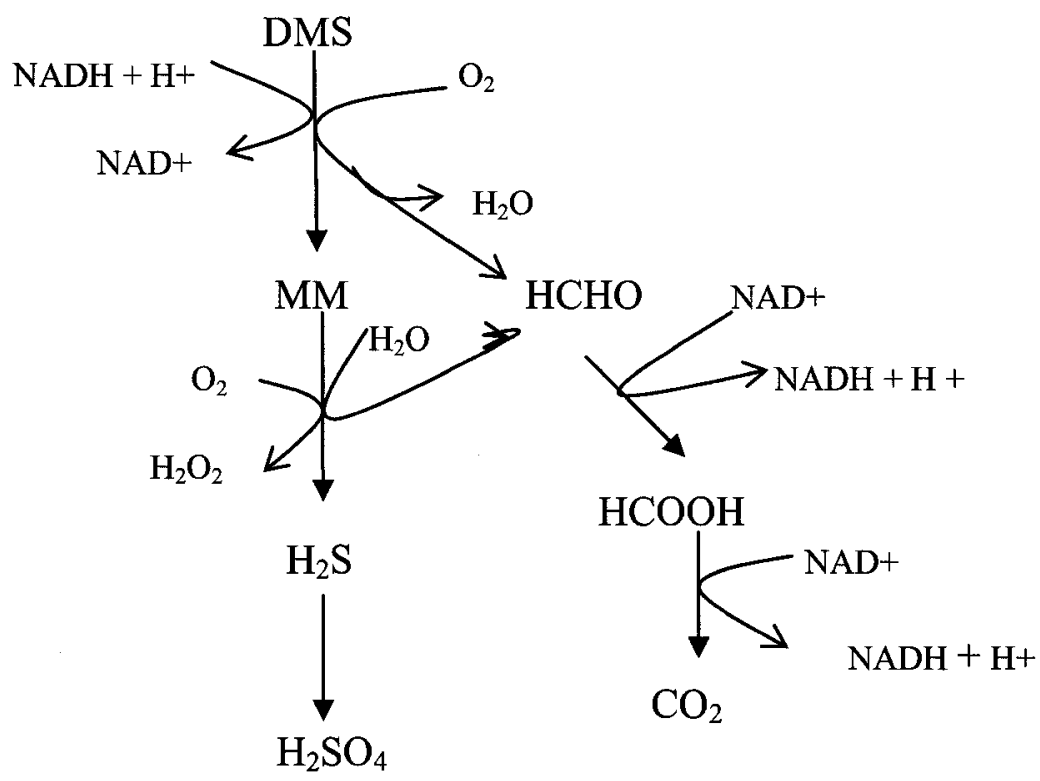

Figure 2.7 Assumed mechanisms for oxidation of DMS

(De Bont et al., 1981)

The overall biological oxidation of $\mathrm{MM}$ and $\mathrm{H}_{2} \mathrm{~S}$ may be written by the following stoichiometric equations (Janssen et al., 1995; Taylor and Kiene, 1989):

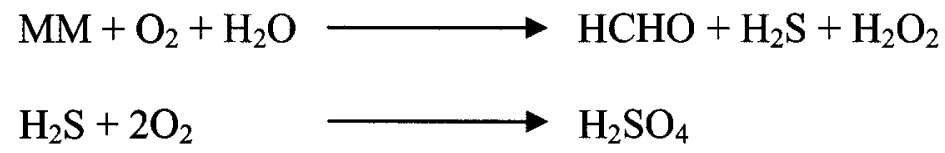

As discussed in the DMDS pathway (Figure 2.6), MM oxidation is probably mediated by an oxidase, which produces $\mathrm{H}_{2} \mathrm{O}_{2}$. Equation 2.3.6 shows the $\mathrm{MM}$ oxidation and its intermediate products such as $\mathrm{HCHO}, \mathrm{H}_{2} \mathrm{~S}$ and $\mathrm{H}_{2} \mathrm{O}_{2}$. These intermediates are subjected to further oxidation to $\mathrm{SO}_{4}{ }^{2-}$ and $\mathrm{CO}_{2}$. 
Upon further review of all the RSC entering the system, it was concluded that one cannot evaluate removal of MM alone in the presence of DMDS and DMS. As shown in Figures 2.6 and 2.7, MM is an intermediate in the DMDS and DMS oxidative pathways. Thus, the concentration of MM will be influenced by the concentration of DMS and DMDS in a biofilter. $\mathrm{H}_{2} \mathrm{~S}$ is also an intermediate in the MM, DMS and DMDS oxidative pathways. From Figures 2.6 and 2.7 and Equations 2.3.6 and 2.3.7, it can be seen that due to biological activity, most of the RSCs are oxidized to $\mathrm{SO}_{4}{ }^{2-}$ (De Bont et al., 1981; Smith and Kelly, 1988b). A number of studies on biofilters have confirmed that sulphuric acid $\left(\mathrm{H}_{2} \mathrm{SO}_{4}\right)$ or $\mathrm{SO}_{4}{ }^{2-}$ was found to be the end product of $\mathrm{H}_{2} \mathrm{~S}$ biological oxidation (Van Langenhove et al., 1986; Cadenhead and Sublette, 1990; Yang and Allen, 1994b; Jensen and Webb, 1995). However elemental sulfur and thiosulfate were also found as intermediate products of the RSC oxidations (Yang and Allen, 1994b). Jensen and Webb (1995) studied several microorganisms that degraded the $\mathrm{H}_{2} \mathrm{~S}$ in a biofilter. Almost all the microbial species that were examined by the authors produced $\mathrm{SO}_{4}{ }^{2-}$ as an end product.

In fixed film systems where there is a mixture of microbial populations there will inevitably be a competition for space as well as limiting nutrients. The degree of competition is influenced by the growth rates of the different populations. These growth rates are a function of the physiological states of the microbes as well as the levels of substrate that are present. Moe and Irvine (2000) reported that, by imposing a feed-starve cycle on biofilters, the performance of biofilters can be enhanced. It is hypothesized that the cyclical nature of offgas contamination in ATAD offgases may cause a feed-starve cycle in biofilters treating the offgases. It is believed that this may have some influence 
on the physiological state of the microbes within the biofilters and hence influence the rate at which they can uptake contaminants during periods of high contaminant concentration. The ability of biofilters to perform under cyclic exposure and after periods of non-exposure is critical for their application to composting operations. Gibson and Otten (1997) conducted a series of experiments on biofiltration using compost as the biofilter medium. They determined that the system responded well to both steps in contaminant concentration and cyclic dynamic loading. Filter beds, which had been unexposed to pollutants for periods of one month, demonstrated an instant removal capacity, and regained maximum removal capacity with 48 hours under cyclic loading conditions.

Kim et al. (2002) studied long term operation of a biofilter for simultaneous removal of $\mathrm{H}_{2} \mathrm{~S}$ and $\mathrm{NH}_{3}$. They observed that elemental sulfur and $\left(\mathrm{NH}_{4}\right)_{2} \mathrm{SO}_{4}$ were formed on the woodchip packing surface. This was confirmed by scanning electron microscope (SEM) images of the woodchips before and after the reaction. It was suggested that some of the RSCs were partially oxidized to elemental sulfur. When $\mathrm{NH}_{3}$ removal and sulfur oxidation take place together in a bed, there is a possibility of forming $\left(\mathrm{NH}_{4}\right)_{2} \mathrm{SO}_{4}$ which are fine white granules or crystals. However it is soluble in water, therefore it does not stay in the packing for a long period. Especially when cyclic loading occurs, formation and dissolution in water can vary with time according to the loading.

Biofiltration has been regularly employed to control odorous compounds in air streams. However, they have not always been successfully employed for treatment of ATAD off 
gases (Pride, 2002). However Pride (2002) has reported the successful application of biofiltration for ATAD off gases, although it is not clear why these biofilters perform better than that observed in some other applications. As indicated above ATAD offgases contain a complex mixture of inorganic and organic compounds that vary on a cyclical basis with time. There is relatively little information in the literature that describes the performance of biofilters under these conditions. There is also little information to describe the behavior of biofilters treating an air stream that varies in composition on a regularly repeating basis.

\subsection{Factors Affecting Biofilter Performance}

\subsubsection{Biofilter media}

Biofiltration is a process that utilizes microorganisms immobilized in the form of a biofilm layer on a porous filter substrate. The "heart" of a biofiltration system is the filter bed, which can provide a nutrient source and a surface for attachment of microorganisms (Corsi and Seed, 1995). Desirable medium properties include optimal microbial environment, large specific surface area, structural integrity, high moisture retention, high porosity and low bulk density (Swanson and Loehr, 1997). Based on these properties, various types of porous materials have been employed as biofilter media, with compost and soil being the most common types (Bohn, 1997). Other materials include wood bark (Van Langenhove et al., 1986; Pride, 2002), sand (Koe and Shanchayan, 2001), sand and loam (Kampbell et al., 1987), a mixture of compost and diatomaceous earth (Hodge and Devinny, 1995), granular activated carbon (Hodge and Devinny, 1995) and some synthetic materials (Koe and Yang, 1999). Kim et al. (2000a) demonstrated that organic 
media was superior to inorganic media when treating ammonia. They indicated that organic packing materials provide a more suitable environment for nitrifying bacteria than inorganic packing materials. Some media are likely to provide micro-nutrients to the microorganisms and may also provide a surface chemistry that promotes their growth.

Biofilter performance is generally affected by the proper selection of the medium (Bohn, 1997). Many mixtures have been tested to develop optimal filter materials with high activities and a low flow resistance. Andrews and Noah (1995) pointed out that the size of bed materials must be small enough to provide a large surface area; however, the bed may be plugged with excess biofilm or water logged by excess moisture in a small medium. The surface area to bed volume (specific surface area) for biofilter media ranges from 100 to $1100 \mathrm{~m}^{2} / \mathrm{m}^{3}$, with wood chips having a ratio of $160 \mathrm{~m}^{2} / \mathrm{m}^{3}$ while a mixture of heather and peat had an area to volume ratio of $1100 \mathrm{~m}^{2} / \mathrm{m}^{3}$ (Phillips et al., 1995).

For maximum compound removal, Corsi and Seed (1995) stated that the bed material should have high moisture retention capacity in order to prevent drying, high porosity of filter bed to reduce head loss and to increase the distribution of incoming waste gas, available nutrients for optimal microbial growth, and a diverse microbial population. Structural stability and low density of the support medium reduces medium compaction potential which otherwise would cause excessive pressure drop. A void volume between $40-80 \%$ keeps the operating pressure drop low and ensures easy gas flow. 
Absorption and adsorption are probably the first processes in the biofilter mechanism. Adsorption capacity of the filter media has been demonstrated in several studies (Hodge and Devinny, 1995; Amanullah et al., 1999). Some filter materials such as GAC and wood chip mixtures have shown their potential adsorption during the start up periods of the biofilters. Amanullah et al. (1999) suggested that support media providing adsorption are capable of handling load fluctuations irrespective of the rate of reaction in the adsorbed phase. However, Van Langenhove et al. (1986) reported that the functioning of the filter couldn't be explained by these processes alone because in the given circumstances the system would be saturated in less than one day for a continuous run wood bark biofilter.

Based on the above review, composted woodchips were identified as a preferred packing material for long run industrial purposes. The composted woodchips which are being used by Ambio Biofilter Inc. and also in this study consist of root woodchips that are sprayed with compost or activated sludge from waste water treatment plant. These composted woodchips have, relatively large specific surface area, high moisture retention, optimal microbial environment and the ability to withstand load fluctuation (adsorption capacity) (Pride, 2002). Therefore they were selected for the ATAD offgas treatment. 


\subsubsection{Microbial consortia}

Selection of support medium and microorganisms is crucial in the design of a biofilter. The inoculation of the biofilter medium with specific and adapted microorganisms reduces the start-up period and may increase the biofiltration performance (Cho et al., 1991a; Smet et al., 1996b). Usually mixed cultures are used for mixed gas pollutants like ATAD offgases. The growth and metabolic activity of microorganisms in a filter depends on a number of factors such as the presence of dissolved oxygen in the biofilm, the absence of compounds that are toxic to microorganisms, the availability of nutrients, sufficient moisture, and suitable ranges for temperature and $\mathrm{pH}$. Accordingly, the control of these parameters is essential for the efficient operation of a biofilter.

Microorganisms degrade pollutants by consuming them for energy to produce $\mathrm{CO}_{2}$, water and other products such as $\mathrm{NH}_{3}, \mathrm{RSC}$. The mechanisms by which microorganisms degrade pollutants are complex in nature. Microorganisms can either directly consume the pollutants or release enzymes that breakdown the pollutants into simple substances and then consume them (Devinny et al., 1999). The microbiology of a biofilter treating ATAD offgases will consist of a mixture of autotrophic and heterotrophic organisms. Autotrophs will develop as a result of the oxidation of ammonia (i.e., Nitrosomonas) and RSCs (i.e. Thiobacillus) (Gibson, 2001). Heterotrophs will grow on organic substances such as volatile organic compounds that may be present in the offgas or are present as metabolic byproducts and products of endogenous decay of autotrophic organisms. 
When a pollutant is introduced into the biofilter upon start-up, the microbial distribution will generally shift towards strains that metabolize the target pollutants. The time required for the change in microbial populations accounts for 'start-up' acclimatization. Acclimation time could greatly be reduced by mean of inoculation with an appropriate culture. In addition, some pure strains demonstrate better performance in terms of removal over a mixed culture for particular target pollutants such as Thiobacillus species for RSCs (Cho et al., 1991a) or especially, Thiobacillus thiooxidans for $\mathrm{H}_{2} \mathrm{~S}$ (Hirano et al., 1996), Hyphomicrobium MS3 for DMS (Smet et al., 1996b) and Thiobacillus thioparus for $\mathrm{H}_{2} \mathrm{~S}, \mathrm{MM}$, DMS and DMDS (Kanagawa and Mikami, 1989; Jensen and Webb, 1995). Cho et al. (1991a) showed that a mixed culture of Hyphomicrobium, thiobacillus, and xanthomonas species was able to efficiently degrade RSCs. Kim et al. (2000b) isolated a new bacterium, Vibrio alginolyticus to remove a high load of ammonia (range of $120-2000 \mathrm{ppmv}$ ). The authors reported that the removal rate by the new bacterium was four times larger than those obtained in nitrifying sludge inoculated on to the same packing material. However when considering a mixture of gases such as ATAD offgas, it was impossible to use a single species of microbial community. Therefore, a mixed culture of microbial community was used for mixture of $\mathrm{NH}_{3}$ and $\mathrm{H}_{2} \mathrm{~S}$ studies (Jones et al., 2004; Kim et al., 2002; Sun et al., 2000). Mixed microorganisms from municipal sludge were cultured on the woodchip packing in this study to treat $\mathrm{NH}_{3}$ and RSC. 


\subsubsection{Essential environmental conditions}

The rate of water addition will impact the process chemistry and microbiology of a biofilter. Systems that have low rates of water supplementation will not generate a leachate stream and hence metabolic products such as nitrate will accumulate in the media. This has been found to result in inhibition of the microbial populations after some period of operation (Smet et al., 2000). Systems that employ higher water supplementation will tend to flush out metabolic byproducts. However, in these designs the media must be able to pass the extra water without becoming excessively saturated. High water content will reduce gas-liquid mass transfer and can result in the development of anaerobic regions in the biofilter. It also increases pressure drop and may cause irreversible structural damage in the media (Lith et al., 1997). Van Langenhove et al. (1986) reported that the water content of wood bark below $60 \%$ of weight resulted in a severe loss of efficiency which could be reestablished by moistening the filter.

Most microorganisms capable of degrading pollutants show optimum growth in a certain $\mathrm{pH}$ range. Sulfur reducing microorganisms can survive even at very low $\mathrm{pH}$. Most of the RSC biodegradation releases acidic substances (e.g., $\mathrm{SO}_{4}{ }^{2-}$ ) in the biofilter leachate. Yang and Allen (1994b) found the media pH dropped from 8.0 to 2.5 in 32 days in a compost biofilter receiving high $\mathrm{H}_{2} \mathrm{~S}$ loading. To buffer acidic by-products in the media and maintain a neutral $\mathrm{pH}$, most suppliers of biofilters add alkaline buffers, usually calcium carbonate or lime, to the filter material (Lith et al., 1997). However, ATAD offgases themselves can provide some buffering capacity. Dissolution of $\mathrm{NH}_{3}$ from the offgas 
acted to buffer against $\mathrm{pH}$ decreases that would result from the biological transformation of RSC and $\mathrm{NH}_{3}$.

Offgas pre-humidification is common in most recent full-scale biofilters to prevent bed drying. The pre-humidification system can also adjust the temperature of the gas entering the biofilter and remove any particulate matter that may clog the biofilter. The prehumidification also absorbs $\mathrm{NH}_{3}$ gas from the ATAD offgases. Therefore pre-humidifiers function as a water scrubber (wet scrubber) as well. As discussed earlier in this chapter, the high concentrations of $\mathrm{NH}_{3}$ may inhibit the biofilter performance. The wet scrubber is a critical step in the ATAD offgas treatment by biofilters.

For mesophilic microorganisms that are almost exclusively used in biofiltration, bed temperatures between 10 and $40^{\circ} \mathrm{C}$ are acceptable, with an optimum range for biological activity of $30-35^{\circ} \mathrm{C}$ (Corsi and Seed 1995; Lith et al., 1997; Swanson and Loehr, 1997). Sun et al. (2000) reported that the optimum operating temperature of biofilter beds is about $37^{\circ} \mathrm{C}$. Biodegradation rates increase with increasing temperature and show an Arrhenius type of temperature dependence. Although non-optimal temperatures can reduce degradation rates, microorganisms often recover rapidly from temperature variations (Bohn, 1997). Therefore, small temperature variations do not affect the overall biofilter performance.

Finally, the support medium should be able to supply adequate amount of nutrients such as nitrogen, potassium and trace elements or the target pollutants should be able to 
provide these nutrients to maintain the colony of microorganisms. Swanson and Loehr (1997) found that there were no guidelines available to identify the amount of available nutrients needed in biofilters. It is necessary to provide nutrients to biofilters operating with inert medium like sand, but not necessary for organic media such as compost. There have been few published accounts of the effects of nutrient limitations on biofilter performance, or temporal changes in nutrient availability within a biofilter bed (Leson and Winer, 1991). Hartikainen et al. (1996) suggested that phosphorus could limit nitrification activity of $\mathrm{NH}_{3}$ removal in a biofilter. However the composted woodchip media with plant water post humidification gave substantial nutrient supply to the microbial community in the biofilter (Pride, 2002).

\subsection{Models}

The transport and removal mechanisms for pollutants in a biofilter are complex. In this section, key models that are presented in the literature are discussed. Their limitations and differences are identified with the objective of defining a comprehensive dynamic biofilter model. This is important for conceptual understanding of biofiltration operation. Table 2.9 shows the important features of the model developments in the literature. As shown in Table 2.9, initial model developments were based on steady state performance. Shareefdeen and Baltzis (1994b) developed a model with transient and steady state mechanisms, but most recently $\mathrm{Li}$ et al. (2002a) developed a dynamic model for biofilter operation. With the exception of Li et al. (2002a), most of the reported models are based on VOC removal with laboratory scale experiments employed in the model development. Here the transient state refers to single steps in concentration that were followed by an 
extended period of constant concentration, where the system was allowed to approach steady state. The dynamic state refers to conditions where the composition and concentration of contaminants varies on a regularly repeating basis (cyclic variation).

Table 2.9 Summary of biofilter model studies in literature and their main features

\begin{tabular}{|c|c|c|c|c|c|c|c|c|}
\hline Year & Authors & $\begin{array}{l}\text { Support } \\
\text { media }\end{array}$ & Pollutants & $\begin{array}{l}\text { Type of } \\
\text { model }\end{array}$ & $\begin{array}{l}\text { Type } \\
\text { of } \\
\text { experi } \\
\text { ment }\end{array}$ & $\begin{array}{l}\text { Biofilm } \\
\text { kinetics }\end{array}$ & $\begin{array}{l}\text { * Model } \\
\text { phases }\end{array}$ & $\begin{array}{l}\text { Biomas } \\
\text { s culture }\end{array}$ \\
\hline 1983 & $\begin{array}{l}\text { Ottengraf } \\
\text { and Oever }\end{array}$ & $\begin{array}{c}\text { Peat \& } \\
\text { compost }\end{array}$ & VOC's 1 & Steady & $\mathrm{Lab}$ & $\begin{array}{c}\text { First or } \\
\text { Zero order }\end{array}$ & $\begin{array}{c}3 \\
\mathrm{~A} / \mathrm{B} / \mathrm{S}\end{array}$ & - \\
\hline 1993 & $\begin{array}{c}\text { Shareefdeen } \\
\text { et al., }\end{array}$ & $\begin{array}{l}\text { Peat }+ \\
\text { pearlite }\end{array}$ & $\begin{array}{l}\text { Methanol } \\
\text { Vapor }\end{array}$ & Steady & $\mathrm{Lab}$ & Monod & $\begin{array}{c}2 \\
\mathrm{~A} / \mathrm{B}\end{array}$ & $\begin{array}{l}\text { Specific } \\
\text { culture }\end{array}$ \\
\hline $\begin{array}{c}1994 \\
\text { b }\end{array}$ & $\begin{array}{l}\text { Shareefdeen } \\
\text { and Baltzis }\end{array}$ & $\begin{array}{l}\text { Peat }+ \\
\text { perlite }\end{array}$ & Toluene & $\begin{array}{c}\text { Steady \& } \\
\text { transient }\end{array}$ & $\mathrm{Lab}$ & Monod & $\begin{array}{c}3 \\
\mathrm{~A} / \mathrm{B} / \mathrm{S}\end{array}$ & $\begin{array}{l}\text { Mixed } \\
\text { culture }\end{array}$ \\
\hline 1995 & $\begin{array}{l}\text { Hodge and } \\
\text { Devinny }\end{array}$ & $\begin{array}{c}\text { Compost, } \\
\text { GAC, } \\
\mathrm{DE}^{\mathrm{m} 1} \\
\end{array}$ & $\begin{array}{l}\text { Ethanol } \\
\text { vapor }\end{array}$ & $\begin{array}{l}\text { Steady \& } \\
\text { non steady }\end{array}$ & Lab & First order & $\begin{array}{c}2 \\
A / S(B)\end{array}$ & $\begin{array}{c}\text { Not } \\
\text { mention }\end{array}$ \\
\hline $\begin{array}{c}1995 \\
\mathrm{a}\end{array}$ & $\begin{array}{c}\text { Deshusses et } \\
\text { al., }\end{array}$ & $\begin{array}{c}\text { Compost } \\
+ \\
\text { polystyren } \\
\mathrm{e} \\
\end{array}$ & $\begin{array}{l}\text { MEK, } \\
\text { MIBK }\end{array}$ & $\begin{array}{l}\text { Steady \& } \\
\text { transient }\end{array}$ & Lab & Monod & $\begin{array}{c}3 \\
\mathrm{~A} / \mathrm{B} / \mathrm{S}\end{array}$ & $\begin{array}{l}\text { Specific } \\
\text { culture }\end{array}$ \\
\hline 1997 & $\begin{array}{c}\text { Baltzis et } \\
\text { al., }\end{array}$ & $\begin{array}{c}\text { Peat }+ \\
\text { perlite } \\
(2: 3) \\
\end{array}$ & $\begin{array}{c}\text { Benzene }+ \\
\text { toluene }\end{array}$ & Steady & $\mathrm{Lab}$ & First order & $\begin{array}{c}3 \\
\mathrm{~A} / \mathrm{B} / \mathrm{S}\end{array}$ & $\begin{array}{l}\text { mixed } \\
\text { culture }\end{array}$ \\
\hline 1998 & $\begin{array}{c}\text { Alonso et } \\
\text { al., }\end{array}$ & $\begin{array}{l}\text { Celite } \\
6 \mathrm{~mm}, \\
\mathrm{R} 635 \\
\end{array}$ & $\begin{array}{l}\text { VOC- } \\
\text { diethyl } \\
\text { ether }\end{array}$ & Dynamic & Lab & Monod & $\begin{array}{c}3 \\
A / L / B\end{array}$ & $\begin{array}{c}\text { Not } \\
\text { mention }\end{array}$ \\
\hline 1999 & $\begin{array}{c}\text { Amanullah } \\
\text { et al., }\end{array}$ & $\begin{array}{l}\text { Compost } \\
\& \text { GAC }\end{array}$ & MEK & Dynamic & $\mathrm{Lab}$ & Monod & $\begin{array}{c}3 \\
\mathrm{~A} / \mathrm{B} / \mathrm{S}\end{array}$ & $\begin{array}{c}\text { Mixed } \\
\text { and } \\
\text { Specific }\end{array}$ \\
\hline $\begin{array}{c}2002 \\
a\end{array}$ & Li et al., & Lava rock & $\mathrm{H}_{2} \mathrm{~S}$ & Dynamic & $\begin{array}{c}\text { Pilot } \\
\& \\
\text { Full } \\
\end{array}$ & Monod & $\begin{array}{c}3 \\
A / L / B\end{array}$ & $\begin{array}{c}\text { Not } \\
\text { mention }\end{array}$ \\
\hline $\begin{array}{c}2002 \\
b\end{array}$ & Li et al., & $\begin{array}{c}\text { Compost } \\
+ \text { wood } \\
\text { chips } \\
\end{array}$ & $\begin{array}{c}\mathrm{H}_{2} \mathrm{~S} \& \\
\mathrm{MM}\end{array}$ & Dynamic & $\begin{array}{c}\text { Pilot } \\
\& \\
\text { Full } \\
\end{array}$ & Monod & $\begin{array}{c}2 \\
\mathrm{~A} / \mathrm{B}\end{array}$ & $\begin{array}{c}\text { Not } \\
\text { mention }\end{array}$ \\
\hline
\end{tabular}

Note:

VOC's 1: Toluene, Butyl Acetate, Ethyl acetate, and Ethanol

MEK : methyl ethyl ketone

MIBK : methyl isobutyl ketone

Model phases: A-air stream, L- liquid, B-biofilm, S-solid material 
Ottengraf and Oever (1983), in their pioneering work, introduced the concept of a biofilm in biofilters. The biofilm is a biologically active liquid layer that coats the top of the support particles. They demonstrated the possibility of reaction and diffusion controlled regimes in the biofilm (Figure 2.8). A reaction-controlled regime, where the activity of the biolayer surrounding the packing particles is fully utilized and no reaction free zone exists, occurred when the loading was higher than the maximum elimination capacity of the filter (curve 1, Figure 2.8). A diffusion-controlled regime, where a reaction-free zone exists in the biolayer, occurs when the rate of diffusion is slow as compared to the substrate utilization rate (curve 2, Figure 2.8). As the rate of diffusion is controlled by the concentration gradient in the biolayer and by the concentration level at the interface, this situation typically occurs at lower gas phase concentration levels. Ottengraf and Oever (1983) provided experimental results and theoretical analysis of this biological process for the elimination of VOCs in a compost biofilter. On this basis they proposed a steadystate model. A plug flow model was assumed for the flow of contaminated gas through the filter bed. Pollutant removal from the gas phase was by absorption followed by simultaneous diffusion and reaction in the biofilm. The microbial-kinetics for substrate elimination in the biofilm was simplified to either zero-order or first-order kinetics.

The model with a zero-order reaction was described by following equation:

$$
D \frac{d^{2} C_{L}}{d x^{2}}=K
$$

The model with a first-order reaction was described by following equation:

$$
D \frac{d^{2} C_{L}}{d x^{2}}-K^{\prime} C_{L}=0
$$

$D \quad$ liquid phase diffusion coefficient

$C_{L} \quad$ liquid phase compound concentration 
$x \quad$ distance in the biofilm (Figure 2.8)

$K \quad$ zero-order reaction rate

$K^{\prime} \quad$ first order reaction rate

The model equations were analytically solved and verified with independent experimental results for the removal of toluene, ethyl acetate, butyl acetate, and butanol mixtures in an air stream. The development of advanced design techniques and a mathematical model initiated by Ottengraf began the transformation of biofiltration research from a "black box" approach to a science-based effort (Devinny et al., 1999).

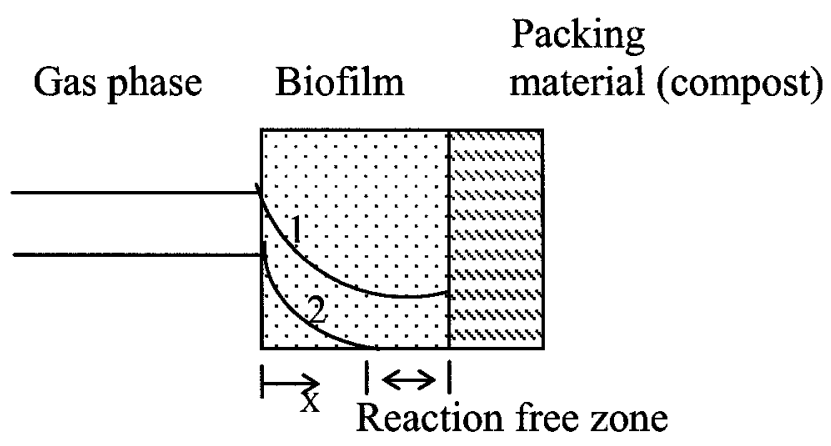

Figure 2.8 The biophysical model for the biological filter bed (Ottengraf and Diks, 1991)

Shareefdeen et al. (1993) proposed a similar steady state model in which methanol and oxygen were the substrates affecting the reaction rate. Diffusion and reaction of these two compounds in the biofilm were considered. The authors suggested that biofiltration of methanol was limited by oxygen diffusion and methanol degradation kinetics. The biodegradation process in the biofilm was described as shown in Equation 2.5.3 and 2.5.4. The specific growth rate was described by an interactive model: it has an Andrews type dependence on the methanol concentration and a Monod type dependence on the 
oxygen concentration. The mass transfer along the column was described as shown in Equation 2.5.5.

$$
\begin{aligned}
& D_{M} \frac{d^{2} S_{M}}{d x^{2}}=\frac{X_{V}}{Y_{M}} \mu\left(S_{M}, S_{O}\right) \\
& \mu\left(S_{M}, S_{O}\right)=\frac{\mu^{*} S_{M}}{K+S_{M}+\left(S_{M}{ }^{2} / K_{I}\right)} \frac{S_{O}}{K_{O}+S_{O}} \\
& u_{g} * \frac{d C_{M}}{d h}=A_{s} * D_{M} *\left[\frac{d S_{M}}{d x}\right]_{x=0}
\end{aligned}
$$

As Biolayer surface area per unit volume of reactor

$C_{M} \quad$ Concentration of methanol in the air at a position $\mathrm{h}$ along the biofilter

$D_{M} \quad$ Diffusion coefficient of methanol in the biofilm

$h \quad$ position in the column

$K \quad$ Constant in the specific growth rate expression for methanol

$K_{I} \quad$ inhibition constant in the specific growth rate expression

$K_{o} \quad$ Constant in the specific growth rate expression for oxygen

$S_{M} \quad$ Methanol concentration at a position in the biolayer

$S_{O} \quad$ Oxygen concentration at a position in the biolayer

$u_{g} \quad$ superficial air velocity in the biofilter

$X_{V} \quad$ Biofilm density

$X \quad$ position in the biolayer

$Y_{M} \quad$ Yield coefficient on methanol

$\mu \quad$ Specific growth rate

$\mu * \quad$ Constant in the specific growth rate expression

This model, originally applied to methanol vapor removal at steady state, was also used to describe the biofiltration of other substances like benzene and toluene (Shareefdeen and Baltzis, 1994a). Later, the same model was extended to describe transient behavior for the removal of toluene vapor (Shareefdeen and Baltsis, 1994b). In this study, the concepts of partial coverage of the support media with biofilm as well as adsorption of the pollutants on the solid media through the uncovered portion were introduced. The results demonstrated that oxygen diffusion might become rate limiting in cases where polar compounds are involved. 
Hodge and Devinny (1995) assumed that biodegradation could be described by first-order kinetics and used an axially dispersed plug flow model for the gas phase and a linear driving force model to approximate the interface mass transfer kinetics. The model assumed that transport in the water and adsorption on the medium, were rapid in comparison to advection and biodegradation. The model treated the porous medium as a two-phase system: the air phase and the water and solid phase (solids/water). Treating the water and solids as single phase ignored important phenomena such as diffusion in the water/biofilm layer and details of the adsorption process at the water solid interface. The model described transfer between the air and solids/water phases, biological degradation of the substrate, $\mathrm{CO}_{2}$ production and accumulation and $\mathrm{pH}$ changes resulting from $\mathrm{CO}_{2}$ accumulation. As shown in Equation 2.5.6, the fundamental equations governing transport of the substrate in the gas phase was dispersion, advection and transfer to the solids/water phase. The mass transfer and the pollutant degradation in solid/water phase were shown in Equation 2.5.7.

$$
\begin{aligned}
& \frac{\partial C}{\partial t}=D \frac{\partial^{2} C}{\partial x^{2}}-V \frac{\partial C}{\partial x}-\left(\frac{1-\theta}{\theta}\right) *\left[k\left(K_{h} C-C_{a d s}\right)\right] \\
& \frac{\partial C_{a d s}}{\partial t}=k\left(K_{h} C-C_{a d s}\right)-b_{1} * C_{a d s}
\end{aligned}
$$

$b_{1} \quad$ First-order biological rate constant

C Concentration in air phase

$C_{a d s} \quad$ Concentration in solids/water phase

$D \quad$ Dispersion coefficient in air phase

$k \quad$ Transfer rate constant

$k_{h} \quad$ Partition coefficient

$t \quad$ Time

$V \quad$ Axial interstitial velocity of air

$x \quad$ Distance of travel in filter

$\theta \quad$ Filter material porosity at field capacity 
Deshusses et al. (1995a, 1995b) developed both steady-state and transient state biofilter models for treatment of a waste air mixture. Based on dynamic mass balances, they proposed a transient model for biofiltration of MEK/MIBK mixtures in which kinetic interaction between the pollutants was taken into account in the degradation reaction model. Diffusion of pollutants in the biofilm was modeled as four mixed reactors in series while oxygen was assumed to be present in excess. The model had a sorption term in a dead volume of water corresponding to the moisture content of the biofilm. The biofilter height was divided into 10 layers and each layers had 3 main sections: the gas phase, the biofilm and the media (Figure 2.9).

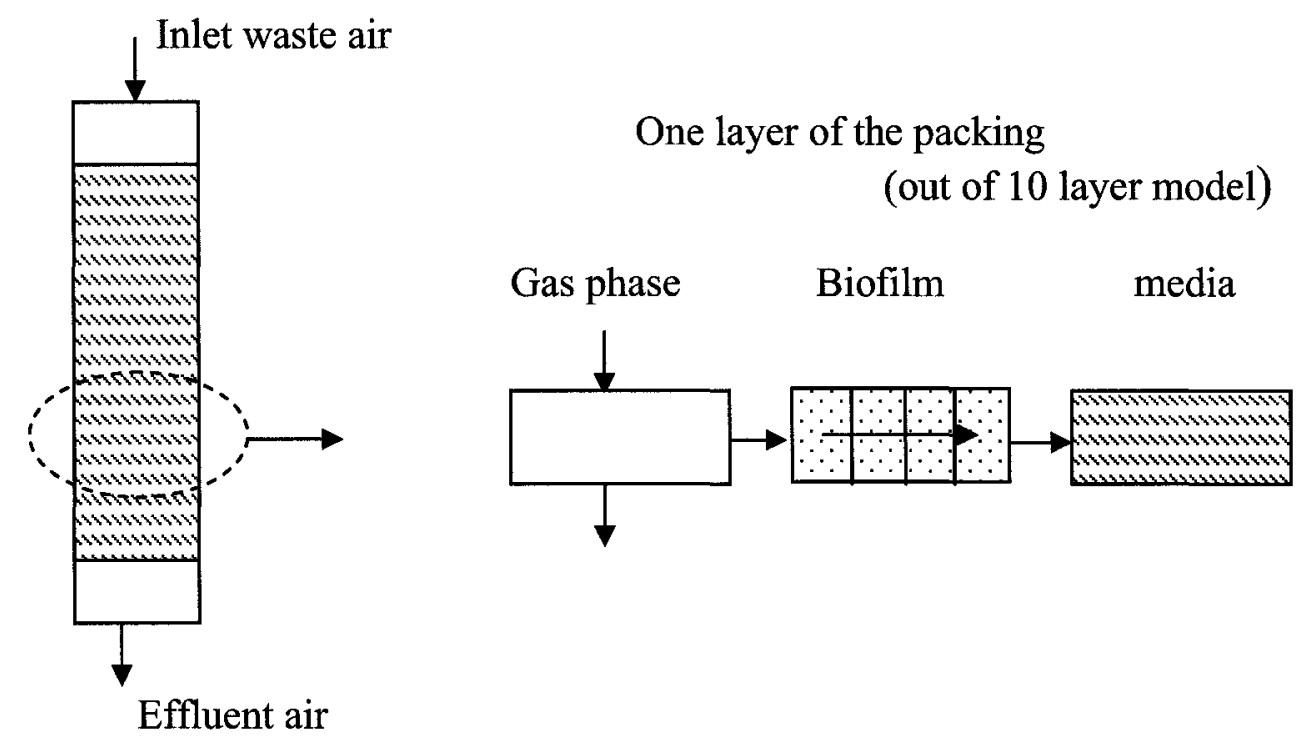

Figure 2.9 Structure considered for finite differencing in the biofilter model (Deshusses et al., 1995a)

Deshusses et al. (1995a) reported that the polluted air flowed downward so that convection was the vector of pollutant transport in the gaseous phase. At the gas-biofilm interface, equilibrium was assumed to exist (Henry's law was applied). In the biofilm, the pollutants simultaneously diffused and were consumed by the microorganisms. The 
authors also reported that adsorption of pollutants to the media was possible, after diffusion through the whole thickness of the biofilm.

Treatment of an air stream contaminated with VOCs in a biofilter under transient and steady state conditions of operation was described with a mathematical model by Amanullah et al. (1999). It was similar to the model developed by Hodge and Devinny (1995), however, Amanullah et al. (1999) assumed three phases: gas phase, biofilm and solid medium for their model development. They also considered direct adsorption to the exposed uncovered solid adsorbent media. The effects of pollutant dispersion in the gas phase, specific surface area available for mass transfer, thickness of the biofilm, and adsorptive capacity of the solid support on the biofilter performance for VOC removal, were investigated by Amanullah et al. (1999).

Dynamic physical and biological processes occurring in a packed trickle bed air bioreactor were studied by Alonso et al. $(1998,2000)$. Three phases were considered in the system: biofilm, liquid and gas (Figure 2.10). One limiting substrate (VOC) and a homogeneous biomass were considered. In the formulation of the mass balance equation, it was assumed that axial diffusion was negligible, microbial growth was described by Monod kinetics and there was no contaminant degradation in the water and gas phase. The mass balance equations for the biofilm phase, water phase and gas phase that the authors used to develop the model, are given in Equations 2.5.8, 2.5.9 and 2.5.10, respectively. The authors analyzed the relationship between biofilter performance and biomass accumulation in the reactor. 


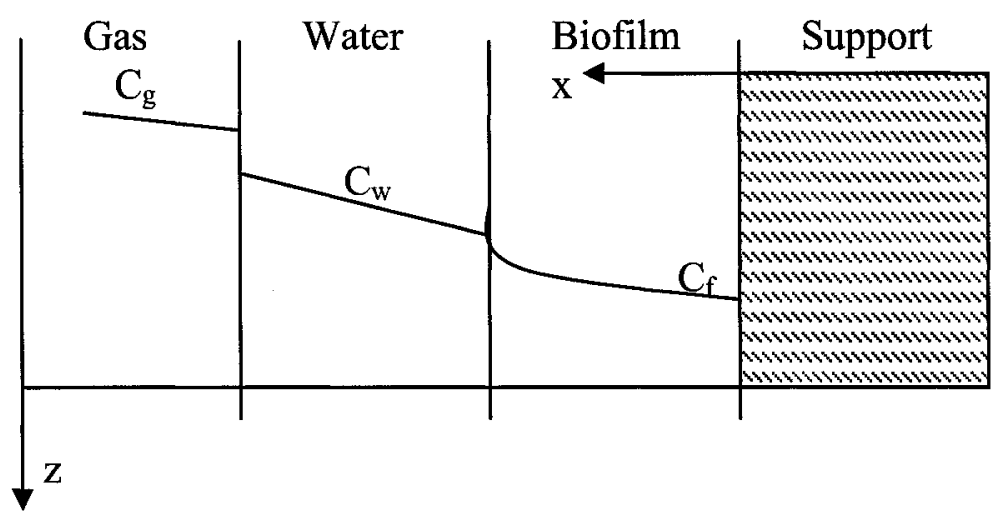

Figure 2.10 Biofilm model representation by Alonso et al., (1998)

$$
\begin{aligned}
& \frac{\partial C_{f}}{\partial t}=D_{f} \frac{\partial^{2} C_{f}}{\partial x^{2}}-\frac{\mu_{\mathrm{m}} X_{f}}{Y}\left[\frac{C_{f}}{K_{s}+C_{f}}\right] \\
& \frac{\partial C_{w}}{\partial t}=D_{w} \frac{\partial^{2} C_{w}}{\partial x^{2}}-V_{w} \frac{\partial C_{w}}{\partial z} \\
& \frac{\partial C_{g}}{\partial t}=D_{g} \frac{\partial^{2} C_{g}}{\partial x^{2}}-V_{g} \frac{\partial C_{g}}{\partial z}
\end{aligned}
$$

$C_{f}, C_{w}, C_{g} \quad$ biofilm, water, and gas phase concentration

$D_{f}, D_{w} \quad$ VOC diffusivity in the biofilm and in water respectively

$K_{s} \quad$ Monod saturation constant

$V_{w}, V_{g} \quad$ velocities of gas and water phase

$X_{f} \quad$ biomass density

$Y \quad$ yield coefficient

$\mu_{m} \quad$ maximum growth rate

Almost all the biofilter models were evaluated with laboratory scale experimental data including MEK/MIBK mixtures (Deshusses et al., 1995b), benzene and toluene (Shareefdeen and Baltzis, 1994a), VOCs (Amanullah et al., 1999). Alonso et al. (1998) studied pilot-scale bioreactors with VOC removal. Recently Li et al. (2002a, 2002b) used pilot and full-scale biofilter data from a wastewater treatment plant. The authors 
developed a dynamic model that describes the mass transport and attenuation of odorcausing air emissions (i.e., $\mathrm{H}_{2} \mathrm{~S}$ and other RSCs) in a biofiltration unit. Figure 2.11 shows the schematic representation of the biofilter. The model equations were represented by Equations 2.5.11 and 2.5.12.

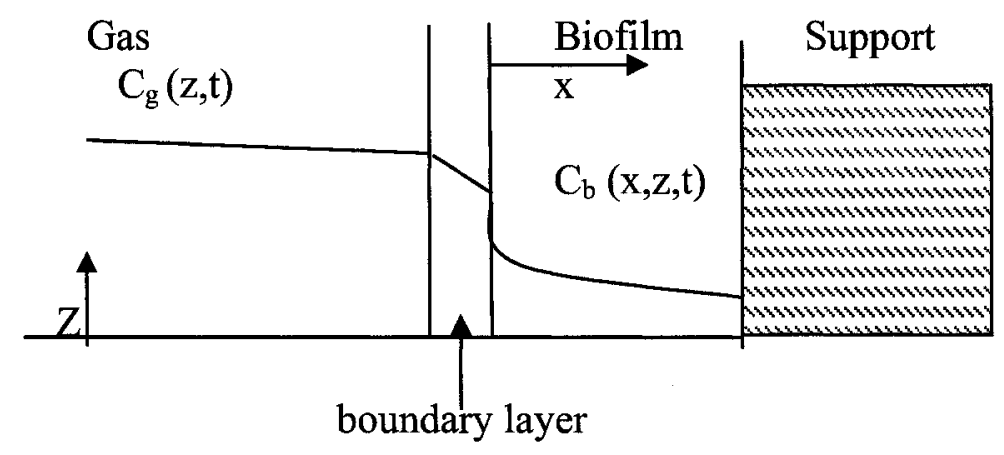

Figure 2.11 Biofilm model representation by Li et al., (2002a)

The mass balance in the gas phase:

$$
\frac{\partial C_{g}(z, t)}{\partial t}=-u \frac{\partial C_{g}(z, t)}{\partial z}-\frac{K_{G} a_{d}}{a_{g}}\left(\frac{C_{g}(z, t)}{\mathrm{H}}-C_{b}(x=0, z, t)\right)
$$

The mass balance in the biofilm phase:

$$
\frac{\partial C_{b}(x, z, t)}{\partial t}=D_{b} \frac{\partial^{2} C_{b}(x, z, t)}{\partial x^{2}}-r_{s u b}(x, z, t)
$$

$a_{d} \quad$ effective diffusion surface area per bed unit volume

$a_{g} \quad$ specific area for the gas phase advection

$C_{b}, C_{g}$ biofilm, and gas phase concentration

$D_{b} \quad$ diffusivity in the biofilm

$H \quad$ dimensionless Henry's law coefficient

$K_{G} \quad$ mass transfer coefficient

$t$ time

$u \quad$ interstitial gas velocity

$x \quad$ biofilm depth

$z \quad$ distance along the biofilter

$r_{s u b}$ biological degradation rate 
This was the first dynamic biofiltration model that was developed for odorous RSCs. This model related process performance to active flow, mass transfer from the bulk phase to the biofilm, biofilm internal diffusion, and biological reactions in the biofilm. This model has several advantages including that it was developed especially for biofiltration of odorous compounds; the mass transport of the target compound at interfaces was modeled as a rate-limited process instead of assuming equilibrium; the active biomass concentration was modeled as a function of axial position, biofilm depth, and time instead of assuming a uniform concentration; and it was incorporated into a user-friendly software called Biofilter ${ }^{\mathrm{TM}}$.

As reported by Li et al. (2002a), the model was developed for a single compound; however, it can also be applied to an individual compound in a mixture if degradation of this compound is not affected by the presence of others. Because the degradation of DMS and DMDS have been found to be inhibited by the presence of $\mathrm{H}_{2} \mathrm{~S}$ and MM (Hirai et al., 1990). However Li et al. (2002b) believed that the degradation of $\mathrm{H}_{2} \mathrm{~S}$ and $\mathrm{MM}$ are not thought to be influenced by the existence of any other gases. Therefore the authors used $\mathrm{H}_{2} \mathrm{~S}$ and $\mathrm{MM}$ to calibrate and validate the model. The authors discussed the effect of the gas residence time and $\mathrm{pH}$ on $\mathrm{MM}$ removal efficiency based on model simulations. Also they reported that control of $\mathrm{pH}$ was critical if one wishes to improve the performance of MM removal during biofiltration. They also found that increasing the gas residence time was important for increasing the MM removal efficiency. 
The above biofilter models, which represent the major developments in this area, differ mainly in the following aspects: models for biodegradation reaction in the biofilm; details of inter-phase transport; and the role of the support media.

In the literature both plug flow and axially dispersed plug flow models have been applied for fluid flow. The choice of reaction model has differed based on the pollutants and the microorganisms used. Although first-order kinetics are more common, there have been other studies that have demonstrated the need for more detailed reaction models. Since the reaction model is specific to the pollutants and microorganisms involved, other types of models such as Monod type and Andrews type are also explored, as the application of biofiltration becomes more widespread (Shareefdeen et al., 1993; Deshusses et al., 1995a; Baltzis et al., 1997).

Based on the review, the interphase mass transfer is closely linked with the assumption regarding the role of support media. Early studies ignored any adsorption and reaction of pollutants in the solid material that was used to grow and maintain the colony of microorganisms. Pollutant biodegradation was assumed to be confined within the biofilm grown on the support media in the biofilter. The limitations of the early biofilter models were gradually relaxed by allowing diffusion at biofilm/solid interface and reaction in the solid support. 


\section{Chapter \\ Three}

\section{Preliminary Full-scale Study}

\subsection{Introduction}

Even though there have been a number of studies on biofiltration, there are a limited number of studies on mixed gas pollutants such as those present in ATAD off gases. Also there is little information to describe the behavior of biofilters treating an air stream that varies in composition on a regularly repeating basis. Therefore it was deemed necessary to study a full-scale dynamic system to characterize its properties and to understand its processes.

The objectives of the full-scale study were to

- Determine the dynamic variations of the ATAD offgases

- Characterize the biofilter inlet and outlet gases and examine the biofilter performance

- Identify the removal mechanism of these offgases within the biofilter

- Analyze the chemical mass balance (N and S) within the biofilter

- Generate data that would allow for a more refined experimental design in the subsequent pilot scale studies.

An existing ATAD and biofilter system located at the McMinnville water reclamation facility (McMinnville, Oregon) was examined in this study. This facility served a population of around 27,500 as of the year 2002 . 


\subsection{Material and methods}

\subsubsection{Existing system setup}

The ATAD system consists of three digesters, each with a volume of $256 \mathrm{~m}^{3}$ and connected in series. Each digester is aerated and mixed with 4 Fuchs style spiral aerators. The digesters are fed a thickened waste activated sludge stream with a feed solids concentration of 4-6\% solids. The solids residence time in the combined digesters is approximately 14.3 days. The digesters are batch fed once daily. The feeding cycle consists of a sequence of operations where digested sludge is initially pumped out of Reactor III (Figure 3.1). The high and low level transfer valves between Reactor II and Reactor III are then opened to transfer sludge between these reactors. Once the levels have stabilized, the transfer valves between Reactor I and II are opened and levels are allowed to equilibrate across the three reactors. The low level valves are then closed and raw sludge is pumped into the Reactor I. This feeding procedure is employed to minimize short-circuiting across the reactors. The procedure takes approximately 45 minutes to complete.

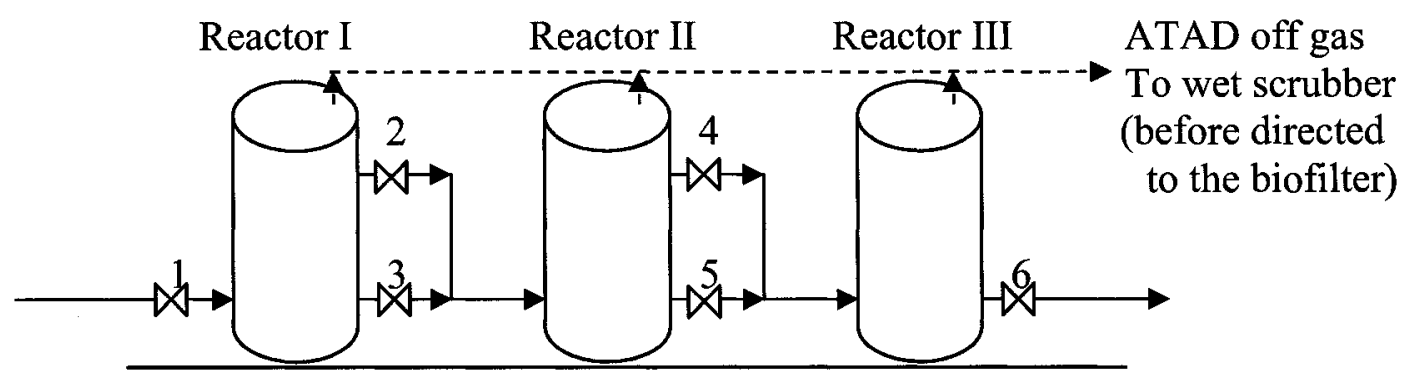

Figure 3.1 Schematic overview of the ATAD digesters feeding pathways

Headspace gases are withdrawn separately from the three ATAD reactors, mixed and then passed through a wet scrubber. To reduce the $\mathrm{NH}_{3}$ gas concentration to a 
concentration that is acceptable for the biofilter, the wet scrubber is operated using city water as scrubbing liquid. The scrubber was not analyzed fully, as it was not focus in the study. In addition to $\mathrm{NH}_{3}$ removal, the scrubber humidifies the air, removes particulates and adjusts the temperature of the gas. The scrubber outlet is directed to the biofilter for further treatment.

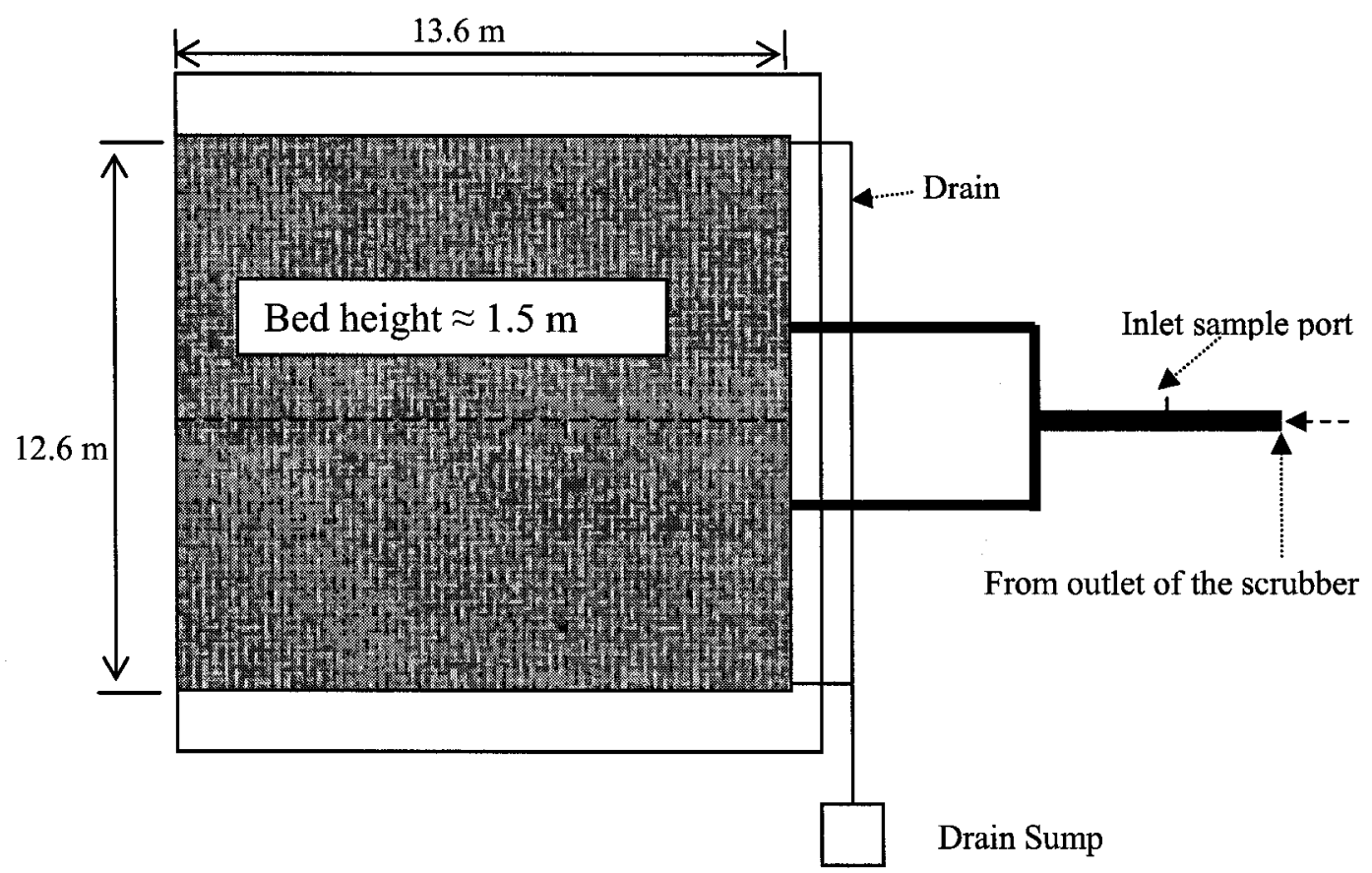

Figure 3.2 Plan view of the biofilter

The biofilter has an open bed design and the packing material is coarse wood chip. The bed has dimensions of approximately $13.6 \mathrm{~m} \times 12.6 \mathrm{~m}$ yielding a total surface area of 172 $\mathrm{m}^{2}$ and has a depth of $1.5 \mathrm{~m}$. As shown in Figure 3.2, the main biofilter inlet pipe is divided into two lines, which convey the gases into an open plenum below the biofilter bed. The bed is post-humidified by city water using a soaker hose system that is distributed over the top of the bed. The leachate from the bed is collected in a sump that is pumped to the wastewater sewer. 


\subsubsection{Gas sampling and analysis}

Gas phase sampling was performed on an hourly basis over a 24-hour period. Table 3.1 summarizes the sampling locations and analyses that were performed. Due to the limited sampling facilities, MM, DMS and DMDS were not analyzed at the scrubber inlet. The biofilter inlet samples were collected at the location shown in Figure 3.2. The biofilter outlet sample location was identified by a smoke test. A smoke candle was ignited and the smoke was blown into the biofilter through the inlet sample port. The outlet sample location was selected from the top of the bed where a relatively higher amount of smoke came out of the bed. A Teflon pipe $(1 \mathrm{~cm}$ diameter) was inserted into the selected point to a depth of $15 \mathrm{~cm}$ and connected to the $\mathrm{SKC}$ sampling pump using Viton ${ }^{\mathrm{TM}}$ tubing. In addition to the sampling that is identified in Table 3.1, additional samples were collected directly from the individual digester headspaces for the last 16 hours of the study. These latter samples were analyzed for $\mathrm{NH}_{3}$ and $\mathrm{H}_{2} \mathrm{~S}$ concentrations.

Table 3.1 Gas sampling summary

\begin{tabular}{|c|c|c|c|c|c|}
\hline \multirow{2}{*}{ Location } & \multicolumn{5}{|c|}{ Analyte } \\
\cline { 2 - 6 } & $\mathrm{H}_{2} \mathrm{~S}$ & $\mathrm{NH}_{3}$ & $\mathrm{MM}$ & $\mathrm{DMS}$ & DMDS \\
\hline Scrubber inlet & $\mathrm{X}$ & $\mathrm{X}$ & - & - & - \\
\hline Biofilter inlet & $\mathrm{X}$ & $\mathrm{X}$ & $\mathrm{X}$ & $\mathrm{X}$ & $\mathrm{X}$ \\
\hline Biofilter outlet & $\mathrm{X}$ & $\mathrm{X}$ & $\mathrm{X}$ & $\mathrm{X}$ & $\mathrm{X}$ \\
\hline
\end{tabular}

Gas phase sampling and analysis for $\mathrm{NH}_{3}$ and $\mathrm{H}_{2} \mathrm{~S}$ was performed with GAS Tech tubes. A mid range detector tube (Gastec No. 3M) with a detection range from 10-1000 ppm was used for $\mathrm{NH}_{3}$ analysis. For $\mathrm{H}_{2} \mathrm{~S}$ measurements, two types of detector tubes were used for high and low $\mathrm{H}_{2} \mathrm{~S}$ concentrations. A Gastec No. 4L was used to measure the range from 1-240 ppm, while a Gastec No. 4LT was used to measure the range of 0.1-4 ppm. 
The gas phase sampling for MM, DMS and DMDS was accomplished using a low flow sampling manifold through which gas samples were drawn by a SKC model $224-44 \mathrm{XR}$ sampling pump. The sample manifold accommodated a cassette holder that held a mercuric acetate impregnated glass fiber filter and two sorbent tubes (Anasorb CSC, coconut charcoal, $50 / 100 \mathrm{mg}, 2$ sections). The sample flow rate through the glass fiber filter was $210 \mathrm{ml} / \mathrm{min}$ and the sampling interval was $45 \mathrm{~min}$. The flows through the charcoal tubes were $120 \mathrm{ml} / \mathrm{min}$ and the sample interval was $45 \mathrm{~min}$. All flows were calibrated with a SKC 'UltraFlo' electronic calibrator prior to starting the sampling. After being removed from the manifold the impregnated filters were transported to the laboratory for extraction and analysis by gas chromatography.

The sampling and analytical method employed for MM was performed as per the OSHA method no 26 (OSHA, 2002). The glass fiber filters impregnated with mercuric acetate were regenerated by shaking with a mixture of $25 \mathrm{ml}$ of concentrated hydrochloric acid (25\%) and $5 \mathrm{ml}$ of dichloromethane (DCM) in a $30 \mathrm{ml}$ separatory funnel. The DCM was then allowed to separate from the acid and analyzed by gas chromatography with detection by a pulsed flame photometric detector (GC/PFPD). The GC conditions are given in Table 3.2 .

The sampling and analytical methods employed for DMS and DMDS were based on the OSHA in-house method (OSHA, 2002). In this method the charcoal was transferred into $10 \mathrm{ml}$ volumetric flasks, which were then filled with $5 \mathrm{ml}$ of Heptane. The flasks were 
then sonicated (table top ultrasonic cleaners, Model FS20H) for 20 min to desorb the target compounds from the charcoal to the heptane solvent. Immediately after sonication, samples were filtered using a glass syringe with a syringe filter $(0.45 \mu \mathrm{m}$ pore size, PTFE filter media) and transferred to a $2 \mathrm{ml}$ vial with a Teflon liner cap. The samples were analyzed by the GC/PFPD system. The GC conditions are given in Table 3.2. The detection limit for each compound is given in Table 3.3. The detection limits of $\mathrm{NH}_{3}$ and $\mathrm{H}_{2} \mathrm{~S}$ were obtained from the Gastec tubes manual. The detection limits of MM, DMS and DMDS were determined by the analytical procedures. The detection limit was determined from the concentration which corresponds to a peak whose height was approximately five times of the baseline noise level in the GC chromatogram.

Table 3.2 GC conditions

\begin{tabular}{|l|l|l|}
\hline GC & \multicolumn{2}{|l|}{ Varian 3600} \\
\hline Column & $\begin{array}{l}\text { VB-1, Capillary column, length- } \\
\text { thickness- } 4.00 \mu \mathrm{m}\end{array}$ & \multicolumn{1}{|c|}{ Method I (for MM) Column ID- $0.32 \mathrm{~mm}$, Film } \\
\hline Method & \multicolumn{1}{|c|}{ Method II (for DMS \& DMDS) } \\
\hline $\begin{array}{l}\text { Injector } \\
\text { condition }\end{array}$ & $\begin{array}{l}\text { Isothermal } 140^{\circ} \mathrm{C}, \\
2 \mu 1 \text { of liquid injection }\end{array}$ & $\begin{array}{l}\text { Isothermal } 200^{\circ} \mathrm{C}, \\
2 \mu 1 \text { of liquid injection }\end{array}$ \\
\hline $\begin{array}{l}\text { Column } \\
\text { condition }\end{array}$ & $\begin{array}{l}35^{\circ} \mathrm{C} \text { for } 12 \text { min then ramping at } \\
20^{\circ} \mathrm{C} / \text { min to } 120^{\circ} \mathrm{C} \text { hold for } 1 \mathrm{~min}\end{array}$ & $\begin{array}{l}50^{\circ} \mathrm{C} \text { for } 2 \text { min then ramping at } 5^{\circ} \mathrm{C} \\
/ \text { min to } 100^{\circ} \mathrm{C} \text { hold for } 0.5 \mathrm{~min}\end{array}$ \\
\hline $\begin{array}{l}\text { Detector } \\
\text { condition }\end{array}$ & $200^{\circ} \mathrm{C}$ & \multicolumn{1}{c|}{$200^{\circ} \mathrm{C}$} \\
\hline
\end{tabular}

Table 3.3 Gas phase detection limits for each compound

\begin{tabular}{|c|c|}
\hline Compound & Detection limit (ppm) \\
\hline $\mathrm{NH}_{3}$ & 10 \\
\hline $\mathrm{H}_{2} \mathrm{~S}$ & 0.1 \\
\hline $\mathrm{MM}$ & 0.004 \\
\hline $\mathrm{DMS}$ & 0.130 \\
\hline DMDS & 0.095 \\
\hline
\end{tabular}




\subsubsection{Liquid sampling and analysis}

Grab samples were collected on an hourly basis from the sump that collected biofilter leachate. In addition occasional samples were collected from the water line providing water to the post humidification systems. The $\mathrm{pH}$ of the water samples was measured immediately. The readings were taken using an Orion Model 290A pH meter. The water samples were then transferred to $40 \mathrm{ml}$ amber vials and acidified with $\mathrm{HCl}$ to less than $\mathrm{pH} 3$ for preservation prior to being transported to the laboratory for analysis.

The samples for $\mathrm{NH}_{3}-\mathrm{N}$ were analyzed by the Phenate method (APHA et al., 1995). Anions $\left(\mathrm{SO}_{4}{ }^{2-}, \mathrm{NO}_{3}^{-}\right.$, and $\mathrm{NO}_{2}^{-}$) were analyzed using an ion chromatograph (IC 5000, Lachat instrument). The mobile phase of $2 \mathrm{mM}$ sodium bicarbonate and $2.6 \mathrm{mM}$ sodium carbonate in reagent water was used as eluent solution. The eluent was delivered at 2.2 $\mathrm{ml} / \mathrm{min}$ at room temperature. A $100 \mu \mathrm{l}$ sample loop was used to directly inject the water samples after first filtering them through glass fiber filters (pore size of $0.20 \mu \mathrm{m}$ ). The IC was operated in background suppression mode with $0.25 \mathrm{M}$ sulfuric acid as regenerant solution.

Gas flows were calculated from air velocities that were measured at the biofilter inlet using a hotwire thermo-anemometer. Liquid flows were measured at the sump inlet using a bucket and stopwatch method. Air temperatures were measured using a handheld digital thermometer equipped with a stainless steel probe. The biofilter inlet air, ambient air and the bed temperatures (10-15 $\mathrm{cm}$ below the bed surface) were recorded. 


\subsection{Results and discussion}

\subsubsection{Gas phase analysis}

Figures 3.3 and 3.4 shows the variation of $\mathrm{H}_{2} \mathrm{~S}$ and $\mathrm{NH}_{3}$ concentrations at the scrubber inlet and biofilter inlet respectively. Shortly after sludge was fed into the ATAD system, the $\mathrm{NH}_{3}$ concentration in the scrubber inlet decreased from 420 to $250 \mathrm{ppm}$, and subsequently increased to above $400 \mathrm{ppm}$ over the sampling period. The $\mathrm{H}_{2} \mathrm{~S}$ concentration increased rapidly from 10 to $20 \mathrm{ppm}$ after the ATAD system was fed and subsequently the concentration decreased over a 4-hour period to a low concentration of approximately $4 \mathrm{ppm}$. After approximately 7 hours at a concentration of $4.5 \mathrm{ppm}$, the $\mathrm{H}_{2} \mathrm{~S}$ concentration then increased over an 8-hour period to a high of $20 \mathrm{ppm}$ at the scrubber inlet. A similar pattern for both $\mathrm{H}_{2} \mathrm{~S}$ and $\mathrm{NH}_{3}$ concentration was observed at the biofilter inlet. The concentrations of $\mathrm{H}_{2} \mathrm{~S}$ and $\mathrm{NH}_{3}$ were however substantially lower than the scrubber inlet. From Figures 3.3 and 3.4, it can be observed that the scrubber removed approximately $85 \%$ of the $\mathrm{NH}_{3}$ and $60 \%$ of the $\mathrm{H}_{2} \mathrm{~S}$. 


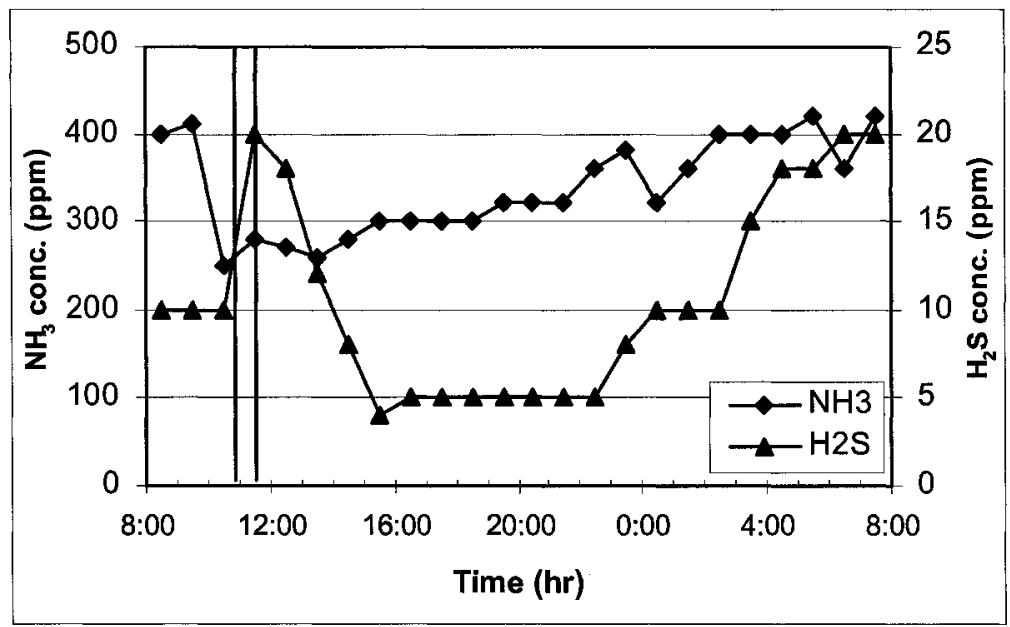

Figure 3.3 Gas phase concentrations of $\mathrm{NH}_{3}$ and $\mathrm{H}_{2} \mathrm{~S}$ at the scrubber inlet

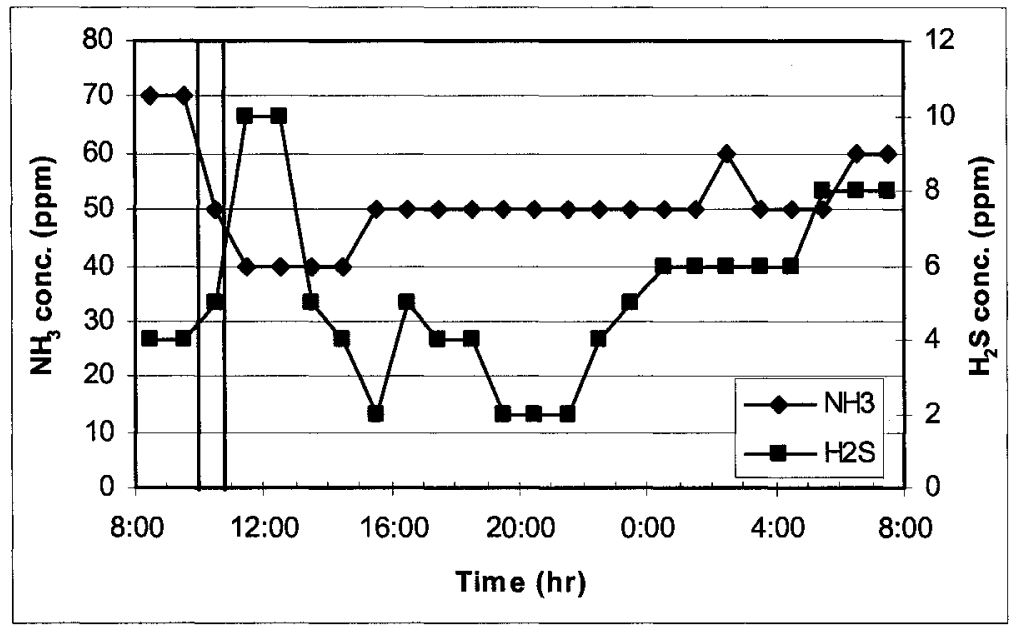

Figure 3.4 Gas phase concentrations of $\mathrm{NH}_{3}$ and $\mathrm{H}_{2} \mathrm{~S}$ at the biofilter inlet 


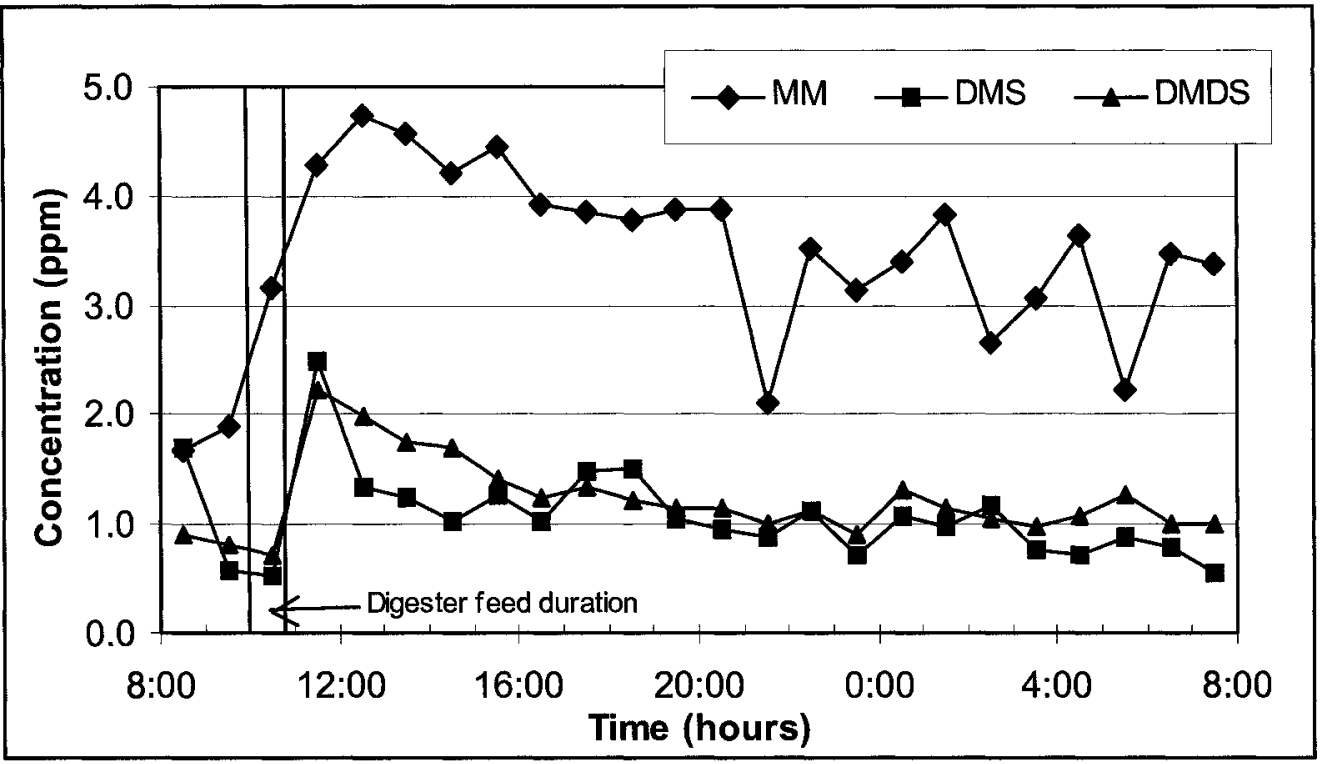

Figure 3.5 Gas phase concentrations of MM, DMS, and DMDS at the biofilter inlet

Figure 3.5 presents the concentrations of MM, DMS and DMDS that were measured at the biofilter inlet. The concentration of MM ranged from 1.5 to $4.8 \mathrm{ppm}$ while DMS and DMDS ranged from 0.5 to $2.5 \mathrm{ppm}$. From Figure 3.5, it can be seen that the concentration of these compounds rapidly increased just after the feeding, it took almost a complete cycle (one day) to return to the lower values. It is interesting to note that, while DMS and DMDS concentrations decreased from around $2.5 \mathrm{ppm}$ to around $0.5 \mathrm{ppm}, \mathrm{MM}$ remained relatively high at 4.8 to $3.0 \mathrm{ppm}$.

At selected time intervals, the headspace gas of each ATAD reactor was sampled. The concentrations of $\mathrm{NH}_{3}$ and $\mathrm{H}_{2} \mathrm{~S}$ are shown in Figure 3.6. $\mathrm{H}_{2} \mathrm{~S}$ concentrations were relatively high in Reactor I, and below the detection limit in Reactors II and III. $\mathrm{NH}_{3}$ concentrations were lowest in the headspace of Reactor I and the concentrations 
increased in Reactor II and Reactor III. It should be noted that the sampling times for the reactor headspaces were relatively late in the feed cycle. The headspace concentrations of the combined headspace samples were in agreement with the values measured at the scrubber inlet.

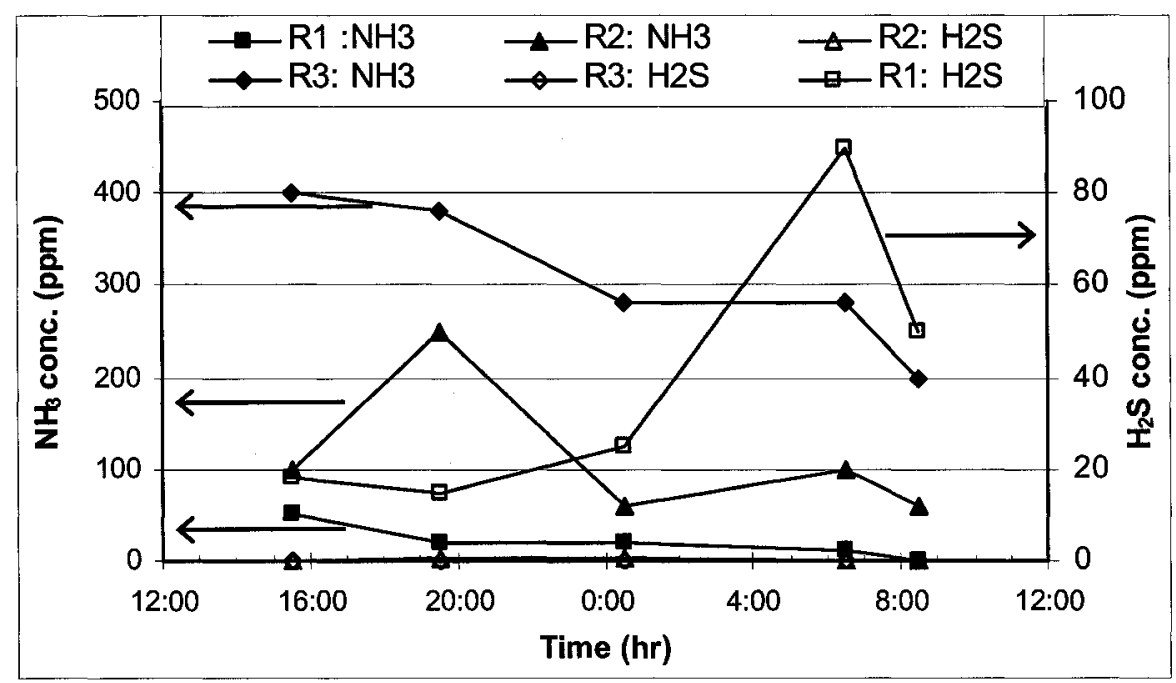

Figure 3.6 Gas phase concentrations of $\mathrm{NH}_{3} \& \mathrm{H}_{2} \mathrm{~S}$ at the headspace of the ATAD reactors

The patterns observed in the gas phase concentrations of $\mathrm{NH}_{3}$ and $\mathrm{RSC}$ concentrations were generally in agreement with those observed elsewhere (Hepner et al., 2002) with some exceptions. The generation of elevated concentrations of RSC shortly after feeding was likely due to the increased microbial activity during that time and accorded at a period when the oxygen demand likely exceeded the oxygen supply. It is however not clear why $\mathrm{H}_{2} \mathrm{~S}$ was generated in Reactor I late in the feed cycle. It is suggested that this may be due to a change in the viscosity of the liquid in the digester that affects mixing within the digester. Perhaps a portion of the thickened sludge did not immediately mix with the remainder of the digester contents when the digester was first fed. As digestion 
proceeded this sludge may have 'turned over' in the digester and hence exerted an oxygen demand later in the cycle.

The gas phase concentrations of $\mathrm{NH}_{3}$ tended to increase with time and location, along the digester sequence as the extent of protein decay increased. In addition the digester temperatures increased (Figure 3.7) in a similar fashion thereby increasing the tendency for $\mathrm{NH}_{3}$ partitioning to the gas phase.

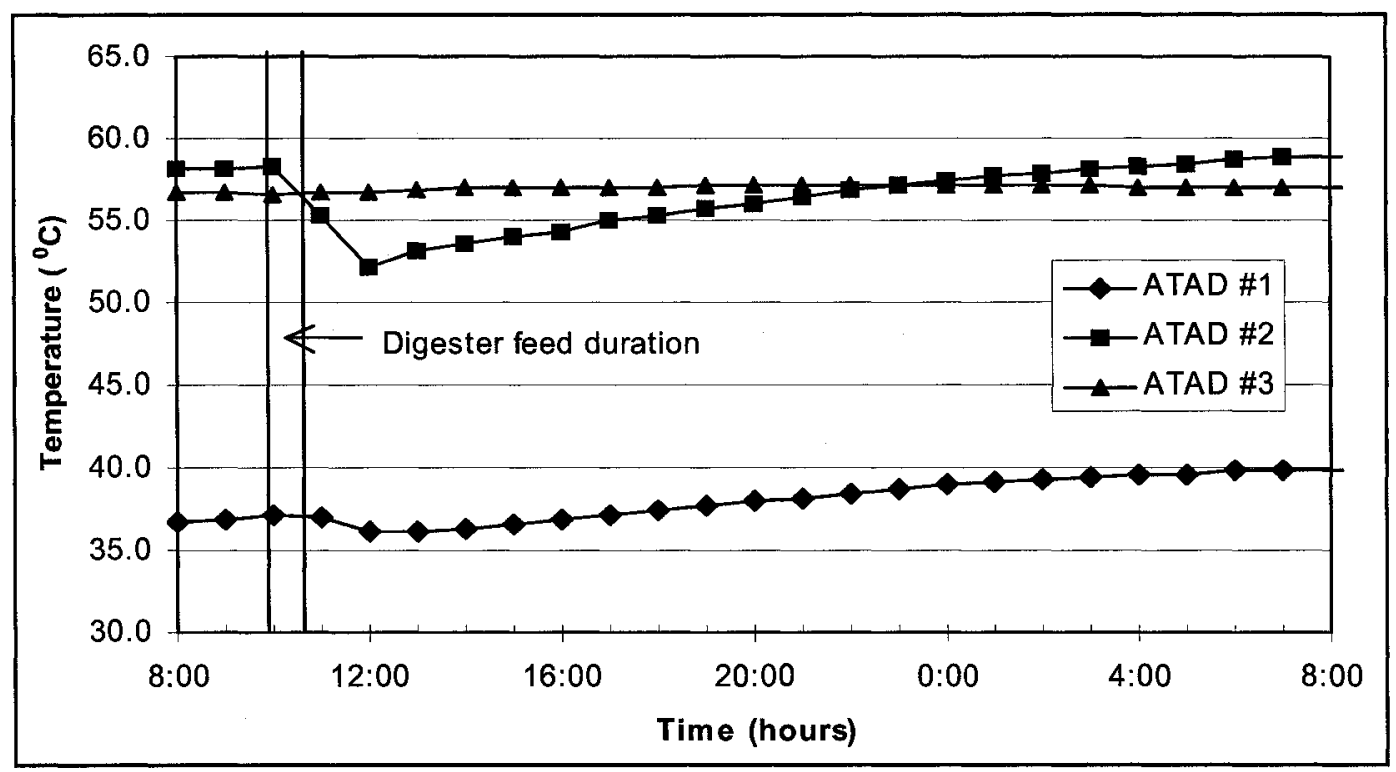

Figure 3.7 The digester temperature variation during one cycle

Even though the digester temperatures ranged between 40 and $60^{\circ} \mathrm{C}$, due to the wet scrubber, the biofilter inlet air temperature was an average of $20.8^{\circ} \mathrm{C}$ during the study period. The temperature of a biofilter bed can be affected by exothermic biological reactions. The bed temperature was around $20^{\circ} \mathrm{C}$ but the areas that were close to the post humidifier soaker hose had a temperature of approximately $15^{\circ} \mathrm{C}$. The ambient temperature was an average of $10.5^{\circ} \mathrm{C}$. The optimal temperatures for aerobic biofilters have been noted to be in the mesophilic temperature range (Corsi and Seed 1995; Lith et 
al., 1997; Swanson and Loehr, 1997). The low temperature close to the post-humidifier soaker hose may have reduced the nitrification process in a portion of the bed.

The removal efficiencies of each compound in the wet scrubber and the biofilter were calculated. The biofilter outlet gas concentrations, which were below the detection limits, were assumed to be equal to half of the detection limits of the compound. A summary of the mean removal efficiencies with standard deviation is presented in Table 3.4. Relatively high mean-removal efficiencies for $\mathrm{NH}_{3}$ and $\mathrm{H}_{2} \mathrm{~S}$ (84.7 and 46.8\%, respectively) were observed in the wet scrubber. As shown in Table 2.2, the $\mathrm{K}_{\mathrm{H}}$ for the $\mathrm{NH}_{3}$ was relatively low $(0.00055)$ which indicates that the $\mathrm{NH}_{3}$ is highly soluble in water. Therefore, high removal of $\mathrm{NH}_{3}$ within the scrubber was expected. The $\mathrm{K}_{\mathrm{H}}$ for the $\mathrm{H}_{2} \mathrm{~S}$ at $20^{\circ} \mathrm{C}$ was 0.37 , and much less removal of $\mathrm{H}_{2} \mathrm{~S}$ was expected within the scrubber. However the results showed that $\mathrm{H}_{2} \mathrm{~S}$ was removed significantly. It may be assumed that the $\mathrm{H}_{2} \mathrm{~S}$ removal was mostly dominated by the biological transformation rather than the mass transfer limitations and it may also due to that the scrubber system may have relatively high specific surface area (high water flow rate) which can increase the mass transfer rate.

Figure 3.8 shows the removal efficiencies variations along the 24 hours cycle in the biofilter. As shown in Table 3.4, the $\mathrm{NH}_{3}$ gas mean-removal efficiency was around $80 \%$ within the biofilter, while, DMDS, $\mathrm{H}_{2} \mathrm{~S}$ and $\mathrm{MM}$ were removed with mean removal efficiency of around 92, 98, and 99\%, respectively. The DMS mean-removal efficiency was $86.2 \%$ with standard deviation of $5 \%$. It was also noticed that the $\mathrm{NH}_{3}, \mathrm{DMS}$ and 
DMDS removal efficiencies decreased between 1 and 3 hours after the feeding. It may be due to the sudden peaks of RSC concentrations within that period of the cycle. The removal efficiency of each compound shows the effectiveness of the biofilter and wet scrubber combination for the ATAD offgas removal.

Table 3.4 Mean removal efficiency of the systems

\begin{tabular}{|c|l|c|c|}
\hline System & Compound & $\begin{array}{c}\text { Mean removal } \\
\text { efficiency (\%) }\end{array}$ & $\begin{array}{c}\text { Standard } \\
\text { deviation }\end{array}$ \\
\hline \multirow{3}{*}{ Wet scrubber } & $\mathrm{NH}_{3}$ & 84.7 & 1.8 \\
\cline { 2 - 4 } & $\mathrm{H}_{2} \mathrm{~S}$ & 46.8 & 17.0 \\
\hline \multirow{5}{*}{ Biofilter } & $\mathrm{NH}_{3}$ & 80.1 & 2.9 \\
\cline { 2 - 4 } & $\mathrm{H}_{2} \mathrm{~S}$ & 97.6 & 1.3 \\
\cline { 2 - 4 } & $\mathrm{MM}$ & 99.9 & 0.1 \\
\cline { 2 - 4 } & $\mathrm{DMS}$ & 86.2 & 5.0 \\
\cline { 2 - 4 } & DMDS & 91.7 & 2.1 \\
\hline
\end{tabular}
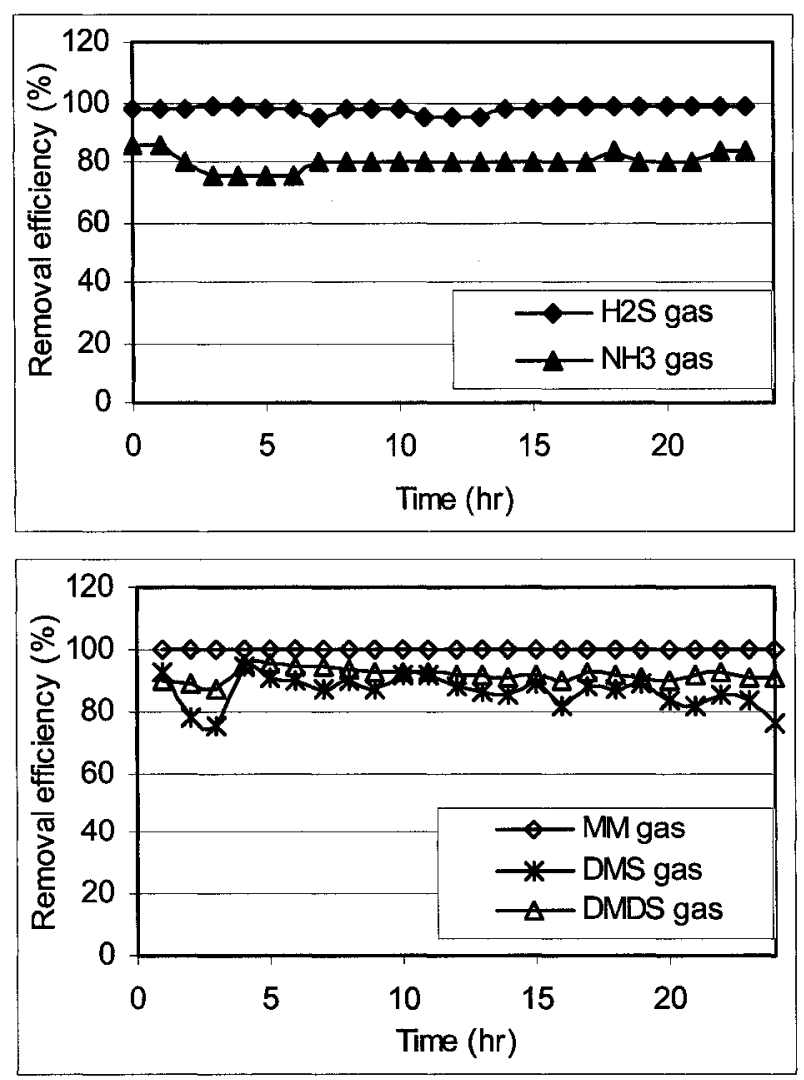

Figure 3.8 Removal efficiencies variations along the cycle in the biofilter 


\subsubsection{Liquid phase analysis}

The leachate from the biofilter was analyzed in order to identify the mechanisms responsible for removal of gas phase contaminants in the biofilter. Figure 3.9 presents the inorganic ions that were measured in the biofilter as a function of time.

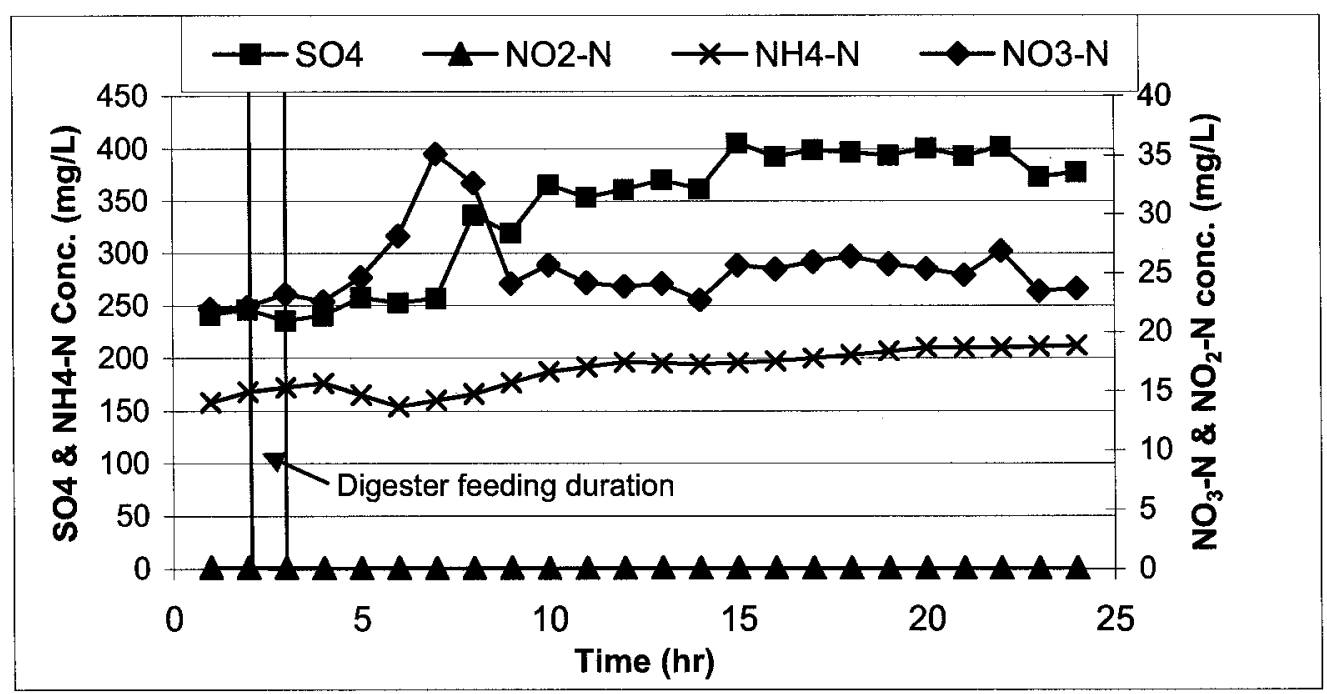

Figure 3.9 Concentrations of $\mathrm{SO}_{4}{ }^{2-}, \mathrm{NH}_{4}{ }^{+}-\mathrm{N}, \mathrm{NO}_{3}{ }^{-} \mathrm{N}$, and $\mathrm{NO}_{2}^{-}-\mathrm{N}$ in leachate samples

As shown in Figure 3.9, the liquid phase concentrations of the ions were observed to change 2-3 hours after feeding of the digesters. The $\mathrm{NH}_{4}{ }^{+}-\mathrm{N}_{(\mathrm{aq})}$ concentration decreased slightly after the feeding and subsequently increased from $154 \mathrm{mg} / \mathrm{L}$ to around $210 \mathrm{mg} / \mathrm{L}$. After feeding, the $\mathrm{NO}_{3}{ }^{-} \mathrm{N}$ concentration increased from $22 \mathrm{mg} / \mathrm{L}$ to $35 \mathrm{mg} / \mathrm{L}$, then, it reduced to around $25 \mathrm{mg} / \mathrm{L}$ within the next few hours, followed by small fluctuations in the concentration for the rest of the cycle. The $\mathrm{NO}_{2}-\mathrm{N}$ concentration was less than 1.4 $\mathrm{mg} / \mathrm{l}$ and there was no significant variation observed in $\mathrm{NO}_{2}-\mathrm{N}$ concentration. 
From Figure 3.9, it can be seen that $\mathrm{NH}_{4}{ }^{+} \mathrm{N}$ concentration in the leachate was substantially higher than both $\mathrm{NO}_{3}{ }^{-}-\mathrm{N}$ and $\mathrm{NO}_{2}^{-}-\mathrm{N}$ concentrations. These results suggest that the main removal mechanism for $\mathrm{NH}_{3}$ was scrubbing rather than nitrification. The presence of some concentration of $\mathrm{NO}_{3}^{-}-\mathrm{N}$ and negligible $\mathrm{NO}_{2}^{-}-\mathrm{N}$ concentration suggests that conversion of $\mathrm{NO}_{2}^{-}$to $\mathrm{NO}_{3}^{-}$was not limiting in the biological aerobic system.

As discussed in Section 2.3.2, due to biological activity, RSCs are oxidized to $\mathrm{SO}_{4}{ }^{2-}$ to produce an acid in the aerobic system. While gas phase RSCs rapidly increased just after the feeding, as shown in Figure 3.9, the $\mathrm{SO}_{4}{ }^{2-}$ concentration started to increase around 5 hours after feeding from $250 \mathrm{mg} / \mathrm{L}$ to around $400 \mathrm{mg} / \mathrm{L}$. After approximately 8 hours at $400 \mathrm{mg} / \mathrm{L}$ of $\mathrm{SO}_{4}$, the concentration started to decrease over the last two hours of the cycle. This shows that after feeding, RSCs were transformed within the biofilter to $\mathrm{SO}_{4}{ }^{2-}$ and then removed with the leachate.

As discussed in Section 2.3.2 it can be seen that biological transformations of the RSCs and $\mathrm{NH}_{3}$ will result in the generation of acids. $\mathrm{NH}_{3}$ that enters the biofilter in the gas phase and alkalinity in the feed water will act to buffer the addition of acid (Equation 2.3.2). The $\mathrm{pH}$ that is measured in the leachate is likely strongly influenced by these processes. Figure 3.10 presents the $\mathrm{pH}$ values that were measured in the biofilter leachate. From Figure 3.10, it can be seen that the biofilter leachate $\mathrm{pH}$ fluctuations were limited within $\mathrm{pH} 7-8$. The $\mathrm{pH}$ dropped from 7.7 to 7.2 approximately 5 hours after the digesters were fed. This corresponded to the period when there was an increase in the concentrations of $\mathrm{NO}_{3}{ }^{-}$and $\mathrm{SO}_{4}{ }^{2-}$ in the liquid phase. The gas phase concentrations of $\mathrm{NH}_{3}$ entering the biofilter were also somewhat lower during this time. The increased 
production of acids that was evidenced by the higher concentrations of $\mathrm{NO}_{3}{ }^{-}$and $\mathrm{SO}_{4}{ }^{2-}$ and the reduced availability of $\mathrm{NH}_{3}$ to act as a buffer were likely responsible for this drop in $\mathrm{pH}$. The $\mathrm{pH}$ did not however depart from the range that is normally considered acceptable for a biological process. Hence the relatively limited amount of nitrification that was observed was not likely due to $\mathrm{pH}$ extremities.

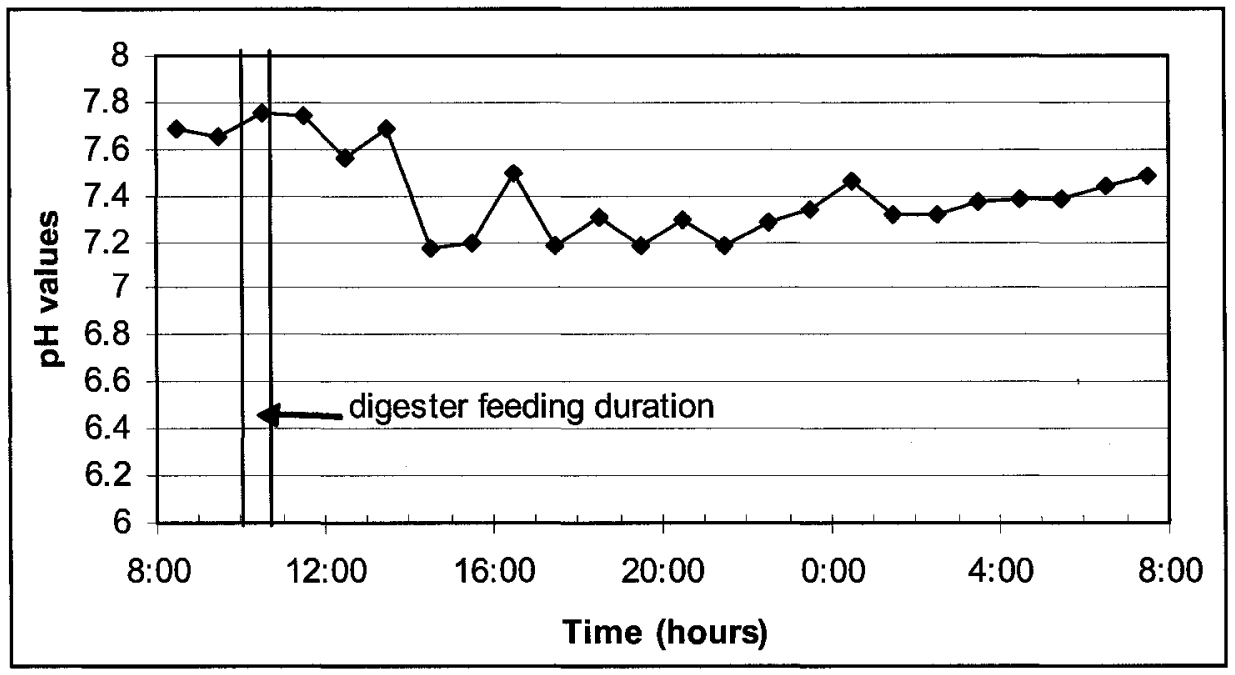

Figure 3.10 biofilter leachate pH vs. cycle time

Table 3.5 presents a summary of the maximum removal rates observed in this study and some relevant literature values. From Table 3.5, it can be seen that the total removal rate of RSC and $\mathrm{NH}_{3}$ were $12.39 \mathrm{~g}-\mathrm{S} / \mathrm{m}^{3}$ of biofilter bed $/ \mathrm{d}$ and $6.47 \mathrm{~g}-\mathrm{N} / \mathrm{m}^{3}$ of biofilter bed $/ \mathrm{d}$, respectively. As shown in Table 3.5, the literature values were relatively much higher than the values obtained in this study. Several factors may be responsible for these differences. The $\mathrm{NH}_{3}$ and $\mathrm{RSC}$ concentrations at the biofilter inlet were relatively low when compared to the literature studies. Most importantly, the values obtained in this study may not have been the maximum removal rates, while the reported values were maximum removal rates. The systems described in the literature were mainly laboratory- 
based biofilters. In general, the full scale system has lower removal rates than the laboratory based system, because the full scale system experiences many constrains such as ambient weather conditions and also some full scale systems are over design.

Table 3.5 Literature comparison of removal rates

\begin{tabular}{|c|c|c|c|c|c|}
\hline \multirow{3}{*}{ Compound } & \multirow{3}{*}{$\begin{array}{l}\text { Value } \\
\text { obtained in } \\
\text { this study }\end{array}$} & \multicolumn{4}{|c|}{ Literature values } \\
\hline & & \multirow{2}{*}{$\begin{array}{l}\text { Reported } \\
\text { value }\end{array}$} & \multirow{2}{*}{ Reference } & \multicolumn{2}{|c|}{ Remarks } \\
\hline & & & & Reactor type & Pollutants \\
\hline $\begin{array}{l}\mathrm{NH}_{3} \\
\left(\mathrm{~g}-\mathrm{N} / \mathrm{m}^{3} / \mathrm{d}\right)\end{array}$ & 6.47 & 216 & Kim et al., 2002 & Lab scale & $\begin{array}{c}\text { Mixed } \\
\text { with } \mathrm{H}_{2} \mathrm{~S}\end{array}$ \\
\hline $\begin{array}{l}\mathrm{H}_{2} \mathrm{~S} \\
\left(\mathrm{~g}-\mathrm{S} / \mathrm{m}^{3} / \mathrm{d}\right)\end{array}$ & 1.84 & 3120 & $\begin{array}{l}\text { Yang and Allen, } \\
1994\end{array}$ & Lab scale & Single \\
\hline $\begin{array}{l}\mathrm{MM} \\
\left(\mathrm{g}-\mathrm{S} / \mathrm{m}^{3} / \mathrm{d}\right)\end{array}$ & 9.12 & n.a. & - & - & - \\
\hline $\begin{array}{l}\text { DMS } \\
\left(\mathrm{g}-\mathrm{S} / \mathrm{m}^{3} / \mathrm{d}\right)\end{array}$ & 0.65 & 68 & $\begin{array}{l}\text { Kong and } \\
\text { Allen, 1997 }\end{array}$ & Lab scale & Single \\
\hline $\begin{array}{l}\text { DMDS } \\
\left(\mathrm{g}-\mathrm{S} / \mathrm{m}^{3} / \mathrm{d}\right)\end{array}$ & 0.78 & 83 & $\begin{array}{l}\text { Gibson and } \\
\text { Otten, } 1997\end{array}$ & Lab scale & Single \\
\hline
\end{tabular}

Note: n.a.: not available in the literature

\subsubsection{Nitrogen and sulfur mass balances}

Based on the gas and liquid phase data, nitrogen $(\mathrm{N})$ and sulfur $(\mathrm{S})$ mass balances on the biofilter system were performed. Cumulative mass balances over the 24-hour sampling period were performed. Since the biofilter outlet concentrations were below the detection limit, it was assumed that the outlet concentrations were equal to half of the detection limits of the each compound for the mass balance calculations. The biofilter humidifier water (city water) did not have significant concentrations of $\mathrm{NO}_{3}{ }^{-} \mathrm{N}^{-}$and $\mathrm{SO}_{4}{ }^{2-}(0.18$ and $4.27 \mathrm{mg} / 1$, respectively). 
Table 3.6 Nitrogen mass balance within the biofilter

\begin{tabular}{|l|c|c|}
\hline Compounds & $\mathbf{N}-\mathbf{i n}$ (g-N/d) & N- out (g-N/d) \\
\hline $\mathrm{NH}_{3}-\mathrm{N}(\mathrm{g})$ & 2073 & - \\
\hline $\mathrm{NH}_{4}{ }^{+}-\mathrm{N}(\mathrm{aq})$ & - & 2573 \\
\hline $\mathrm{NO}_{2}{ }^{-}-\mathrm{N}$ & - & 12 \\
\hline $\mathrm{NO}_{3}{ }^{-}-\mathrm{N}$ & - & 344 \\
\hline
\end{tabular}

In the case of the $\mathrm{N}$ balance, it was assumed that $\mathrm{NH}_{3}$ gas was the sole $\mathrm{N}$ source into the biofilter and $\mathrm{NH}_{4}{ }^{+}$(aq), $\mathrm{NO}_{3}{ }^{-}$and $\mathrm{NO}_{2}{ }^{-}$were the only forms discharged from biofilter in the leachate. As shown in Table 3.6, of the total mass of $\mathrm{N}$ leaving the biofilter, only $12 \%$ consisted of the nitrification products while the remainder was in the form of $\mathrm{NH}_{4}{ }^{+}-\mathrm{N}_{\text {(aq) }}$. A total mass of $2073 \mathrm{~g}$ of $\mathrm{N}$ as $\mathrm{NH}_{3}$ gas entered the system during the 24 hour period, while almost $2929 \mathrm{~g}$ of $\mathrm{N}$ left the system (Table 3.6). The unbalanced condition may have resulted from the error associated with the gas phase $\mathrm{NH}_{3}$ measurements (the Gastec tubes measurement error), the error associated with calculation of masses. $\mathrm{N}$ that was released from decay of biofilter media may also have been present in the leachate and contributed to the unbalance.

Table 3.7 Sulfur mass balance within the biofilter

\begin{tabular}{|l|c|c|}
\hline Components & S-in (g-S/d) & S- out (g-S/d) \\
\hline $\mathrm{H}_{2} \mathrm{~S}-\mathrm{S}$ & 480 & - \\
\hline $\mathrm{MM}-\mathrm{S}$ & 319 & - \\
\hline $\mathrm{DMS}-\mathrm{S}$ & 88 & - \\
\hline $\mathrm{DMDS}-\mathrm{S}$ & 211 & - \\
\hline $\mathrm{SO}_{4}{ }^{2-}-\mathrm{S}$ & - & 1526 \\
\hline
\end{tabular}

The $\mathrm{S}$ balance presented in Table 3.7 indicates that the outlet mass of $\mathrm{S}(1526 \mathrm{~g})$ was higher than the inlet mass of $\mathrm{S}(1098 \mathrm{~g})$. In this calculation, it was assumed that $\mathrm{SO}_{4}{ }^{2-}$ 
was the only $\mathrm{S}$ containing compound in the leachate and $\mathrm{H}_{2} \mathrm{~S}, \mathrm{MM}$, DMS, and DMDS were the $\mathrm{S}$ containing compounds in the inlet gas. The unbalanced condition may have resulted from the presence of feed gases other than $\mathrm{H}_{2} \mathrm{~S}, \mathrm{MM}$, DMS, and DMDS (i.e., carbon disulfide $\left(\mathrm{CS}_{2}\right)$ and dimethyl trisulfide (DMTS). It can also be seen in Figure 3.9 that $\mathrm{SO}_{4}{ }^{2-}$ concentration was almost $400 \mathrm{mg} / \mathrm{l}$ at the end of the 24 -hour period while at the beginning it was $250 \mathrm{mg} / \mathrm{L}$. Hence the concentration did not follow a perfect cyclic variation during the 24-hour study period. Therefore, it may be chances of $\mathrm{SO}_{4}{ }^{2-}$ presence in the leachate coming from previously accumulated $S$ compounds in the woodchip packing. In general, during the microbial decomposition of organic and inorganic $\mathrm{S}$ compounds, $\mathrm{SO}_{4}{ }^{2-}$ is formed along with other incomplete oxidized substances such as elemental S, thiosulfates, etc. It could be that these compounds may have accumulated along the biofilter under some previous operating condition and that they were now being released. Hence the mass of $\mathrm{S}$ as $\mathrm{SO}_{4}{ }^{2-}$ leaving would be more than inlet mass of $\mathrm{S}$ as RSC in the gas phase.

\subsection{Conclusions}

This study evaluated the effectiveness of the biofilter for the treatment of ATAD offgases. Due to the sludge-feeding pattern, the ATAD reactors released $\mathrm{NH}_{3}$ and $\mathrm{RSCs}$ in a time-varying pattern. The series of ATAD reactors released maximum concentrations of 420 ppm $\mathrm{NH}_{3}, 20$ ppm $\mathrm{H}_{2} \mathrm{~S}, 4.8$ ppm MM, 2.5 ppm DMS and $2.2 \mathrm{ppm}$ DMDS. The generation of elevated concentrations of RSC shortly after feeding was likely due to the fact that oxygen demand exceeded oxygen supply at this time. The gas phase concentrations of $\mathrm{NH}_{3}$ tended to increase with time and location, along the digester 
sequence. The wet scrubber removed approximately $85 \%$ of $\mathrm{NH}_{3}$ and $60 \%$ of $\mathrm{H}_{2} \mathrm{~S}$. All the biofilter outlet gas phase concentrations were below the detection limit. The biofilter removal efficiencies were more than $99 \%$ for $\mathrm{H}_{2} \mathrm{~S} \& \mathrm{MM}$ and more than $94 \%$ for DMS \& DMDS. The removal efficiency of each compound demonstrated the effectiveness of the biofilter and wet scrubber combination for the ATAD offgas removal. The total elimination rate of $\mathrm{RSC}$ and $\mathrm{NH}_{3}$ were $3195 \mathrm{~g}-\mathrm{S} / \mathrm{m}^{3} / \mathrm{d}$ and $1668 \mathrm{~g}-\mathrm{N} / \mathrm{m}^{3} / \mathrm{d}$ respectively.

The biological transformations of the RSCs and $\mathrm{NH}_{3}$ result in the generation of acids. $\mathrm{NH}_{3}$ that enters the biofilter in the gas phase and alkalinity in the feed water act to buffer the addition of acid. Therefore, the biofilter leachate $\mathrm{pH}$ fluctuations were limited within pH 7-8. Almost $88 \%$ of the total $\mathrm{N}$ left the biofilter as $\mathrm{NH}_{4}{ }^{+}-\mathrm{N}_{(\mathrm{aq})}$ in the leachate. The remaining $12 \%$ of the total $\mathrm{N}$ left as nitrification products $\left(\mathrm{NO}_{3}-\mathrm{N}\right.$ and $\left.\mathrm{NO}_{2}-\mathrm{N}\right)$. From $\mathrm{N}$ and $\mathrm{S}$ mass balances, the outlet masses of $\mathrm{S}$ and $\mathrm{N}$ were higher than the inlet masses. The unbalanced conditions may have resulted from the feed containing gases other than the gases considered in this study. Also $\mathrm{N}$ that was released from decay of biofilter media may have been present in the leachate. In addition $\mathrm{S}$ may have accumulated in the biofilter as elemental $\mathrm{S}$ and thiosulfates. These reduced substances may be oxidized to $\mathrm{SO}_{4}{ }^{2-}$ with time and released with leachate. The unbalanced conditions may also due to the relative accuracy of gas and liquid measurements.

From the full-scale study, following points were noted for the design of the pilot-scale study. In addition to the $\mathrm{NH}_{3}$ removal, a significant amount of $\mathrm{H}_{2} \mathrm{~S}$ gas also removed within the scrubber. Therefore the RSCs removal in the scrubber was considered an 
important factor in the dynamic ATAD off gas analysis. From the lack of mass balance closure, it was believed that some $\mathrm{S}$ and $\mathrm{N}$ containing compounds were not considered in the full scale study. In terms of sampling techniques, the Gastec tube measurements $\left(\mathrm{NH}_{3}\right.$ and $\mathrm{H}_{2} \mathrm{~S}$ ) were considered likely approximate measurements and a more accurate measurement technique may be useful for a better mass balance closure. The hourly analysis of gas and liquid samples was considered reasonably feasible to do 24 hours continuous sampling in the pilot scale study. However, it would be better to analyze as soon as sampling was done to reduce the errors and mass loss while preserving and transporting the samples of gas phase and liquid phase. 


\section{Chapter}

\section{Four}

\section{The Pilot Scale Study: Materials and Methodology}

\subsection{Introduction}

The full-scale ATAD and biofilter study at the McMinnville water reclamation facility demonstrated dynamic variations of off gas and leachate concentrations. However some mechanisms such as scrubber removal, $\mathrm{RSC}$ oxidation, $\mathrm{NH}_{3}$ removal and nitrification that affect the biofilter performance require further analysis. This section deals with studies that provided an improved understanding of biofiltration of ATAD off gases under more controlled conditions. The literature review demonstrated that there was little information available on dynamic biofilter systems. ATAD off gases vary in composition on a regularly repeating basis. The pilot scale study focused on this cyclic variation of off gases from the ATAD system and their treatment in the biofilter.

The pilot scale study further elucidated the active removal processes in a biofilter under controlled conditions. Through varying process parameters, monitoring process performance and process chemistry in the biofilter an improved understanding of the mechanisms responsible for biofilter performance was demonstrated in this study.

\subsection{Experimental approach}

The experimental work focused on a pilot plant that included ATAD and biofilter processes. In order to obtain different off gas combination to the biofilter, the ATAD processes were changed. 


\subsubsection{Pilot scale studies on ATAD and biofilter system}

The biofilter and ATAD pilot plants were supplied by Ambio Biofiltration Inc. and Thermal Process Systems Inc., respectively. The pilot plant study was conducted at the Robert O. Pickard Environmental Centre (ROPEC) and thickened waste activated sludge (TWAS) was drawn from the ROPEC streams to provide the ATAD feed. The ATAD and biofilter schematic diagram is shown in Figure 4.1. The off gases from the ATAD headspace were passed through a prehumidification (wet scrubber) system and they were then directed to the biofilter.

ATAD

Off gases from headspace

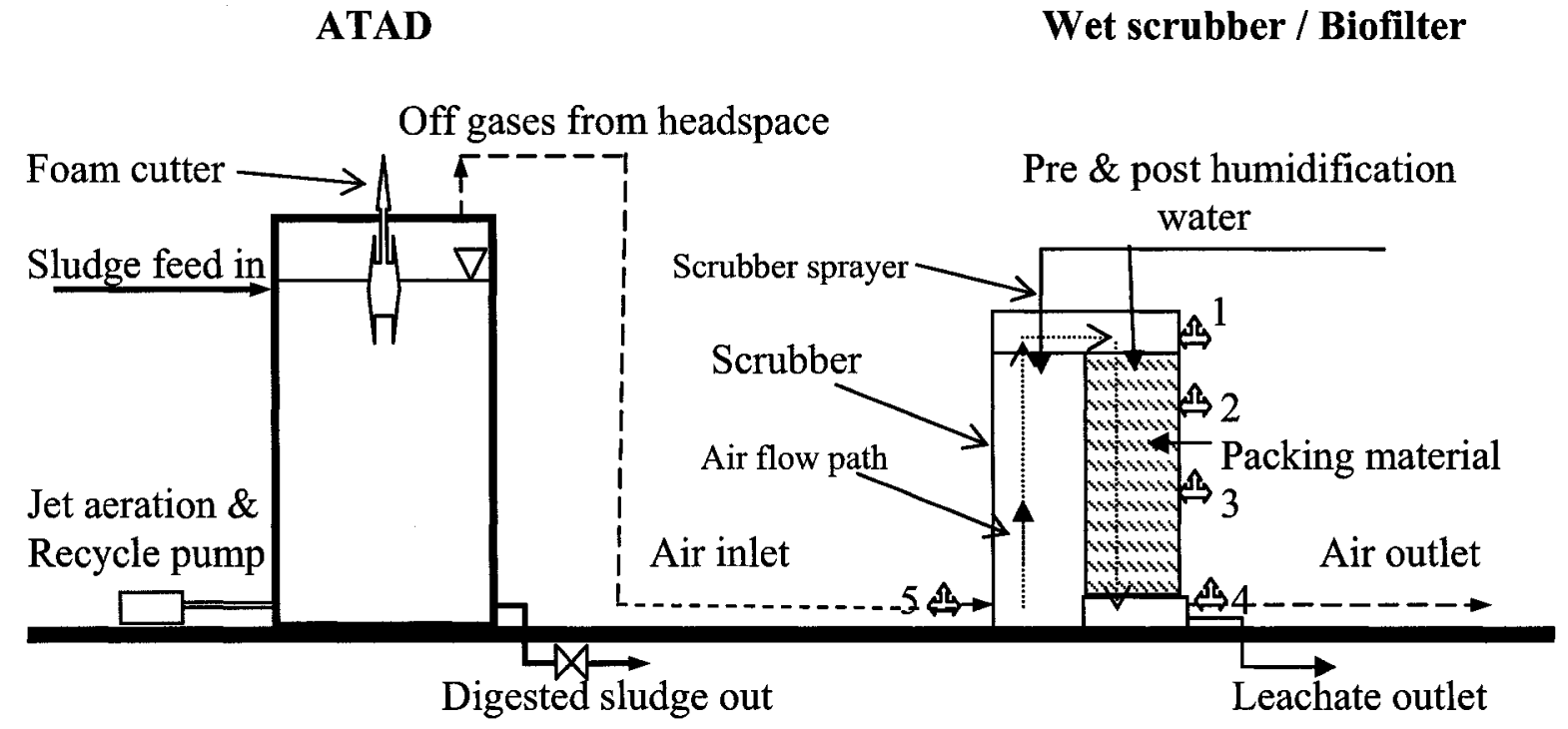

Figure 4.1 Schematic diagram of the pilot scale ATAD and biofilter system
Wet scrubber / Biofilter

Pre \& post humidification

water

The ATAD reactor was a cylindrical tank with capacity of around $4 \mathrm{~m}^{3}$. The metal tank was insulated around the tank wall. A foam cutter was mounted on top of the reactor. As shown in Figure 4.1, a recycle pump was used to recirculate the sludge for a better mixing and aeration within the reactor. Compressed air was used to aerate the sludge at the outlet of the recycle pump which was located at the bottom of the tank. 
(a)

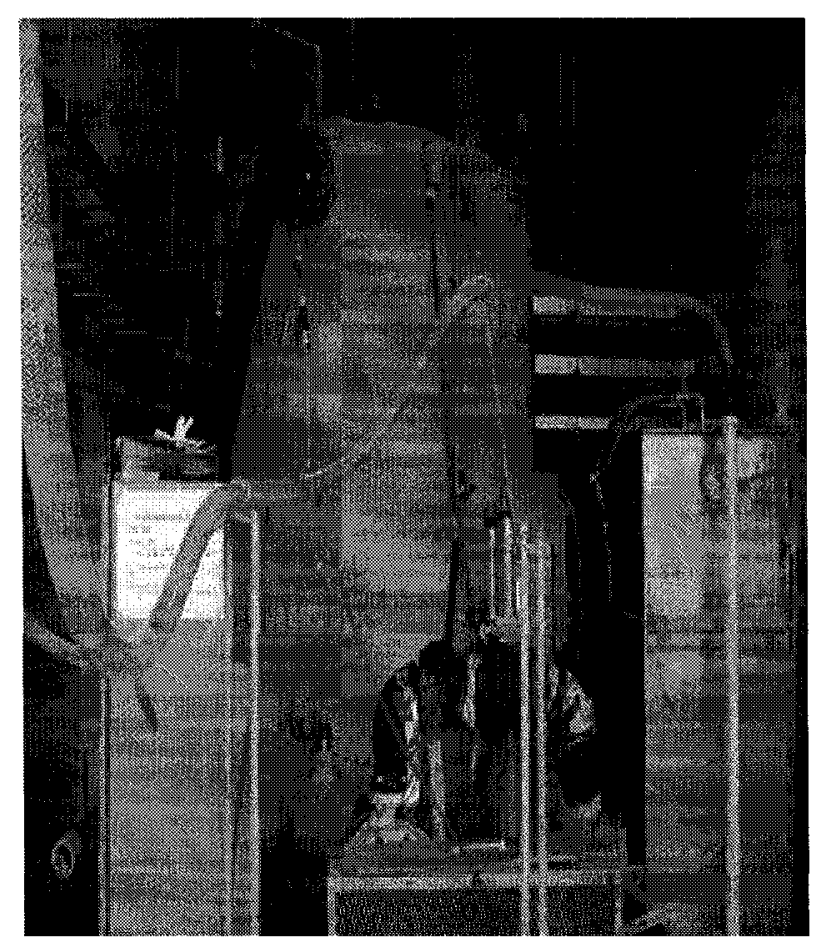

(b)

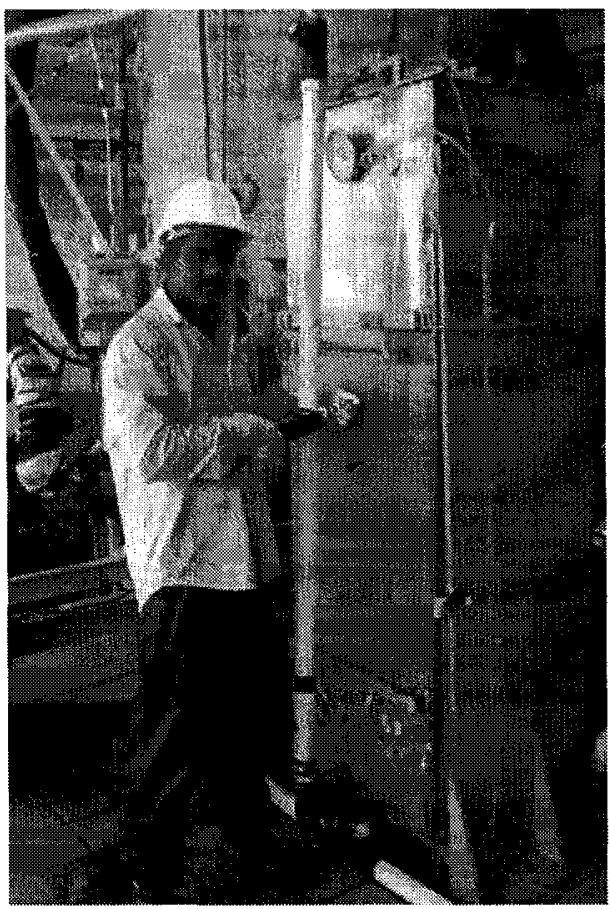

Figure 4.2 The pilot scale ATAD and biofilter system at ROPEC

The wet scrubber had dimensions of $0.3 \mathrm{~m}$ length $\times 0.2 \mathrm{~m}$ width $\times 1.2 \mathrm{~m}$ height and counter-current flow of gas and liquid. A spray nozzle was used to spray water within the scrubber. The biofilter was a closed bed stainless steel reactor with dimension of $0.6 \mathrm{~m}$ length $\times 0.3 \mathrm{~m}$ width $\times 0.75 \mathrm{~m}$ height and had a co-current down flow of gas and liquid. Coarse wood chips were initially used as the packing material, however later in the study crushed lime stone was spread on top of the woodchips to increase the bed $\mathrm{pH}$. The bed had a post-humidification system that employed a spray nozzle. 


\subsubsection{Experimental plan for the pilot study}

By changing the ATAD and biofilter variables, the ATAD and biofilter performance were evaluated. Sampling events were scheduled with different combination of ATAD and biofilter conditions. A sampling event was defined as activities of sampling during the period of time between one hour before sludge feeding into the ATAD and the following day sludge feeding hour. It was approximately a 24 hours continuous sampling and data collection from the ATAD and the biofilter.

Experimental variables that were analyzed in this study are given in Table 4.2.1. Air flow rates of $30,50,100$, and 150 SLPM and sludge loading rates of 150,245 , and $290 \mathrm{l} / \mathrm{d}$ were evaluated in this ATAD study. Gas retention times of 8,20 , and $80 \mathrm{~s}$. were evaluated as a variable of the scrubber system. Table 4.2 .2 shows the biofilter variables and their corresponding conditions, while Table 4.2.3 shows the experimental variable combinations that were analyzed for the biofilter study. At least two sampling events were done for each combination of the biofilter variables. A detail experimental schedule with ATAD and biofilter operating conditions are given in Appendix A. The sampling events names that are used in this dissertation are corresponding to Appendix A. The raw sampling events data is included on a CD-Rom in Appendix F.

\section{Table 4.2.1 Experimental variable}

\begin{tabular}{|l|l|}
\hline System & variable \\
\hline ATAD & Air flow rate \\
\cline { 2 - 2 } & Sludge loading \\
\hline Scrubber & Gas retention time \\
\hline Biofilter & Empty bed residence time (EBRT) \\
\cline { 2 - 2 } & Bed temperature \\
\cline { 2 - 2 } & Post humidification water \\
\cline { 2 - 2 } & Bed pH \\
\hline
\end{tabular}


Table 4.2.2 Experimental conditions for the biofilter

\begin{tabular}{|c|c|c|c|c|}
\hline Variable & \multicolumn{4}{|c|}{ Conditions } \\
\hline EBRT (s) & 150 & 75 & 40 & 15 \\
\hline Bed temperature & \multicolumn{2}{|c|}{ cold } & \multicolumn{2}{|c|}{ warm } \\
\hline Post humidification water & \multicolumn{2}{|c|}{ potable } & \multicolumn{2}{|c|}{ plant } \\
\hline Packing condition (bed $\mathrm{pH}$ ) & \multicolumn{2}{|c|}{ woodchip } & \multicolumn{2}{|c|}{ woodchip + lime stone } \\
\hline
\end{tabular}

Table 4.2.3 Biofilter experimental variable combination

\begin{tabular}{|l|c|c|c|c|}
\hline No. & EBRT (s) & $\begin{array}{l}\text { Bed } \\
\text { temperature }\end{array}$ & $\begin{array}{l}\text { Post humidification } \\
\text { water }\end{array}$ & Bed pH \\
\hline 1 & 150 & cold & potable & woodchip \\
\hline 2 & 150 & warm & potable & woodchip \\
\hline 3 & 150 & cold & plant & woodchip \\
\hline 4 & 150 & warm & plant & woodchip \\
\hline 5 & 150 & warm & potable & woodchip + lime stone \\
\hline 6 & 150 & warm & plant & woodchip + lime stone \\
\hline 7 & 75 & cold & potable & woodchip \\
\hline 8 & 75 & warm & potable & woodchip \\
\hline 9 & 40 & cold & potable & woodchip \\
\hline 10 & 40 & warm & potable & woodchip \\
\hline 11 & 40 & warm & plant & woodchip \\
\hline 12 & 15 & cold & potable & woodchip \\
\hline
\end{tabular}

\subsubsection{Gas sampling and analysis}

As discussed in Section 3.3.3, the lack of mass balances on $\mathrm{S}$ and $\mathrm{N}$ may have been due to gases that were not considered in the full-scale study. In addition to $\mathrm{NH}_{3}$, there may be some other gas phase $\mathrm{N}$ compounds $\left(\mathrm{NO}, \mathrm{NO}_{2}\right.$ and $\left.\mathrm{N}_{2} \mathrm{O}\right)$ in the biofilter inlet. In this study, these gas phase compounds were also examined in the off gas.

As discussed in Chapters 2 and 3, the odorous compounds in ATAD off gases consist of mainly $\mathrm{NH}_{3}$ and some RSCs. In addition, as discussed in the literature review, high $\mathrm{CO}_{2}$ concentration in the off gases may also influence removal mechanisms as well as the $\mathrm{pH}$ of the leachate. Therefore, $\mathrm{CO}_{2}$ gas was also measured in this study. 
At the outset of the pilot study, the RSCs which were in the ATAD off gases were investigated. An Agilent GC (6890N) equipped with a mass spectrometer as detector $(5973 \mathrm{~N})$ was employed in this study. After the ATAD operation was started, the process was allowed to stabilize for around one month, with daily feed and discharge of sludge. After that, ATAD head space samples were collected in Tedlar bags and immediately transported for the GC analysis. These off gas samples were collected 2 hours after the feeding when relatively high concentration of off gases was detected.

Gas phase sampling was performed on an hourly and/or bi-hourly basis during each sampling event. Three sampling ports (before the scrubber system, before the biofilter and after the biofilter (ports 5, 1 and 4 in Figure 4.1)) were used for sampling. In addition, two more sampling ports (ports 2 and 3 in Figure 4.1) along the biofilter were considered when the off gas variation along the biofilter was analyzed.

$\mathrm{NH}_{3}$ gas was analyzed using a PhoCheck $3000 \mathrm{EX}$ ammonia gas monitor which is equipped with photo ionization detector (PID) detector. The $\mathrm{NH}_{3}$ gas readings were taken directly by inserting the instrument inlet tube-head into the sample ports. Between instrument gas inlet and the head tube, a filter $(25 \mathrm{~mm}$ diameter probe fiber, pore size of $0.5 \mu \mathrm{m}$ ) was used to trap the particulate matter. $\mathrm{NH}_{3}$ detection range was between 0.1 ppm and 10000 ppm. Calibration detail is given in Section 4.3.1.

$\mathrm{N}$ containing gases, other than $\mathrm{NH}_{3}$, such as $\mathrm{NO}_{2}$ (nitrogen dioxide), $\mathrm{NO}$ (nitric oxide) and $\mathrm{N}_{2} \mathrm{O}$ (nitrous oxide) were also analyzed. $\mathrm{NO}_{2}$ and $\mathrm{NO}$ were analyzed using OSHA 
method ID 182. The samples were collected using a sampling tube containing a triethanolamine - impregnated molecular sieve (TEA-IMS) and a calibrated sampling pump is used. The sample was then desorbed from the solid sorbent using a $1.5 \%$ triethanolamine (TEA) solution $(3 \mathrm{ml})$. The desorbed solution was allowed to settle for at least 1 hour, and then the solution was filtered (pore size of $0.20 \mu \mathrm{m}$ filter) and analyzed as nitrite $\left(\mathrm{NO}_{2}{ }^{-}\right)$by ion chromatography (as described in Section 4.2.4).

The $\mathrm{N}_{2} \mathrm{O}$ was analyzed with a GC/TCD system (GC: SRI 8400). GC conditions were: 3' $x$ 1/8" stainless steel column packed with Spherocarb, 100/120 mesh; column temperature isothermal $\left(90^{\circ} \mathrm{C}\right)$; injector temperature of $100^{\circ} \mathrm{C}$; detector temperature of $100^{\circ} \mathrm{C}$; helium as carrier gas and sample size of $1 \mathrm{ml}$. Samples were collected in Tedlar bags from in and out of the biofilter, and then injected into the GC.

Carbon dioxide $\left(\mathrm{CO}_{2}\right)$ gas was analyzed by a GTCO2 portable gas monitor on site. $\mathrm{CO}_{2}$ detection range was between 0 and $20 \%$ of volume ratio. It was calibrated before the sampling events using $10 \% \mathrm{CO}_{2}$ gas.

The RSC were analyzed by a GC/PFPD system (GC: Varian star 3600; PFPD-pulse flame photometric detector). The gas samples were drawn directly from sampling ports using syringes (Hamilton sample lock syringe) and injected into the GC. The GC calibration and preparation of standards are given in Section 4.3.1. The GC conditions are given in Table 4.2.4. The detection limit for each compound based on GC setup is given in Table 4.2.5. 
Table 4.2.4 GC conditions

\begin{tabular}{|l|l|}
\hline GC & Varian 3600 \\
\hline Column & $\begin{array}{l}\text { VB-1, Capillary column, length- } 30 \mathrm{~m}, \text { Column ID- } 0.32 \mathrm{~mm} \text {, Film } \\
\text { thickness- } 4.00 \mu \mathrm{m}\end{array}$ \\
\hline $\begin{array}{l}\text { Injector } \\
\text { condition }\end{array}$ & $\begin{array}{l}\text { Isothermal } 140^{\circ} \mathrm{C}, \\
2 \mathrm{ml} \text { of gas injection }\end{array}$ \\
\hline $\begin{array}{l}\text { Column } \\
\text { condition }\end{array}$ & $35^{\circ} \mathrm{C}$ for 5 min then ramping at $20^{\circ} \mathrm{C} / \mathrm{min}$ to $140^{\circ} \mathrm{C}$ then hold for $4 \mathrm{~min}$ \\
\hline $\begin{array}{l}\text { Detector } \\
\text { condition }\end{array}$ & Pulse flame photo ionization detector (PFPD), $200^{\circ} \mathrm{C}$ \\
\hline
\end{tabular}

Table 4.2.5 Gas phase detection limits for each compound

\begin{tabular}{|c|c|}
\hline Compound & Detection limit $(\mathrm{ppm})$ \\
\hline $\mathrm{NH}_{3}$ & 0.100 \\
\hline $\mathrm{H}_{2} \mathrm{~S}$ & 0.170 \\
\hline $\mathrm{MM}$ & 0.150 \\
\hline $\mathrm{DMS}$ & 0.100 \\
\hline $\mathrm{CS} 2$ & 0.160 \\
\hline $\mathrm{DMDS}$ & 0.060 \\
\hline $\mathrm{DMTS}$ & 0.030 \\
\hline $\mathrm{CO}_{2}(\%)$ & 0.1 \\
\hline
\end{tabular}

\subsubsection{Liquid sampling and analysis}

The water streams entering and leaving the biofilter were also characterized. The grab samples were collected on an hourly or bi-hourly basis from the biofilter and the scrubber leachate during each sampling period. In addition, occasional samples were collected from the water line providing water to the post humidification system.

The removal of $\mathrm{RSCs}$ and $\mathrm{NH}_{3}$ can result in the fluctuation of leachate $\mathrm{pH}$. The $\mathrm{pH}$ of the water samples was measured immediately after collection using an Orion model $290 \mathrm{~A} \mathrm{pH}$ meter. The samples for $\mathrm{NH}_{3}-\mathrm{N}$ were analyzed by the selective ion electrode method (APHA, 1995) at the site using an Orion model $400 \mathrm{pH} / \mathrm{mV}$ meter with $\mathrm{NH}_{3}$ probe. The water samples were then transferred to $40 \mathrm{ml}$ amber vials and acidified with $\mathrm{HCl}$ to less 
than $\mathrm{pH} 3$ for preservation prior to being transported to the laboratory for analysis of $\mathrm{SO}_{4}^{2-}, \mathrm{NO}_{3}^{-}$, and $\mathrm{NO}_{2}^{-}$.

Anions $\left(\mathrm{SO}_{4}{ }^{2-}, \mathrm{NO}_{3}^{-}\right.$, and $\left.\mathrm{NO}_{2}^{-}\right)$were analyzed using an ion chromatograph (IC 5000, Lachat instrument). Samples were filtered using glass fiber filters (pore size of $0.20 \mu \mathrm{m}$ ) before analysis. In addition, the total Kjeldahl-nitrogen (TKN) was analyzed in certain sampling event to characterize the leachate $\mathrm{N}$ compounds. TKN analysis was done by an external laboratory (Caduceon Environmental Laboratories, Ottawa) based on standard method EPA 351.2.

Gas flows were calculated by multiplying air velocity and cross sectional area of the pipe which was used to connect ATAD outlet and scrubber inlet. The air velocity was measured using a hotwire thermo-anemometer (Extech instrument, model 407123). At least three readings of air velocities were measured at the center of the 3 inch scrubber inlet line and then the average of these values was taken as the air velocity. Liquid flows were measured at the leachate outlet using a bucket and stopwatch method. At least three measurements were taken to obtain an average liquid flow at a time.

\subsubsection{Evaluation of ATAD variables}

In this portion of the study, the operating conditions of the ATAD were varied to assess the impact on the ATAD off gases. In this study, the sludge loading rate and the aeration rate into the ATAD were varied. The ATAD responses that were measured included total solids (TS) reduction, volatile solids (VS) reduction, oxidation reduction potential (ORP), 
and temperature. The ORP and temperature readings were measured directly from a probe which was attached in the recycle pipe line of the ATAD reactor. The probe was cleaned and calibrated at least once every three months period. The solids content measurements were done according to the standard method (Section 2540, APHA, 1995). The TS was calculated by the matter that remains as residue upon evaporation and drying at $105^{\circ} \mathrm{C}$. The concentration of TS was the weight of dry solids divided by the volume of the sample, in $\mathrm{g} / \mathrm{l}$. The VS was calculated by the mass of dry solid matter (TS) that was burned off at $550^{\circ} \mathrm{C}$. The residue that remained after burning was the fixed solids. The solids samplings were done daily for the ATAD feed and discharge samples.

The sludge entering the ATAD was thickened waste activated sludge (TWAS). Since TWAS was easily accessible at the ATAD operating room and TWAS is an almost homogeneous mixture with relatively consistent solid percentage compare to the primary sludge, it was chosen to feed the ATAD in this study. The average TS content of TWAS was $61.9 \mathrm{~g} / 1$ with standard deviation of $8.2 \mathrm{~g} / 1$ while VS content of TWAS content was $42.8 \mathrm{~g} / 1$ with standard deviation of $6.1 \mathrm{~g} / 1$.

The sludge loading rate was set based on the solid retention time (SRT). In this study an SRT of 12 days was maintained for most of the tests and hence $245 \mathrm{l} / \mathrm{d}(65 \mathrm{gal} / \mathrm{d})$ of sludge was fed into the ATAD every day. Selected runs were performed with SRT's of 8 and 20 days and during these runs 290 and $150 \mathrm{l} / \mathrm{d}$ of sludge were loaded, respectively. 


\subsubsection{Evaluation of biofilter variables}

Biofilter process variables were adjusted to assess their impact on overall process performance as well as to evaluate the contributions of the removal mechanisms to the process performance. In this portion of the study, the air flow rate to the biofilter, the contaminant loading rate, the source of post-humidification water and bed $\mathrm{pH}$ were varied.

The composition of the gas stream entering the biofilter was varied by adjusting the ATAD operating conditions as described in Section 4.2.5. In some cases, clean air was provided (from an air compressor which was used for the ATAD aeration) as make-up air to dilute the ATAD off gas when studies on the impact of contaminant loading were performed. For example, at a given air flow rate the concentration of contaminants was varied by adjusting the fraction of ATAD off gas that was present in the gas stream entering the biofilter.

The impact of bed temperature on the biofilter performance was evaluated during winter and summer weather conditions. The bed temperature was controlled by the ambient temperature and post humidification water temperature. In some cases a water heater was used to increase the post humidification water temperature subsequently to increase the bed temperature. Warm bed temperatures were established when the ambient temperatures were above $25^{\circ} \mathrm{C}$ and the humidification water temperature was approximately $22^{\circ} \mathrm{C}$, resulting in a bed temperature of approximately $26^{\circ} \mathrm{C}$. Cold bed temperatures were established when the ambient temperatures were between $-30{ }^{\circ} \mathrm{C}$ and 
$-10^{\circ} \mathrm{C}$ and the humidification water temperature was approximately $4{ }^{\circ} \mathrm{C}$, yielding a bed temperature of approximately $5^{\circ} \mathrm{C}$. When a water heater was used during cold temperature, the bed temperature only raised by around $10^{\circ} \mathrm{C}$. Therefore, bed temperatures between 5 to $26^{\circ} \mathrm{C}$ were analyzed in this study.

Initial studies on the pilot scale biofilter showed that the bed $\mathrm{pH}$ was around 6 . It was believed that the acidic $\mathrm{pH}$ may influence the removal mechanisms in the biofilter. The impact of bed $\mathrm{pH}$ on performance was evaluated by adding crushed limestone on top of the woodchips filter bed to increase the bed $\mathrm{pH}$. The volume of limestone was around $0.036 \mathrm{~m}^{3}$ (around $0.2 \mathrm{~m}$ depth of filter bed) and the size of the stones was around $10 \mathrm{~mm}$. This was carried out near the end of the pilot scale study, after finishing the woodchips alone conditions.

The impact of the source of post-humidification water on process performance was evaluated. Some installations employ treatment plant water (secondary treated wastewater or treated effluent) for this purpose. However in some cases potable water may be employed. In the full-scale study at McMinnville, potable city water was used as post-humidification water in the open biofilter. However, the treated effluent contains nutrients that may stimulate biofilter performance and in addition contains high levels of microorganisms that may continuously inoculate the biofilter. The two water sources may also have different chemistries (i.e., $\mathrm{NH}_{4}{ }^{+}, \mathrm{NO}_{3}{ }^{-}$, and $\mathrm{pH}$ ) that may impact on biofilter performance. This operating practice was evaluated to identify whether the use of treated effluent is preferable to the use of potable water. 


\subsubsection{Biofilter media analysis}

To check for any accumulation of $\mathrm{N}$ compound on the packing, the woodchip samples were analyzed for $\mathrm{TKN}, \mathrm{NH}_{4}{ }^{+}(\mathrm{aq})$ and $\mathrm{NO}_{3}{ }^{-}$. Three samples from fresh packing, top and bottom of the filter bed were taken for this analysis. The samples with their triplicates were taken by weight (around $100 \mathrm{~g}$ ) and kept in $250 \mathrm{ml}$ plastic bottles with the addition of $100 \mathrm{ml}$ of de-ionized water. Then the samples were centrifuged for $15 \mathrm{~min}$ at 10000 rpm. The supernatant was analyzed for $\mathrm{NH}_{4}{ }^{+}(\mathrm{aq}), \mathrm{NO}_{3}{ }^{-}$and $\mathrm{TKN}$ by the same methods which were used for the liquid analysis.

Packing media properties (porosity, bulk density and moisture content) that were used for the model development were measured in this study. Sample packing material was collected from around $20 \mathrm{~cm}$ below the top of the biofilter bed. The samples were collected after around 1 year of biofilter operation.

\section{Porosity:}

The porosity of woodchip packing was estimated by determining the void space sample to volume ratio. The volume of the sample was determined with a graduated cylinder. The sample was weighed with an analytical balance before water was added to fill the void space volume. Air bubbles were dislodged by periodically tapping the cylinder. The saturated sample weight was then determined and percent porosity was calculated from the following relationship:

Porosity $(\%)=\frac{\text { void space volume }}{\text { volume of sample }}$ 
Porosity $(\%)=\frac{\text { (weight of sample }+ \text { cylinder }+ \text { water })-(\text { weight of sample }+ \text { cylinder })}{\frac{\text { density of water }}{\text { volume of sample }}}$

\section{Bulk density:}

The biofilter material density analysis was evaluated by weighing a sample of known volume at the field condition. The bulk volume includes the volume of solids and the pore space.

\section{Moisture content:}

The moisture content of the biofilter material was measured as weight lost on heating to $105^{\circ} \mathrm{C}$ for $24 \mathrm{~h}$.

\subsection{Standard preparation and calibration}

\subsubsection{Gas phase standard preparation and calibration}

An $\mathrm{NH}_{3}$ gas standard was purchased to calibrate the Phocheck $3000 \mathrm{EX}$ instrument for the $\mathrm{NH}_{3}$ gas calibrations. According to the Phocheck 3000EX operating manual, it was initially calibrated in the factory and onsite calibration was advised before usage. 300 and $1000 \mathrm{ppm}$ calibration standard gases were used in this study and the instrument was calibrated before every 24-hours sampling event.

Gas phase RSC's standards were prepared using certified Teflon membrane permeation devices (Kin-Tec Laboratories Inc.) Table 4.3.1 presents the compounds for which permeation tubes were available. 
Table 4.3.1 Characteristics of permeation tubes for target compounds

\begin{tabular}{|c|c|c|c|c|}
\hline $\begin{array}{l}\text { Compound } \\
\text { name }\end{array}$ & $\mathrm{MW}(\mathrm{g} / \mathrm{mol})$ & $\begin{array}{c}\text { Permeation rate }(\mathrm{F}) \\
(\mathrm{ng} / \mathrm{min})\end{array}$ & $\begin{array}{c}\text { Oven temperature } \\
\left({ }^{\circ} \mathrm{C}\right)\end{array}$ & Ko \\
\hline $\mathrm{H}_{2} \mathrm{~S}$ & 34.08 & 2825 & 40 & 0.657 \\
\hline \multirow{4}{*}{ MM } & \multirow{4}{*}{48.11} & 6951 & 40 & \multirow{4}{*}{0.466} \\
\hline & & 1019 & 30 & \\
\hline & & 436 & 40 & \\
\hline & & 431 & 40 & \\
\hline \multirow{3}{*}{ DMS } & \multirow{3}{*}{62.13} & 1921 & 40 & \multirow{3}{*}{0.361} \\
\hline & & 1961 & 40 & \\
\hline & & 116 & 30 & \\
\hline $\mathrm{CS}_{2}$ & 76.10 & 3586 & 30 & 0.294 \\
\hline \multirow{2}{*}{ DMDS } & \multirow{2}{*}{94.20} & 3371 & 80 & \multirow{2}{*}{0.238} \\
\hline & & 155 & 40 & \\
\hline DMTS & 126.26 & 2816 & 100 & 0.177 \\
\hline
\end{tabular}

Ko is a factor that relates the molar mass of the compound to the volume occupied by an ideal gas at standard temperature and pressure. The calculation of the standard concentrations was made applying the formula:

$$
C=\frac{K o * F}{Q}
$$

Where: $C$ - standard concentration (ppm); Ko - constant; $F$ - permeation rate (ng/min);

$Q$ - the flow rate base gas measured at standard conditions: $0^{\circ} \mathrm{C}$ and $1 \mathrm{~atm}(\mathrm{ml} / \mathrm{min})$.

The permeation devices were placed individually and in combinations in a thermostatted glass chamber (Kin-Tek laboratories Inc.) A base flow of high purity (99.99\%) nitrogen gas was maintained through the permeation chamber at $50 \mathrm{ml} / \mathrm{min}$, and the concentration of the target compounds was varied using additional dilution gas. The temperature inside the chamber was measured with a temperature probe. The flow was measured at room conditions with an SKC UltraFlo device and corrected afterwards for standard conditions. 
Since the actual pilot study gas samples were fully humidified, the standards were also humidified using a Nafion membrane humidifier (Perma Pure Inc.) before GC calibration.

Initially the standard gases were generated individually and injected into the GC to find the retention time in the chromatogram. Later, combinations of all the target compounds were generated together with humidified samples. All standards were generated and transported immediately to ROPEC for the GC calibration. At least triplicate injections were made for each standard and the calibration curves were developed based on standard procedures. The calibration data are given in Appendix B.

\subsubsection{Liquid standard preparation and calibration}

For liquid phase analysis, the $\mathrm{NH}_{4}{ }^{+} \mathrm{N}(\mathrm{aq})$ was measured using the selective electrode method (APHA, 1995). Standard solutions were prepared for on-site calibration of the electrode. A sample calibration curve is given in Appendix C. In order to verify the $\mathrm{NH}_{4}{ }^{+}-\mathrm{N}(\mathrm{aq})$ measurements that were obtained with the electrode method, liquid samples that were collected in two sampling events were sent to the external laboratory (Accutest laboratories Ltd, Ottawa) where they were analyzed by the Phenate method (APHA, 1995).

Calibrations of the Ion chromatograph for $\mathrm{NO}_{2}^{-}, \mathrm{NO}_{3}{ }^{-}$, and $\mathrm{SO}_{4}{ }^{2-}$ were performed as stated in QuickChem method 10-510-00-1-A (Karmarkar and Bahowick, 2001). A 
certified standard solution was purchased and the standard stock solution concentrations are given in Table 4.3.2.

Table 4.3.2 IC standard stock solution

\begin{tabular}{|c|c|}
\hline Components & Concentration (mg/l) \\
\hline $\mathrm{NO}_{3}-\mathrm{N}$ & 25 \\
\hline $\mathrm{NO}_{2}-\mathrm{N}$ & 25 \\
\hline $\mathrm{SO}_{4}{ }^{2-}$ & 150 \\
\hline
\end{tabular}

From the stock solution, 5 different standard solutions were prepared and were used in generating the internal calibration curve in the IC software. A sample IC calibration curve is given in Appendix C. At least one standard solution was prepared and analyzed in each sampling event to check the calibration data. If the standard solution measurement different from the actual concentration by more than $15 \%$, a new calibration curve was generated. During the sampling events, if sample measurements were above the calibration range, the samples were diluted accordingly and the analyses were repeated. In addition, a blank sample (distilled water) was run in this method before each batch of samples to confirm the quality of the data.

\subsubsection{Air Flow measurement corrections}

Off gas flow rates were calculated from air velocities that were measured at the off gas flow line using a hotwire thermo-anemometer (EXTECH instrument, model 407123). The anemometer measurements were validated by measuring a known flow rate reading in a model setup using ATAD off gas. The pilot plant conditions were created with a $3 \mathrm{~m}$, 3 inch PVC pipe with a sample port in the middle. A factory calibrated rotameter (flow 
meter) from the Mechanical Engineering Department, Carleton University, was used to measure the flow rates concurrently with the anemometer for several flow rates through the PVC pipe. Table 4.3.3 shows the rotameter flow rates versus the calculated flow using the anemometer readings. As shown in Table 4.3.3, the anemometer reading typically differed from the actual flow values by $16 \%$. Therefore, the flow rates which were used in all calculations were adjusted accordingly.

Table 4.3.3 Rotameter vs. anemometer readings

\begin{tabular}{|c|c|c|c|}
\hline \multicolumn{2}{|c|}{ Rotameter reading } & \multicolumn{2}{c|}{ Anemometer reading } \\
\hline SCFH & $\begin{array}{c}\text { Corresponding } \\
1 / \mathrm{min}\end{array}$ & $\mathrm{m} / \mathrm{s}$ & $\begin{array}{c}\text { Corresponding } \\
1 / \mathrm{min}\end{array}$ \\
\hline 100 & 47.2 & 0.2 & 54.7 \\
\hline 200 & 94.4 & 0.4 & 109.5 \\
\hline 300 & 141.6 & 0.6 & 164.2 \\
\hline 400 & 188.8 & 0.8 & 219.0 \\
\hline
\end{tabular}

\subsection{Quality control}

Precision measures the reproducibility of repeated measurements. Analytical precision is a measurement of the variability associated with replicate analyses of the same sample in the laboratory. The standard gases were analyzed to check the precision with multiple injections. However, during 24-hours sampling time, it was very difficult to make duplicate analysis, since each sample took almost $30 \mathrm{~min}$ for the $\mathrm{GC}$ analysis at the site. Therefore the day before the sampling, at least duplicate samples of ATAD off gas were analyzed to assess the analytical precision. Accuracy is a statistical measurement of correctness. It reflects the total error associated with a measurement. A measurement is 
accurate when the value reported does not differ from the true value of the standard. For each day of analysis the standards were checked. If the measured value was within $15 \%$ of the true value of the standard, it was considered accurate. Statistical analyses were done on each set of data which are presented in this dissertation. For each set of data, mean values were calculated based on Equation 4.2. Then standard deviation was calculated according to Equation 4.3.

$$
\text { Mean }=\frac{\sum X i}{N}
$$

$X_{i}$ - measured values; $N$ - Number of measurements

$$
S T D E V=\sqrt{\frac{\sum(X i-m e a n)^{2}}{(N-1)}}
$$

The standard deviation is a measure of how much the data in a certain collection are scattered around the mean. A low standard deviation means that the data are tightly clustered while a high standard deviation means that they are widely scattered. Therefore the standard deviation of a group of repeated measurements gives the precision of those measurements. 


\section{Chapter}

Five

\section{The Pilot Scale Study: Results and Discussions}

\subsection{Introduction}

The ATAD and biofilter pilot scale reactors were operated for a period of almost 20 months and around fifty 24-hours sampling events were carried out. The gas and liquid phases were analyzed in each sampling event. In this chapter, the experimental results are presented and discussed. The ATAD parameters are discussed in Section 5.2. The gas phase pollutant responses are given in Section 5.3 while the liquid phase pollutant responses are given in Section 5.4. $\mathrm{S}$ and $\mathrm{N}$ mass balance within the biofilter are discussed in Section 5.5. The $\mathrm{N}$ compounds $\left(\mathrm{NH}_{4}{ }^{+}\right.$and $\left.\mathrm{NO}_{3}{ }^{-}\right)$variations along the cycle are discussed in Section 5.6. Finally, the impact of bed temperature, source of posthumidification water, biofilter bed $\mathrm{pH}$, and pollutant loadings were studied under controlled operating conditions and are presented in Section 5.7.

\subsection{ATAD conditions versus cycle time}

In this study, ATAD operating parameters were varied to obtain different pollutant loading conditions on the biofilter. Throughout the study, the ATAD reactor was monitored with respect to ORP, reactor temperature and total and volatile solids contents of the reactor sludge. Figure 5.2.1 shows a typical ORP response for a 24-hour cycle. The ATAD conditions included air flow rate of 60 SLPM; sludge loading rate of $245 \mathrm{1} / \mathrm{d}$; TWAS as feed sludge; and the temperature around $60^{\circ} \mathrm{C}$. As shown in Figure 5.2.1, immediately after the sludge feeding the ORP value started to decrease to the lowest 
value of the cycle that was obtained within the next 6 hours. It then increased to an almost constant ORP value for the rest of the cycle (last 10 hours). As reported by Kelly et al. (1993) a similar ORP variation was observed between the feed cycles.

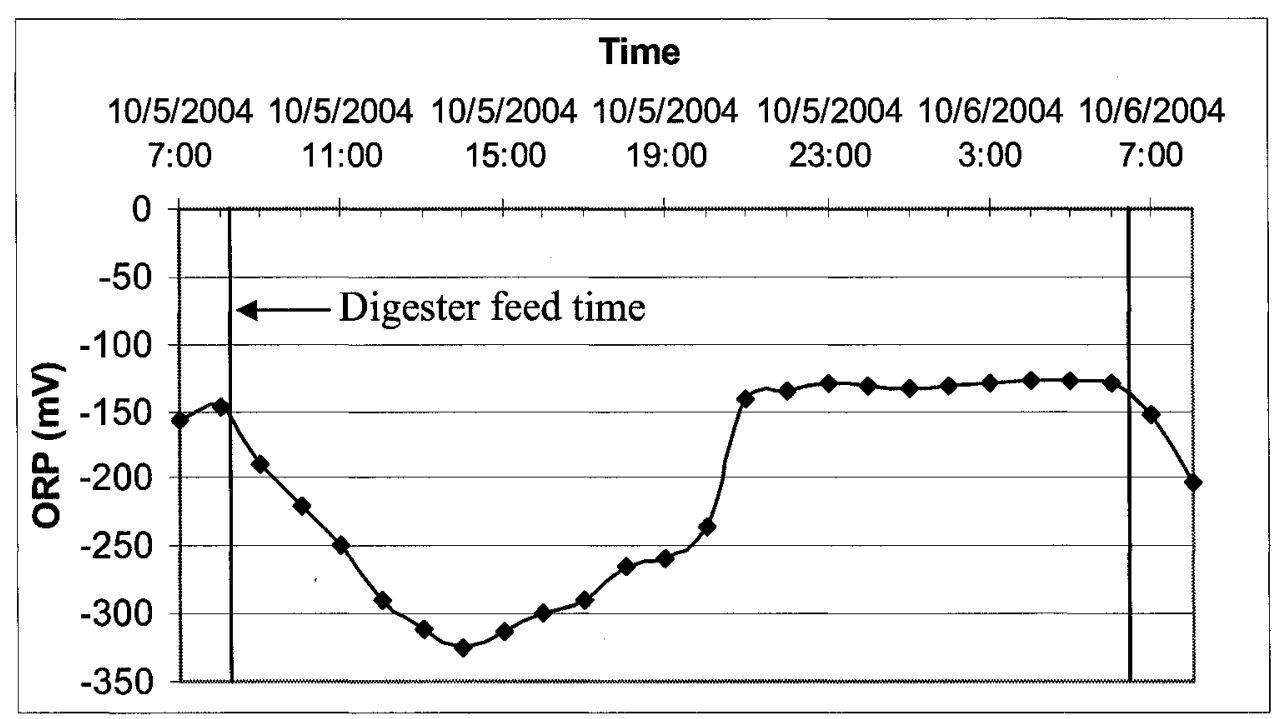

Figure 5.2.1 ORP value variations along the cycle within the ATAD

During the first half of the cycle, microbial activity increased due to the loading of fresh sludge and hence the oxygen demand increased, therefore the ORP value decreased. When oxygen supply exceeded the demand, the ORP profile changed towards aerobic conditions. As stated by Kelly (1990), Smith and Kelly (1988b), and De Bont et al. (1981), the microbial activity increases in the initial period of time and due to that, the $\mathrm{NH}_{3}$ gas production and the RSCs production peak during this time. When the ORP values became stable, the $\mathrm{NH}_{3}$ and $\mathrm{RSC}$ gas productions also reached stable and relatively low concentrations along the cycle (the gas production will be discussed later in Section 5.3). 
The $\mathrm{pH}$ levels typically observed in ATAD systems tend to be slightly basic (USEPA, 1990). With the feed sludge (TWAS) $\mathrm{pH}$ of around 7, the ATAD pH was between 8 and 8.4 in this study. After the feeding, the $\mathrm{pH}$ decreased slightly due to the low $\mathrm{pH}$ of the feed and this may also be due to the accumulation of volatile fatty acids in the ATAD when the ORP values were low (around $-400 \mathrm{mV}$ ) as suggested by Li and Bishop (2002) and Fothergill and Mavinic (2000). Then within a short period of time (around 4 hours), the reactor $\mathrm{pH}$ became almost stable throughout the cycle.

Figure 5.2.2 shows the digester temperature response corresponding to the ATAD conditions given in Figure 5.2.1. The temperature decreased by around $4^{\circ} \mathrm{C}$ immediately after the sludge was fed into the ATAD then gradually increased to a stable temperature. The temperature drop was found to depend on the volume of fresh sludge, consistency of the feed and the feed temperature. When the volume of fresh sludge feed was increased, the temperature drop was high. The temperature drop was also affected by the sludge consistency. As discussed in Chapter 4, the sludge consistency varied based on the ROPEC operating conditions. 


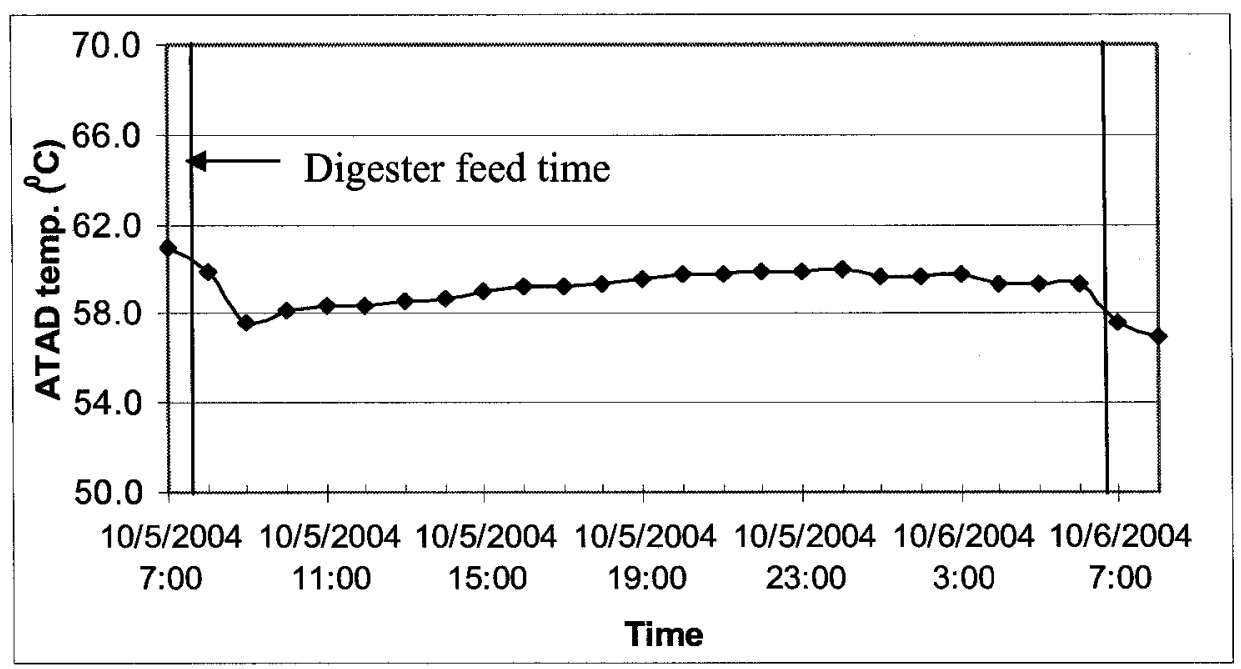

Figure 5.2.2 - The digester temperature variation during one cycle

In an ATAD system, the thermophilic temperature conditions lead to an increase in off gas (e.g., $\mathrm{CO}_{2}, \mathrm{NH}_{3}, \mathrm{RSC}$ ) stripping as compared to mesophilic temperature conditions. This is due to variations in the Henry's law coefficient of a compound. Equation 5.2.1 shows the temperature dependence for Henry's coefficient of $\mathrm{NH}_{3}(\mathrm{Ni}, 1999)$.

$$
\begin{gathered}
\ln (H)=\frac{-4200}{T}+3.133 \\
K_{H}=\frac{H}{R^{*} T}
\end{gathered}
$$

Where, $H \quad$-Henry's law coefficient $\left(\mathrm{atm} / \mathrm{m}^{3} / \mathrm{mol}\right)$

$K_{H}$-Dimensionless Henry's law coefficient

From Equation 5.2.2, when the temperature increases in the aqueous phase, the $\mathrm{K}_{\mathrm{H}}$ also increases accordingly; hence at equilibrium the compound concentration in the aqueous phase would decrease. For example, when the $\mathrm{NH}_{3}$-water system is considered, $\mathrm{K}_{\mathrm{H}}-\mathrm{NH}_{3}$ at $25^{\circ} \mathrm{C}$ is 0.00062 , according to Equation 5.2.1 and Equation 5.2.2, the $\mathrm{K}_{\mathrm{H}}-\mathrm{NH}_{3}$ at $60^{\circ} \mathrm{C}$ is 0.0026 . Therefore, the equilibrium $\mathrm{NH}_{3}(\mathrm{aq})$ concentration at $60^{\circ} \mathrm{C}$ is reduced to almost $1 / 4$ of its value at $25^{\circ} \mathrm{C}$. As shown in Equations 2.1.3 and 2.1.4, the concentration of $\mathrm{NH}_{3}$ 
increases with increasing $\mathrm{pH}$ and with increasing temperature. The $\mathrm{NH}_{3}$ stripping is much more efficient at thermophilic temperature and alkaline $\mathrm{pH}$ condition, because partitioning of free $\mathrm{NH}_{3}$ to the gas phase is favored.

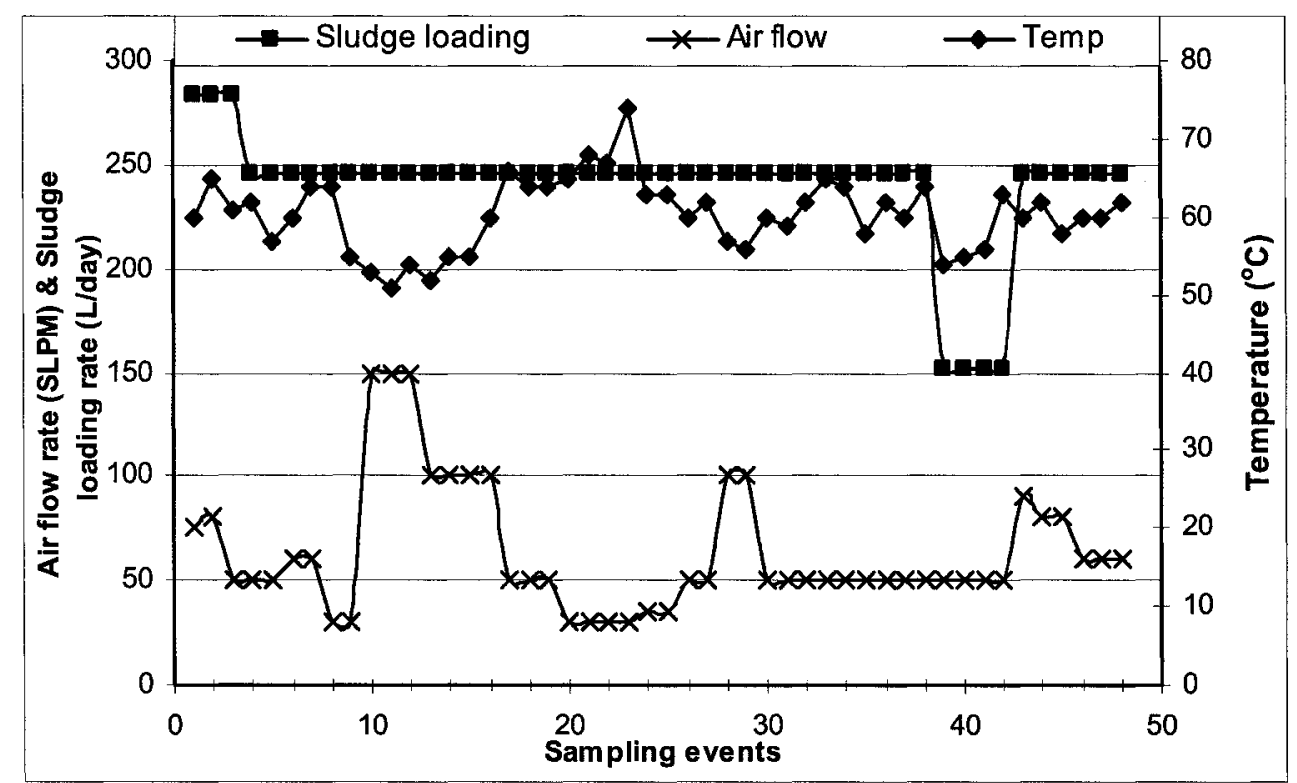

Figure 5.2.3 ATAD temperature, air flow rate and sludge loading rate variations

Figure 5.2.3 shows the ATAD temperature, air flow, and sludge loading over a period of 48 sampling events. The sampling events operating conditions are given in Appendix A. There was usually a one-week time gap between consecutive sampling events. When the ATAD operating condition was changed, the time gap between the sampling events was two or more weeks, depending on how fast the ATAD conditions (e.g., temperature and ORP) became relatively stable. The temperature responded to the changes in the air flow rate and sludge loading to the ATAD. As stated in Section 4.2.4, most of the time the ATAD was run with a 12 day HRT (245 1/d loading); however, for a few weeks it was run with a 20 day HRT ( $1501 / \mathrm{d}$ loading). The temperature varied around $60^{\circ} \mathrm{C}$; however, there were a few occasions when it dropped below $55^{\circ} \mathrm{C}$. Usually the temperature drops 
were related to air flow rate increases and sludge loading reductions. As shown in Figure 5.2.3, the temperature drop after the $8^{\text {th }}$ event and the $27^{\text {th }}$ event were due to the increase in air flow rate. However, the temperature drop after the $38^{\text {th }}$ event was due to the low sludge loading. When the air flow rate was 30 SLPM, the maximum ATAD temperature, which was around $70^{\circ} \mathrm{C}$, was observed during the $22^{\text {nd }}$ to the $24^{\text {th }}$ events.

Figures 5.2.4(a) and (b) show the ATAD air flow rate (when sludge loading was $245 \mathrm{l} / \mathrm{d}$ ) and the digester temperature versus sludge loading rate (when air flow rate was 50 SLPM), respectively. In these figures, the digester temperature refers to the stable temperature during one cycle (the temperature during the later part of the cycle). Based on preliminary runs, four air flow rates were chosen to analyze the temperature response of the ATAD. The lowest air flow rate that could be established in the ATAD system was 30 SLPM, while the highest was around 150 SLPM. The standard deviation corresponding to mean ATAD temperature variations along with the air flow rates and the sludge loading rates are shown in the Figures 5.2.4(a) and (b). The standard deviations were relatively small which indicated that the temperature variations along the air flow rates and the sludge loading rates were clustered closely around the mean value. As shown in Figure 5.2.4(a), the lowest air flow into the digester resulted in a temperature that was $15^{\circ} \mathrm{C}$ higher than that observed with the highest air flow rate. The cooling effects associated with excess air likely limited the temperature rise within the ATAD when the air flow rate was 150 SLPM. 
Figure 5.2.4(b) shows the ATAD temperature when the sludge-loading rate was changed. As shown in Figure 5.2.4(b), when the sludge loading was increased from 150 to $245 \mathrm{1} / \mathrm{d}$, the temperature increased by around $8^{\circ} \mathrm{C}$. However, when sludge loading was increased from 245 to $2901 / \mathrm{d}$, there was little further temperature increase. When the sludge loading was increased to more than $245 \mathrm{l} / \mathrm{d}$, the ORP readings were consistently in the anaerobic region (below $-300 \mathrm{mV}$ ). When the sludge loading was less than $150 \mathrm{l} / \mathrm{d}$, it was very difficult to keep the thermophilic temperature range. The low sludge loading was not favorable for maintaining the thermophilic temperatures and thermophilic microbial activities; and hence the temperature rise was limited. As stated by Staton et al. (2001), it was necessary to keep the solids content in the ATAD reactor between 3 and $6 \%$ to obtain the optimum thermophilic temperature. Therefore the sludge loadings were kept between 150 and $290 \mathrm{l} / \mathrm{d}$ in this study.

(a)

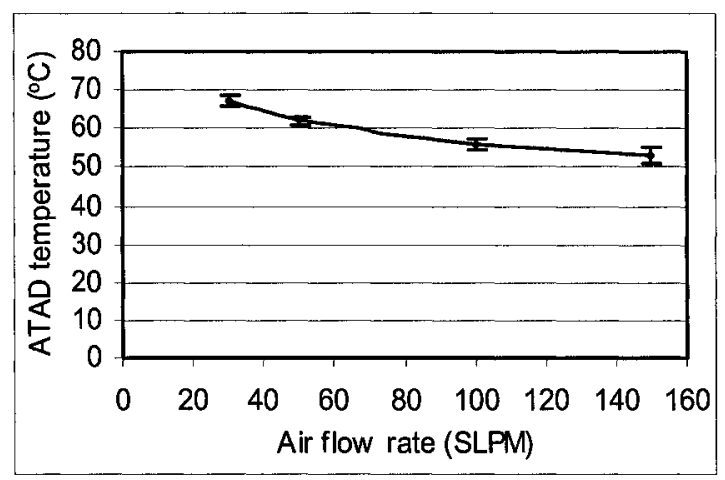

(b)

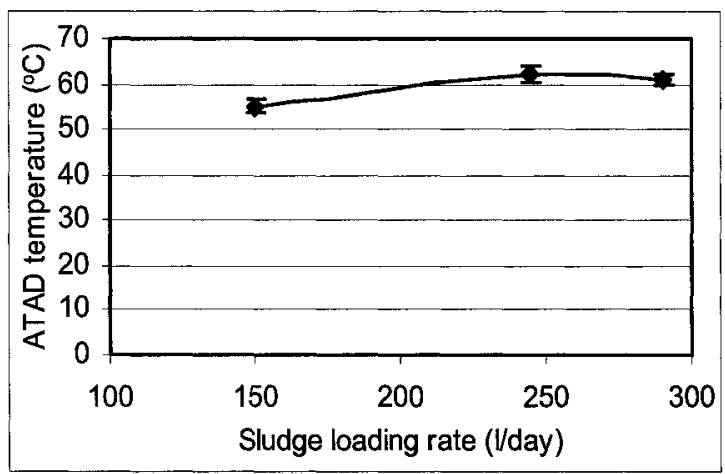

Figure 5.2.4 ATAD temperature vs. (a) air flow rates and (b) sludge loading rate

One of the important objectives of sludge digestion is to reduce the solids content of the sludge thereby reducing the total mass of biosolids requiring disposal and producing a stabilized final product suitable for reuse. Unlike other digestion processes, the ATAD 
process has been proven to produce high total solids removal in the treatment of sludge (Scisson, 2003). The solids reduction depends on various operational conditions of the ATAD. Total solids (TS) and volatile solids (VS) of feed and effluent sludge were measured on a daily basis to obtain an understanding of the solids removal in the ATAD. Based on the TS and VS data, the ATAD feed and discharge were regulated to maintain the required solids content in the ATAD.

The TS and VS concentrations and their destruction are summarized versus sampling event in Figure 5.2.5. During this time period, several operating conditions were changed in the ATAD as shown in Figure 5.2.3, however, the TS and VS reduction efficiencies fluctuated within a limited range. As shown in Figure 5.2.5, the feed TS varied from 50 to $80 \mathrm{~g} / \mathrm{l}$ and the feed VS varied from 30 to $50 \mathrm{~g} / \mathrm{l}$. The ATAD feed (TWAS) was directly taken from the sludge line at ROPEC. The solids content of the sludge varied depending on the ROPEC operational conditions. The solid reduction was calculated as follows,

$$
\text { Solid reduction }(\%)=\frac{(\text { Feed solids content }- \text { Effluent solids content }) \times 100}{\text { Feed solids content }}
$$

The solid reduction was computed on a daily basis according to the daily feed solids content and effluent solids content. The TS reduction efficiency ranged from 40 to $55 \%$ while the VS reduction ranged from 50 to $70 \%$. This is typical of $2^{\text {nd }}$ generation ATAD solids removal percentages as stated by Scisson (2003) and Staton et al. (2001). Throughout the study period, the average TS reduction in the ATAD was $48.3 \%$ with a standard deviation of $6.1 \%$, while the average VS reduction was $58.4 \%$ with a standard deviation of $5.6 \%$. 
(a)

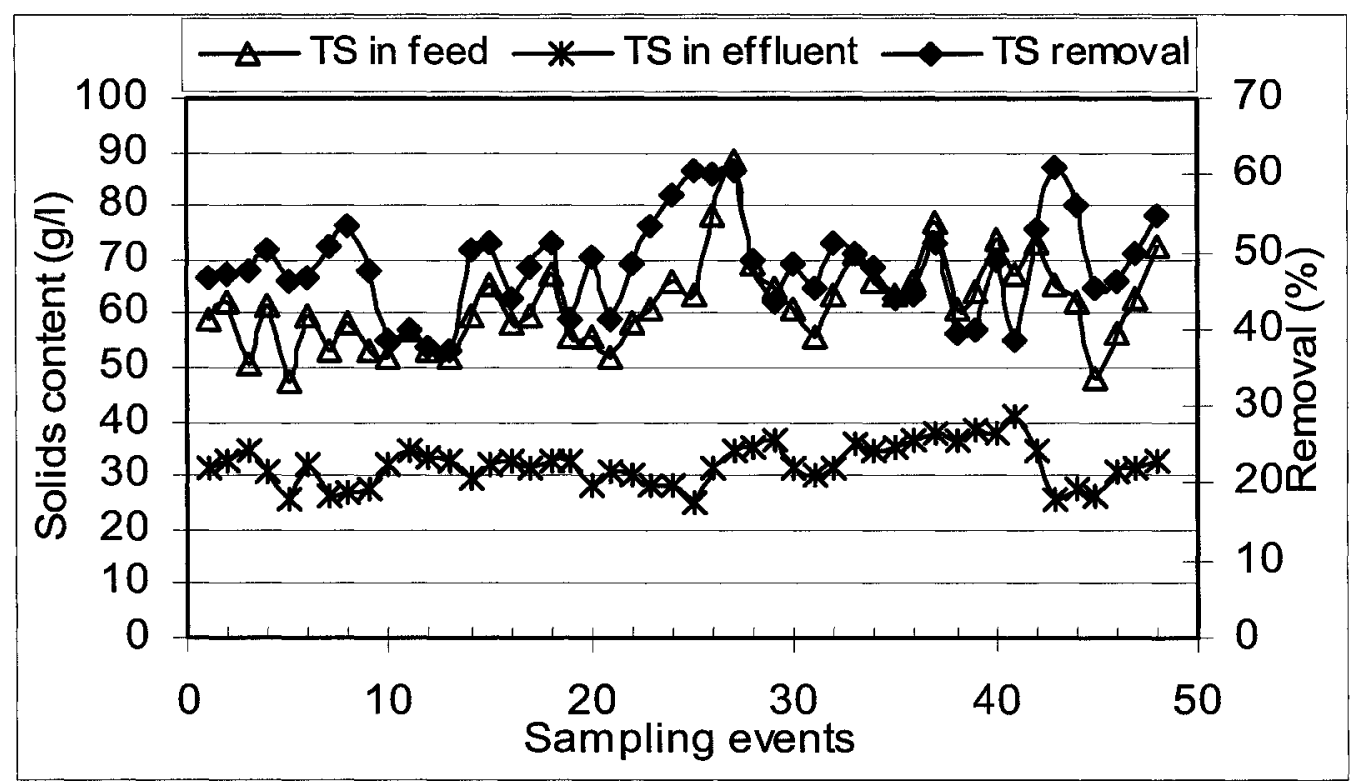

(b)

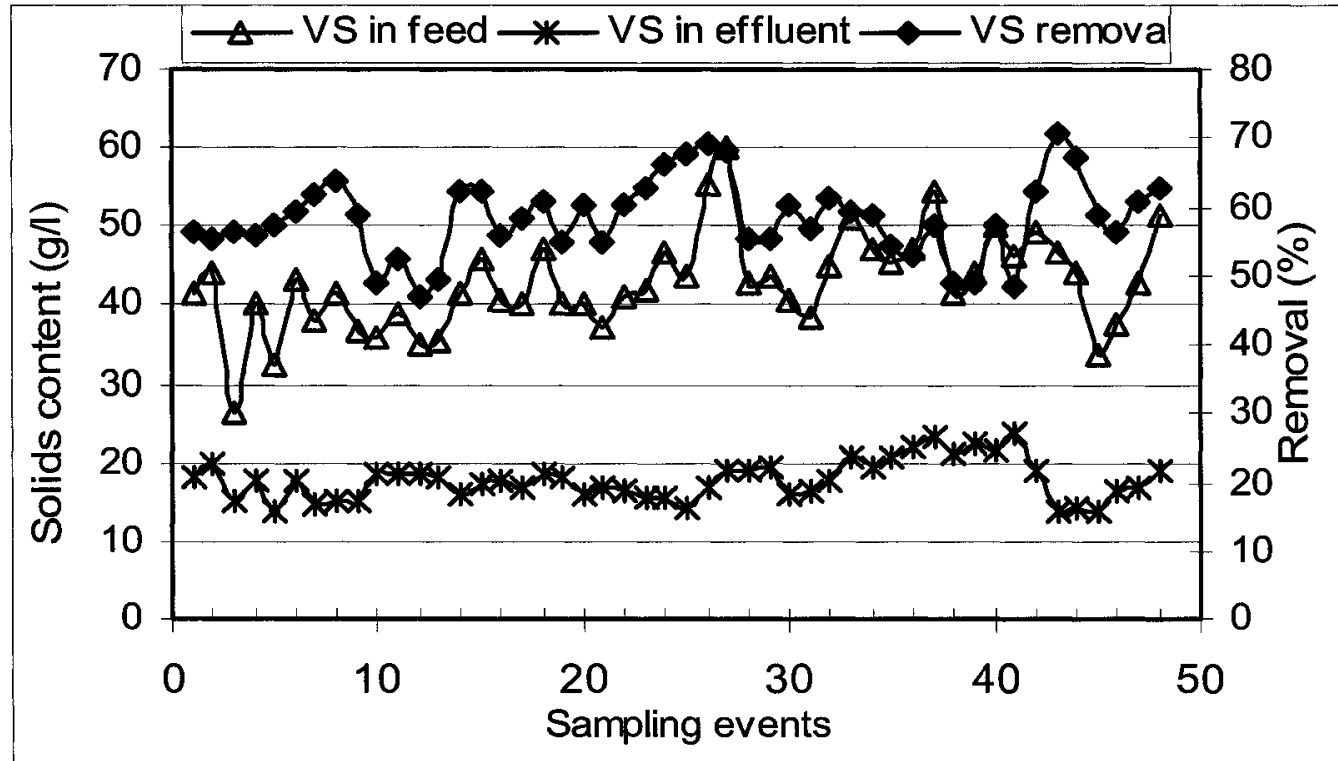

Figure 5.2.5 Total and volatile solids destruction in the ATAD 


\subsection{Gas phase analysis}

\subsubsection{ATAD off gas analysis at the scrubber inlet}

The properties of the off gases from the pilot scale ATAD were changed by varying the ATAD air flow and sludge loading. As discussed in Section 4.2.3, the ATAD off gas was investigated using GC/mass spectrometer. The RSCs that dominated the ATAD off gases included $\mathrm{H}_{2} \mathrm{~S}, \mathrm{MM}, \mathrm{DMS}, \mathrm{CS}_{2}$, DMDS and DMTS. Two sample result sheets are given in Appendix B. The ATAD off gases were initially characterized at the scrubber inlet. As discussed in Section 4.2.1, the ATAD off gases were directed through the wet scrubber then subsequently through the biofilter. Even though the main objective of this study was to identify the dynamic removal in the biofilter, the scrubber removal of these off gases was considered to be important.

(a)

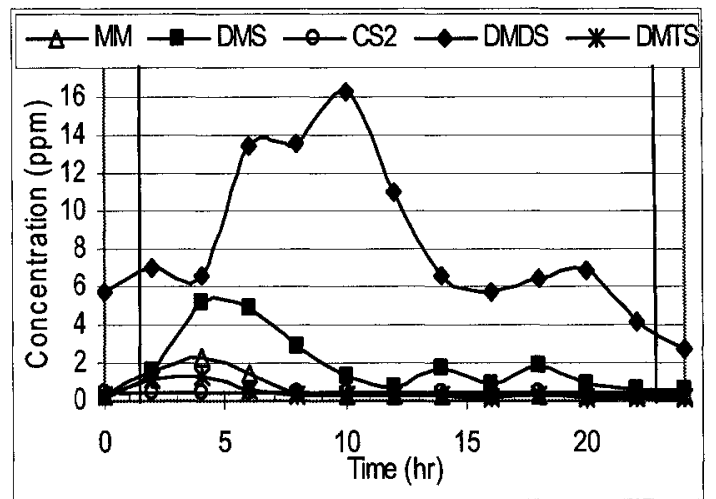

(b)

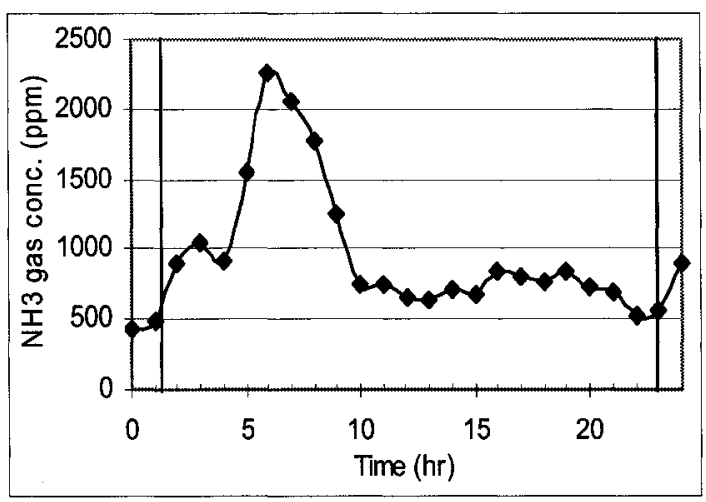

Figure 5.3.1 ATAD off gas variation at the scrubber inlet

Figure 5.3.1 shows a typical ATAD off gas profile at the scrubber inlet versus cycle time. In this case the ATAD was operated at an air flow rate of 150 SLPM; sludge loading rate of $250 \mathrm{l} / \mathrm{d}$ with feed TS and VS concentrations of 52.2 and $36 \mathrm{~g} / \mathrm{l}$, respectively; stable 
ORP of $\sim 150 \mathrm{mV}$; stable temperature of $\sim 55^{\circ} \mathrm{C}$. The stable ORP and temperature refers to the values that were observed during the later part of the cycle as shown in Figures 5.2.1 and 5.2.2. The corresponding data was obtained from the sampling event E10. As shown in Figure 5.3.1, almost $5 \mathrm{ppm}$ of DMDS and around $500 \mathrm{ppm}$ of $\mathrm{NH}_{3}$ gases were present before the feeding started. As soon as the ATAD was fed, the concentrations of RSC rapidly increased to their peak values. However, the concentration of RSC started to decrease after around 10 hours to stable low values as shown in Figure 5.3.1. A similar trend was observed in the $\mathrm{NH}_{3}$ gas concentrations. After the feeding, it took around 6 hours to reach the $\mathrm{NH}_{3}$ peak (2200 ppm), after which $\mathrm{NH}_{3}$ concentrations decreased to around $800 \mathrm{ppm}$, and then fluctuated between 500 to $900 \mathrm{ppm}$ for the rest of the cycle.

As shown in Figures 5.2.1 and 5.3.1, the gas production peaked when the ORP values decreased to the lowest values of a cycle. However, the lowest ORP values of each cycle, which were observed after feeding, were between -400 and $-600 \mathrm{mV}$, a relatively anaerobic condition within the ATAD. As discussed in the literature, the anaerobic condition may enhance the production of some RSCs (e.g., $\mathrm{H}_{2} \mathrm{~S}, \mathrm{MM}$ ). The microbial activity also increased after the feeding hence, $\mathrm{NH}_{3}$ and $\mathrm{RSCs}$ production increased. Therefore, as shown in Figure 5.3.1, the gas production was stimulated after sludge was fed into the ATAD.

\subsubsection{ATAD operating conditions versus gas production}

The impact of air flow and sludge loading on $\mathrm{RSCs}$ and $\mathrm{NH}_{3}$ production was analyzed. Figure 5.3.2 shows the gas phase RSCs and $\mathrm{NH}_{3}$ gas production in each sampling event 
versus ATAD condition. For this study, the sampling events E7 to E21 (as shown in Appendix A) were used to analyze the off gas production in the ATAD. In this case, the sludge loading was kept constant while changing the air flow rates to identify the ORP and temperature response on the gas production. The ATAD gas production versus sludge loading is given in Table 5.3.1. In this study the ORP and temperature values refer to the relatively constant ORP and temperature values during the later part of the 24 hours cycle.

Table 5.3.1 ATAD gas production versus sludge loading (when air flow rate was 50 SLPM)

\begin{tabular}{|c|l|c|c|}
\hline $\begin{array}{l}\text { Sludge loading rate } \\
(\mathrm{l} / \mathrm{d})\end{array}$ & Description & $\begin{array}{l}\text { RSCs production } \\
(\mathrm{g} / \mathrm{d})\end{array}$ & $\begin{array}{l}\mathrm{NH}_{3} \text { gas production } \\
(\mathrm{g} / \mathrm{d})\end{array}$ \\
\hline \multirow{2}{*}{245} & Mean & 2.2 & 203.0 \\
\cline { 2 - 4 } & Standard deviation & 1.2 & 98.6 \\
\hline \multirow{2}{*}{150} & Mean & 0.8 & 64.1 \\
\cline { 2 - 4 } & Standard deviation & 0.4 & 1.0 \\
\hline
\end{tabular}

The RSC was analyzed as a combined mass of all individual RSC compounds because as discussed in Section 2.1.2, MM and DMS can be oxidized to either DMDS or DMTS along the off gas line. DMDS was the only RSC that was detected through the cycle in all sampling events and the individual concentrations varied with small changes in operational conditions. Therefore the gas production was analyzed based on total mass of RSC and $\mathrm{NH}_{3}$ during 24 hours cycle because the total mass was more representative of the ATAD condition variations than the individual compound concentrations.

As shown in Figure 5.3.2, the mass of VS varied between 9 and $11 \mathrm{~kg} \mathrm{VS} / \mathrm{d}$ while the sludge loading was kept constant at $245 \mathrm{l} / \mathrm{d}$. Due to the limited VS loading changes, there 
were no significant changes on ATAD conditions observed with varying VS loading. As shown in Figure 5.3.2, when the air flow was low (30 SLPM) for sampling events 2 and 3, the ORP values of the ATAD became more negative (around $-400 \mathrm{mV}$ ) and the total mass of $\mathrm{S}$ and $\mathrm{N}$ produced increased. The stable ATAD temperature was between 60 and $65^{\circ} \mathrm{C}$. When the air flow rate increased to 150 SLPM for sampling events 4,5 and 6 , the ORP values increased (around $-100 \mathrm{mV}$ or more), but the total mass of gas production peaked (600 g of $\mathrm{N} / \mathrm{d}$ and $10 \mathrm{~g}$ of $\mathrm{S} / \mathrm{d})$ and the stable ATAD temperature decreased to between 50 and $55^{\circ} \mathrm{C}$. As discussed in Section 5.2, the drop in temperature was likely due to the cooling effect of the excess air flow in the ATAD. However, when the air flow rate was reduced to 100 SLPM for sampling events 7,8 and 9 , the ORP value decreased to around $-300 \mathrm{mV}$; the gas production decreased to $200 \mathrm{~g}$ of $\mathrm{N} / \mathrm{d}$ and $3 \mathrm{~g}$ of S /d; and the temperature increased to around $60^{\circ} \mathrm{C}$. Finally, when the air flow was decreased to 50 SLPM for sampling events 10 and 11, the ORP values were between -200 and $-100 \mathrm{mV}$; the ATAD temperature was above $60^{\circ} \mathrm{C}$. It is also noticed that when air flow was decreased from 100 SLPM to 50 SLPM, the $\mathrm{NH}_{3}$ gas production decreased (from 200 to $100 \mathrm{~g} / \mathrm{d}$ ) while the RSCs production increased from 3 to $5 \mathrm{~g} / \mathrm{d}$. In summary, the air flow variations affected the ORP and temperature in the ATAD, hence the gas production also varied accordingly. Relatively high $\mathrm{NH}_{3}$ and $\mathrm{RSCs}$ production was observed at the high air flow rate (150 SLPM) condition.

As shown in Figure 5.3.2, sampling events 2 and 3 and events 4, 5 and 6 were replicate events in terms of ATAD operating conditions; however the gas production varied significantly. This trend may be due to other factors such as ATAD feed consistency and 
solids content of the sludge. As discussed earlier, the feed consistency varied significantly at ROPEC depending on operational and environmental conditions (weather conditions). The events 7,8 and 9 ; events 10 and 11 ; and events 12 and 13 were replicates with respective to the ATAD conditions. Therefore almost similar ORP and temperature variations and gas productions were observed with respect to similar ATAD conditions.
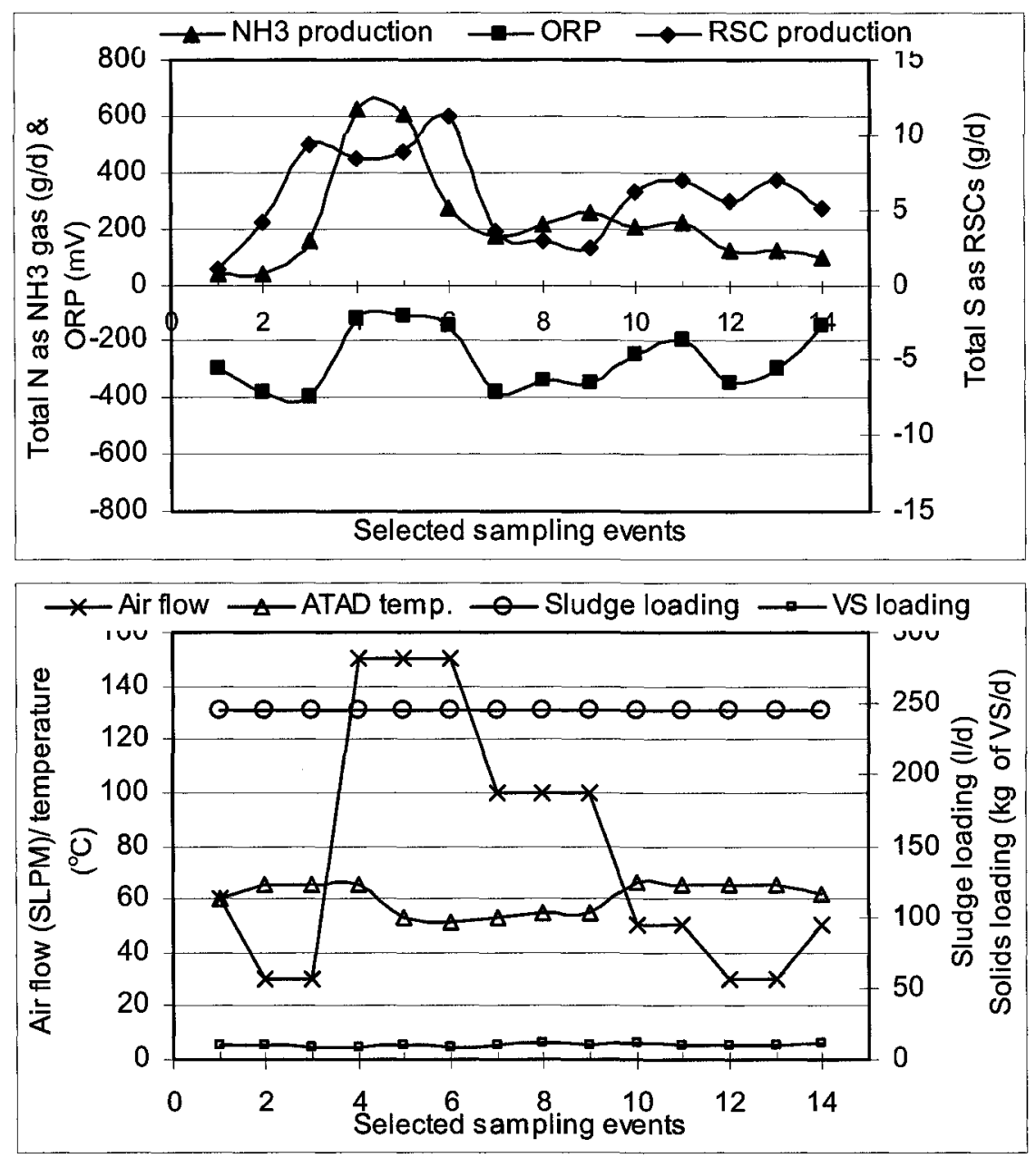

Figure 5.3.2 Production of ATAD off gases related to ORP, air flow, sludge loading, VS loading and ATAD temperature 
In summary, the air flow rate had an impact on the ATAD ORP and hence the gas production in the ATAD. When the air flow rate was high (150 SLPM), the gas production increased and the ORP values became less negative (towards aerobic conditions). While the low air flow rate (30 SLPM) reduced the gas production and the ORP values became more negative (towards anaerobic conditions).

Table 5.3.1 shows the ATAD gas production versus sludge loading rates. When the sludge-loading rate was reduced from 245 to $150 \mathrm{l} / \mathrm{d}$, while air flow rate was $50 \mathrm{SLPM}$; the ORP was around $-200 \mathrm{mV}$, the ATAD off gas production reduced significantly. When sludge loading was reduced, as shown in Figure 5.2.3, a reduction in stable ATAD temperature was also observed. When the sludge loading was high $(245 \mathrm{l} / \mathrm{d})$, the standard deviation of $98.6 \mathrm{~g} / \mathrm{d}$ for the mean $\mathrm{NH}_{3}$ gas production of $203 \mathrm{~g} / \mathrm{d}$ was relatively high. However the standard deviations for other conditions were relatively small. The small standard deviation indicated that the gas productions are closely clustered around the mean production values corresponding to the sludge loading conditions. In summary, the ATAD off gas production was influenced by the sludge loading rates. When the sludge loading was high $(2451 / \mathrm{d})$, the gas production was relatively high and when the sludge loading was low $(150 \mathrm{l} / \mathrm{d})$, the gas production was also low. 


\subsubsection{Scrubber removal}

Scrubber removal efficiencies for the gas phase $\mathrm{NH}_{3}$ and $\mathrm{RSC}$ against gas retention time were analyzed in this study. The removal efficiency was calculated as follows, Removal efficiency $(\%)=\frac{(\text { inlet mass }- \text { outlet mass }) \times 100}{\text { inlet } \text { mass }}$

The inlet and the outlet mass per sampling event (mass of $\mathrm{N}$ or $\mathrm{S} / \mathrm{d}$ ) of each compound were used to calculate the removal efficiency, because the individual RSC concentrations varied with ATAD operating conditions and there was no significant relationship observed between the concentrations and the operating conditions. Figure 5.3.3 shows the scrubber removal efficiency versus gas retention time for $\mathrm{NH}_{3}$, total $\mathrm{RSC}, \mathrm{MM}$, DMS and DMDS. Three gas retention times $(8,20,80 \mathrm{~s})$ were chosen as minimum, intermediate and maximum gas retention times which corresponded to ATAD air flow rates of 150, 100 and 30 SLPM, respectively. For each gas retention time, at least two sampling events were carried out to analyze the removal efficiency of the scrubber. Based on the data, the mean removal efficiency and corresponding standard deviations were calculated from the replicate run. The error bars on Figure 5.3.3 show the standard deviations of the removal efficiencies. In this study, the scrubber liquid flow rate was maintained at around $10 \mathrm{l} / \mathrm{min}$.

As shown in Figure 5.3.3, when gas retention time was increased, there were no significant changes in the $\mathrm{NH}_{3}$ gas removal. However the total RSCs removal efficiency significantly increased. The MM removal efficiency did not change significantly; however, the DMDS removal efficiency increased significantly with the increased 
scrubber gas retention time. The DMS removal efficiency increased when the retention time increased from 8 to $20 \mathrm{~s}$. However, when the retention time increased from 20 to 80 $\mathrm{s}$, the DMS removal efficiency did not change significantly.

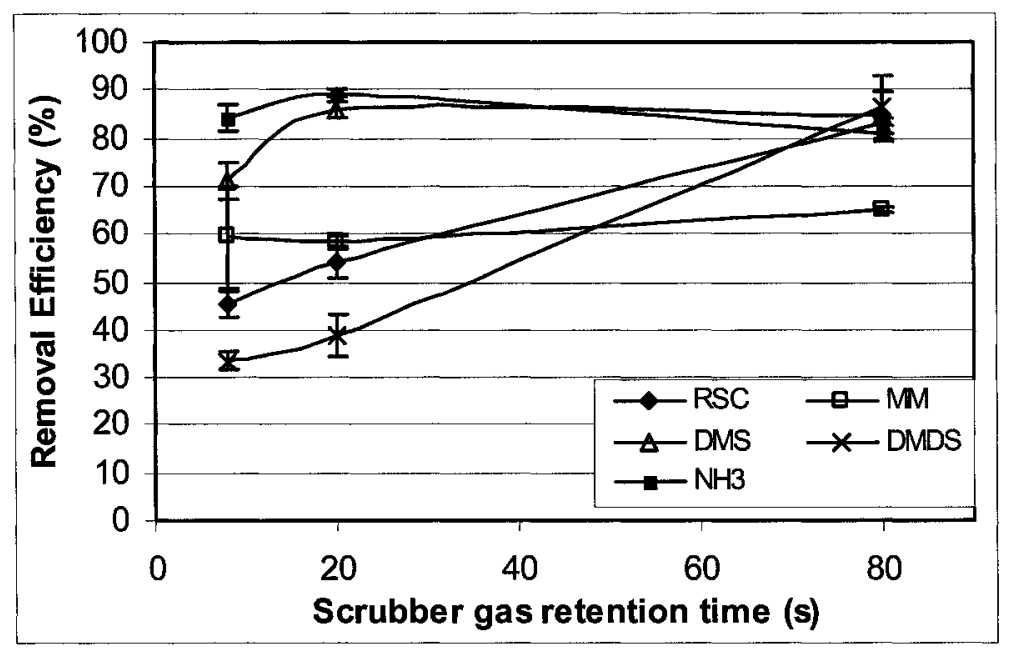

Figure 5.3.3 The scrubber removal efficiency vs. gas retention time

The mass transfer in the scrubber can be discussed by the material balance of a counter current system. Figure 5.3.4 shows the schematic diagram of a scrubber system.

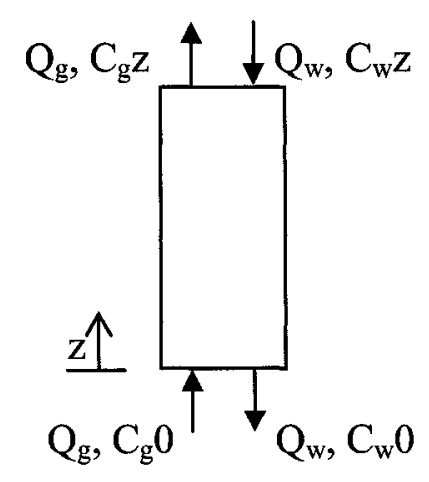

Figure 5.3.4 Schematic diagram of a scrubber

Where, $Q_{g}$ and $Q_{w}$ - gas and water volumetric flow rate $\mathrm{C}_{\mathrm{g}}$ and $\mathrm{C}_{\mathrm{w}}$ - molar concentrations of a pollutant in gas and water at $\mathrm{Z}=0$ and $\mathrm{Z}=\mathrm{z}$, respectively 
A mass balance of a pollutant over the scrubber is described by Equation 5.3.2.

$$
\begin{aligned}
& Q_{g} *\left(C_{g 0}-C_{g z}\right)=Q_{w} *\left(C_{w 0}-C_{w z}\right) \\
& C_{g z}=\frac{Q_{w} *}{Q_{g}} C_{w z}+\frac{\left(Q_{g} * C_{g 0}-Q_{w} * C_{w 0}\right)}{Q_{g}}
\end{aligned}
$$

From Equation 5.3.3, it can be stated that the gas phase outlet concentration $\left(\mathrm{C}_{\mathrm{gz}}\right)$ depends on the liquid-gas ratio $\left(\mathrm{Q}_{\mathrm{w}} / \mathrm{Q}_{\mathrm{g}}\right)$. Hence the gas phase removal efficiency depends on the liquid-gas ratio. However, as shown in Figure 5.3.3, $\mathrm{NH}_{3}$ gas phase removal efficiency did not change significantly when liquid-gas ratio was changed. Therefore, it can be believed that $\mathrm{NH}_{3}$ mass transfer from gas to liquid may also influence on the $\mathrm{NH}_{3}$ removal. The mass transfer rate from air to aqueous phase can be estimated from Equation 5.3.4.

$$
\text { Mass transfer rate }=K_{l} a *\left(\frac{C_{g}}{K_{H}}-C_{W}\right)
$$

From Equation 5.3.4, the mass transfer rate depends on Henry's coefficient $\left(\mathrm{K}_{\mathrm{H}}\right)$ and the mass transfer coefficient $\left(\mathrm{K}_{1} \mathrm{a}\right)$ of the pollutant. The $\mathrm{K}_{\mathrm{H}}$ value contributes to the driving force (concentration difference between gaseous and aqueous phases) of the mass transfer. When $\mathrm{K}_{\mathrm{H}}$ is low (highly soluble in water, e.g., $\mathrm{NH}_{3}$ ) the mass transfer rate is high. As shown in Figure 5.3.3, the $\mathrm{RSC}$ and $\mathrm{NH}_{3}$ removal efficiencies were around $80 \%$ when the scrubber retention time was $80 \mathrm{~s}$.

When the scrubber retention time was 8 and $20 \mathrm{~s}$, the DMDS removal efficiencies were less than that of DMS and MM. However, based on the Henry's law coefficients (as shown in Table 2.2), the DMDS removal efficiency was expected to be relatively more 
than that of DMS and MM. The oxidation of MM and DMS to DMDS within the scrubber system, as discussed in the literature, may contribute to the high removal of MM and DMS.

As shown in Equation 5.3.4, the mass transfer coefficient may also contribute to the overall mass transfer hence, the removal efficiency may change. The mass transfer coefficient can be increased by increasing turbulence which is often done by adjusting the liquid/gas flow rate and by increasing the surface area for mass transfer. The liquid-gas ratios that were employed in this study are given in Table 5.3.2. Higher liquid-gas ratios resulted in higher $\mathrm{RSC}$ removal, however, the $\mathrm{NH}_{3}$ removal did not vary significantly. In this study, the $\mathrm{NH}_{3}$ loading was relatively higher than literature studies. The $\mathrm{NH}_{3}$ gas is highly soluble in water (low $\mathrm{K}_{\mathrm{H}}$ ) and it is referred to as a gas phase controlled mass transfer system. The mass transfer of $\mathrm{NH}_{3}$ can be improved by modifying gas phase conditions. However in this study, when air flow rate was decreased, the $\mathrm{NH}_{3}$ gas removal did not change significantly. It may be due to that the mass transfer area in a spray tower scrubber system (no packing) was limited by the scrubber water particle size. The water particle size was almost the same under all conditions since a single nozzle was used in this study to spray water at the top of the scrubber. Therefore the $\mathrm{NH}_{3}$ mass transfer may be controlled by the available limited surface area. Due to that the $\mathrm{NH}_{3}$ gas removal efficiencies were between around 80 and $90 \%$ within the scrubber.

The ATAD off gases concentrations were varied significantly as shown in Figure 5.3.1, the time average data can not be used to identify the controlling parameters (i.e., mass 
transfer vs. equilibrium). Therefore, more control analysis is needed. Since the scrubber system did not focus in this study, a detail experimental analysis did not conduct to identify the mechanisms.

Table 5.3.2 Removal efficiencies in the scrubber

\begin{tabular}{|c|c|c|c|c|}
\hline $\begin{array}{l}\text { Scrubber retention } \\
\text { time (s) }\end{array}$ & $\begin{array}{l}\text { Gas flow rate } \\
\left(\mathrm{m}^{3} / \mathrm{s}\right)\end{array}$ & $\begin{array}{l}\text { Liquid/gas flow } \\
\text { rate }\end{array}$ & $\begin{array}{l}\text { RSCs removal } \\
\text { efficiency (\%) }\end{array}$ & $\begin{array}{l}\mathrm{NH}_{3} \text { removal } \\
\text { efficiency }(\%)\end{array}$ \\
\hline 8 & 0.00912 & 0.018 & 45.3 & 84.2 \\
\hline 20 & 0.00365 & 0.046 & 54.0 & 89.3 \\
\hline 80 & 0.00091 & 0.183 & 83.3 & 81.0 \\
\hline
\end{tabular}

\subsubsection{Dynamic gas loading on the biofilter}

Dynamic loading of $\mathrm{NH}_{3}$ and $\mathrm{RSCs}$ were analyzed to obtain the loading effect on the biofilter along the cycle. Three different aeration conditions were chosen to change the dynamic loading on the pilot scale biofilter. The loading conditions were obtained from the sampling events data E11, E16, and E21 as given in Appendix A. Figure 5.3.5 shows the gas phase concentrations of $\mathrm{RSC}$ and $\mathrm{NH}_{3}$ at the biofilter inlet versus cycle time for the three ATAD aeration rates. The replicates followed a similar trend as observed in Figure 5.3.5. From Figure 5.3.5, it can be seen that when the air flow rate was low (30 SLPM), higher concentrations of RSC were present in the biofilter inlet. At the same time it can be noticed that high air flow rate (150 SLPM) did not necessarily generate the lowest concentrations of RSC. Among the three aeration rates, the air flow of 100 SLPM resulted in the lowest concentrations of RSC. When the air flow to the ATAD was 30 SLPM, the maximum MM peak occurred 6 hours after feeding the ATAD and had a value of $14 \mathrm{ppm}$. The maximum of DMS and DMDS peaks occurred 9 hours after feeding and had values of 12 and $8 \mathrm{ppm}$, respectively, for the same air flow rate. The 
DMTS peak was also around 10 hours after feeding but this peak value was relatively low as compared to the other RSC. Figure 5.3.5(c) shows that the MM concentrations, at the biofilter inlet for the air flow rate of 30 SLPM, were considerably higher than for the high aeration rates (100 and 150 SLPM). When the air flow was 100 SLPM, relatively higher concentrations of DMDS and DMTS were released than MM and DMS.

It is believed that, the MM and DMS were oxidized to DMDS or DMTS in the ATAD at the higher air flow rates. When the air flow rate was high in the ATAD, the ORP values indicated more aerobic conditions (less negative $\mathrm{mV}$ values) as compared to the low aeration condition. This high ORP conditions had more potential to oxidize the off gas compounds. In terms of the scrubber removal, as shown in Figure 5.3.3, at the low air flow rate of 30 SLPM, relatively high removal of RSC was observed. However the RSC concentrations at the biofilter inlet were higher for the low air flow condition than that of the high air flow condition.

The dynamic variation of $\mathrm{NH}_{3}$ gas concentrations at the biofilter inlet was also highly influenced by the air flow into the ATAD. As shown in Figure 5.3.5(e), when the air flow was 30 SLPM, relatively high concentrations of $\mathrm{NH}_{3}$ gas were observed while relatively low concentrations of $\mathrm{NH}_{3}$ were observed when the air flow was 100 SLPM. As shown in the Figure 5.3.2, when the air flow rates were high in the ATAD; the ORP values were relatively aerobic conditions (less negative $\mathrm{mV}$ values); the mass of $\mathrm{NH}_{3}$ gas production in the ATAD was high. The scrubber removal efficiencies for all three-air flow rates were 
between 80 and $90 \%$. Therefore the $\mathrm{NH}_{3}$ concentration patterns in the Figure 5.3.4(e) were assumed to be due to the air flow variations in the ATAD.

(a)

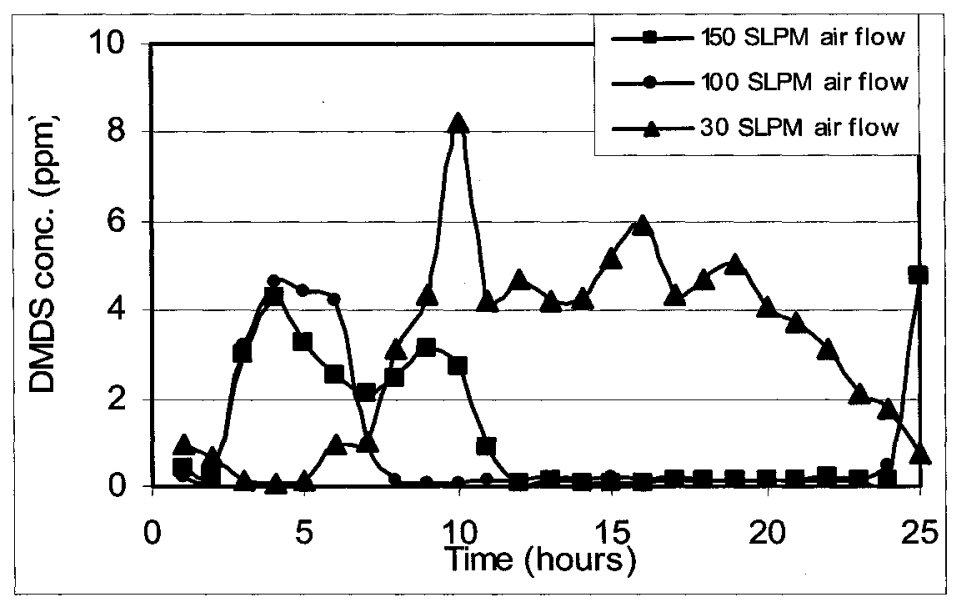

(b)

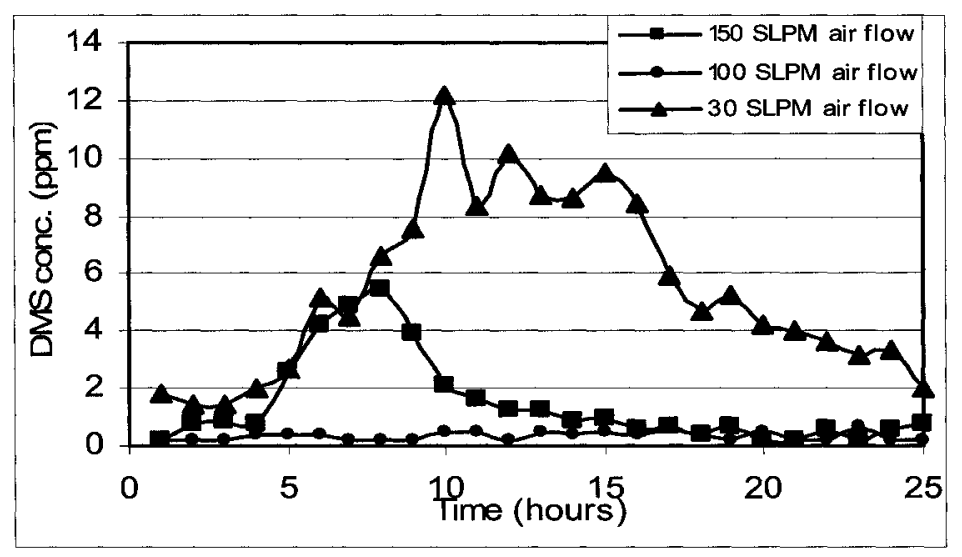

(c)

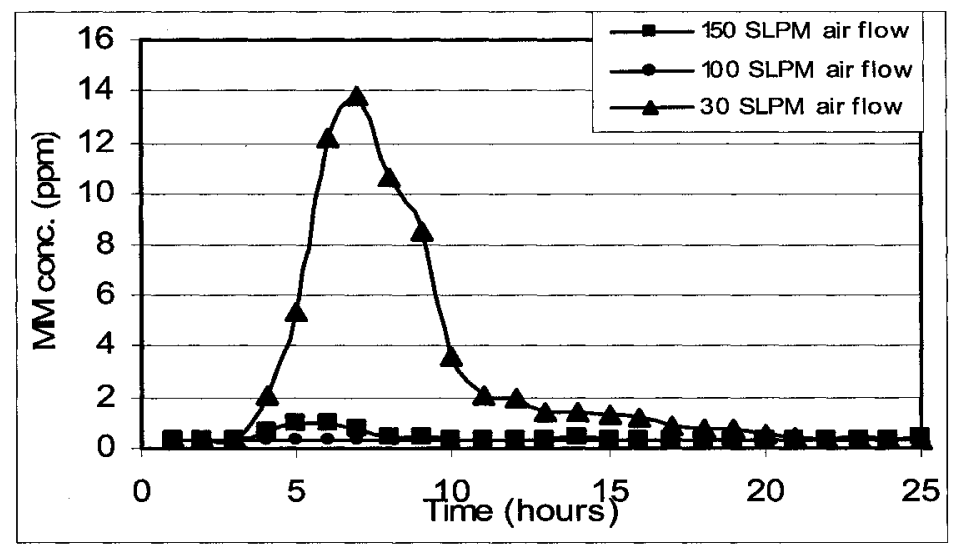


(d)

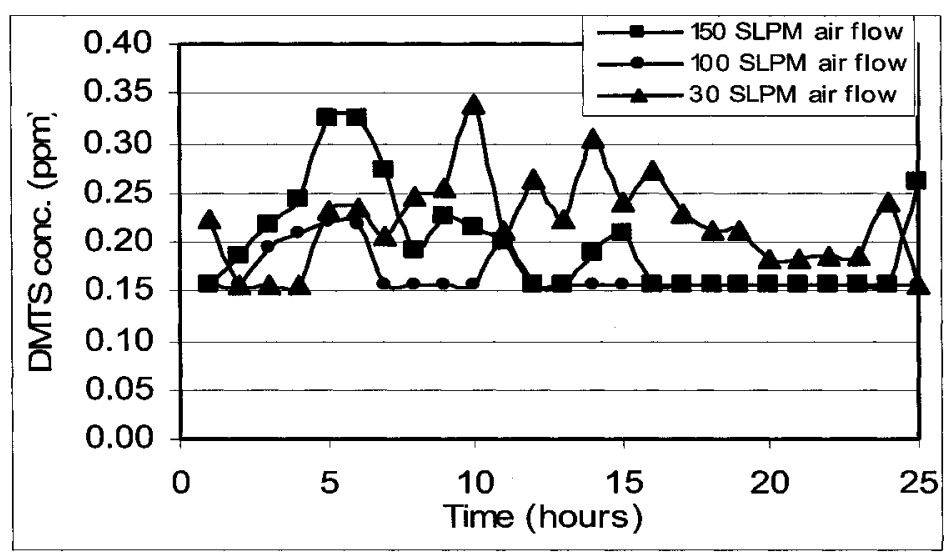

(e)

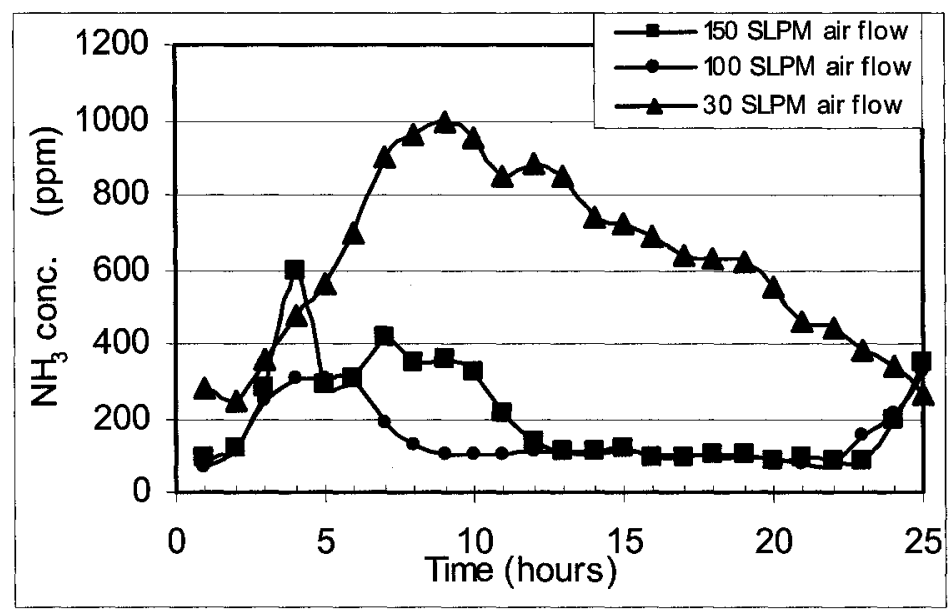

Figure 5.3.5 Odorant concentrations at biofilter inlet (a) DMDS, (b) DMS, (c) MM, (d) DMTS, (e) $\mathrm{NH}_{3}$

As discussed in Section 5.2, the off gas stripping from the ATAD was relatively high due to the elevated temperature. When the microbial activity increased, the $\mathrm{CO}_{2}$ gas production also increases because $\mathrm{CO}_{2}$ is one of the end products of microbial reactions. Figure 5.3.6 shows the $\mathrm{CO}_{2}$ concentration variation along the feed cycle at the three sampling locations when the air flow rate in to the ATAD was 100 SLPM. When a batch of fresh sludge was introduced into the ATAD it exerted a very high oxygen demand in the process and hence released a relatively high concentration of $\mathrm{CO}_{2}$. As shown in 
Figure 5.3.6, the $\mathrm{CO}_{2}$ gas concentration rapidly increased from 6 to $13 \%$ within 6 hours. This was followed by small fluctuations in the concentration for around 10 hours and then gradually decreased to $5 \%$ for the rest of the cycle. The concentration of $\mathrm{CO}_{2}$ gas confirmed that the microbial activities were high during that period of the cycle. It can also be observed from Figure 5.3.6, that approximately 2 to $4 \%$ of the $\mathrm{CO}_{2}$ was removed within the scrubber and around 1 to $2 \%$ of $\mathrm{CO}_{2}$ was removed within the biofilter. This relatively high $\mathrm{CO}_{2}$ removal likely influenced the $\mathrm{pH}$ in these processes and this $\mathrm{pH}$ variation may affect the $\mathrm{NH}_{3}$ removal mechanisms. This will be discussed in Section 5.5.

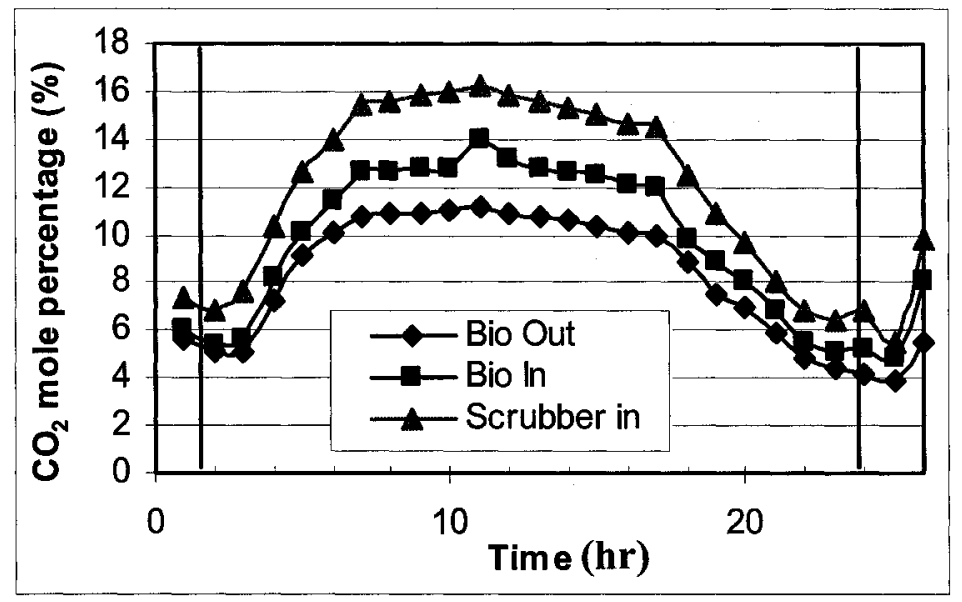

Figure 5.3.6 $\mathrm{CO}_{2}$ gas concentration variation 


\subsubsection{Peak concentrations and cumulative mass variation with air flow rates}

As discussed in Section 5.3.2, the gas phase concentrations dynamically varied through the cycle and the concentration variations depended on the air flow rates into the ATAD. When the gas phase concentrations were changing with time, it was difficult to analyze the gas phase removal efficiencies in the scrubber and the biofilter for different sampling events and to analyze the replicate samples. Therefore, peak concentration of RSCs along the cycle and cumulative mass of RSCs of three air flow conditions were selected to study the relative mass loading on the scrubber and the biofilter.

(a)

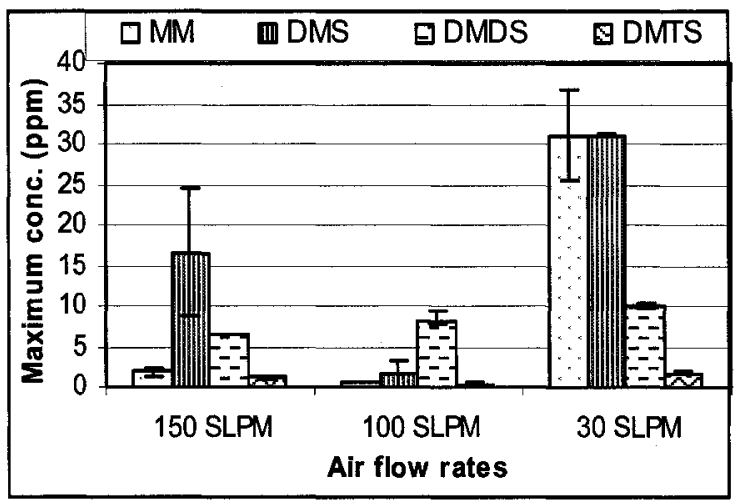

(b)

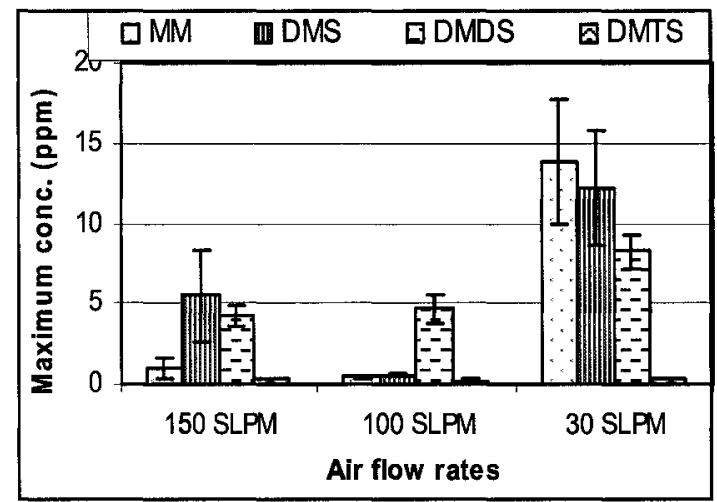

(c)

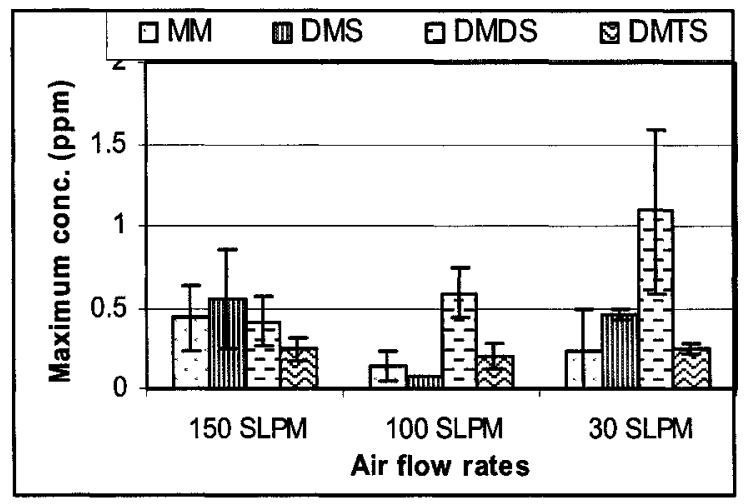

Figure 5.3.7 Maximum concentrations of RSCs at (a) scrubber inlet (b) biofilter inlet (c) biofilter outlet 
Three different air flow rates $(30,100$ and 150 SLPM) into the ATAD were chosen to characterize the peak concentrations and the cumulative mass loading. For this study, the scrubber and the biofilter conditions were maintained constant for each air flow rate. Potable water was used for the scrubber and biofilter humidification. The water flow rate in the scrubber was $10 \mathrm{l} / \mathrm{min}$. The post humidification flow rate was $1 \mathrm{l} / \mathrm{min}$.

Figure 5.3.7 shows the maximum (peak) concentrations of RSCs at three air flow conditions in the three sampling locations (Ports 5, 1 and 4 as shown in Figure 4.1). The error bars on Figure 5.3.7 shows the standard deviations of the maximum concentration values of the replicate runs. As shown in Figure 5.3.7, maximum concentrations of all RSCs were observed at low air flow rate conditions. At low air flow conditions (30 SLPM): MM and DMS concentrations were relatively high compared to DMDS and DMTS at the scrubber inlet; MM, DMS and DMDS had significant concentration at the biofilter inlet; and DMDS concentration was relatively high among other RSCs at the biofilter outlet. This revealed that, while the incoming RSCs were removed in the scrubber and the biofilter, oxidation of RSCs may have been active in both systems. As discussed in the literature, MM and DMS may oxidize to DMDS or DMTS within the systems. At high air flow condition (150 SLPM), the major RSCs were DMS and DMDS at the scrubber and the biofilter and all the RSCs were present at the biofilter outlet at relatively low concentrations. When ATAD air flow rate was 100 SLPM, DMDS was the only RSC dominant at the scrubber and biofilter inlet and other RSCs such as MM and DMS were relatively very low in concentration. In summary, the low air flow rate 
condition released relatively high concentration of RSCs from the ATAD and due to that relatively high concentrations of RSCs were observed at the biofilter inlet and outlet.

(a)

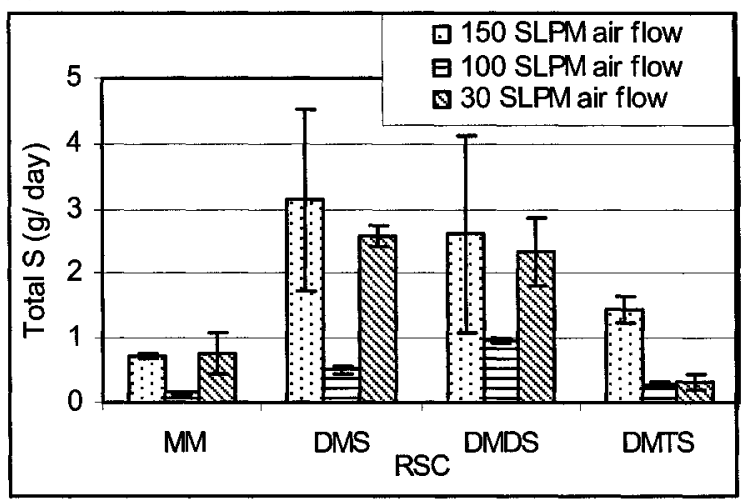

(b)

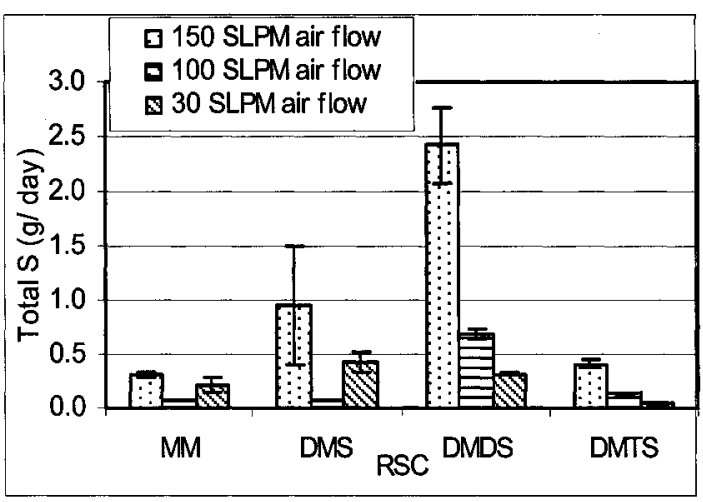

(c)

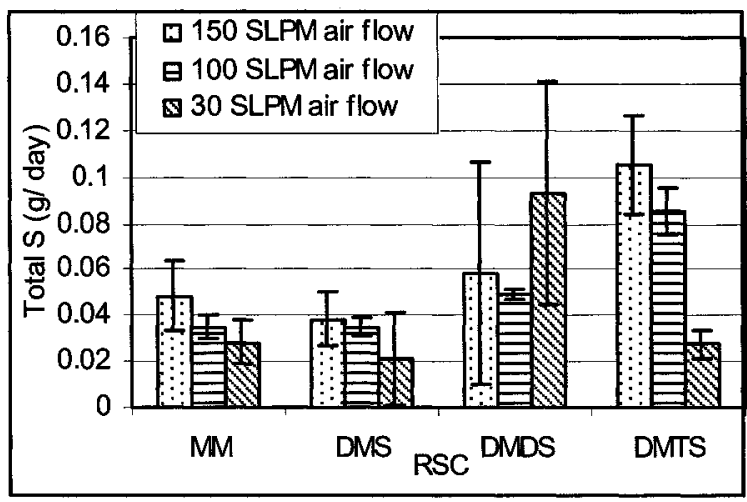

Figure 5.3.8 Cumulative mass of RSCs (a) at scrubber inlet (b) biofilter inlet (c) biofilter outlet

Figure 5.3.8 shows the 24-hour mean cumulative masses of MM, DMS, DMDS, and DMTS expressed as mass of $\mathrm{S}$ at the three sampling locations. As shown in Figure 5.3.8(a), when the air flow was 150 SLPM, a relatively higher mass of DMS was released by the ATAD than when the air flow was 30 SLPM. DMS and DMDS had higher total masses than those of MM and DMTS. However when the air flow was 100 SLPM, the 
highest contributor to the RSC that were released from the ATAD was DMDS. As discussed earlier, when the air flow rate was high, the ORP values were relatively aerobic conditions. This high ORP values produced relatively high amount of mass of DMS among the RSCs when compared to MM, DMDS and DMTS masses. It can be stated that the high air flow rate condition enhanced DMS production in the ATAD. When the air flow rate was low, the ORP values were also low, both DMS and DMDS productions were relatively high in the ATAD.

When the off gases arrived at the biofilter inlet, the relative composition of the odorants had changed. From Figures 5.3.8(a) and 5.3.8(b), it can be observed that the total mass of DMDS in the biofilter inlet was relatively the same as in the scrubber inlet for the air flow of 150 SLPM, while the other RSC amounts were removed during scrubbing. The results suggest that other than the scrubbing, oxidation processes may also have occurred within the scrubber, when air flow was relatively high. As discussed in the literature (Section 2.1.2), MM and DMS may be aerobically degraded to DMDS or DMTS within the scrubber by biochemical oxidation. From Figure 5.3.8(c), it can be seen that, the biofilter outlet gas contained relatively high mass of DMDS and DMTS. When the air flow rate was low, the DMDS was relatively high in the biofilter off gas. However, when the air flow rate was high, the DMTS was relatively high in the biofilter off gas. These results also suggest that at high air flow rate conditions, the RSCs may oxidized to DMDS or DMTS along the biofilter pathways, other than the biological oxidation to $\mathrm{SO}_{4}{ }^{2-}$. As shown in Table 2.2, the DMDS has a low $\mathrm{K}_{\mathrm{H}}\left(0.034\right.$ at $\left.20^{\circ} \mathrm{C}\right)$ while $\mathrm{K}_{\mathrm{H}}-\mathrm{MM}=$ 0.176 and $\mathrm{K}_{\mathrm{H}}-\mathrm{DMS}=0.072$. According to the Henry's coefficients, the DMDS is 
relatively more soluble in water than MM and DMS. However the above results show that the DMDS was present in relatively high amounts in the biofilter inlet and biofilter outlet. Therefore it would appear that the RSCs removal was not dominated by solubility in water; other process such as chemical and biological initiatives may have influenced RSCs removal within the scrubber and biofilter.

Figure 5.3.9 shows the maximum concentrations of $\mathrm{NH}_{3}$ and 24 hour cumulative mass of $\mathrm{NH}_{3}$ expressed as $\mathrm{N}$ at the three sampling locations. As shown in Figure 5.3.9(a), the low air flow condition released a relatively high concentration of $\mathrm{NH}_{3}$ in the ATAD. However as discussed in Section 5.3.2, the 100 SLPM air flow condition release relatively low concentration of $\mathrm{NH}_{3}$ peak value. As shown in Figure 5.3.9(b), the total $\mathrm{NH}_{3}$ production in the ATAD was strongly correlated to the air flow rates. When air flow rate was high, the ORP values were also high and this condition enhanced the $\mathrm{NH}_{3}$ gas release in the ATAD. As shown in Figure 5.3.5(e), when the air flow rate was low, the concentration of $\mathrm{NH}_{3}$ gas released was higher relative to the other two-air flow rate conditions. However the total cumulative mass of $\mathrm{NH}_{3}$ per cycle showed that the mass of $\mathrm{NH}_{3}$ released from the ATAD was much higher when the air flow rate was high than that of the low air flow rate. However the $\mathrm{NH}_{3}$ removal at the scrubber and the biofilter was not significantly affected by the $\mathrm{NH}_{3}$ loading differences. The biofilter loading effects will be discussed in Section 5.7.4. 
(a)

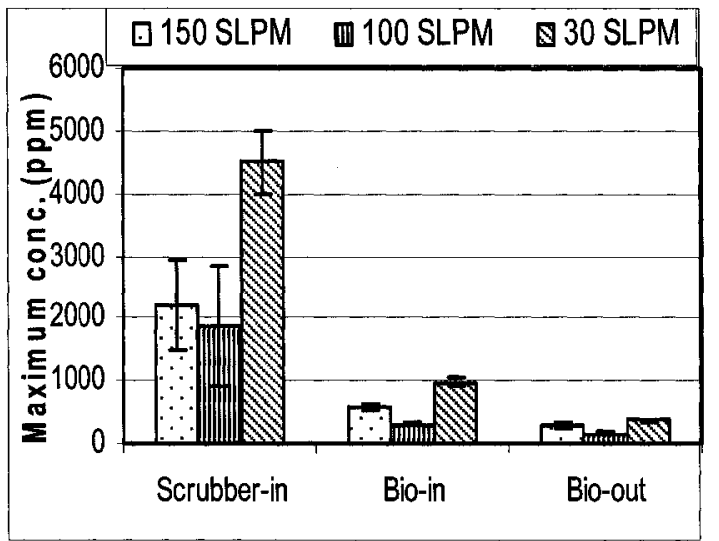

(b)

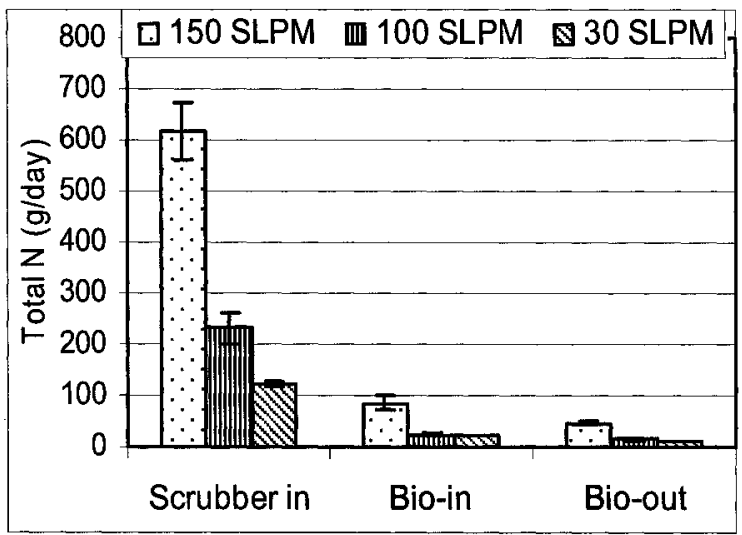

Figure 5.3.9 Maximum concentrations and cumulative mass of $\mathrm{NH}_{3}$ at three sampling ports

\subsubsection{Off gas variation along the biofilter}

Figure 5.3.10 shows the off gas concentration/mass variations along the biofilter. As shown in Figure 4.1, the sampling ports (ports 1, 2, 3 and 4 referred to as P1, P2, P3 and P4, respectively) were used for analysis of the off gas concentrations along the biofilter. Tables 5.3.3 and 5.3.4 show the cumulative $\mathrm{S}$ and $\mathrm{N}$ removal efficiencies against the sampling ports along the biofilter. Two different set of sampling events were chosen to characterize the removal efficiencies along the biofilter. The biofilter operating conditions for these events were,

Case 1: EBRT of $150 \mathrm{~s}$; bed temperature of $26^{\circ} \mathrm{C}$; potable water as post-humidification water source with 1 1/min flow rate; corresponding sampling event data $\mathrm{E} 40$ and $\mathrm{E} 44$.

Case 2: EBRT of $40 \mathrm{~s}$; bed temperature of $20^{\circ} \mathrm{C}$; potable water as post-humidification water source with 1 1/min flow rate; corresponding sampling event data $E 42$ and E 43. 
Table 5.3.3 Case 1: Total mass of $S$ and $N$ removal along the biofilter

\begin{tabular}{|c|c|c|c|c|c|}
\hline \multirow{2}{*}{$\begin{array}{l}\text { Sampling } \\
\text { ports }\end{array}$} & \multirow{2}{*}{$\begin{array}{l}\text { Ports distance } \\
\text { along the biofilter }\end{array}$} & \multicolumn{2}{|c|}{ Total mass of S } & \multicolumn{2}{|c|}{ Total mass of $\mathrm{N}$} \\
\hline & & $\begin{array}{l}\text { mean } \\
\text { removal (\%) }\end{array}$ & $\begin{array}{l}\text { standard } \\
\text { deviation }\end{array}$ & $\begin{array}{l}\text { mean } \\
\text { removal (\%) }\end{array}$ & $\begin{array}{l}\text { standard } \\
\text { deviation }\end{array}$ \\
\hline P1 & Biofilter inlet & - & - & - & - \\
\hline P2 & $\begin{array}{l}15 \mathrm{~cm} \text { below the } \\
\text { bed top }\end{array}$ & 54.8 & 4.1 & 40.3 & 0.4 \\
\hline P3 & $\begin{array}{l}30 \mathrm{~cm} \text { below the } \\
\text { bed top }\end{array}$ & 71.4 & 5.4 & 60.4 & 2.1 \\
\hline P4 & Biofilter outlet & 85.5 & 1.4 & 84.6 & 0.8 \\
\hline
\end{tabular}

Table 5.3.4 Case 2: Total mass of $S$ and $N$ removal along the biofilter

\begin{tabular}{|l|l|c|c|c|c|}
\hline \multirow{2}{*}{$\begin{array}{l}\text { Sampling } \\
\text { ports }\end{array}$} & \multirow{2}{*}{$\begin{array}{l}\text { Ports distance } \\
\text { along the biofilter }\end{array}$} & \multicolumn{2}{|l|}{ Total mass of S } & \multicolumn{2}{l|}{ Total mass of N } \\
\cline { 3 - 6 } & & mean & $\begin{array}{l}\text { standard } \\
\text { deviation }\end{array}$ & $\begin{array}{l}\text { mean } \\
\text { removal (\%) }\end{array}$ & $\begin{array}{l}\text { standard } \\
\text { deviation }\end{array}$ \\
\hline P1 & Biofilter inlet & - & - & - & - \\
\hline P2 & $\begin{array}{l}15 \mathrm{~cm} \text { below the } \\
\text { bed top }\end{array}$ & 57.2 & 10.3 & 28.8 & 3.3 \\
\hline P3 & $\begin{array}{l}30 \mathrm{~cm} \text { below the } \\
\text { bed top }\end{array}$ & 66.8 & 8.0 & 45.6 & 2.5 \\
\hline P4 & Biofilter outlet & 83.1 & 0.2 & 68.4 & 4.4 \\
\hline
\end{tabular}

As shown in Table 5.3.3, around $55 \%$ of the mass of $\mathrm{S}$ and around $40 \%$ of the mass of $\mathrm{N}$ were removed within the first $15 \mathrm{~cm}$ of the bed height while the first $30 \mathrm{~cm}$ of bed removed around $71 \%$ of the mass of $\mathrm{S}$ and $60 \%$ of the mass of $\mathrm{N}$ in Case 1. As shown in Table 5.3.4, around $57 \%$ of the mass of $\mathrm{S}$ and around $29 \%$ of the mass of $\mathrm{N}$ were removed within the first $15 \mathrm{~cm}$ of the bed height while the first $30 \mathrm{~cm}$ of bed removed around $67 \%$ of the mass of $\mathrm{S}$ and $46 \%$ of the mass of $\mathrm{N}$ in Case 2 . The Case 2 biofilter conditions resulted in relatively low $\mathrm{NH}_{3}$ removal while $\mathrm{RSCs}$ removal efficiency did not change significantly between two cases. The low $\mathrm{NH}_{3}$ removal in the Case 2, was likely due to the low EBRT and bed temperature (this will be discussed in Section 5.7). 
As shown in Figure 5.3.10, the RSCs at the biofilter outlet were below the detection limit other than during the compound peaking time. However, the removal efficiencies were around 85 and $83 \%$, because of the following calculation procedures. When the concentrations of the analytes were below the detection limits, a value that was $50 \%$ of the detection limits was used for the biofilter outlet concentration for the purposes of the calculation. In general, this tended to result in lower removal efficiencies for the RSCs as these compounds were often removed to below their detection limits.

As shown in Figure 5.3.10(c), the DMS concentration variation along the biofilter reveals that the DMS removal was relatively low within the first $15 \mathrm{~cm}$ bed; however most of the DMS was removed within the first $30 \mathrm{~cm}$ of the filter bed. It would appear that DMS oxidation required more retention time than DMDS and MM. As shown in Figure 5.3.10(d), most of the MM was removed within the first $15 \mathrm{~cm}$ of the filter bed. As discussed earlier, the MM could be oxidized to DMDS and DMTS (biochemical oxidation) or it could be directly oxidized to sulfate (biological oxidation). In terms of $\mathrm{NH}_{3}$ gas removal as shown in Figure 5.3.10(e), it was almost similar to the trend of RSCs removal variations along the biofilter. However the first $15 \mathrm{~cm}$ of bed removed a relatively lower percentage of $\mathrm{NH}_{3}$ than that of the RSCs. This may be due to the $\mathrm{NH}_{3}$ loading was relatively higher than the RSC loading on the biofilter. 
(a)

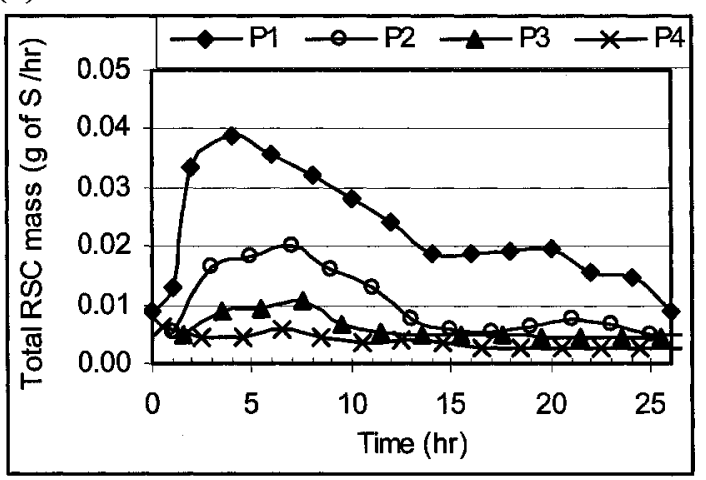

(c)

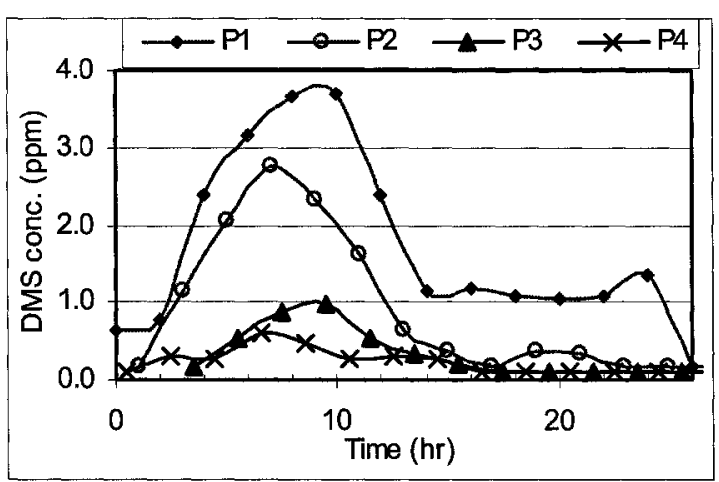

(b)

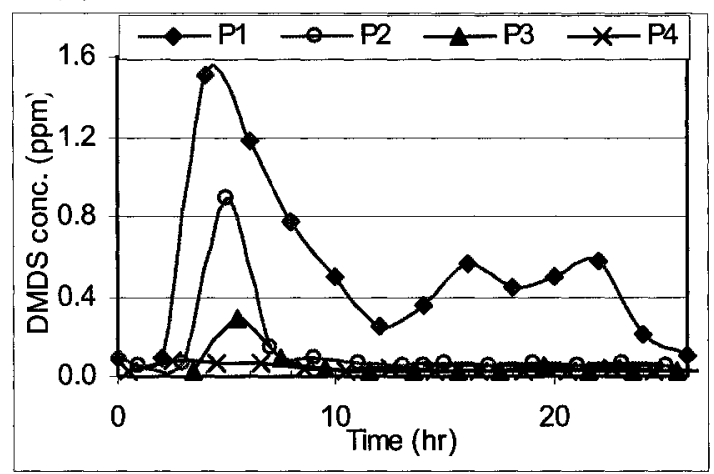

(d)

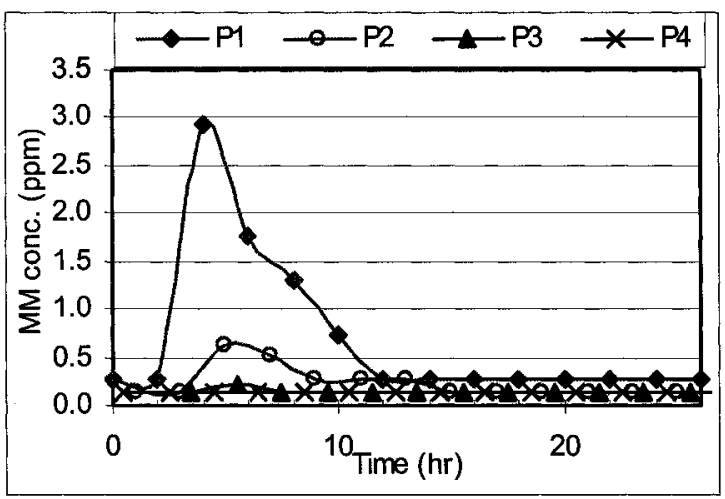

(e)

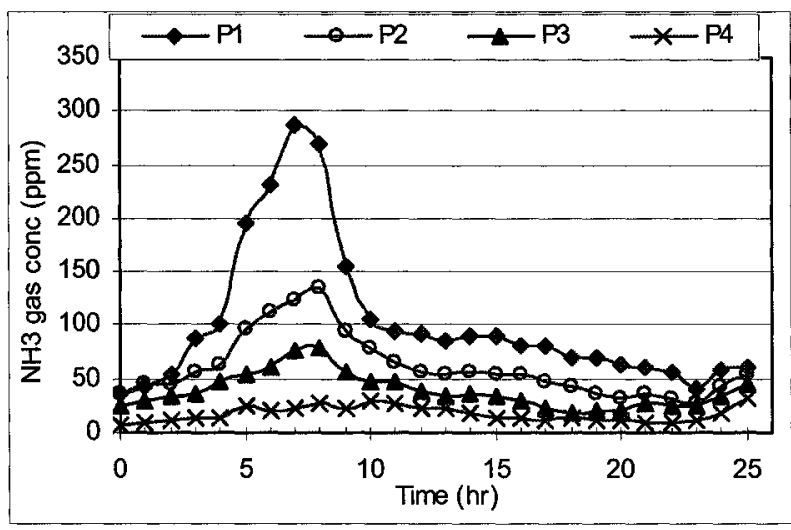

Figure 5.3.10 Off gas concentrations along the biofilter in Case 1 


\subsection{5 $\mathrm{N}$ containing compounds other than $\mathrm{NH}_{3}$ gas}

In this study, preliminary testing was performed to analyze gas phase $\mathrm{N}$-containing compounds other than $\mathrm{NH}_{3}$ gas. Based on the literature review, $\mathrm{NO}, \mathrm{NO}_{2}$ and $\mathrm{N}_{2} \mathrm{O}$ were analyzed in gas samples taken from the biofilter inlet and biofilter outlet as discussed in Section 4.2.2. However, these gases were not detected at significant concentrations in this study. The $\mathrm{NO}_{2}$ and $\mathrm{NO}$ gas concentrations varied between 0.20 and $0.64 \mathrm{ppm}$ while $\mathrm{N}_{2} \mathrm{O}$ was not detected.

As shown in Table 2.2, the Henry's law coefficients $\left(\mathrm{K}_{\mathrm{H}}\right)$ of $\mathrm{NO}, \mathrm{NO}_{2}$ and $\mathrm{N}_{2} \mathrm{O}$ were much higher than $\mathrm{NH}_{3}$ gas. However, $\mathrm{K}_{\mathrm{H}}-\mathrm{N}_{2} \mathrm{O}$ and $\mathrm{K}_{\mathrm{H}^{-}}-\mathrm{NO}_{2}$ are relatively low value among $\mathrm{NO}, \mathrm{NO}_{2}$ and $\mathrm{N}_{2} \mathrm{O}$, therefore the tendency to dissolve in water is high for $\mathrm{N}_{2} \mathrm{O}$ and $\mathrm{NO}_{2}$. Among $\mathrm{N}$ containing gases, $\mathrm{NO}$ has high possibility to release in the biofilter off gas. When $\mathrm{N}_{2} \mathrm{O}$ and $\mathrm{NOx}$ concentrations were very low compared to the $\mathrm{NH}_{3}$ outlet gas concentration (minimum value of around $20 \mathrm{ppm}$ ), NOx concentrations that were detected in this study did not represent a significant quantity of the total outlet mass of $\mathrm{N}$. 


\subsection{Leachate analysis}

Leachate samples from the scrubber and the biofilter systems were analyzed in each sampling event along with gas phase analysis. It was observed that, the scrubber leachate ion concentrations followed a similar trend for all the scrubber conditions. Figure 5.4.1 shows the scrubber leachate concentrations versus time with corresponding gas phase pollutant loadings. In this study, the sampling event E10 data was used to analyze the scrubber leachate. The scrubbing liquid was potable water with a flow rate of around 10 $1 / \mathrm{min}$. The $\mathrm{NH}_{4}{ }^{+}$concentration in the feed water was around $0.28 \mathrm{mg} / \mathrm{L}$. As shown in Figure 5.4.1, there was no significant variation in $\mathrm{NO}_{2}{ }^{-}, \mathrm{NO}_{3}{ }^{-}$, and $\mathrm{SO}_{4}{ }^{2-}$ concentrations during the cycle. However the $\mathrm{NH}_{4}{ }^{+}$concentrations changed significantly. As shown in Figure 5.4.1, after the feeding, when the $\mathrm{NH}_{3}$ gas concentration was peaking, the $\mathrm{NH}_{4}{ }^{+}$ concentration started to decrease from around $20 \mathrm{mg} / 1$ to a low value of around $10 \mathrm{mg} / \mathrm{l}$. The $\mathrm{NH}_{4}{ }^{+}$concentration then gradually increased to around $22 \mathrm{mg} / 1$, until the next feed cycle started. It was also noticed that the variation of $\mathrm{pH}$ coincided with the variation of $\mathrm{NH}_{4}{ }^{+}$. The leachate $\mathrm{pH}$ decreased from 8 to 6 within the first 6 hours of feeding. After this the $\mathrm{pH}$ gradually increased to 8 .

From the $\mathrm{pH}$ data, it would appear that $\mathrm{NH}_{3}$ scrubbing was not the only active process within the scrubber, and acid-forming reactions were also active. However, $\mathrm{SO}_{4}{ }^{2-}$ and $\mathrm{NO}_{3}{ }^{-}$concentrations did not contribute to this acid forming because the $\mathrm{SO}_{4}{ }^{2-}$ and $\mathrm{NO}_{3}{ }^{-}$ concentrations in the feed water were on average 25.8 and $0.3 \mathrm{mg} / 1$, respectively, which were almost close to the leachate concentration values. Therefore, other factors may be dominated for the $\mathrm{NH}_{4}{ }^{+}$concentration variation which will be discussed in Section 5.6.2. 

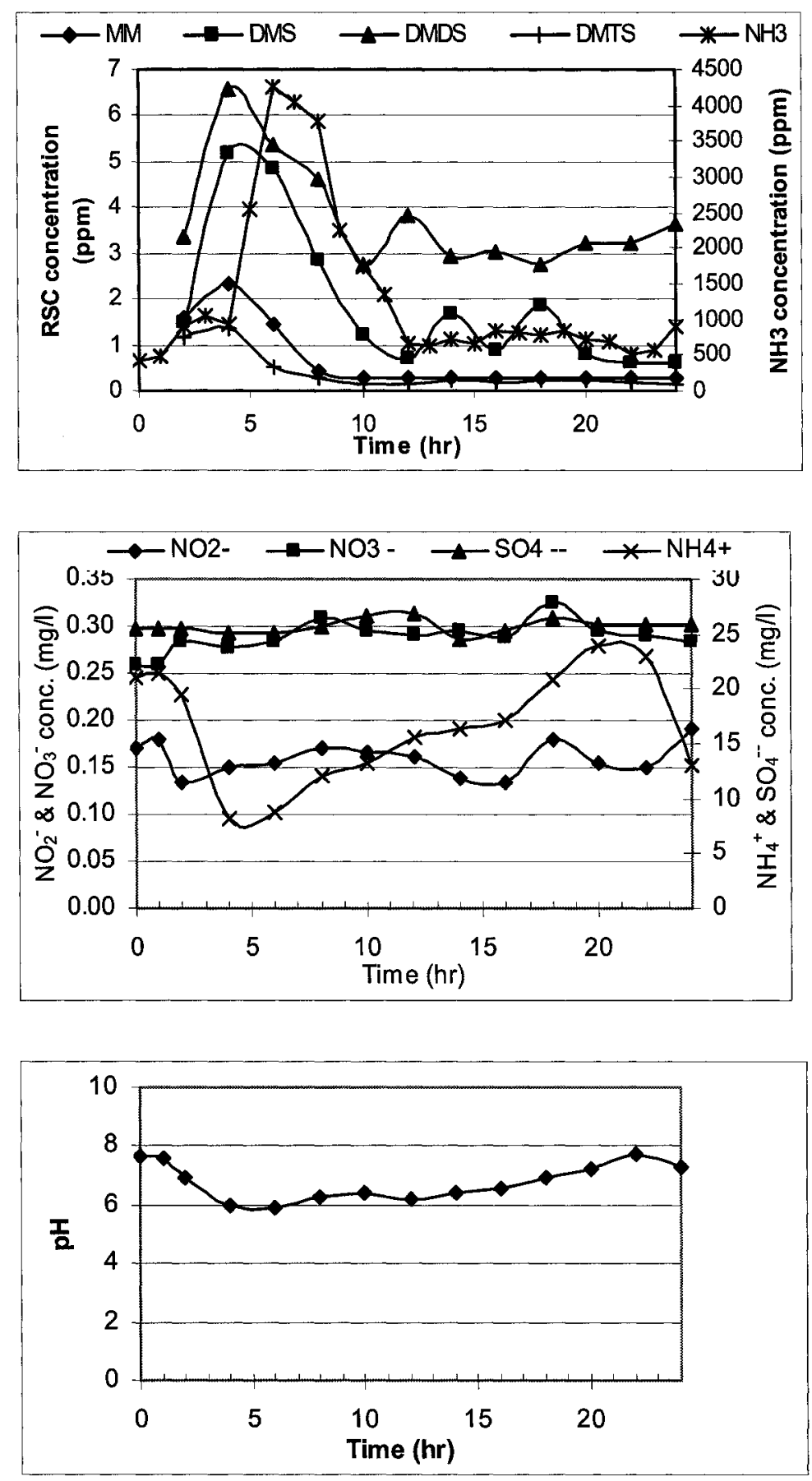

Figure 5.4.1 Scrubber leachate variations versus time with corresponding gas phase pollutant loading

When plant water was used as scrubbing water, a similar trend was observed. However, due to the high $\mathrm{NH}_{4}{ }^{+}-\mathrm{N}$ concentration of around $27 \mathrm{mg} / \mathrm{l}$ in the feed (plant water), the decreases in the leachate $\mathrm{NH}_{4}{ }^{+}-\mathrm{N}$ concentration when the $\mathrm{NH}_{3}$ gas was peaking was 
reduced. The $\mathrm{NH}_{4}{ }^{+}-\mathrm{N}$ concentration decreased from 38 to $30 \mathrm{mg} / 1$ then gradually increased to around $38 \mathrm{mg} / \mathrm{l}$. From this data, it would appear the plant water also showed similar effect that the $\mathrm{NH}_{4}{ }^{+}$concentration decreased when the $\mathrm{NH}_{3}$ gas was peaking.

The biofilter leachate ion concentrations varied with the gas phase pollutant loadings. However, it was observed that the leachate ion concentration patterns were similar for all the biofilter conditions. However, the nitrification product concentrations varied substantially between cold and warm bed conditions and will be discussed in Section 5.5. Figures 5.4.2 and 5.4.3 show the leachate ion concentrations versus time for two distinct biofilter loading conditions (Case 1 and Case 2). These biofilter loading conditions were corresponding to E46 and E38 of event data. Table 5.4.1 shows the ATAD and the biofilter conditions for Case 1 and Case 2.

Table 5.4.1 The ATAD and the biofilter conditions for the leachate analysis

\begin{tabular}{|l|l|c|c|}
\hline System & Parameters & Case 1 & Case 2 \\
\hline \multirow{3}{*}{ ATAD } & Air flow rate (SLPM) & 50 & 50 \\
\cline { 2 - 4 } & Sludge loading $(1 / \mathrm{d})$ & 245 & 245 \\
\cline { 2 - 4 } & Stable temperature $\left({ }^{\circ} \mathrm{C}\right)$ & 60 & 64 \\
\hline \multirow{5}{*}{ Biofilter } & EBRT $(\mathrm{s})$ & 150 & 150 \\
\cline { 2 - 4 } & Post humidification water flow $(1 / \mathrm{min})$ & 1 & 1 \\
\cline { 2 - 4 } & Source of post humidification & Potable water & Potable water \\
\cline { 2 - 4 } & Bed temperature $\left({ }^{\circ} \mathrm{C}\right)$ & 18 & 28 \\
\hline Scrubber & Liquid flow rate $(1 / \mathrm{min})$ & 30 & 10 \\
\hline
\end{tabular}

As shown in Figure 5.4.2, for low pollutant loading (Case 1), the $\mathrm{NH}_{4}-\mathrm{N}(\mathrm{aq}$ ) concentration decreased after 2 hours of the digester feeding and subsequently increased from around $0.3 \mathrm{mg} / 1$ to around $0.4 \mathrm{mg} / \mathrm{l}$. After the feeding, the $\mathrm{NO}_{3}{ }^{-} \mathrm{N}$ concentration decreased from 0.25 to $0.20 \mathrm{mg} / \mathrm{l}$ by around 5 hours, then, started to increase gradually to 
around $0.25 \mathrm{mg} / \mathrm{l}$ within the next few hours. A similar trend was observed in Figure 5.4.3 for the relatively high loading case (Case 2). As shown in Figure 5.4.3, the $\mathrm{NH}_{4}{ }^{+} \mathrm{N}$ concentration decreased after 4 hours of the digester feeding and subsequently increased from around 0.5 to around $0.8 \mathrm{mg} / \mathrm{l}$. After the feeding, the $\mathrm{NO}_{3}^{-}-\mathrm{N}$ concentration decreased from 1.1 to $0.8 \mathrm{mg} / \mathrm{l}$ by around 5 hours, then, it started to increase gradually to around $1.20 \mathrm{mg} / \mathrm{l}$ within the next few hours. The $\mathrm{NO}_{2}{ }^{-}-\mathrm{N}$ concentration was less than 0.05 $\mathrm{mg} / 1$ and there was no significant variation observed in $\mathrm{NO}_{2}^{-}-\mathrm{N}$ concentration.
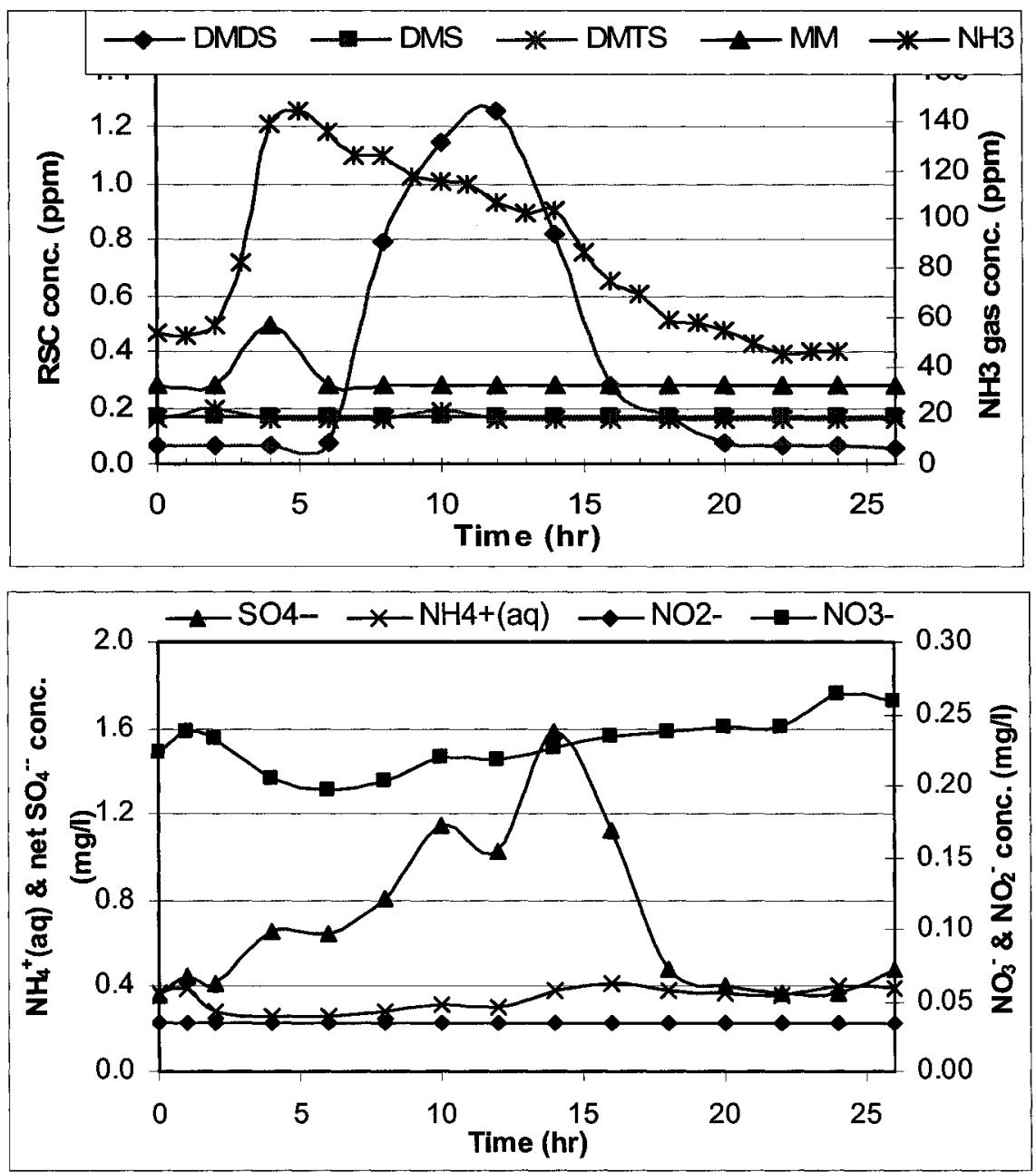

Figure 5.4.2 Case 1: Concentrations of net $\mathrm{SO}_{4}{ }^{2-}, \mathrm{NH}_{4}{ }^{+}, \mathrm{NO}_{3}{ }^{-}$, and $\mathrm{NO}_{2}{ }^{-}$in the biofilter leachate and corresponding gas phase concentrations 

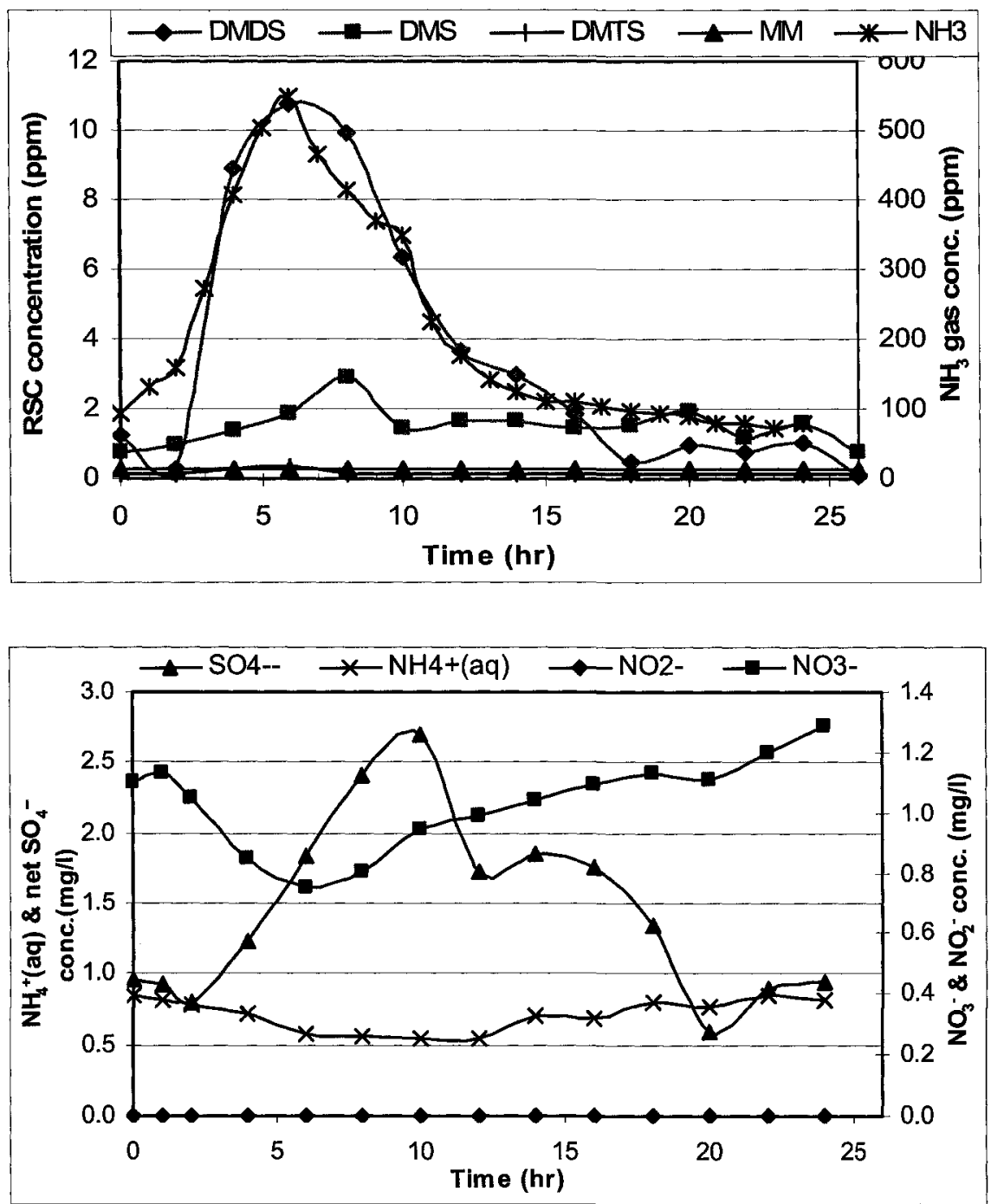

Figure 5.4.3 Case 2: Concentrations of net $\mathrm{SO}_{4}{ }^{2-}, \mathrm{NH}_{4}{ }^{+}, \mathrm{NO}_{3}{ }^{-}$, and $\mathrm{NO}_{2}{ }^{-}$in the biofilter leachate and corresponding gas phase concentrations

As shown in Figures 5.4.2 and 5.4.3, the maximum $\mathrm{NH}_{3}$ gas peak occurred around 5 hours after the feeding, however, the $\mathrm{NH}_{4}^{+}$and $\mathrm{NO}_{3}{ }^{-}$concentrations decreased. The behavior of $\mathrm{NH}_{4}{ }^{+}$and $\mathrm{NO}_{3}{ }^{-}$in the aqueous phase relative to the gas phase concentration was not expected. Based on the data, it would appear that there may have been more than one removal mechanism (other than biological oxidation) active in the aqueous systems and this will be discussed in Section 5.6. 
As shown in Figure 5.4.2, the net $\mathrm{SO}_{4}{ }^{2-}$ concentration increased from 0.4 to $1.6 \mathrm{mg} / 1$ within the first 15 hours after feeding and then decreased to the previous value. As shown in Figure 5.4.3, the net $\mathrm{SO}_{4}{ }^{2-}$ concentration increased from 0.9 to $2.7 \mathrm{mg} / 1$ within the first 10 hours after feeding and then decreased to the previous value. The RSC peaking time was different between the cases which may be due to the differences in the ATAD conditions because the gas production depended on the ORP values, the reactor temperature and the solids content of the reactor. However, the $\mathrm{SO}_{4}{ }^{2-}$ concentration peak almost coincided with the RSC concentration peaks in each case. This revealed that the incoming RSCs were biologically oxidized to $\mathrm{SO}_{4}{ }^{2-}$ within the biofilter.

(a)

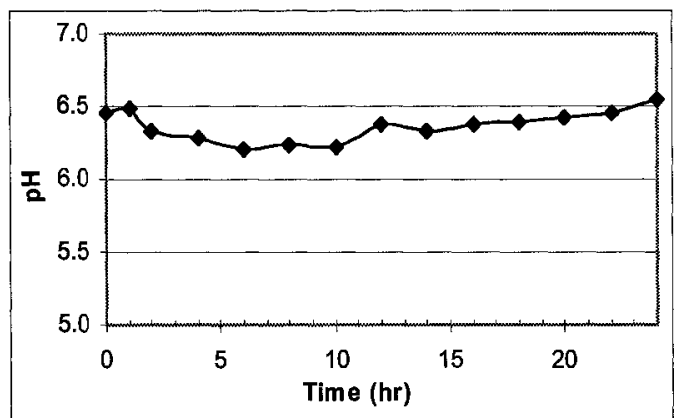

\section{(b)}

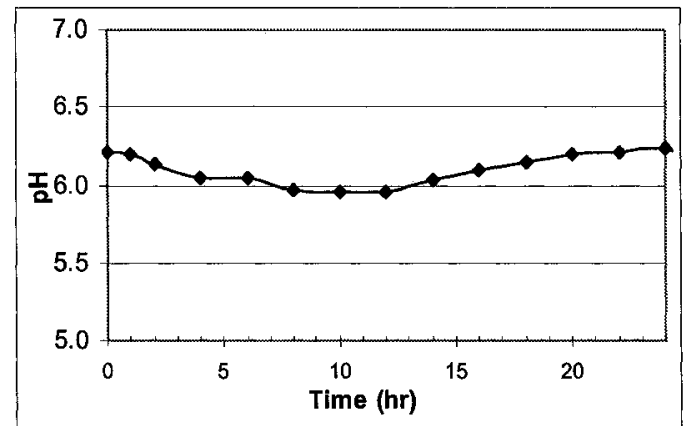

Figure 5.4.4 The variation of $\mathrm{pH}$ in the biofilter leachate (a) Case 1 (b) Case 2

Figure 5.4.4 presents the biofilter leachate $\mathrm{pH}$ variations which were analyzed for the two cases (which corresponded to Figures 5.4.2 and 5.4.3 and the ATAD and biofilter conditions as shown in Table 5.4.1). The $\mathrm{pH}$ variations in the biofilter leachate followed similar trends for all the biofilter conditions other than when the packing material changed. From Figure 5.4.4, it can be seen that the biofilter leachate $\mathrm{pH}$ ranged from 6.5 to 6.2 for Case 1 and from 6.3 to 5.9 for Case 2 while the feed $\mathrm{pH}$ for both cases was 
around 8.8. The pH dropped approximately 2 to 3 hours after the digester was fed. This corresponded to the period when there was an increase in the concentration of $\mathrm{SO}_{4}{ }^{2-}$ in the liquid phase. The increased production of acids that was evidenced by the higher concentration of $\mathrm{SO}_{4}{ }^{2-}$ and the increased concentration of $\mathrm{CO}_{2}$ gas in the off gas (Figure 5.3.5) may also have influenced nitrification reactions. The $\mathrm{pH}$ that is more preferable for nitrification is between 7.2 and 8.8 (Sincero and Sincero, 2003). The relatively limited amount of nitrification in this study was likely due to the $\mathrm{pH}$ extremes and cold weather conditions. This will be discussed more in Section 5.7 .

$\mathrm{NH}_{4}^{+}$and TKN were analyzed to identify any significant concentration of organic nitrogen compounds in the leachate. Figure 5.4.5 shows the $\mathrm{NH}_{4}^{+}$and TKN concentrations in the biofilter and the scrubber leachate along the cycle. As shown in Figure 5.4.5, there were no significant differences in the concentrations of $\mathrm{NH}_{4}^{+}$and TKN along the cycle. This data confirms that the biofilter and the scrubber leachate did not have significant concentrations of organic nitrogen-compounds.

(a)

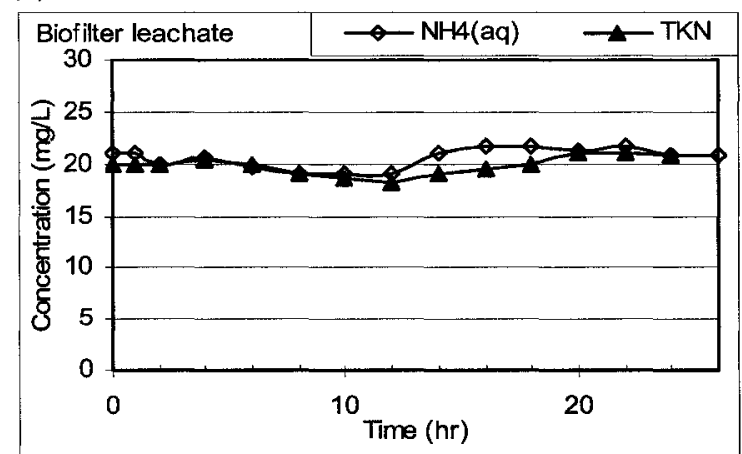

Figure 5.4.5 Concentration of $\mathrm{NH}_{4}{ }^{+}$and TNK along the cycle (b)

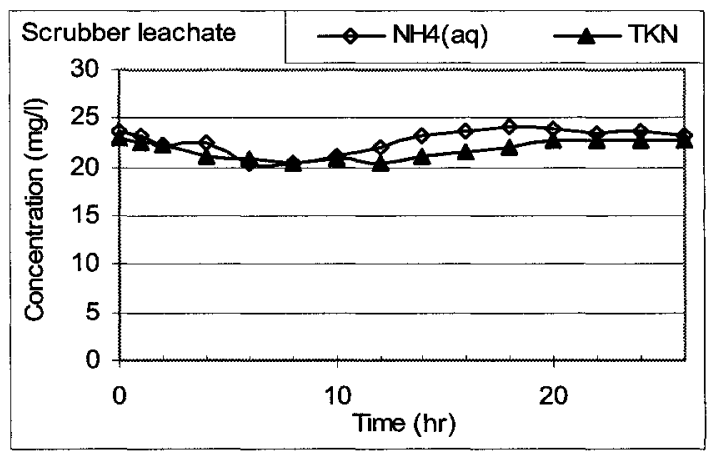




\section{5 $\mathrm{S}$ and $\mathrm{N}$ mass balance within the biofilter}

The total cumulative masses of S and $\mathrm{N}$ over 24-hour sampling periods were calculated based on each compound that was analyzed at the biofilter inlet and outlet. Tables 5.5.1 and 5.5.2 show the $\mathrm{S}$ and $\mathrm{N}$ mass balances, respectively, for the events. The corresponding sampling event data (Appendix A) were given within the bracket in the events name column. The percentage of mass differences was calculated based on Equation 5.5.1.

Mass difference $(\%)=\frac{(\text { total mass } \text { in }- \text { total mass out }) * 100}{\text { total } \text { mass in }}$

Sampling event names starting with ' $A$ ' refers to the potable water as post humidification water and ' $\mathrm{B}$ ' refers to the plant water as post humidification water. The feed plant water had a high $\mathrm{NH}_{4}^{+}$concentration (around 20 to $30 \mathrm{mg} / \mathrm{l}$ ) as compared to the amount of $\mathrm{NH}_{4}{ }^{+}$(less than $0.2 \mathrm{mg} / \mathrm{l}$ ) in the potable feed water.

As shown in Tables 5.5.1 and 5.5.2, the lack of mass balance closure varied between +/$30 \%$ of the mass entering the biofilter. As discussed in the literature review, a lack of mass balance within biofilter systems is not an uncommon phenomenon. As discussed in Chapter 3, the full scale biofilter study also showed a significant lack of mass balance closure. Based on the full scale study experience, careful measures were taken to obtain a better mass balance within the pilot biofilter, by analyzing all known species in the pilot study. However the difference could not be eliminated. It may be necessary to analyze other trace gases in and out of the biofilter. The lack of mass balance could also be due to measurement errors. Also the technique employed to estimate the mass balance with 
the time varying concentrations may have introduced errors. Usually the concentrations were taken at constant time intervals; however a dynamic system such as ATAD off gases may change over very short time intervals. In addition to this, the total mass of each compound was calculated based on the off gas flow rates that were measured at the scrubber inlet. Small changes in the air flow rate measurements may affect the overall mass balance. Therefore by modifying the sampling and analysis methods, the mass balance differences may be minimized.

Table 5.5.1 S mass balance on the biofilter

\begin{tabular}{|c|c|c|c|c|c|c|c|c|}
\hline 壱 & 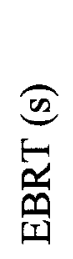 & 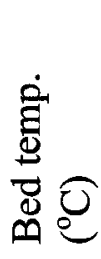 & 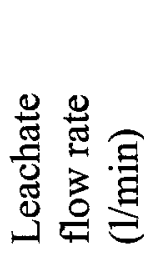 & 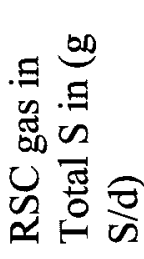 & 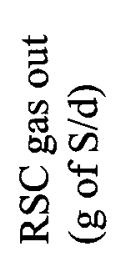 & 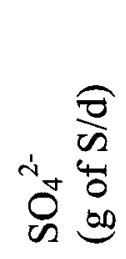 & 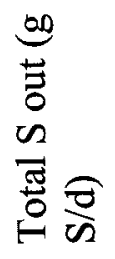 & 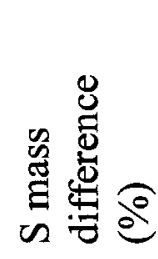 \\
\hline A1M1 (E6) & 150 & 5 & 1 & 0.79 & 0.16 & 0.71 & 0.87 & -10.5 \\
\hline A1M2 (E20) & 150 & 12 & 5 & 1.09 & 0.22 & 1.09 & 1.31 & -20.6 \\
\hline A1M3 (E46) & 150 & 18 & 1 & 0.26 & 0.07 & 0.27 & 0.34 & -26.9 \\
\hline A1M4 (E41) & 150 & 26 & 1 & 1.15 & 0.08 & 1.23 & 1.31 & -13.5 \\
\hline A1M5 (E38) & 150 & 28 & 1 & 0.32 & 0.04 & 0.36 & 0.40 & -24.1 \\
\hline A2M1 (E17) & 75 & 5 & 5 & 0.57 & 0.16 & 0.48 & 0.64 & -12.4 \\
\hline $\mathrm{A} 2 \mathrm{M} 2(\mathrm{E} 23)$ & 75 & 10 & 2.5 & 0.68 & 0.10 & 0.73 & 0.83 & -21.7 \\
\hline A2M3 (E24) & 75 & 15 & 1 & 1.51 & 0.20 & 1.49 & 1.69 & -11.1 \\
\hline A3M1 (E15) & 40 & 5 & 5 & 1.25 & 0.27 & 1.17 & 1.44 & -14.3 \\
\hline A3M2 (E13) & 40 & 10 & 5 & 5.61 & 1.08 & 4.45 & 5.53 & 1.5 \\
\hline $\mathrm{A} 3 \mathrm{M} 3(\mathrm{E} 26)$ & 40 & 15 & 1 & 1.49 & 0.31 & 1.35 & 1.66 & -11.3 \\
\hline A3M4 (E27) & 40 & 20 & 1 & 2.06 & 0.21 & 2.24 & 2.45 & -18.8 \\
\hline A3M5 (E42) & 40 & 26 & 1 & 1.36 & 0.16 & 1.38 & 1.54 & -12.9 \\
\hline A4M1 (E10) & 15 & 5 & 5 & 4.69 & 1.14 & 4.34 & 5.48 & -16.9 \\
\hline B1M1 (E47) & 150 & 18 & 2 & 0.26 & 0.07 & 0.26 & 0.33 & -24.0 \\
\hline B1M2 (E31) & 150 & 20 & 1 & 0.24 & 0.05 & 0.24 & 0.29 & -19.8 \\
\hline B1M3 (E35) & 150 & 22 & 1 & 0.18 & 0.04 & 0.18 & 0.22 & -23.2 \\
\hline B1M4 (E45) & 150 & 26 & 2 & 0.43 & 0.05 & 0.43 & 0.48 & -11.3 \\
\hline B2M1 (E29) & 40 & 20 & 1 & 1.10 & 0.19 & 1.07 & 1.26 & -14.0 \\
\hline
\end{tabular}


Table 5.5.2 N mass balance within the biofilter

\begin{tabular}{|c|c|c|c|c|c|c|c|c|c|c|c|}
\hline 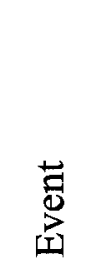 & 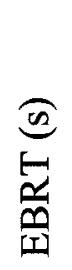 & 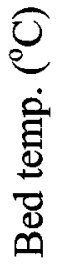 & 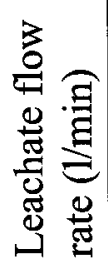 & 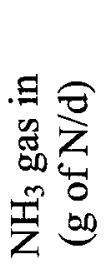 & 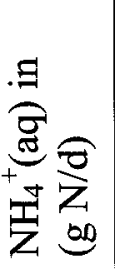 & 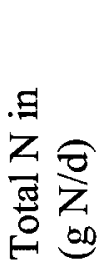 & 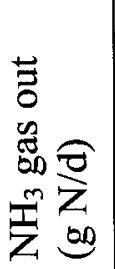 & 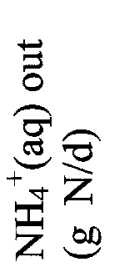 & $\delta^{\frac{\partial}{Z}}$ & 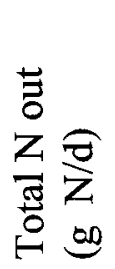 & 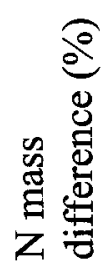 \\
\hline AlM1 & 150 & 5 & 1 & 17.51 & 0.21 & 17.71 & 7.86 & 7.13 & 0.70 & 15.69 & 11.4 \\
\hline A1M2 & 150 & 12 & 5 & 23.06 & 3.27 & 26.33 & 11.89 & 8.29 & 0.18 & 20.36 & 22.7 \\
\hline A1M3 & 150 & 18 & 1 & 4.01 & 0.11 & 4.12 & 1.10 & 1.18 & 0.69 & 2.97 & 28.1 \\
\hline AlM4 & 150 & 26 & 1 & 5.86 & 0.15 & 6.00 & 1.11 & 1.26 & 2.53 & 4.90 & 18.5 \\
\hline A1M5 & 150 & 28 & 1 & 5.38 & 0.10 & 5.48 & 0.51 & 1.56 & 2.45 & 4.52 & 17.6 \\
\hline A2M1 & 75 & 5 & 5 & 14.93 & 3.40 & 18.33 & 7.78 & 6.89 & 0.27 & 14.94 & 18.6 \\
\hline A2M2 & 75 & 10 & 2.5 & 33.49 & 1.51 & 35.00 & 18.95 & 13.44 & 0.03 & 32.42 & 7.3 \\
\hline A2M3 & 75 & 15 & 1 & 52.17 & 0.63 & 52.80 & 24.66 & 20.69 & 0.07 & 45.42 & 14.0 \\
\hline A3M1 & 40 & 5 & 5 & 24.00 & 3.07 & 27.06 & 13.91 & 12.03 & 0.23 & 26.17 & $\begin{array}{l}3.3 \\
\end{array}$ \\
\hline $\mathrm{A} 3 \mathrm{M} 2$ & 40 & 10 & 5 & 57.27 & 5.17 & 62.44 & 29.66 & 34.68 & 0.27 & 64.61 & -3.5 \\
\hline A3M3 & 40 & 15 & 1 & 49.33 & 0.73 & 50.05 & 22.79 & 26.19 & 0.24 & 49.22 & 1.7 \\
\hline $\mathrm{A} 3 \mathrm{M} 4$ & 40 & 20 & 1 & 45.35 & 0.72 & 46.08 & 10.07 & 30.58 & 1.54 & 42.19 & 8.4 \\
\hline A3M5 & 40 & 26 & 1 & 37.89 & 0.10 & 37.99 & 3.89 & 25.00 & 3.57 & 32.46 & 14.6 \\
\hline A4M1 & 15 & 5 & 5 & 79.36 & 1.64 & 81.00 & 42.96 & 27.98 & 0.81 & 71.75 & 11.4 \\
\hline B1M1 & 150 & 18 & 2 & 6.03 & 30.21 & 36.23 & 1.25 & 29.10 & 1.73 & 32.08 & 11.5 \\
\hline B1M2 & 150 & 20 & 1 & 6.53 & 35.80 & 42.33 & 1.79 & 28.58 & 4.13 & 34.50 & 18.5 \\
\hline B1M3 & 150 & 22 & 1 & 4.04 & 33.07 & 37.11 & 0.67 & 15.80 & 16.98 & 33.45 & 9.9 \\
\hline B1M4 & 150 & 26 & 2 & 4.81 & 38.99 & 43.80 & 0.67 & 33.09 & 4.06 & 37.82 & 13.7 \\
\hline B2M1 & 40 & 20 & 1 & 38.88 & 48.90 & 87.78 & 9.95 & 51.99 & 6.16 & 68.10 & 22.4 \\
\hline
\end{tabular}

As shown in Table 5.5.1, the total mass of $\mathrm{S}$ in the outlet was higher than the total mass of $\mathrm{S}$ in the inlet, other than a single event (event A3M2). When RSC outlet concentration was below the detection limit, a half of the detection limit was taken as the outlet concentration for the mass balance calculations. However, when the RSC outlet concentrations were set to zero, the mass of S differences between inlet and outlet varied between $+/-20 \%$ of the total mass of $S$ entering the biofilter (the total mass of $S$ in the outlet was not always higher than total mass of $\mathrm{S}$ in the inlet). According to the analytical methods, the detection limits (Table 4.2.2) were above the odor recognition threshold values (Table 2.1), therefore, the outlet concentration was not set to zero. In addition to that, for the purpose of process modeling, the outlet concentration values had an 
important role in determining the degradation rates. Therefore, the RSC outlet concentration was set to $50 \%$ of the detection limit, when outlet concentrations were below the detection limit. As shown in Table 5.5.2, the total mass of $\mathrm{N}$ in the outlet was lower than the total mass of $\mathrm{N}$ in the inlet, other than a single event (event A3M2). The lower total mass of $\mathrm{N}$ in the biofilter outlet was suggesting that there may be denitrification process active within the biofilter, due to that formation of other $\mathrm{N}$ containing compound may exist and this will be discussed in Section 5.6.2.

\subsection{The effects of $N$ compounds variations}

\subsubsection{The effects on nitrification process}

From biofilter leachate analysis (Section 5.4), it was observed that limited nitrification process occurred within the biofilter system. Therefore, factors that affect the nitrification process were analyzed by varying bed temperature and biofilter empty bed resident time (EBRT). Figure 5.6.1 shows the effects of temperature and EBRT on the nitrification process. Two EBRT (150 and $40 \mathrm{~s}$ ) were chosen to characterize the $\mathrm{NO}_{3}{ }^{-}$production at different bed temperatures. For this analysis, the sampling events data of E6, E46, E40, and E38 were used for EBRT of 150 s case while the sampling events data of E14, E26, E27, and E42 were used for EBRT of $40 \mathrm{~s}$ case. Potable water was used as the source of post humidification water for this study to eliminate any effect of the high $\mathrm{NH}_{4}^{+}$ concentration in the plant water feed. 
(a)

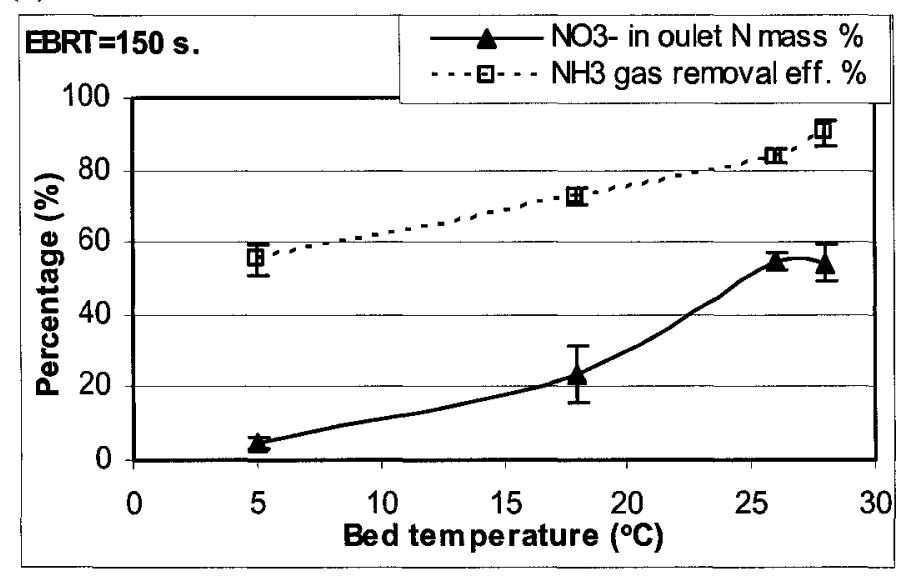

(b)

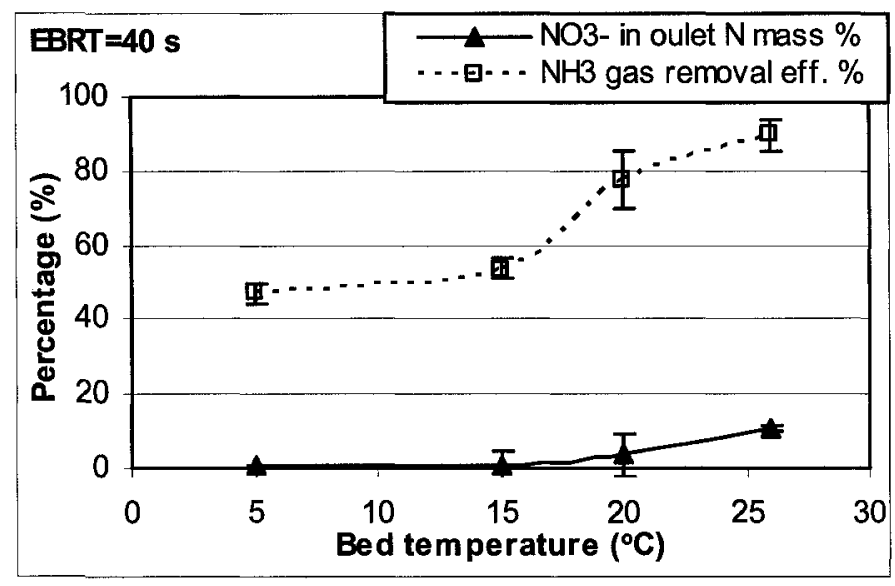

Figure 5.6.1 The effects of temperature and EBRT on the nitrification

As shown in Figure 5.6.1(a) and (b), the bed temperature was varied for each EBRT. To evaluate the relative amount of nitrification, Equation 5.6.1 was used to calculate the percentage of $\mathrm{NO}_{3}{ }^{-}$production in the biofilter leachate Mass of $\mathrm{N}$.

$\mathrm{NO}_{3}{ }^{-}$production $(\%)=\frac{\text { mass of } \mathrm{NO}_{3}^{-}-\mathrm{N} \text { in the leachate } \times 100}{\text { total mass of } N \text { in the outlet }}$

Removal efficiency $(\%)=\frac{\left(\text { inlet } \text { mass of } \mathrm{N}_{\text {as }} \mathrm{NH}_{3} \text { gas }- \text { outlet mass of } \mathrm{Nas} \mathrm{NH}_{3} \text { gas) } x 100\right.}{\text { inlet mass of } \mathrm{Nas} \mathrm{NH}_{3} \text { gas }}$ 
As shown in Figure 5.6.1, for both EBRT conditions, the $\mathrm{N}$ removal efficiencies increased with increasing temperature. However, for the EBRT of $40 \mathrm{~s}$, the $\mathrm{N}$ removal efficiency increased significantly between temperature of 15 and $20^{\circ} \mathrm{C}$. The $\mathrm{NO}_{3}{ }^{-}$ production (fraction of total mass of $\mathrm{N}$ ) in the leachate also increased with increasing temperature. However, the percentage of nitrification increased significantly with the EBRT. When the EBRT was $40 \mathrm{~s}$, the $\mathrm{NO}_{3}{ }^{-}$production increased slightly with temperature, however, when the EBRT was $150 \mathrm{~s}$, the $\mathrm{NO}_{3}^{-}$production increased significantly. As discussed in the literature review, the nitrification process depends on the $\mathrm{NH}_{3}$ retention time within the biofilter. The results indicate that the biofilter bed temperature enhanced nitrification and more contact time (EBRT) was needed to accommodate the nitrification process.

\subsubsection{The effects of $\mathbf{N}$ compound variations in the leachate}

In this study, when $\mathrm{NH}_{3}$ gas concentration peaked, the $\mathrm{NH}_{4}^{+}$and $\mathrm{NO}_{3}{ }^{-}$concentrations decreased along the cycle in both the scrubber and the biofilter. Based on chemical and physical reviews, this pattern could be due to the cooling down of water-saturated off gases, the production of other gaseous $\mathrm{N}$ containing compounds during high $\mathrm{NH}_{3}$ loading in the biofilter, the effects of $\mathrm{NH}_{3}$ solubility in the presence of $\mathrm{CO}_{2}$ or a chromatographic effect within the biofilter which had a dense organic woodchip packing. However, the above effects were observed in both the scrubber and the biofilter and hence the chromatographic effect was not likely active in the scrubber system. Therefore, the fourth possibility was eliminated from this discussion. Three other possibilities are discussed in the following sections. 


\subsubsection{Cooling down of water saturated off gases}

When the ATAD off gases came out of the reactor, the off gases were likely fully saturated with water vapor. The ATAD off gas temperature was typically in the range of 50 to $60^{\circ} \mathrm{C}$ at the $\mathrm{ATAD}$ outlet. When this off gas reached the wet scrubber, the temperature cooled down to around $30^{\circ} \mathrm{C}$ in the scrubber and then further cooled to around $20^{\circ} \mathrm{C}$ within the biofilter. During the cooling down, a fraction of the off gas vapor likely condensed to form water and contributed to the volume of humidification water. At the same time, it could be assumed that the condensed water was in equilibrium with $\mathrm{NH}_{3}$ gas. The mass of $\mathrm{NH}_{3}-\mathrm{N}$ in the condensed water along the 24 hours cycle was calculated based on the saturated vapor density and equilibrium $\mathrm{NH}_{3}$ concentration (using Henry's coefficient). The $\mathrm{K}_{\mathrm{H}}$ of $\mathrm{NH}_{3}$ can be estimated from Equations 5.2.1 and 5.2.2.

$$
\text { Equilibrium aqueous } \mathrm{NH}_{3} \text { concentration }=\frac{\text { gas phase } \mathrm{NH}_{3}}{K_{H}}(\mathrm{mg} / \mathrm{l})
$$

The 24 hours off gas temperature profile was used to calculate the quantity of condensed water and the equilibrium $\mathrm{NH}_{3}$ concentration. Equations 5.6.3 was used to calculate the $\mathrm{NH}_{3}$ mass in the condensed water. Both potable and plant water were evaluated as a source of post-humidification water in this study. As discussed earlier, the feed plant water had a high $\mathrm{NH}_{4}^{+}$concentration compared to the negligible amount of $\mathrm{NH}_{4}^{+}$in the potable feed water.

Equation 5.6.4 shows the expression for the saturated vapor density (VD, g/m $\mathrm{m}^{3}$ ) as a function of temperature. To calculate the quantity of condensed water, Equation 5.6.4 was used in this study. The condensed water quantity was not a significant when 
compared to the feed flow rate (less than $0.5 \%$ ). Therefore, it can be assumed that the quantity of condensed water did not affect the concentration calculations along the scrubber and the biofilter.

$V D=5.018+0.32321^{*} T c+8.1847^{*} 10^{-3} * T c^{2}+3.1243^{*} 10^{-4} * T c^{3}$

Where $T c=$ temperature in ${ }^{\circ} \mathrm{C}$

(Nave, 2000)

The condensed water effects on the scrubber and biofilter feed water were evaluated based on typical operating conditions. For this analysis, following conditions were assumed, scrubber liquid flow rate $=10 \mathrm{l} / \mathrm{min}$; scrubber gas retention time $=80 \mathrm{~s}$; biofilter EBRT $=150 \mathrm{~s}$; biofilter post humidification water flow rate $=11 / \mathrm{min}$; feed potable water $\mathrm{NH}_{4}^{+}$concentration $=0.1 \mathrm{mg} / \mathrm{l}$ and feed plant water $\mathrm{NH}_{4}^{+}$concentration $=$ $20 \mathrm{mg} / \mathrm{l}$. The dynamic $\mathrm{NH}_{3}$ gas loading into the scrubber and the biofilter and the gas and liquid temperature profiles along the cycle were selected from one sampling event. Tables 5.6.1 and 5.6.5 show the Henry's coefficient variation along the cycle and corresponding equilibrium $\mathrm{NH}_{3}(\mathrm{aq})$ concentration. Tables 5.6.2 and 5.6.6 show the vapor density variation along the cycle and corresponding condensed water quantity. Tables 5.6.3 and 5.6.4 and Tables 5.6.7 and 5.6.8 show the corrected $\mathrm{NH}_{4}^{+}$concentration along the cycle for potable and plant water conditions, respectively. 
Table 5.6.1 Henry's law coefficient variation for scrubber condition

\begin{tabular}{|c|c|c|c|c|c|c|c|}
\hline \multirow{2}{*}{$\begin{array}{l}\text { Time } \\
\text { (hr) }\end{array}$} & \multirow{2}{*}{$\begin{array}{c}\text { Temp. } \\
\left({ }^{\circ} \mathrm{K}\right)\end{array}$} & \multirow[t]{2}{*}{$\ln (\mathrm{H})$} & \multirow{2}{*}{$\begin{array}{c}\mathrm{H} \\
\left(\mathrm{atm} / \mathrm{m}^{3} / \mathrm{mol}\right)\end{array}$} & \multirow[t]{2}{*}{$\mathrm{K}_{\mathrm{H}}(-)$} & \multicolumn{2}{|c|}{$\mathrm{NH}_{3}$ gas inlet conc. } & \multirow{2}{*}{$\begin{array}{l}\text { Equilibrium liquid } \\
\text { conc. }(\mathrm{mg} / \mathrm{l})\end{array}$} \\
\hline & & & & & $\mathrm{ppm}$ & $(\mathrm{mg} / \mathrm{l})$ & \\
\hline 0 & 295 & -11.1043 & $1.50 \mathrm{E}-05$ & $6.22 \mathrm{E}-04$ & 455 & 0.30 & 479.3 \\
\hline 4 & 294 & -11.1527 & 1.43E-05 & $5.94 \mathrm{E}-04$ & 987 & 0.55 & 928.4 \\
\hline 8 & 295 & -11.1043 & 1.50E-05 & $6.22 \mathrm{E}-04$ & 734 & 0.52 & 827.8 \\
\hline 12 & 295 & -11.1043 & 1.50E-05 & $6.22 \mathrm{E}-04$ & 455 & 0.32 & 513.1 \\
\hline 16 & 295 & -11.1043 & $1.50 \mathrm{E}-05$ & $6.22 \mathrm{E}-04$ & 365 & 0.33 & 524.4 \\
\hline 20 & 294 & -11.1527 & $1.43 \mathrm{E}-05$ & $5.94 \mathrm{E}-04$ & 365 & 0.33 & 548.6 \\
\hline 24 & 294 & -11.1527 & $1.43 \mathrm{E}-05$ & $5.94 \mathrm{E}-04$ & 375 & 0.33 & 560.4 \\
\hline
\end{tabular}

Table 5.6.2 Condensed vapour water vs. temperature for the scrubber conditions

\begin{tabular}{|c|c|c|c|c|c|}
\hline Time (hr) & Temp. $\left({ }^{\circ} \mathrm{K}\right)$ & $\begin{array}{c}\text { Volume of air } \\
\left(\mathrm{m}^{3} / \mathrm{hr}\right)\end{array}$ & $\begin{array}{c}\text { Vapour density } \\
\left(\mathrm{g} / \mathrm{m}^{3}\right)\end{array}$ & $\begin{array}{c}\text { Mass condensed } \\
\text { water }(\mathrm{g} / \mathrm{hr})\end{array}$ & $\begin{array}{c}\text { Vol. of condensed } \\
\text { water }(1 / \mathrm{hr})\end{array}$ \\
\hline 0 & 325 & 4.93 & 87.9 & 433.0 & 0.43 \\
\hline 4 & 314 & 4.93 & 53.6 & 263.9 & 0.26 \\
\hline 8 & 315 & 4.93 & 56.2 & 276.8 & 0.28 \\
\hline 12 & 319 & 4.93 & 67.6 & 333.2 & 0.33 \\
\hline 16 & 321 & 4.93 & 73.9 & 364.3 & 0.36 \\
\hline 20 & 324 & 4.93 & 84.2 & 415.0 & 0.42 \\
\hline 24 & 325 & 4.93 & 87.9 & 433.0 & 0.43 \\
\hline
\end{tabular}

Table 5.6.3 $\mathrm{NH}_{4}{ }^{+}$concentration after the off gas condensed in to the potable feed water of the scrubber

\begin{tabular}{|c|c|c|c|c|c|c|}
\hline $\begin{array}{c}\text { Time } \\
(\mathrm{hr})\end{array}$ & $\begin{array}{c}\text { Equilibrium } \\
\text { liquid conc. } \\
(\mathrm{mg} / \mathrm{l})\end{array}$ & $\begin{array}{c}\text { Vol. of } \\
\text { condensed } \\
\text { water }(\mathrm{l} / \mathrm{hr})\end{array}$ & $\begin{array}{c}\text { Condensed } \\
\text { mass of } \mathrm{NH}_{3} \\
(\mathrm{mg} / \mathrm{hr})\end{array}$ & $\begin{array}{c}\text { mass of } \mathrm{NH}_{3} \\
\text { in the feed } \\
\text { water }(\mathrm{mg} / \mathrm{hr})\end{array}$ & $\begin{array}{c}\text { Total mass of } \\
\mathrm{NH}_{3} \text { in the } \\
\text { feed water } \\
(\mathrm{mg} / \mathrm{hr})\end{array}$ & $\begin{array}{c}\mathrm{Corrected}^{+} \\
\mathrm{NH}_{4}{ }^{+}(\mathrm{aq}) \text { in } \\
\text { the feed } \\
(\mathrm{mg} / \mathrm{l})\end{array}$ \\
\hline 0 & 479.3 & 0.43 & 207.55 & 48 & 255.55 & 0.40 \\
\hline 4 & 928.4 & 0.26 & 245.02 & 48 & 293.02 & 0.50 \\
\hline 8 & 827.8 & 0.28 & 229.13 & 48 & 277.13 & 0.45 \\
\hline 12 & 513.1 & 0.33 & 170.95 & 48 & 218.95 & 0.40 \\
\hline 16 & 524.4 & 0.36 & 191.06 & 48 & 239.06 & 0.40 \\
\hline 20 & 548.6 & 0.42 & 227.68 & 48 & 275.68 & 0.45 \\
\hline 24 & 560.4 & 0.43 & 242.66 & 48 & 290.66 & 0.50 \\
\hline
\end{tabular}

Table 5.6.4 $\mathrm{NH}_{4}{ }^{+}$concentration after the off gas condensed in to the plant feed water of the scrubber

\begin{tabular}{|c|c|c|c|c|c|c|}
\hline $\begin{array}{c}\text { Time } \\
(\mathrm{hr})\end{array}$ & $\begin{array}{c}\text { Equilibrium } \\
\text { liquid conc. } \\
(\mathrm{mg} / \mathrm{l})\end{array}$ & $\begin{array}{c}\text { Vol. of } \\
\text { condensed } \\
\text { water }(1 / \mathrm{hr})\end{array}$ & $\begin{array}{c}\text { Condensed } \\
\text { mass of } \mathrm{NH}_{3} \\
(\mathrm{mg} / \mathrm{hr})\end{array}$ & $\begin{array}{c}\text { mass of } \mathrm{NH}_{3} \\
\text { in the feed } \\
\text { water }(\mathrm{mg} / \mathrm{hr})\end{array}$ & $\begin{array}{c}\text { Total mass of } \\
\mathrm{NH}_{3} \text { in the } \\
\text { feed water } \\
(\mathrm{mg} / \mathrm{hr})\end{array}$ & $\begin{array}{c}\mathrm{Corrected}^{+} \\
\mathrm{NH}_{4}{ }^{+}(\mathrm{aq}) \text { in } \\
\text { the feed } \\
(\mathrm{mg} / \mathrm{l})\end{array}$ \\
\hline 0 & 479.3 & 0.43 & 207.55 & 12000 & 12207.55 & 20.4 \\
\hline 4 & 928.4 & 0.26 & 245.02 & 12000 & 12245.02 & 20.4 \\
\hline 8 & 827.8 & 0.28 & 229.13 & 12000 & 12229.13 & 20.4 \\
\hline 12 & 513.1 & 0.33 & 170.95 & 12000 & 12170.95 & 20.3 \\
\hline 16 & 524.4 & 0.36 & 191.06 & 12000 & 12191.06 & 20.3 \\
\hline 20 & 548.6 & 0.42 & 227.68 & 12000 & 12227.68 & 20.4 \\
\hline 24 & 560.4 & 0.43 & 242.66 & 12000 & 12242.66 & 20.4 \\
\hline
\end{tabular}


Table 5.6.5 Henry's law coefficient variation for biofilter condition

\begin{tabular}{|c|c|c|c|c|c|c|c|}
\hline \multirow{2}{*}{$\begin{array}{l}\text { Time } \\
\text { (hr) }\end{array}$} & \multirow{2}{*}{$\begin{array}{c}\text { Temp. } \\
\left({ }^{\circ} \mathrm{K}\right)\end{array}$} & \multirow[t]{2}{*}{$\ln (\mathrm{H})$} & \multirow{2}{*}{$\begin{array}{c}\mathrm{H} \\
\text { (atm/m } 3 / \mathrm{mo} \\
\text { l) }\end{array}$} & \multirow[t]{2}{*}{$\mathrm{K}_{\mathrm{H}}(-)$} & \multicolumn{2}{|c|}{$\mathrm{NH}_{3}$ gas inlet conc. } & \multirow{2}{*}{$\begin{array}{l}\text { Equilibrium liquid } \\
\text { conc. (mg/l) }\end{array}$} \\
\hline & & & & & $\mathrm{ppm}$ & $(\mathrm{mg} / \mathrm{l})$ & \\
\hline 0 & 294 & -11.153 & $1.43 \mathrm{E}-05$ & 5.94E-04 & 90 & 0.06 & 106.2 \\
\hline 4 & 293 & -11.201 & 1.37E-05 & $5.68 \mathrm{E}-04$ & 135 & 0.10 & 166.7 \\
\hline 8 & 294 & -11.153 & 1.43E-05 & 5.94E-04 & 105 & 0.07 & 123.9 \\
\hline 12 & 294 & -11.153 & 1.43E-05 & 5.94E-04 & 90 & 0.06 & 106.2 \\
\hline 16 & 295 & -11.104 & $1.50 \mathrm{E}-05$ & $6.22 \mathrm{E}-04$ & 80 & 0.06 & 90.2 \\
\hline 20 & 295 & -11.104 & $1.50 \mathrm{E}-05$ & $6.22 \mathrm{E}-04$ & 80 & 0.06 & 90.2 \\
\hline 24 & 295 & -11.104 & $1.50 \mathrm{E}-05$ & $6.22 \mathrm{E}-04$ & 85 & 0.06 & 95.9 \\
\hline
\end{tabular}

Table 5.6.6 vapour condense water vs. temperature for the biofilter conditions

\begin{tabular}{|c|c|c|c|c|c|}
\hline $\begin{array}{c}\text { Time } \\
(\mathrm{hr})\end{array}$ & Temp. $\left({ }^{\circ} \mathrm{K}\right)$ & $\begin{array}{c}\text { Volume of air } \\
\left(\mathrm{m}^{3} / \mathrm{hr}\right)\end{array}$ & $\begin{array}{c}\text { Vapour density } \\
\left(\mathrm{g} / \mathrm{m}^{3}\right)\end{array}$ & $\begin{array}{c}\text { Mass condensed } \\
\text { water }(\mathrm{g} / \mathrm{hr})\end{array}$ & $\begin{array}{c}\text { Vol. of condensed } \\
\text { water }(\mathrm{l} / \mathrm{hr})\end{array}$ \\
\hline 0 & 308 & 3.28 & 39.8 & 130.6 & 0.13 \\
\hline 4 & 299 & 3.28 & 24.4 & 80.3 & 0.08 \\
\hline 8 & 301 & 3.28 & 27.3 & 89.8 & 0.09 \\
\hline 12 & 303 & 3.28 & 30.5 & 100.3 & 0.10 \\
\hline 16 & 307 & 3.28 & 37.7 & 124.0 & 0.12 \\
\hline 20 & 308 & 3.28 & 39.8 & 130.6 & 0.13 \\
\hline 24 & 308 & 3.28 & 39.8 & 130.6 & 0.13 \\
\hline
\end{tabular}

Table 5.6.7 $\mathrm{NH}_{4}^{+}(\mathrm{aq})$ concentration after the off gas condensed in to the potable feed water of the biofilter

\begin{tabular}{|c|c|c|c|c|c|c|}
\hline $\begin{array}{c}\text { Time } \\
(\mathrm{hr})\end{array}$ & $\begin{array}{c}\text { Equilibrium } \\
\text { liquid conc. } \\
(\mathrm{mg} / \mathrm{l})\end{array}$ & $\begin{array}{c}\text { Vol. of } \\
\text { condensed } \\
\text { water }(\mathrm{L} / \mathrm{hr})\end{array}$ & $\begin{array}{c}\text { Condensed } \\
\text { mass of } \mathrm{NH}_{3} \\
(\mathrm{mg} / \mathrm{hr})\end{array}$ & $\begin{array}{c}\text { mass of } \mathrm{NH}_{3} \\
\text { in the feed } \\
\text { water }(\mathrm{mg} / \mathrm{hr})\end{array}$ & $\begin{array}{c}\text { Total mass of } \\
\mathrm{NH}_{3} \text { in the } \\
\text { feed water } \\
(\mathrm{mg} / \mathrm{hr})\end{array}$ & $\begin{array}{c}\text { Corrected } \\
\mathrm{NH}_{4}{ }^{+}(\mathrm{aq}) \text { in } \\
\text { the feed } \\
(\mathrm{mg} / \mathrm{l})\end{array}$ \\
\hline 0 & 106.2 & 0.13 & 17.38 & 4.8 & 22.18 & 0.40 \\
\hline 4 & 166.7 & 0.08 & 16.77 & 4.8 & 21.57 & 0.35 \\
\hline 8 & 123.9 & 0.09 & 13.94 & 4.8 & 18.74 & 0.30 \\
\hline 12 & 106.2 & 0.10 & 13.34 & 4.8 & 18.14 & 0.30 \\
\hline 16 & 90.2 & 0.12 & 14.02 & 4.8 & 18.82 & 0.30 \\
\hline 20 & 90.2 & 0.13 & 14.77 & 4.8 & 19.57 & 0.30 \\
\hline 24 & 95.9 & 0.13 & 15.69 & 4.8 & 20.49 & 0.35 \\
\hline
\end{tabular}

Table 5.6.8 $\mathrm{NH}_{4}{ }^{+}$concentration after the off gas condensed in to the plant feed water of the biofilter

\begin{tabular}{|c|c|c|c|c|c|c|}
\hline $\begin{array}{c}\text { Time } \\
(\mathrm{hr})\end{array}$ & $\begin{array}{c}\text { Equilibrium } \\
\text { liquid conc. } \\
(\mathrm{mg} / \mathrm{l})\end{array}$ & $\begin{array}{c}\text { Vol. of } \\
\text { condensed } \\
\text { water }(1 / \mathrm{hr})\end{array}$ & $\begin{array}{c}\text { Condensed } \\
\text { mass of } \mathrm{NH}_{3} \\
(\mathrm{mg} / \mathrm{hr})\end{array}$ & $\begin{array}{c}\text { mass of } \mathrm{NH}_{3} \\
\text { in the feed } \\
\text { water }(\mathrm{mg} / \mathrm{hr})\end{array}$ & $\begin{array}{c}\text { Total mass of } \\
\mathrm{NH}_{3} \text { in the } \\
\text { feed water } \\
(\mathrm{mg} / \mathrm{hr})\end{array}$ & $\begin{array}{c}\text { Corrected } \\
\mathrm{NH}_{4}{ }^{+}(\mathrm{aq}) \text { in } \\
\text { the feed } \\
(\mathrm{mg} / \mathrm{l})\end{array}$ \\
\hline 0 & 106.2 & 0.13 & 17.38 & 1200 & 1217.38 & 20.3 \\
\hline 4 & 166.7 & 0.08 & 16.77 & 1200 & 1216.77 & 20.3 \\
\hline 8 & 123.9 & 0.09 & 13.94 & 1200 & 1213.94 & 20.2 \\
\hline 12 & 106.2 & 0.10 & 13.34 & 1200 & 1213.34 & 20.2 \\
\hline 16 & 90.2 & 0.12 & 14.02 & 1200 & 1214.02 & 20.2 \\
\hline 20 & 90.2 & 0.13 & 14.77 & 1200 & 1214.77 & 20.3 \\
\hline 24 & 95.9 & 0.13 & 15.69 & 1200 & 1215.69 & 20.3 \\
\hline
\end{tabular}


Based on the results shown in the tables (Tables 5.6.1 to 5.6.8), corrected $\mathrm{NH}_{4}{ }^{+}$ concentrations of the feed water were plotted along the cycle. Figures 5.6.2 and 5.6.3 show the $\mathrm{NH}_{4}{ }^{+}$feed concentrations and corrected $\mathrm{NH}_{4}{ }^{+}$concentrations after adding the condensed $\mathrm{NH}_{3}$ mass, when dynamic $\mathrm{NH}_{3}$ gas loading was applied. The condensed $\mathrm{NH}_{4}{ }^{+}$ effects are clearly shown in Figures 5.6.2 and 5.6.3. Since the experimental leachate $\mathrm{NH}_{4}{ }^{+}$concentration depended on all the biofilter processes (scrubbing and nitrification), it was not possible to compare the $\mathrm{NH}_{4}{ }^{+}$variations quantitatively. However the trend showed some effects on the above discussed similarity in the $\mathrm{N}$ compounds dynamic variations along the 24 hours cycle. Therefore, cooling down of water saturated off gases may contribute to the variations that were observed in the $\mathrm{NH}_{4}{ }^{+}$and $\mathrm{NO}_{3}{ }^{-}$concentrations along the cycle.

(a) Potable water

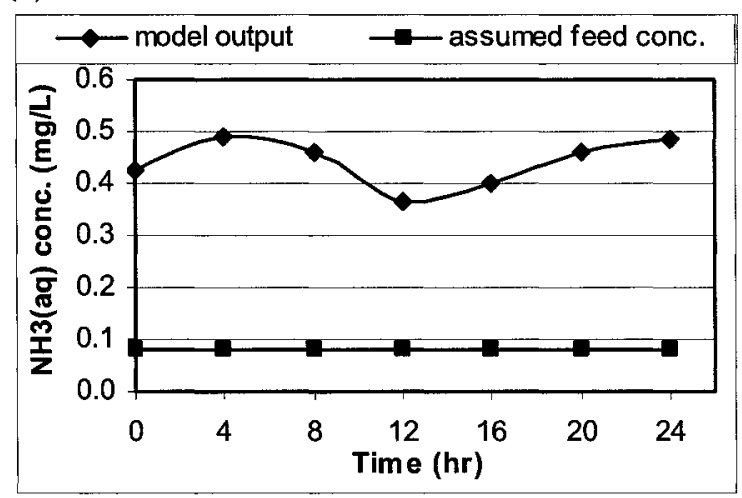

(b) Plant water

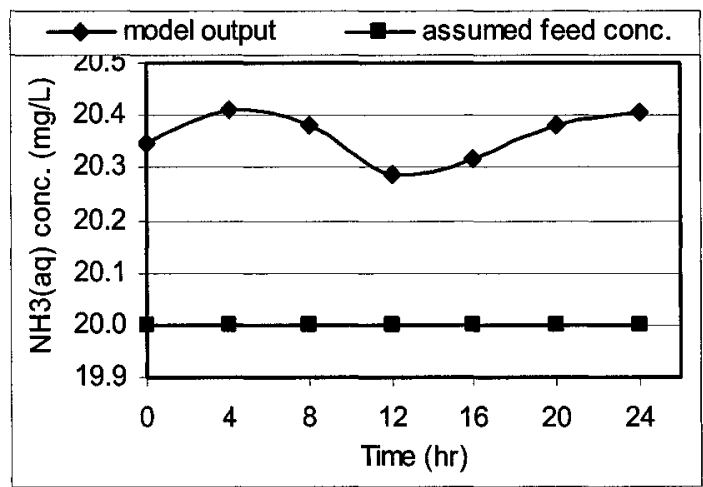

Figure 5.6.2 The predicted $\mathrm{NH}_{4}{ }^{+}$concentrations versus time after adding condensed $\mathrm{NH}_{3}$ mass in to the scrubber feed water 
(a) Potable water

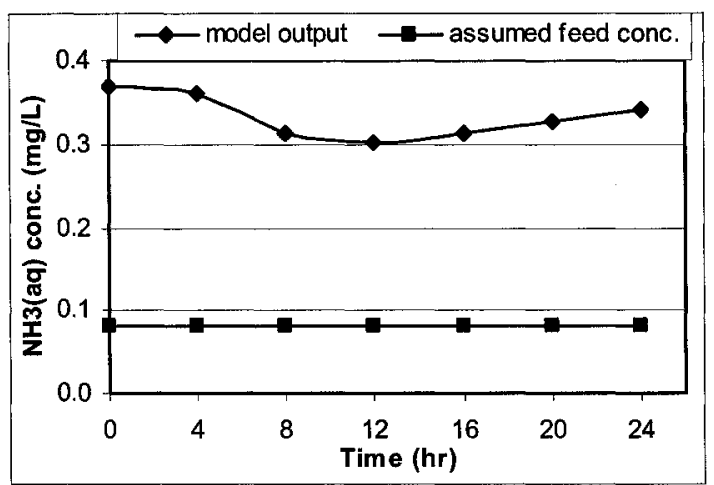

(b) Plant water

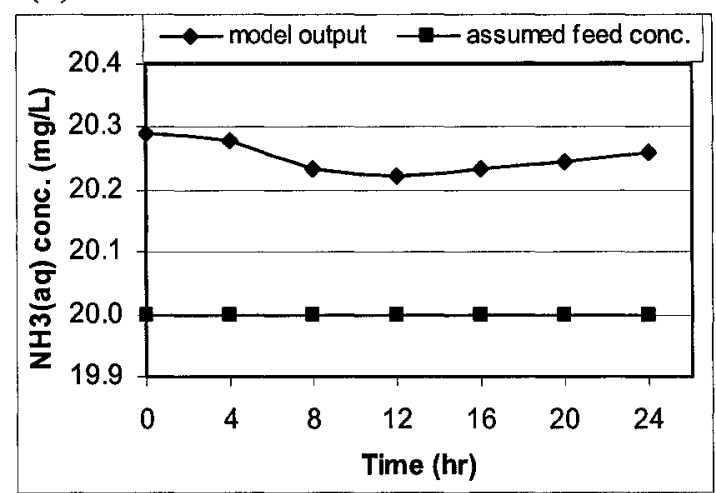

Figure 5.6.3 The predicted $\mathrm{NH}_{4}{ }^{+}$concentrations versus time after adding condensed $\mathrm{NH}_{3}$ mass into the biofilter feed water

\subsubsection{Production of other $N$ containing compounds}

As discussed in the literature review (Section 2.3.1), the possibility of $\mathrm{NO}_{\mathrm{x}}$ production in the biofilter was highly favorable when $\mathrm{NH}_{3}$ loading was high. As reported in several reports, there was a lack of mass balance of $\mathrm{N}$ across the biofilter system (Clemens and Cuhls, 2003; Malhautier et al., 2003; Sun et al., 2000). As reported by Smet et al. (2000), $41 \%$ of the $\mathrm{NH}_{3}$ input into the biofilter could neither be accounted for as mineral $\mathrm{N}$ $\left(\mathrm{NH}_{4}^{+}, \mathrm{NO}_{3}^{-}, \mathrm{NO}_{2}^{-}\right)$in the biofilter leachate nor as $\mathrm{NH}_{3}$ emitted with the treated air. This 'nitrogen gap' was attributed to gaseous losses in the form of $\mathrm{N}_{2} \mathrm{O}$ and $\mathrm{NO}_{\mathrm{x}}$. However Smet et al., (2000) did not analyze this. Clemens and Cuhls (2003) reported that on average of $26.2 \%$ of $\mathrm{NH}_{3}-\mathrm{N}$ that was removed was transformed into $\mathrm{N}_{2} \mathrm{O}-\mathrm{N}$ within the biofilter. Malhautier et al. (2003) also suggested that the $\mathrm{N}$ mass balance different in the biofilter, could be due to some gaseous $\mathrm{N}$ compounds other than $\mathrm{NH}_{3}$ gas release during the biofiltration. 
In this study, these gases $\left(\mathrm{N}_{2} \mathrm{O}\right.$ and $\left.\mathrm{NO}_{\mathrm{x}}\right)$ were not detected at significant concentrations (Section 5.3.5). However, the $\mathrm{N}$ mass balance between inlet and outlet of biofilter had a 'gap' (around $+/-30 \%$ ) in this study. It could be another possibility of $\mathrm{N}_{2}$ gas release from the biofilter. $\mathrm{NO}_{\mathrm{x}}$ compounds may be further reduced to $\mathrm{N}_{2}$ gas as the end product of the denitrification process. $\mathrm{NO}$ and $\mathrm{N}_{2} \mathrm{O}$ are products of biological denitrification and their presence in this study thus suggests the occurrence of this process. Evidence of complete reduction of $\mathrm{NO}_{2}^{-}$to $\mathrm{N}_{2} \mathrm{O}$ and $\mathrm{NO}_{\mathrm{x}}$ gases in a biofilter by a strain of Nitrosomonas europea has also been reported (Joshi et al., 2000). As stated by Joshi et al. (2000), high inlet $\mathrm{NH}_{3}$ concentrations and loading rates can lead to incomplete nitrification and accumulation of nitrite, perhaps resulting in production of low concentrations of $\mathrm{N}_{2} \mathrm{O}$ and $\mathrm{NO}_{x}$ gases.

In this study, it was not possible to measure $\mathrm{N}_{2}$ release in the biofilter. Even though $\mathrm{N}_{2} \mathrm{O}$ and $\mathrm{NO}_{\mathrm{x}}$ were not a major component in the biofilter outlet, it could be contributing to some portion of the $\mathrm{N}$ mass balance especially when $\mathrm{NH}_{3}$ gas was peaking. Because of this gaseous release when $\mathrm{NH}_{3}$ gas was peaking, it could be contributed to the critical observation that the $\mathrm{NH}_{4}{ }^{+}$and $\mathrm{NO}_{3}{ }^{-}$concentration decreased in the leachate.

The high loads of $\mathrm{NH}_{3}$ might have inhibited complete nitrification by an increased concentration of free $\mathrm{NH}_{3}$ or alternatively a high nitrification rate may have resulted in $\mathrm{NO}_{2}^{-}$accumulation and drop in $\mathrm{pH}$ (Section 2.3.1., Equation 2.5). Both processes might lead to $\mathrm{NO}_{2}^{-}$accumulation that can enhance the formation of gaseous $\mathrm{NO}_{\mathrm{x}}$ and $\mathrm{N}_{2}$. When the $\mathrm{NH}_{4}{ }^{+}$and $\mathrm{NO}_{3}{ }^{-}$concentrations decreased in a cycle, the $\mathrm{pH}$ was also decreased. As 
discussed earlier, the acid forming reactions were RSC biological oxidation, nitrification, and $\mathrm{CO}_{2}$ dissociation. However RSC loading was relatively low when compared to the $\mathrm{NH}_{3}$ loading and $\mathrm{CO}_{2}$ removal also low (as discussed in Section 5.3.2). Therefore it was believed that the nitrification was the dominant process within the acid forming reactions. However the $\mathrm{NO}_{3}{ }^{-}$concentration was relatively low in the scrubber and biofilter leachate. As discussed in the literature, the first part of the biological nitrification process (Equation 2.5) releases the $\mathrm{H}^{+}$ions with $\mathrm{NO}_{2}^{-}$. If the second part of the nitrification was inhibited by low $\mathrm{pH}$, high $\mathrm{NO}_{2}^{-}$, or high free $\mathrm{NH}_{3}$, the $\mathrm{NO}_{2}{ }^{-}$accumulation could enhanced $\mathrm{NO}_{\mathrm{x}}$ and $\mathrm{N}_{2}$ formation as well as $\mathrm{pH}$ drop. However, further control study is needed to get a better understanding about $\mathrm{NO}, \mathrm{NO}_{2}, \mathrm{~N}_{2} \mathrm{O}$ and $\mathrm{N}_{2}$ release from the biofilter, when treating high loading of $\mathrm{NH}_{3}$ gas.

For the scrubber case, $\mathrm{NO}_{\mathrm{x}}$ and $\mathrm{N}_{2}$ formation might have contributed in decreases of $\mathrm{NH}_{4}{ }^{+}(\mathrm{aq})$ when $\mathrm{NH}_{3}$ gas was peaking. In terms of $\mathrm{NO}_{\mathrm{x}}$ gas production, it is also possible in the scrubber. As shown in Figure 5.4.1, $\mathrm{NO}_{2}{ }^{-}$was in the scrubber leachate with average concentration of $0.15 \mathrm{mg} / \mathrm{l}$ while feed $\mathrm{NO}_{2}{ }^{-}$concentration was nearly zero. This was the evident that nitrification was happening in the scrubber leachate. When $\mathrm{NH}_{3}$ gas was peaking, immediate accumulation of $\mathrm{NO}_{2}{ }^{-}$as the first step of nitrification may enhance the $\mathrm{N}_{2} \mathrm{O}$ and $\mathrm{NO}_{\mathrm{x}}$ production. It is important to state here that the scrubber system had stagnant water at the bottom of the reactor. This stagnant water could make the above reaction feasible. 


\subsubsection{Effect of $\mathrm{NH}_{3}$ solubility in the presence of $\mathrm{CO}_{2}$}

The simultaneous solubility of weak electrolyte gases like $\mathrm{NH}_{3}, \mathrm{CO}_{2}$, and $\mathrm{H}_{2} \mathrm{~S}$ in aqueous solutions is known in many applications. Typical examples are ATAD off gas and sewage air in the scrubber and biofiltration process. Literature on the simultaneous solubility of $\mathrm{NH}_{3}, \mathrm{CO}_{2}$, and RSC in dynamic aqueous systems is scarce. A few articles (Pazuki et al., 2006; Rumpf et al., 1999; Thomsen and Rasmussen 1999; Kurz et al., 1995) have discussed $\mathrm{NH}_{3}, \mathrm{CO}_{2}$, and $\mathrm{H}_{2} \mathrm{O}$ complex phenomena $\left(\mathrm{NH}_{3}-\mathrm{CO}_{2}-\mathrm{H}_{2} \mathrm{O}\right.$ system). All of these studies were based on equilibrium state studies in batch systems which had reactors without continuous aqueous flow. The dissolved gases and their numerous ionic species (e.g., $\mathrm{NH}_{3}(\mathrm{aq}), \mathrm{CO}_{2}(\mathrm{aq}), \mathrm{NH}_{4}^{+}, \mathrm{HCO}_{3}{ }^{-}, \mathrm{CO}_{3}{ }^{2-}, \mathrm{H}^{+}, \mathrm{OH}^{-}, \mathrm{NH}_{2} \mathrm{COO}^{-}$) were equilibrated within the system. However in the present study, the $\mathrm{NH}_{3}-\mathrm{CO}_{2}-\mathrm{H}_{2} \mathrm{O}$ system had dynamic $\mathrm{NH}_{3}$ and $\mathrm{CO}_{2}$ variations with continuous aqueous flow. Therefore the system conditions varied significantly between the literature and the present study.

According to the literature, the simultaneous solubility of $\mathrm{NH}_{3}$ and $\mathrm{CO}_{2}$ in aqueous phases is extremely complex. This complexity is partially caused by chemical reactions in the liquid phase but is also due to the formation of solid phases (salt formation). The critical observation of $\mathrm{NH}_{4}^{+}$and $\mathrm{NO}_{3}^{-}$variation in the leachate was observed in both scrubber and biofilter systems in this study. But salt formation was unlikely to happen in the scrubber (spray tower) system. The nature of the reactor condition in this study eliminates the possibilities of formation of solid phase complex products. Therefore, the chemical reactions in the liquid phase were considered as a prime factor for the $\mathrm{NH}_{3}$ solubility changes. Due to the chemical reactions in the liquid phase and a strong 
deviation from ideal conditions, correlating and predicting the thermodynamic properties of aqueous systems containing $\mathrm{NH}_{3}$ and other gases is an extremely difficult task (Rumpf et al., 1999).

The gases (e.g., $\mathrm{NH}_{3}, \mathrm{CO}_{2}$ ) dissolve in water and form ions. In addition, the resulting ions may form new species by combining with each other. For almost all chemical compounds, which dissolve in water, there are limits to their solubility. This solubility varies when other chemical compounds are present in the aqueous solution (Pazuki et al., 2006; Rumpf et al., 1999; Thomsen and Rasmussen, 1999; Kurz et al., 1995).

The traditional solubility calculation of $\mathrm{NH}_{3}$ is based on two equilibrium processes. The first step involves interphase transport of gaseous $\mathrm{NH}_{3}$ to form an undissociated dissolved species (Equation 5.6.5).

$$
\mathrm{NH}_{3} \text { (gas) } \longleftrightarrow \mathrm{NH}_{3}(\mathrm{aq})
$$

The subsequent dissociation of this species produces ammonium ions and hydroxide ions (Equation 5.6.6).

$$
\mathrm{NH}_{3}(\mathrm{aq})+\mathrm{H}_{2} \mathrm{O} \longleftrightarrow \mathrm{NH}_{4}^{+}+\mathrm{OH}^{-}
$$

When the simultaneous addition of $\mathrm{NH}_{3}$ and $\mathrm{CO}_{2}$ occurs in an aqueous phase, a complex chemical reaction may occur. Based on the literature, a conceptual model is given in Figure 5.6.4. As shown in Figure 5.6.4, both $\mathrm{NH}_{3}$ and $\mathrm{CO}_{2}$ were dissolved in water and subsequently dissociated into ions. However, Hales and Drewes (1979) proposed a 
possible pathway which can control the $\mathrm{NH}_{3}$ solubility in the aqueous phase. They introduced an additional mechanism for escape of $\mathrm{NH}_{3}$ to the gaseous phase. Hales and Drewes (1979) proposed that the dissolved undissociated $\mathrm{NH}_{3}(\mathrm{aq})$ and $\mathrm{CO}_{2}(\mathrm{aq})$ may form an intermediate compound as shown in Equation 5.6.7.

$$
\mathrm{NH}_{3}(\mathrm{aq})+\mathrm{CO}_{2}(\mathrm{aq}) \longleftrightarrow \mathrm{NH}_{3} \mathrm{CO}_{2}(\mathrm{aq})
$$

This unstable intermediate compound subsequently escapes to the gaseous phase via the pathway shown in Equation 5.6.8.

$$
\mathrm{NH}_{3} \cdot \mathrm{CO}_{2} \text { (aq) } \longleftrightarrow \quad \mathrm{NH}_{3} \cdot \mathrm{CO}_{2} \text { (gas) }
$$

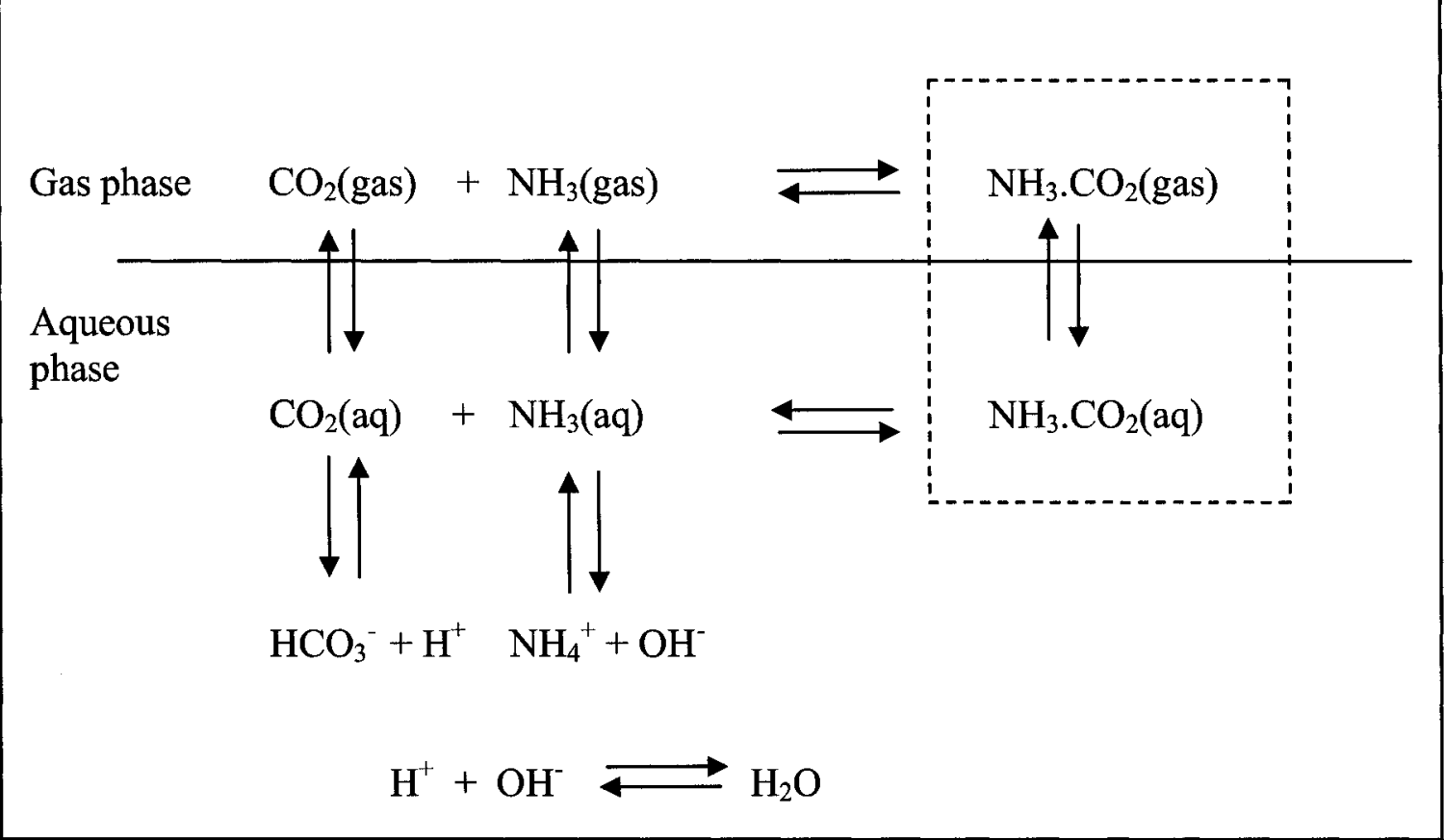

Figure 5.6.4 Conceptual model diagram for $\mathrm{NH}_{3}-\mathrm{CO}_{2}-\mathrm{H}_{2} \mathrm{O}$ system (After Hales and Drewes, 1979) 
The proposed intermediate reactions (as shown in Equations 5.6.7 and 5.6.8), may be demonstrated by carbamic acid formation within the aqueous system. In $\mathrm{NH}_{3}$ and $\mathrm{CO}_{2}$ reactions (e.g., urea production), carbamic acid is formed as a transient intermediate compound. However this compound has never been observed experimentally in general conditions (Tsipis and Karipidis, 2005). Due to its high volatility and its propensity to decompose into $\mathrm{NH}_{3}$ and $\mathrm{CO}_{2}$, carbamic acid returns to the gaseous phase. However, as reported by Tsipis and Karipidis (2005), the formation of carbamic acid and subsequent volatilization were very fast and it was believed that these reactions were in equilibrium. When $\mathrm{NH}_{3}$ and $\mathrm{CO}_{2}$ gas concentrations increase, the intermediate formation may increase and subsequently the volatilization may also increase. Therefore the resultant solubility of these gases decreases, while the gaseous concentrations simultaneously peak.

The effect of $\mathrm{NH}_{4}{ }^{+}$and $\mathrm{NO}_{3}{ }^{-}$concentration variations in this study's leachate analysis can be explained by the proposed intermediate reaction mechanism of the conceptual model. As discussed in Section 5.3.2, the $\mathrm{NH}_{3}$ and $\mathrm{CO}_{2}$ gas concentrations peaked at the same time in the cycle and the $\mathrm{NH}_{4}{ }^{+}$and $\mathrm{NO}_{3}{ }^{-}$concentration reached a minimum during that period. When $\mathrm{NH}_{3}$ and $\mathrm{CO}_{2}$ concentrations were peaking, the solubility of the gases was reduced due to the intermediate formation and subsequent volatilization. Therefore, due to the decrease in $\mathrm{NH}_{4}{ }^{+}$concentration, the $\mathrm{NO}_{3}{ }^{-}$concentration also decreased in the leachate.

In summary, the trend of $\mathrm{NH}_{4}{ }^{+}$and $\mathrm{NO}_{3}{ }^{-}$concentration variations in the leachate samples may be due to the combined effects of the cooling down of water saturated off gases, the 
production of other $\mathrm{N}$ containing compounds, and the effects of $\mathrm{NH}_{3}$ solubility in the presence of $\mathrm{CO}_{2}$.

\subsubsection{Accumulation of $N$ compound on the packing}

As discussed in Section 5.6.2, during removal of $\mathrm{NH}_{3}$ in the biofilter, the $\mathrm{NH}_{3}$ was oxidized to several $\mathrm{N}$ containing compounds. However it was not confirmed that any of these compounds accumulated within the biofilter. To verify any accumulation of $\mathrm{N}$ compound on the packing, the woodchip samples were analyzed for $\mathrm{TKN}, \mathrm{NH}_{4}{ }^{+}$and $\mathrm{NO}_{3}^{-}$. The results showed that there was no significant variation on three samples (woodchip packing from top of the biofilter, bottom of the biofilter and the fresh woodchip). The $\mathrm{NH}_{4}{ }^{+}, \mathrm{NO}_{3}{ }^{-}$and TKN concentrations varied between 0.2 and $4.7 \mu \mathrm{g}, 0.8$ and $1.1 \mu \mathrm{g}$ and 18.4 and $78 \mu \mathrm{g}$, respectively, per $1 \mathrm{~g}$ of woodchip. The fresh woodchips that were available for the packing had already been sprayed with activated sludge to use in the biofilters. Therefore it was difficult to conclude that there was significant $\mathrm{N}$ mass accumulation on the filter bed during the biofiltration process. At the same time the accumulation of compounds may vary with time in a dynamic loading system (it was not measured). Therefore the packing analysis along a cycle may help to obtain better results about the $\mathrm{N}$-compound accumulations on the packing. 


\subsection{Effects of biofilter operating conditions on performance}

In this study, four operating parameters were evaluated to identify the optimum biofilter operating conditions and corresponding removal mechanisms. The parameters were evaluated by varying them one at a time and maintaining the other operating conditions constant. The total mass of RSC was used as S loading, because for most of the events the biofilter outlet concentrations of RSCs were below the detection limits and all the RSCs biological end product was $\mathrm{SO}_{4}{ }^{2-}$ in the biofilter. The biofilter performance was evaluated based on removal efficiency and relative quantity of compounds in the gas and leachate outlets.

\subsubsection{Biofilter bed temperature}

Figure 5.7.1 presents the concentrations of $\mathrm{NH}_{4}{ }^{+}, \mathrm{NO}_{3}{ }^{-}$and $\mathrm{SO}_{4}{ }^{2-}$ in the biofilter leachate for the warm and the cold bed conditions. In this study the biofilter was operated at an EBRT of $150 \mathrm{~s}$; the source of post humidification water was potable water; the post humidification water flow was $11 / \mathrm{min}$; the bed temperature was $26^{\circ} \mathrm{C}$ for the warm bed and $5^{\circ} \mathrm{C}$ for the cold bed. The corresponding sampling events data were E44 and E6 for warm and cold bed conditions, respectively. As discussed in Section 5.3, the concentrations in the biofilter inlet gas increased rapidly after digester feeding and then declined slowly as the aeration in the digester reached the demand. As shown in Figures 5.7.1(a) and 5.7.1(c) the concentrations of $\mathrm{NH}_{4}{ }^{+}$and $\mathrm{SO}_{4}{ }^{2-}$ in the biofilter leachate were similar for both temperatures. As shown in Figure 5.7.1(d), the $\mathrm{pH}$ of the cold bed leachate was slightly lower than the warm bed leachate. However the $\mathrm{NO}_{3}{ }^{-}$ concentrations differed substantially between the warm and cold conditions. As shown in 
Figure 5.7.1(b), the $\mathrm{NO}_{3}{ }^{-}$concentration did not vary substantially with time during the cycle for the cold bed condition, however in the warm bed condition, the $\mathrm{NO}_{3}{ }^{-}$ concentration varied significantly. The $\mathrm{NO}_{3}{ }^{-}$concentration decreased shortly after the gas phase $\mathrm{NH}_{3}$ concentrations started to increase and increased later in the cycle as the gas phase $\mathrm{NH}_{3}$ concentrations decreased. As would be expected, the results indicate that the warm bed temperature increased the rate of nitrification. However as discussed in Section 5.6.2, the trend in $\mathrm{NO}_{3}{ }^{-}$concentrations during the cycle did not match the trend of $\mathrm{NH}_{3}$ gas phase concentrations.

(a)

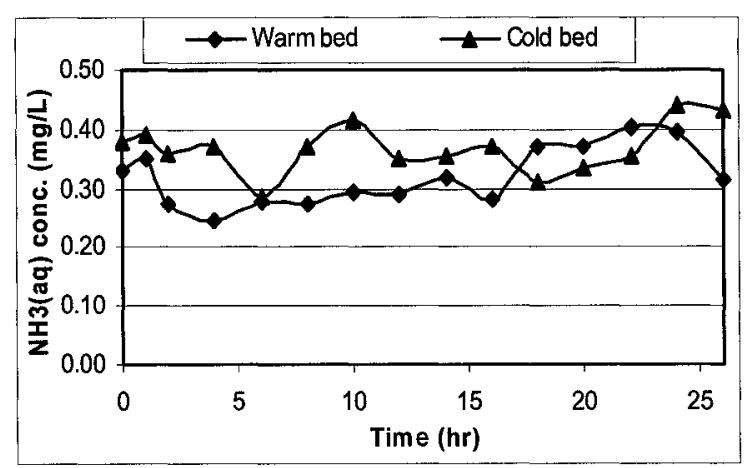

(c)

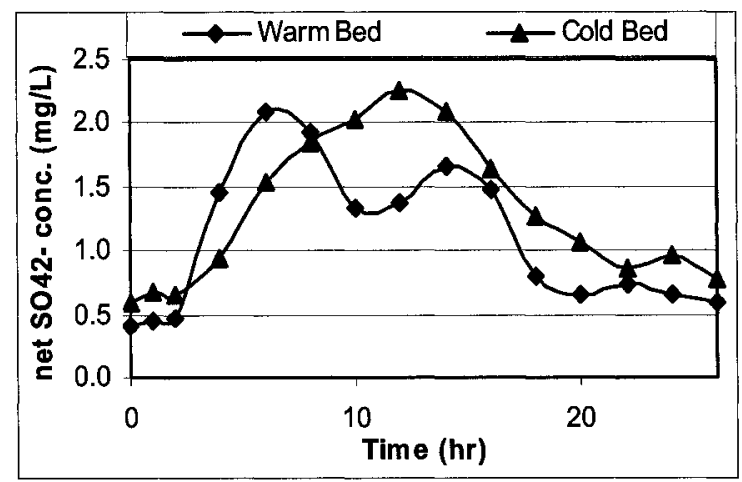

(b)

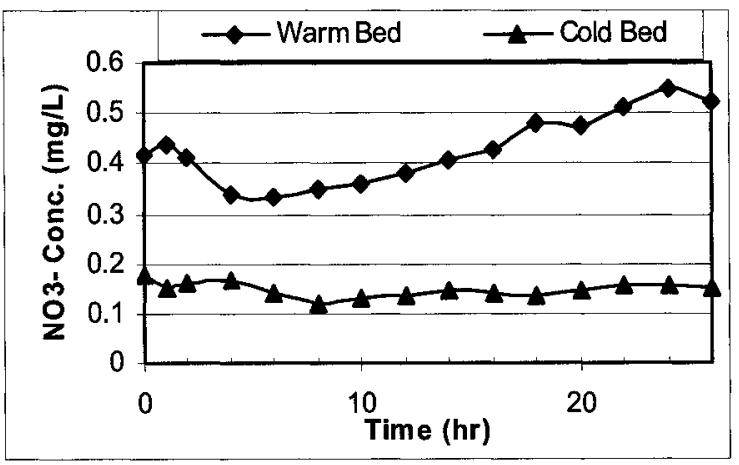

(d)

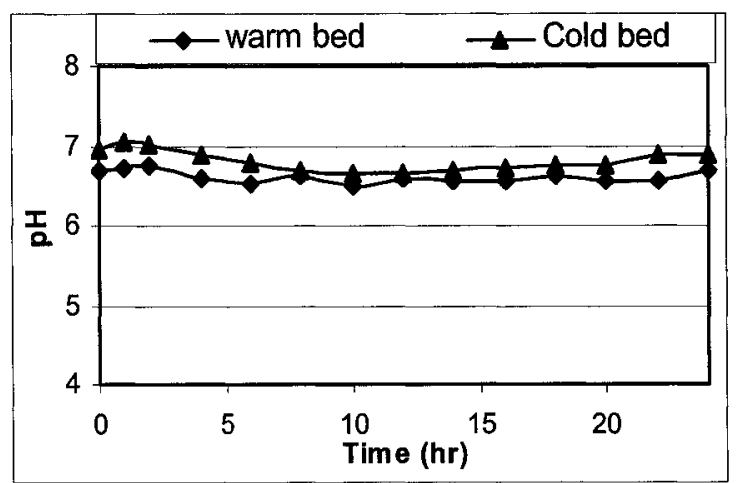

Figure 5.7.1 Concentrations of (a) $\mathrm{NH}_{4}{ }^{+}$(b) $\mathrm{NO}_{3}{ }^{-}$(c) net $\mathrm{SO}_{4}{ }^{2-}$ (d) $\mathrm{pH}$ at the biofilter leachate for the warm bed versus cold bed

The biofilter bed temperature was around $5^{\circ} \mathrm{C}$ during cold weather conditions. This temperature is below the optimal temperatures for aerobic biofilter performance (Bohn 
and Bohn, 1999; Lith et al., 1997; Swanson and Loehr, 1997; Bohn, 1991). Also the nitrifiers are temperature sensitive organisms and nitrification is a very slow process at low temperatures (e.g., $5^{\circ} \mathrm{C}$ or lower). The temperature affects the microorganisms (Nitrosomonas and Nitrobactor) growth rates (Rittmann and McCarty, 2001). Therefore the low temperature reduced the nitrification process within the biofilter.

Figure 5.7.2 shows the removal efficiencies of both total $\mathrm{S}$ and total $\mathrm{N}$ masses within the biofilter for three different operating conditions. These operating conditions were selected to show the effect of the EBRT (150 s and $40 \mathrm{~s})$ and the source of posthumidification water (potable and plant water) on different bed temperature conditions. Table 5.7.1 shows the three selected operating conditions and all these conditions were with the woodchip packing bed. As discussed in Section 4.2.6, during the cold temperature periods, the water heater was used to increase the bed temperature. However, the bed temperature was able to rise by around $10^{\circ} \mathrm{C}$. Therefore, a range of bed temperatures (from 5 to $26^{\circ} \mathrm{C}$ ) was analyzed on the biofilter bed performance. In this study, the selected bed temperatures were $5,15,20$, and $26^{\circ} \mathrm{C}$ with variations of $\pm 2{ }^{\circ} \mathrm{C}$. The removal efficiencies were calculated using the cumulative masses of the target compounds entering and leaving the biofilter over the 24 hour study period. The error bars indicated in Figure 5.7.2, show the standard deviation of the removal efficiencies for the corresponding biofilter condition. As shown in Figure 5.7.2, total mass of S removal efficiencies were almost around $80 \%$ for all conditions and the removal efficiencies varied between cold and warm conditions by less than $10 \%$. In contrast, the total $\mathrm{N}$ removal efficiencies were strongly affected by the temperature. The low removal 
efficiency (around 50\%) for the cold bed temperature $\left(\mathrm{BT} 1-5^{\circ} \mathrm{C}\right.$ and $\mathrm{BT} 2-15^{\circ} \mathrm{C}$ ) was observed in the $\mathrm{N}$ removal. It was likely due to the fact that the nitrification process was inhibited in the cold temperatures. As shown in Figure 5.7.2(c), the total S and $\mathrm{N}$ mass removal efficiencies were not significantly varied between two temperatures (20 and $26^{\circ} \mathrm{C}$ ), it may be due to the bed temperatures were close to warm condition.

Table 5.7.1 Selected biofilter conditions for the bed temperature study

\begin{tabular}{|c|c|c|c|}
\hline Conditions & EBRT (s) & Source of water & $\begin{array}{c}\text { Corresponding } \\
\text { sampling events }\end{array}$ \\
\hline BT1 & 150 & Potable & E6, E7, E44, E40 \\
\hline BT2 & 40 & Potable & E26, E13, E27, E42 \\
\hline BT3 & 150 & Plant & E47, E31, E45 \\
\hline
\end{tabular}

(a)

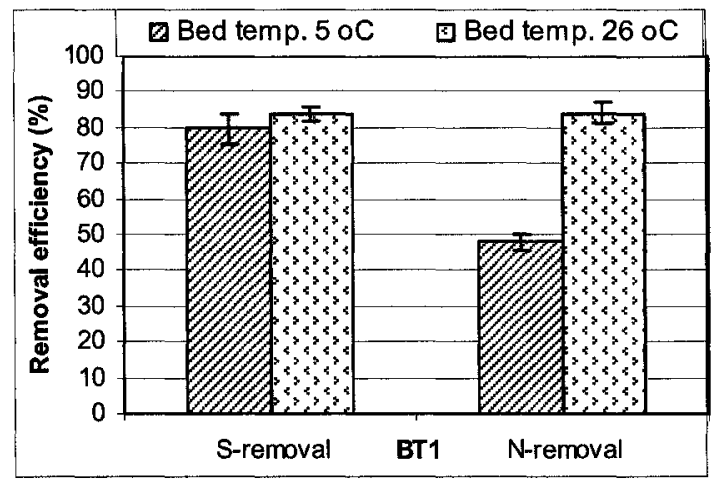

(b)

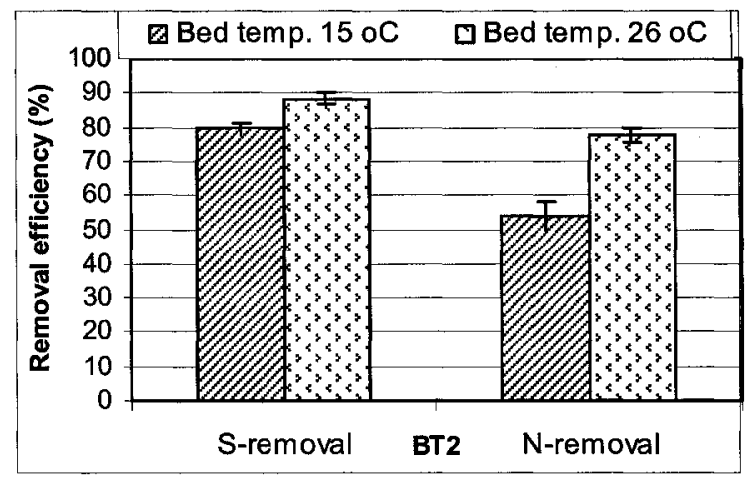

(c)

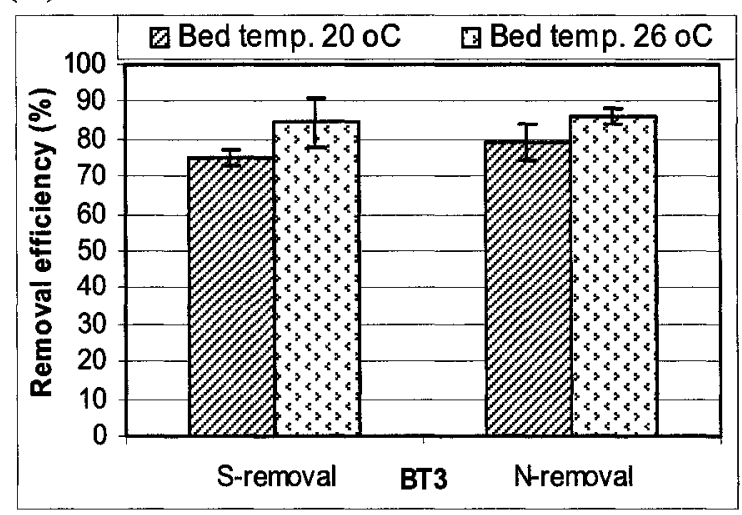

Figure 5.7.2 Effect of bed temperature on biofilter performance 
When the bed temperature was around $26^{\circ} \mathrm{C}$, total $\mathrm{S}$ removal efficiencies were more than $80 \%$ regardless of EBRT. However the total $\mathrm{N}$ removal efficiencies were more than $80 \%$ when the EBRT was $150 \mathrm{~s}$, and the total $\mathrm{N}$ removal efficiency decreased by $5-10 \%$ when the EBRT time was $40 \mathrm{~s}$ It can be stated that, the total $\mathrm{N}$ removal was affected by the EBRT; however, the total mass of $\mathrm{S}$ removal did not change significantly when EBRT was increased.

In summary, the biofilter bed temperature had impact on the biofilter removal efficiency, regardless of EBRT and source of water for the post humidification. When the bed temperature was $26^{\circ} \mathrm{C}$ and EBRT was $150^{\circ} \mathrm{C}$, more than $80 \%$ of the $\mathrm{N}$ removal was observed. However when the bed temperature was $5^{\circ} \mathrm{C}$, the $\mathrm{N}$ removal was around $50 \%$. The high bed temperature increases the nitrification process within the biofilter.

\subsubsection{Post-humidification water}

The impacts of the source of post-humidification water were analyzed in this portion of the study. Figure 5.7.3 shows the biofilter feed and leachate $\mathrm{pH}$ values along a cycle for both humidification water sources. In this study the biofilter conditions were EBRT of $150 \mathrm{~s}$; post humidification water flow rate of $1 \mathrm{l} / \mathrm{min}$; and bed temperature of $26^{\circ} \mathrm{C}$. The corresponding sampling events data were E45 and E44 for plant and potable water conditions, respectively. As shown in Figure 5.7.3(a), when plant water was used as humidification water, the biofilter feed $\mathrm{pH}$ was around 7.4 and the biofilter leachate $\mathrm{pH}$ was around 7 . When potable water was used, the biofilter feed $\mathrm{pH}$ was around 9 and the biofilter leachate $\mathrm{pH}$ was around 6.7 . 
(a)

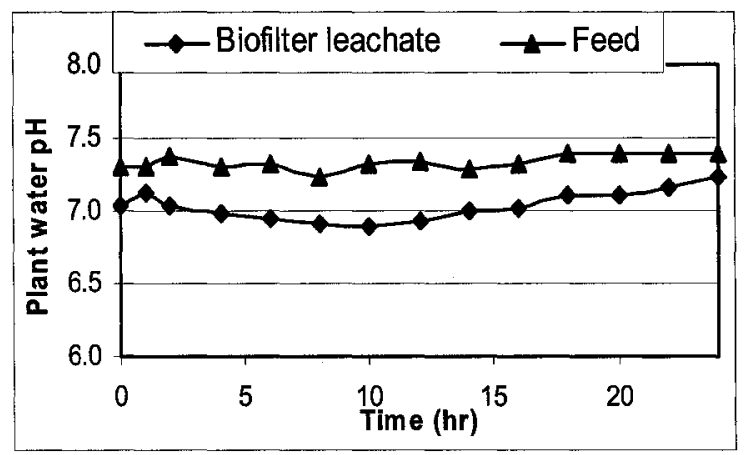

(b)

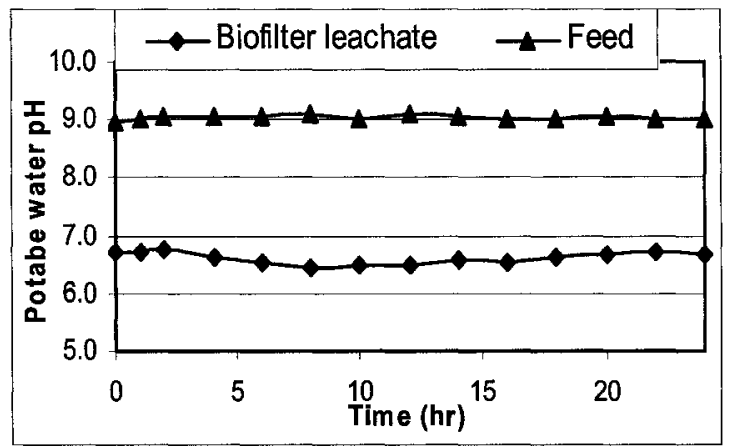

Figure 5.7.3 Feed water and biofilter leachate pH with (a) plant water and (b) potable water

As discussed in Section 2.3.1, the absorbed gas phase $\mathrm{NH}_{3}$ exists as either $\mathrm{NH}_{3(\mathrm{aq})}$ or $\mathrm{NH}_{4}{ }^{+}$. Hence the addition of $\mathrm{NH}_{3}$ to the liquid phase will tend to elevate the $\mathrm{pH}$ of the liquid. However, the decrease in $\mathrm{pH}$ was likely due to the formation of acids that resulted from the oxidation of RSC and $\mathrm{NH}_{4}^{+}$and dissociation of $\mathrm{CO}_{2}$. As discussed in the literature review, the $\mathrm{RSC}$ generates sulphuric acid, $\mathrm{NH}_{4}^{+}$generates nitric acid and $\mathrm{CO}_{2}$ generates carbonic acid. This was confirmed by the increase in concentration of these ions in the leachate (Section 5.4). The large decrease in $\mathrm{pH}$ when potable water was employed was indicative of the low buffering capacity of this water source compared to the plant water.

Figure 5.7.4 shows the $\mathrm{NH}_{4}{ }^{+}, \mathrm{NO}_{3}{ }^{-}$and $\mathrm{SO}_{4}{ }^{2-}$ concentrations in the biofilter leachate along a cycle. As shown in Figure 5.7.4(a), the plant water biofilter leachate had a relatively high concentration of $\mathrm{NH}_{4}{ }^{+}$because of the high concentration of $\mathrm{NH}_{4}{ }^{+}$in the feed water. However the trend in $\mathrm{NH}_{4}{ }^{+}$concentrations was similar for both water sources. 
(a)

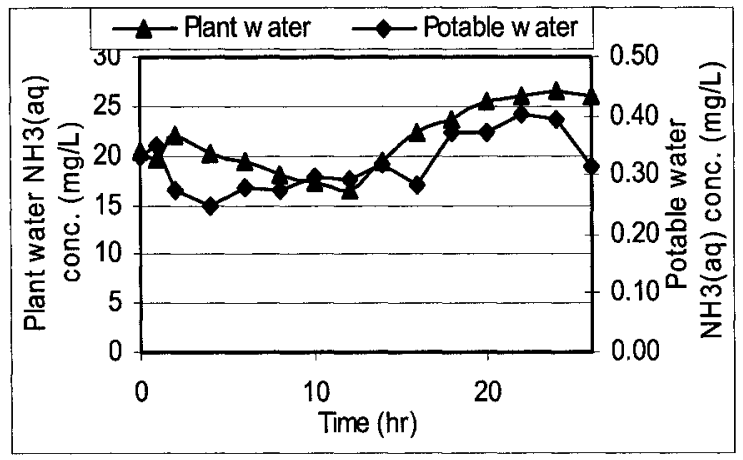

(c)

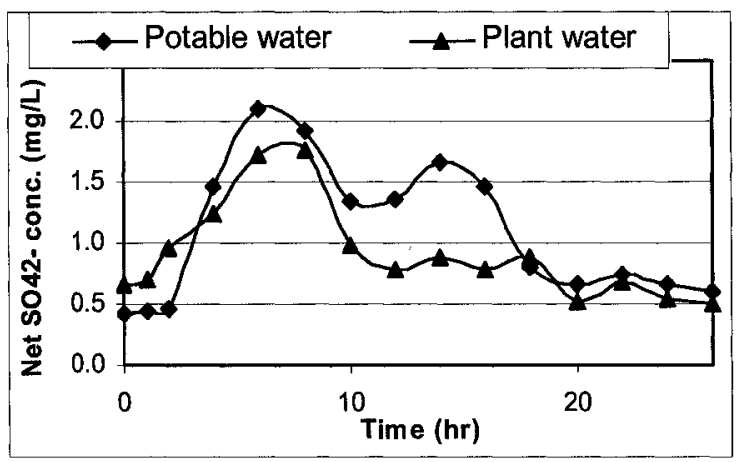

(b)

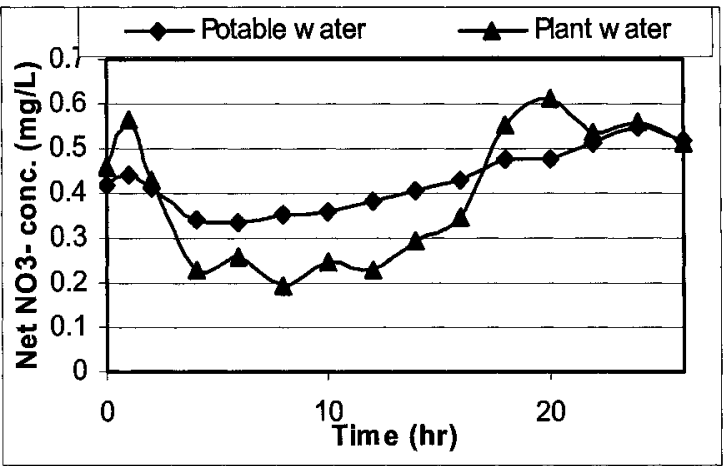

Figure 5.7.4 Biofilter leachate concentrations of (a) $\mathrm{NH}_{4}^{+}$(b) net $\mathrm{NO}_{3}{ }^{-}$(c) net $\mathrm{SO}_{4}{ }^{2-}$ for potable and plant water

Figures 5.7.4(b) and 5.7.4(c) show the net $\mathrm{NO}_{3}{ }^{-}$and $\mathrm{SO}_{4}{ }^{2-}$ concentrations in the biofilter leachate. The net concentrations were calculated by subtracting the feed concentrations from the leachate concentrations. The variation of $\mathrm{SO}_{4}{ }^{2-}$ concentrations were similar for both humidification waters. The plant water likely contained negligible concentrations of RSC and hence the variations in the leachate were due to the oxidation of the gas phase RSC. From Figure 5.7.4(b), it can be seen that the concentrations of $\mathrm{NO}_{3}^{-}$in the plant water leachate varied somewhat lower than those in the potable water leachate. However, the magnitudes of the net concentration changes were similar despite the additional $\mathrm{NH}_{4}^{+}$loading to the biofilter from the plant water. In both cases the concentrations of $\mathrm{NO}_{3}{ }^{-}$decreased while the gas phase loadings to the biofilter were 
peaking. As discussed in Section 5.6.2, this may be due to the cooling of water saturated off gases, the production of other gaseous $\mathrm{N}$ compounds and the effects of $\mathrm{NH}_{3}$ solubility in the presence of $\mathrm{CO}_{2}$.

The removal efficiencies of total $\mathrm{N}$ and total $\mathrm{S}$ in the biofilter for the different water sources are shown in Figure 5.7.5. Table 5.7.2 shows three operating conditions that were selected for this study. These operating conditions were selected to show the effect of the EBRT and the bed temperature changes on the post humidification water study. From Figure 5.7.5, it can be seen that there was little difference in the removal efficiencies of both total $\mathrm{S}$ and $\mathrm{N}$ masses in each operating condition of the biofilter. However, the removal efficiencies were slightly varied with different operating conditions (EBRT and bed temperatures). As shown in Figure 5.7.5, the biofilter condition PHW2 showed relatively better removal efficiencies for both $\mathrm{S}$ and $\mathrm{N}$, because the PHW2 condition had high EBRT (150 s) and relatively warmer bed temperature $\left(26^{\circ} \mathrm{C}\right)$.

The results suggest that the presence of the additional nutrients and microorganisms in the plant water did not stimulate the biofilter performance. However, at the time of this testing the biofilter had been operated for almost a year and the biofilm was likely well established on the woodchip packing. As described in the literature (Chapter 2), the use of plant water may be beneficial during the start-up of biofilters. However once the biofilter packing were well immobilized with microorganisms, then the source of posthumidification did not affect the removal performance. 
Table 5.7.2 Selected biofilter conditions for the source of post humidification study

\begin{tabular}{|c|c|c|c|}
\hline Conditions & EBRT (s) & Bed temperature $\left({ }^{\circ} \mathrm{C}\right)$ & $\begin{array}{c}\text { Corresponding } \\
\text { sampling events }\end{array}$ \\
\hline PHW1 & 150 & 18 & E46, E21, E47, E30 \\
\hline PHW2 & 150 & 26 & E44, E40, E45, E34 \\
\hline PHW3 & 40 & 20 & E27, E26, E29, E28 \\
\hline
\end{tabular}

(a)

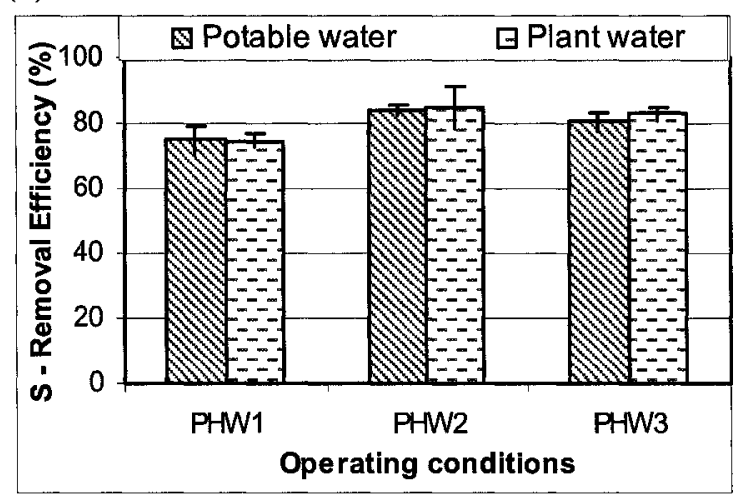

(b)

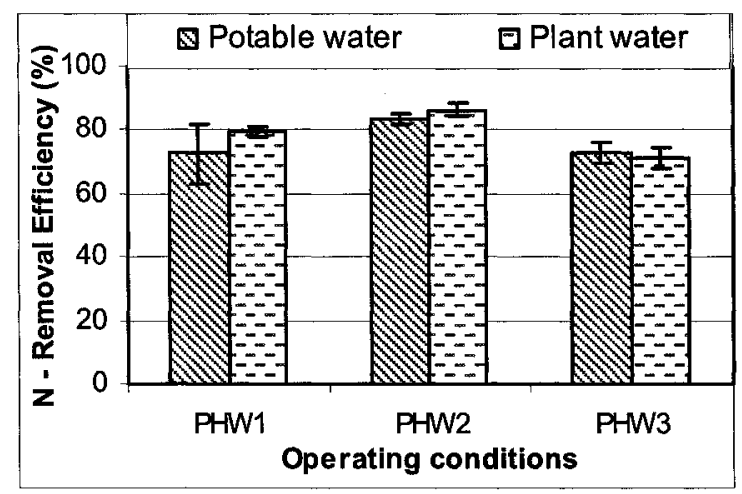

Figure 5.7.5 Source of post humidification effects on different biofilter operating conditions

\subsubsection{Biofilter bed $\mathrm{pH}$}

As reported in the literature, the biofilter bed $\mathrm{pH}$ highly influences biological reactions within the biofilter. The principle concern was that acidic bed conditions may inhibit the nitrification process. Therefore, the potential to enhance nitrification within the biofilter by maintaining an optimum bed $\mathrm{pH}$ was examined. In this study, the biofilter was operated for a period of more than one year with woodchips as a packing material and the bed $\mathrm{pH}$ was consistently below $\mathrm{pH} 7$ and occasionally below $\mathrm{pH} 6$. At the same time, relatively low $\mathrm{NH}_{3}$ removal efficiencies (especially during cold weather conditions) and relatively low nitrate concentrations were observed. 
The $\mathrm{NH}_{3}$ loading effect on the biofilter bed $\mathrm{pH}$ was analyzed based on overall sampling events data. When $\mathrm{NH}_{3}$ gas loading changed, the leachate $\mathrm{pH}$ did not change significantly. Regardless of S and N loading, the leachate $\mathrm{pH}$ was between 5.9 and 6.8 in different sampling events. It was observed that the $\mathrm{pH}$ variation in the sampling events was dependent on the feed $\mathrm{pH}$. The potable water $\mathrm{pH}$ varied significantly between 7 and 9, while the plant water had a relatively constant $\mathrm{pH}$ around 7.3. As discussed in Section 5.4, when the pollutant loading $\left(\mathrm{NH}_{3}\right.$ and $\mathrm{RSC}$ ) was peaking, the $\mathrm{pH}$ decreased by a maximum of 0.5 in the biofilter leachate.

To study the effect of $\mathrm{pH}$ on biofilter performance, crushed limestone was applied on top of the woodchip bed to raise the $\mathrm{pH}$ of the leachate. After adding crushed limestone, the biofilter was allowed to run around one month before sampling events were started. The $\mathrm{pH}$ values observed in the biofilter leachate with and without limestone addition are shown in Figure 5.7.6. The $\mathrm{pH}$ variations were similar trend for both cases. Therefore, a typical variation is shown in Figure 5.7 .6 corresponding to biofilter conditions of EBRT of $150 \mathrm{~s}$; post-humidification of plant water with the flow rate of $11 / \mathrm{min}$; and the bed temperature of $22^{\circ} \mathrm{C}$. The corresponding sampling events data were E36 and E45 for without and with limestone bed conditions, respectively. When the crushed limestone was added to the woodchips the $\mathrm{pH}$ increased by approximately 1 unit. However, a slight variation of the $\mathrm{pH}$ along the 24-hr cycle was observed and the trend was similar for both conditions. When the $\mathrm{RSC}$ and $\mathrm{NH}_{3}$ mass loadings were peaking, the $\mathrm{pH}$ value decreased slightly and then gradually increased to the average $\mathrm{pH}$ once the loadings decreased. It is clear that the addition of limestone resulted in a $\mathrm{pH}$ increase from the range that was 
marginal for nitrification (6 - 6.2) to a range that is generally considered acceptable (6.9 7.2).

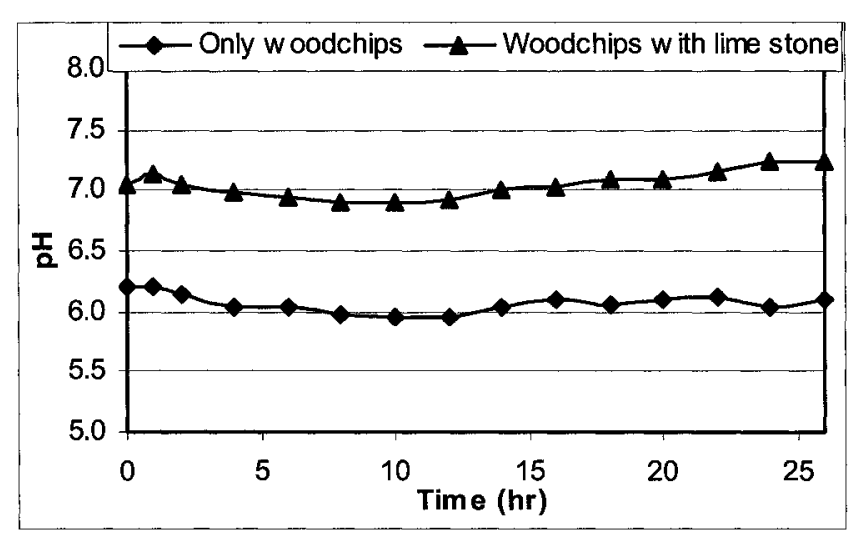

Figure 5.7.6 Biofilter leachate $\mathrm{pH}$ values for different packing conditions

Figure 5.7.7 presents the mass flows of $\mathrm{NO}_{3}{ }^{-}$and $\mathrm{SO}_{4}{ }^{2-}$ in the leachate leaving the biofilter over the duration of a cycle. From Figure 5.7.7(a), it can be seen that the mass flows of $\mathrm{NO}_{3}{ }^{-}$in the leachate were similar for the two different bed conditions. Hence, it was concluded that the rate of nitrification was not impacted by the increased bed $\mathrm{pH}$. The lack of impact of $\mathrm{pH}$ on nitrification in the biofilter was unexpected as nitrifiers are known to be sensitive to $\mathrm{pH}$ over the range of values tested. The RSC removal was not affected by adding limestone on the woodchip bed. As shown in the Figure 5.7.7(b), the mass flows of $\mathrm{SO}_{4}{ }^{2-}$ were similar for both conditions. Some of the bacteria that are responsible for oxidation of RSC are acidophiles. Hence, it could be expected that low $\mathrm{pH}$ values would have little effect on the removal of RSC. 
(a)

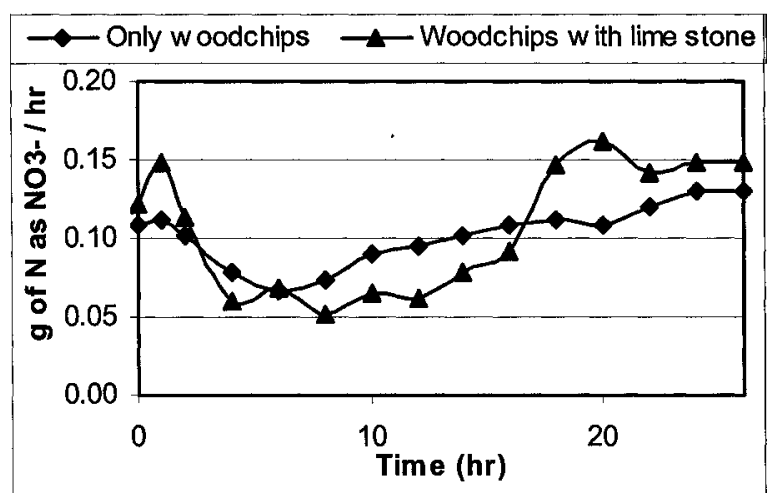

(b)

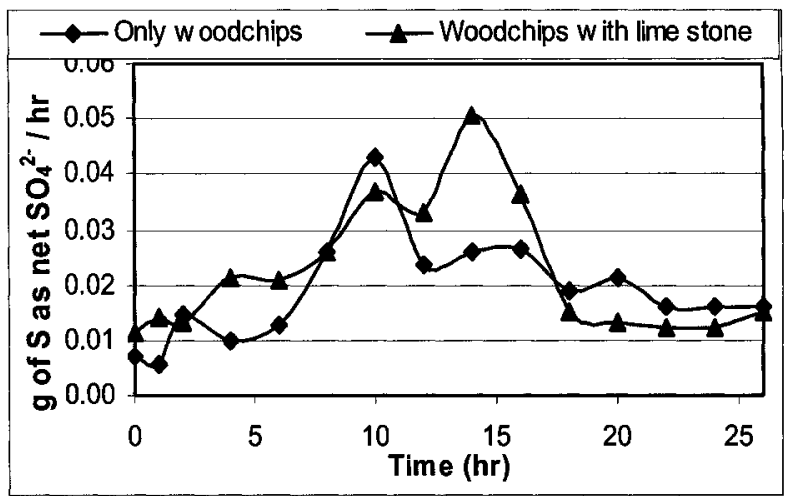

Figure 5.7.7 Leachate mass flows of (a) $\mathrm{NO}_{3}^{-}$(b) net $\mathrm{SO}_{4}{ }^{2-}$ for different packing conditions

The removal efficiencies of total $\mathrm{N}$ and total $\mathrm{S}$ in the biofilter for the different bed condition (bed $\mathrm{pH}$ ) are shown in Figure 5.7.8. Three different operating conditions were selected to show the effect of bed temperature and source of water on the bed $\mathrm{pH}$ variations. The selected biofilter operating conditions are given in Table 5.7.3. As shown in Figure 5.7.8, there were no significant effects on the $\mathrm{S}$ and $\mathrm{N}$ compounds removal efficiencies for both bed conditions when the source of water changed. When bed temperature decreased from 26 to $20^{\circ} \mathrm{C}$; the removal efficiencies of $\mathrm{S}$ and $\mathrm{N}$ also decreased by 5 to $10 \%$ on both bed $\mathrm{pH}$ conditions. However, relatively small increments in efficiencies were observed for lime and woodchips packing in most of the biofilter conditions. In summary, changes in the bed $\mathrm{pH}$ had little impact on the biofilter removal efficiency. 
Table 5.7.3 Selected biofilter conditions for the packing effects study

\begin{tabular}{|c|c|c|c|c|}
\hline Conditions & EBRT (s) & $\begin{array}{c}\text { Bed temperature } \\
\left({ }^{\circ} \mathrm{C}\right)\end{array}$ & $\begin{array}{c}\text { Source of } \\
\text { water }\end{array}$ & $\begin{array}{c}\text { Corresponding } \\
\text { sampling events }\end{array}$ \\
\hline Bed pH1 & 150 & 26 & Potable & E40, E41, E44 \\
\hline Bed pH2 & 150 & 26 & Plant & E36, E35, E45 \\
\hline Bed pH3 & 150 & 20 & Plant & E30, E31, E47 \\
\hline
\end{tabular}

(a)

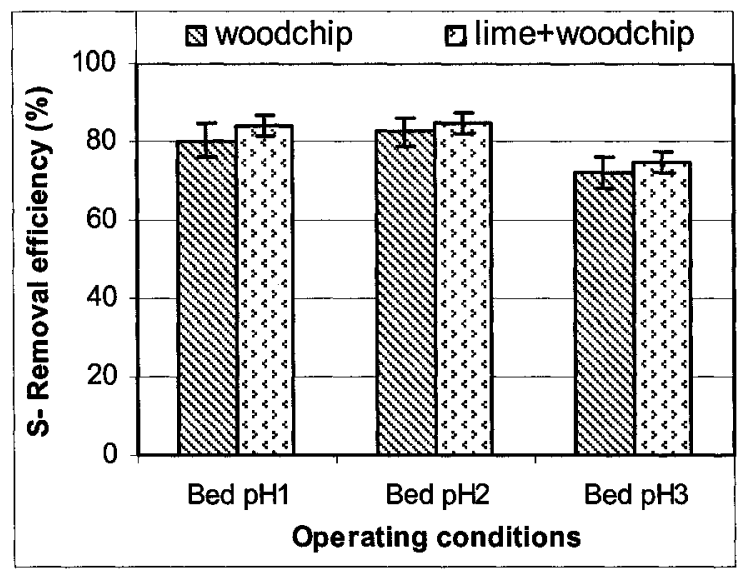

(b)

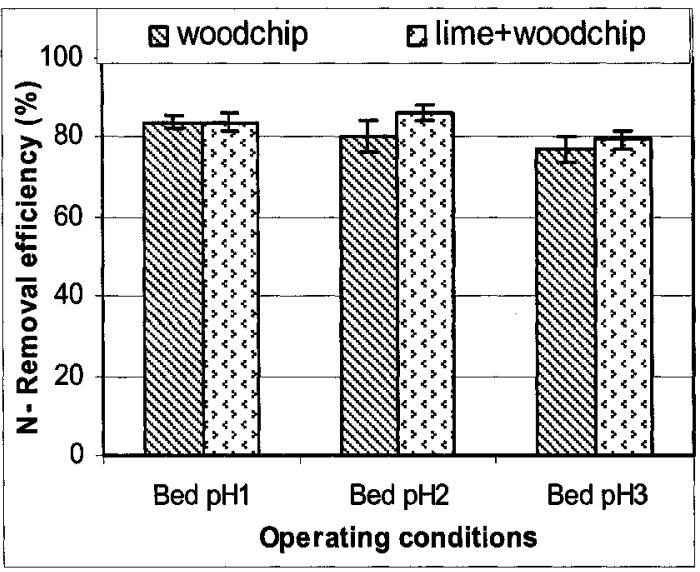

Figure 5.7.8 The packing conditions effects on different biofilter operating conditions

\subsubsection{Biofilter pollutant loading rate}

In this study, two different mass loadings of total $\mathrm{S}$ and total $\mathrm{N}$ were introduced to the three different biofilter conditions as shown in Table 5.7.4. As discussed in Section 4.2.6, the mass loading was changed by introducing make-up air to dilute the ATAD off gas. The pollutant loading was changed by controlling the air flow rate into the biofilter with the diluted off gas. The remaining ATAD off gas was released to outside the ATAD room. Figure 5.7.9 shows the pollutant mass loading and removal efficiencies for the different biofilter conditions. As shown in Figure 5.7.9 the removal efficiencies of total S did not change significantly when the loadings were increased in each condition. However, as shown in Figure 5.7.9(a), the maximum S removal efficiency of around 94\% 
was observed for the $\mathrm{S}$ loading of $1.2 \mathrm{~g} / \mathrm{d}$. This maximum S removal efficiency was obtained in PL2 loading condition because the biofilter operating conditions $($ EBRT $=$ $150 \mathrm{~s}$, bed temperature $=28^{\circ} \mathrm{C}$ ), employed in this part of the study, were believed best condition for maximum removal of pollutants.

Table 5.7.4 Selected biofilter conditions for the pollutant loading study

\begin{tabular}{|c|c|c|c|c|}
\hline $\begin{array}{c}\text { Loading } \\
\text { conditions }\end{array}$ & EBRT (s) & $\begin{array}{c}\text { Bed temperature } \\
\left({ }^{\circ} \mathrm{C}\right)\end{array}$ & $\begin{array}{c}\text { Source of } \\
\text { water }\end{array}$ & $\begin{array}{c}\text { Corresponding } \\
\text { sampling events }\end{array}$ \\
\hline PL1, PL2 & 150 & 28 & Potable & E40, E38, E41, E43 \\
\hline PL3, PL4 & 75 & 15 & Potable & E18, E22, E19, E13 \\
\hline PL5, PL6 & 150 & 22 & Plant & E36, E47, E32, E36 \\
\hline
\end{tabular}

As shown in Figure 5.7.9(e) and (f), the $\mathrm{N}$ loading difference was relatively small compared to the S loading difference in the loading conditions of PL5 and PL6. In these loading conditions, plant water was used as source of water for post-humidification. The total mass of $\mathrm{N}$ loading into the biofilter contributed by $\mathrm{NH}_{4}{ }^{+}$in the feed water and $\mathrm{NH}_{3}$ gas. Within the total mass loading, almost $24 \mathrm{~g} \mathrm{~N} / \mathrm{d}$ was from plant water $\mathrm{NH}_{4}{ }^{+}$in both loading conditions; therefore overall $\mathrm{N}$ loading difference was relatively small. 
(a)

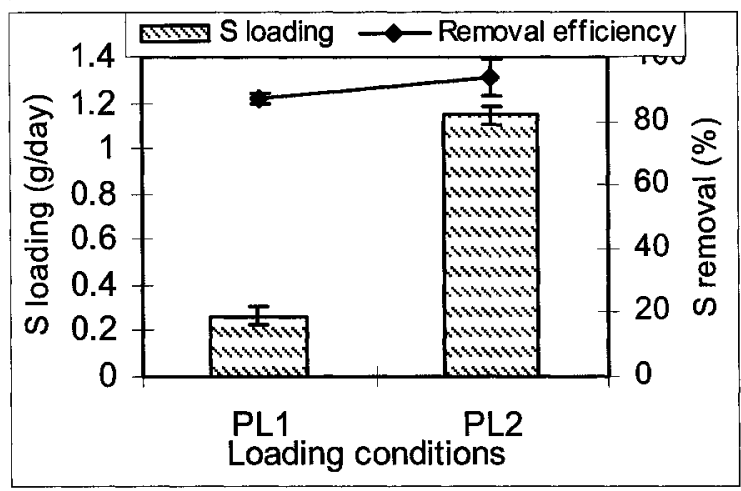

(c)

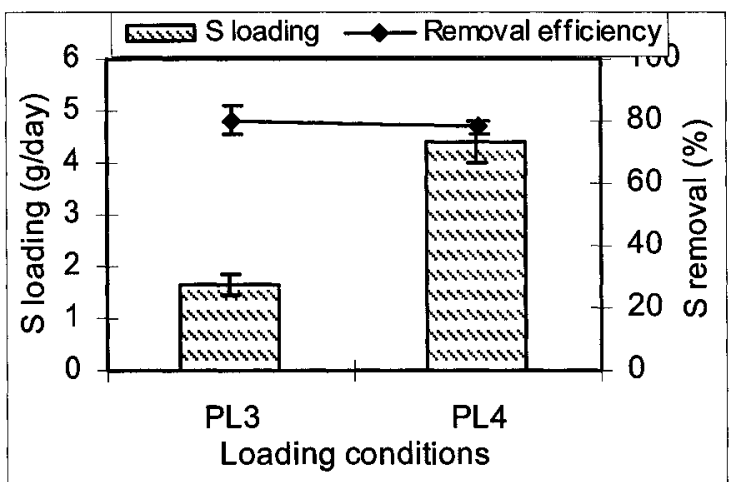

(e)

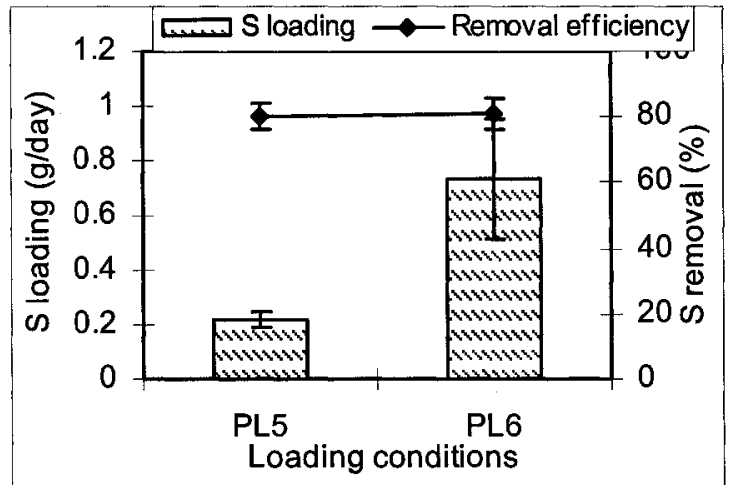

(b)

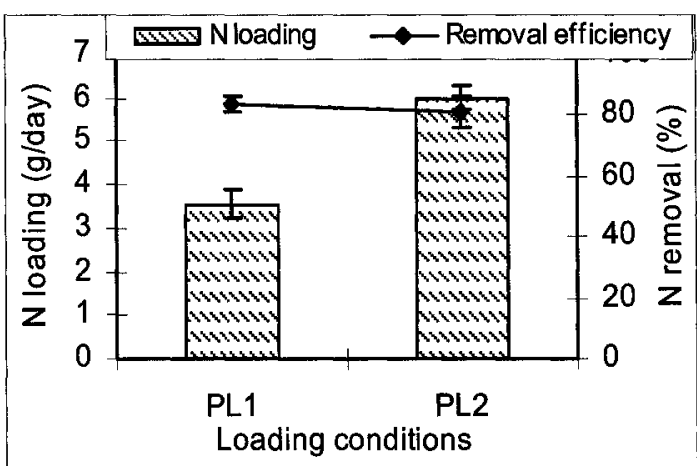

(d)

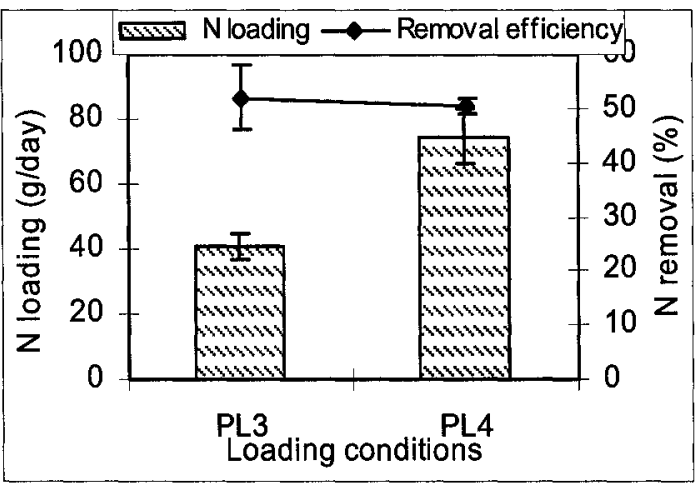

(f)

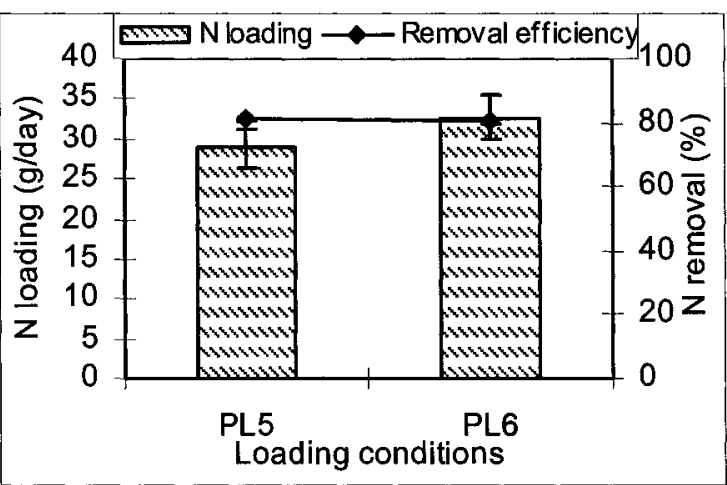

Figure 5.7.9 Biofilter pollutant loading effects for different operating conditions

As shown in Figure 5.7.9 the removal efficiencies of total $\mathrm{N}$ also did not change significantly when the $\mathrm{N}$ loadings were increased in each condition. However the removal efficiency varied significantly when the biofilter operating conditions were changed. The effect of bed temperature was discussed in Sections 5.7.1. It could be 
concluded that the biofilter removal was highly dependent on the biofilter conditions such as bed temperature and EBRT. The studied mass loadings of both $\mathrm{S}$ and $\mathrm{N}$ did not affect the removal efficiency significantly. It can be stated that the studied mass loadings of both $\mathrm{S}$ and $\mathrm{N}$ were within the elimination capacity of the respective compounds. However, as discussed in Section 5.6, the high loading of $\mathrm{NH}_{3}$ changed the removal mechanisms and it was believed that the high loading of $\mathrm{NH}_{3}$ inhibited the complete nitrification in this study. 


\section{Chapter \\ Six}

\section{Biofilter Model Development}

\subsection{Introduction}

Early biofilter studies have addressed modeling of biofilter performance based on mostly single pollutant and/or a set of similar pollutants (i.e., VOC) removal. As stated in Section 2.5 , there have been a number of modeling developments since the early $1980 \mathrm{~s}$. However there is a little information to describe the dynamic biofilter model studies. Since the biofiltration is a complex process, the objectives of the modeling studies are to organize experimental data and to understand simple relationships between parameters such as biological activity, pollutant removal, etc. An important part of this study was to develop a dynamic biofilter model to describe the biofilter performance for a complex gas mixture. The model was calibrated using the pilot plant experimental data.

The objective of this portion of study was to establish a mathematical description of processes important in dynamic biofiltration. The model that was developed in this study, describes transport, physical, chemical and biological processes that occur during biofiltration. As air passes through the filter, advection, absorption, diffusion, and reaction affect contaminant removal. The model focused on the impact of various parameters on biofilter performance and captured the essential features of its dynamics while ensuring unambiguous estimates of the model parameters. 


\subsection{Model development}

Mathematical interpretations were developed based on various physical, chemical, and biological processes. These interpretations were incorporated into equations that described the relevant phases and processes. In this study, a computer program called AQUASIM was used to integrate the equations for the various processes. The AQUASIM offers an open structure for the description of the biological, physical and chemical processes. This was therefore the most appropriate tool to solve a complex system of equations using a step-by-step approach. Once the model is defined by the user, the AQUASIM program offers the possibilities to perform simulations, sensitivity analyses and parameter estimations.

AQUASIM was initially developed by Swiss Federal Institute for Environmental Science and Technology (EAWAG) to analyze water based systems such as activated sludge and anaerobic digester. However, it is demonstrated in this study that it can be used to model systems with multiple phases such as biofilters.

\subsubsection{Model concept}

The fundamental concepts of the model are shown schematically in Figure 6.1. For modeling purposes, the biofilter height was divided into eight layers. Within each layer, two main zones are considered: the gas phase, and the biofilm/water phase. Such zones are called compartments. The compartments can be combined to more complicated configurations with the aid of the links which are two types: convective links and 
diffusive links. Therefore the biofilter system was divided into compartments based on their phases and layers then connected with appropriate links.

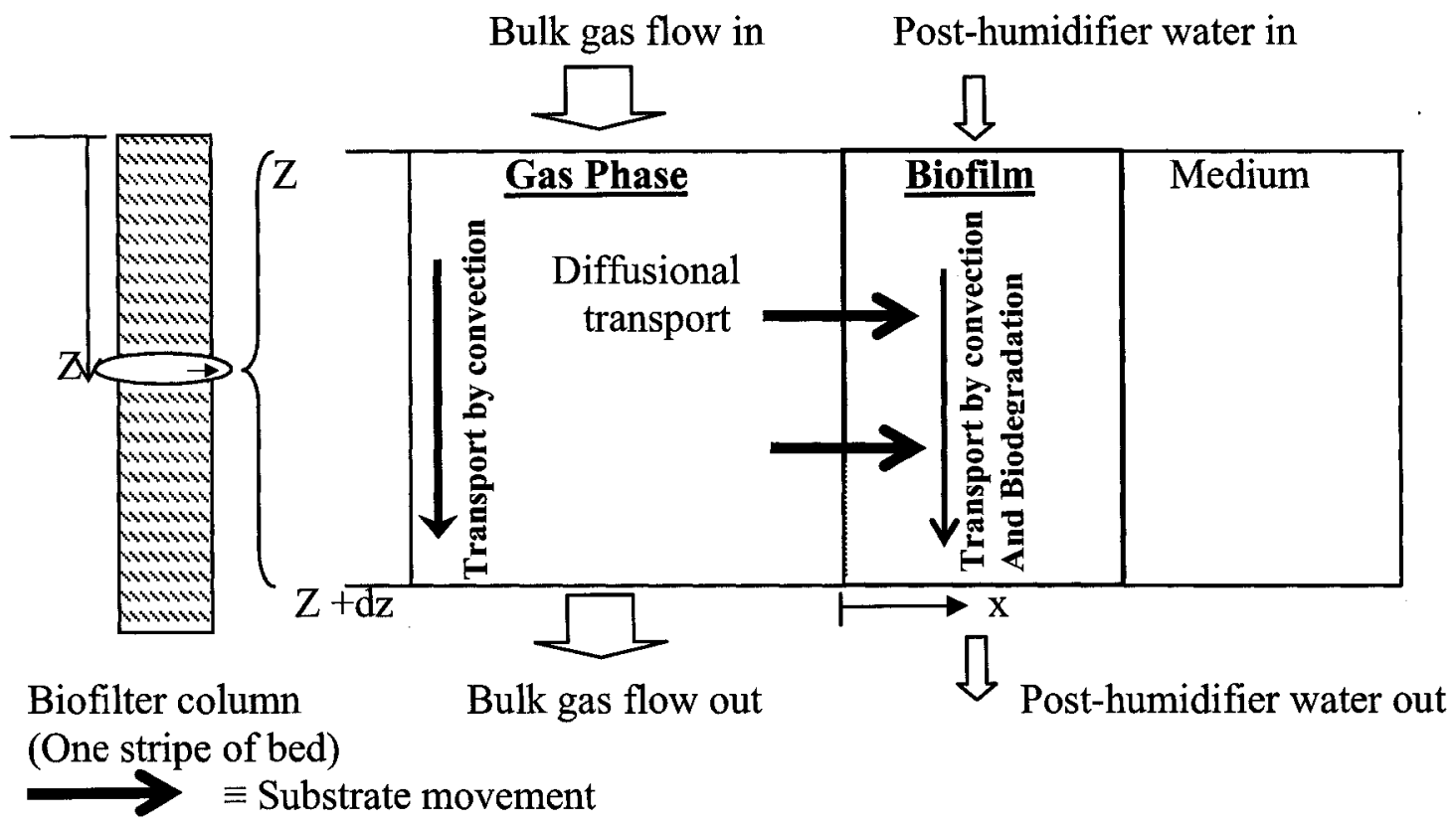

Figure 6.1 Schematic representations of model concepts

Figure 6.2 shows schematic representations of two compartments in a single layer of the biofilter. Based on AQUASIM system, mixed reactors, and biofilm reactors are suitable compartments types for this study as shown in Figure 6.2. The gas phase zone was considered as mixed flow reactor and biofilm/water zone was considered as biofilm reactor. The biofilm reactor compartment consists of three zones: bulk fluid, biofilm solid matrix, and biofilm pore water. The bulk fluid is assumed to be completely mixed and a liquid boundary layer between the biofilm and bulk fluid can be considered. A plug flow biofilm reactor can be modeled by a series of connected biofilm reactor compartments using a convective link, which is used to model convective mass fluxes between two reactor compartments. In this biofilm reactor, mass transfer in the flow direction occurs 
only between the bulk fluid zones of the compartments, while diffusional transport in the biofilm occurs only in the direction perpendicular to the biofilm surface.

Phase:

Compartment:

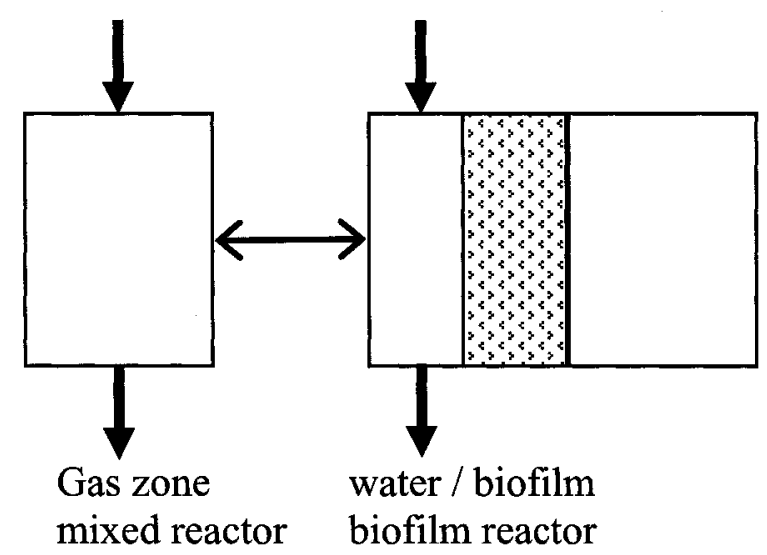

Convective link

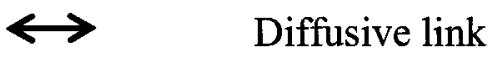

Figure 6.2 Schematic representations of model for one layer

In addition to the spatial configuration of the system described by compartments and links, the interactions within the system have to be represented by elements of the program. Two types of processes can be configured in AQUASIM. Equilibrium processes are used to describe very fast processes while dynamic processes are used to describe transformation processes, the dynamics of which are of importance on the time scale examined. Other important elements are variables representing substance concentrations, model parameters, growth rates, constants, etc. These elements are presented and defined in subsequent sections. Types and categories of variables and more structural definitions of AQUASIM systems were given in the AQUASIM user manual (Reichert, 1998). 


\subsubsection{Basic assumptions for a structured model development}

The model was developed based on the following assumptions:

* An axial dispersed plug flow is assumed for the gas flow through the packed bed.

* The frictional pressure drop is assumed to be negligible. The gas phase volume and volumetric flow rate are constant along the column

* Pollutant transport at the gas/biofilm interface is a rate-limited process. Since this study is based on dynamic pollutant variations, it is assumed that the pollutant loading is higher than the maximum elimination capacity. No reaction free zone exists within the biofilm.

* Biodegradation of the pollutant occurs aerobically in the biofilm. When a relatively high porous medium (woodchip) is used in this aerobic biofilter, it is assumed that the air stream passes through the entire woodchip surface.

* It is assumed that the gas stream has enough oxygen for the biodegradations. Oxygen limitation does not occur in the biofilm.

* The rate of biodegradation depends on concentrations of the pollutants. The rate equations are defined in Table 6.1.

* It is assumed that transport of pollutants within the biofilm occurs through diffusion perpendicular to the biofilter axis and through convective mass transfer by bulk fluid along the axis. These transport assumptions are made to reduce the complexity of the model development even though it seems contradictory to experimental observations which show that some biofilm consist of three dimensional transports.

* The packing material is entirely covered with the biofilm. This assumption is based on previous long-term biofilter studies with woodchip packing. 
The pollutants may transport into the filter media by diffusion, however, the filter media was not analyzed in this study. Since there was no experimental data for the filter media along the dynamic cycle, it would have been difficult to calibrate and validate model parameters.

\subsubsection{Contaminants analysis: governing equations}

The mass balance for a gas mixed reactor compartment (Figure 6.2) was obtained by adding the convective transport terms and the interfacial mass transport terms and equating the sum to contaminant mass accumulation in the mixed reactor compartment volume. The contaminants were transported by convection along the biofilter (zdirection). Interfacial transport from the gas phase to the liquid/biofilm phase took place perpendicular to the biofilm surface (x-direction). The initial condition (I.C.) and the boundary condition (B.C.) are given followed by the equation. The proposed model equation for the gas phase system is as follows,

$\frac{\partial C_{g i}}{\partial t}=-v_{g} \frac{\partial C_{g i}}{\partial Z}-K l a_{i} *\left(\frac{C_{g i}}{H_{i}}-C_{l i}\right)$

I.C.: $\mathrm{C}_{\mathrm{gi}}(\mathrm{z}, \mathrm{t}=0)=\mathrm{C}_{\mathrm{gi} \_}$ini $\quad$ B.C.: $\mathrm{C}_{\mathrm{gi}}(\mathrm{z}=0, \mathrm{t})=\mathrm{C}_{\mathrm{gi} \_}$inlet

The mechanisms that were incorporated in the bulk fluid of the biofilm compartment were mass transport by convective flow in the biofilm bulk fluid, interfacial mass transport from the gas phase, and mass flux into the biofilm matrix. The proposed model equation for biofilm bulk volume analysis is as follows,

$\frac{\partial C_{l i}}{\partial t}=-v_{l} \frac{\partial C_{l i}}{\partial Z}+K l a_{i} *\left(\frac{C_{g i}}{H_{i}}-C_{l i}\right)+A_{S} * N$ 
I.C.: $\mathrm{C}_{\mathrm{li}}(\mathrm{z}, \mathrm{t}=0)=\mathrm{C}_{\mathrm{li} \_}$ini $\quad$ B.C.: $\mathrm{C}_{\mathrm{li}}(\mathrm{z}=0, \mathrm{t})=\mathrm{C}_{\mathrm{li} \_}$inlet

$\mathrm{N}$ is the mass flux into the biofilm solid matrix from biofilm bulk volume and $\mathrm{N}$ is defined by Fick's law as shown in Equation 6.3.

$$
N=D_{b i} \frac{\partial C_{b i}}{\partial X}
$$

The mechanisms that were incorporated in the biofilm matrix of the biofilm compartment were internal diffusion in the biofilm and biological reaction in the biofilm. The proposed model equation for the biofilm matrix analysis is as follows,

$$
\frac{\partial C_{b i}}{\partial t}=D_{b i} \frac{\partial^{2} C_{b i}}{\partial X^{2}}-R_{i b f}
$$
I.C.: $\mathrm{C}_{\mathrm{bi}}(\mathrm{z}, \mathrm{t}=0)=\mathrm{C}_{\mathrm{bi}}$ ini
B.C. (1): $x=\delta, \frac{\partial C_{b i}}{\partial X}=0$

B.C. (2): continuity conditions at the biofilm surface, mass flux due to $\mathrm{C}_{\mathrm{li}}=$ mass flux due to $\mathrm{C}_{\mathrm{bi}}$

\subsubsection{Contaminants degradation}

The objective of this investigation was to demonstrate the process mechanisms in the biofilter system. In this model study, $\mathrm{NH}_{3}, \mathrm{DMDS}$ and $\mathrm{CO}_{2}$ were chosen as a mixture of pollutant in the gas phase loading. The model that predicts the concentrations of the end products such as $\mathrm{NH}_{3}(\mathrm{aq}), \mathrm{NO}_{3}{ }^{-}, \mathrm{SO}_{4}{ }^{2-}$ and $\mathrm{pH}$, was developed based on appropriate removal mechanisms and rate equations. The variables of interest in gas phase were $\mathrm{NH}_{3}$ and DMDS. As DMDS was the only RSC that was detected in all sampling events, DMDS was selected to represent the total mass of $S$ in the inlet and outlet of the gas phase RSC. Individual RSCs were not considered in this model study to reduce the complexity of the model process. The variables of interest in the aqueous phase were 
$\mathrm{NH}_{4}^{+}(\mathrm{aq}), \mathrm{NH}_{3}(\mathrm{aq}), \mathrm{NO}_{3}^{-}, \mathrm{SO}_{4}{ }^{2-}$, and $\mathrm{pH} . \mathrm{CO}_{2}(\mathrm{aq})$ and $\mathrm{HCO}_{3}^{-}$were not considered as variables of interest because there was no experimental data to calibrate the model output of these two variables. However $\mathrm{CO}_{2}(\mathrm{aq})$ and $\mathrm{HCO}_{3}{ }^{-}$were incorporated with model calculations to predict other variables. $\mathrm{X}_{\mathrm{N}}, \mathrm{X}_{\mathrm{S}}$ and $\mathrm{X}_{\mathrm{H}}$ were concentrations of nitrifying biomass, sulfur oxidizing biomass and heterotroph biomass, respectively. When $\mathrm{X}_{\mathrm{H}}$ decayed within the biofilm, one portion of biomass became inert biomass $\left(\mathrm{X}_{\mathrm{i}}\right)$, while the remaining portion became soluble biomass $\left(\mathrm{X}_{\mathrm{sp}}\right)$, which is converted to soluble substrate $\left(\mathrm{C}_{\mathrm{sp}}\right)$ for the heterotrophs. The rate equations were developed for each of the reactions. A summary of the reactions and their rate equations are given in Table 6.1.

Table 6.1 shows the processes that were considered in the model study, the corresponding rate equations and the references. Degradation of $\mathrm{NH}_{4}{ }^{+}$in the biofilm was represented by Andrews kinetic expression. As discussed in the Chapter 5, high loading of $\mathrm{NH}_{3}$ may inhibit the degradation process. An appropriate kinetic expression with loading inhibition was included for the biodegradation of $\mathrm{NH}_{4}{ }^{+}$(Shareefdeen and Baltzis, 1994a; Baquerizo et al., 2004). The degradation of DMDS was represented by a single Monod type expression because the DMDS loading was relatively low and other limitations were neglected. Li et al. (2003) proposed a similar expression for $\mathrm{H}_{2} \mathrm{~S}$ and MM biodegradation.

Table 6.2 shows the model process with corresponding stoichiometric matrix. The stoichiometric coefficients for Uptake_NH4, Uptake_DMDS and other processes were chosen from Rittmann and McCarty (2001), Smith and Kelly (1988b) and the corresponding references as shown in Table 6.1, respectively. When Uptake_NH4 and 
Uptake_DMDS processes were considered, both processes were autotrophic reactions. As shown in Table 6.2, the stoichiometric coefficient for $\mathrm{CO}_{2}$ in Uptake_NH4 process was 0.41 while in Uptake_DMDS process was +0.94. This was due to the fact that the DMDS oxidized to $\mathrm{CO}_{2}$ and $\mathrm{SO}_{4}{ }^{-2}$ in the biofilter as shown in the proposed mechanism of oxidation of DMDS by microorganisms (Figure 2.6).

Heterotrophic biomass grows on soluble polymers formed by the hydrolysis of dead biomass entrapped in the biofilm and other trace organic pollutants. However in this study, the soluble substrate refers to only the soluble polymers formed by the hydrolysis of dead biomass. The growth of heterotrophs was also represented by a single Monod type expression as proposed by Arcangeli and Arvin (1999). The hydrolysis processes were represented by first-order rate equations with respect to biomass concentrations (Arcangeli and Arvin, 1999). The biomass decay processes were also represented by a first-order rate equation corresponding to the respective biomass concentrations as proposed by Batstone et al. (2002). $\mathrm{NH}_{3}$ and $\mathrm{CO}_{2}$ dissociation processes were represented by dynamic rate equations as shown in the Table 6.1. Batstone et al. (2002) also discussed a similar dynamic rate equation for the dissociation of $\mathrm{CO}_{2}$ in aqueous phase, based on a dissociation constant $\left(\mathrm{Ka} \_\mathrm{CO} 2\right)$ and kinetic rate constant (KAB_CO2). 
Table 6.1 A summary of processes and rate equations used in the model

\begin{tabular}{|c|c|c|c|}
\hline Description & Process & Rate equation & Reference \\
\hline $\begin{array}{l}\text { Degradation } \\
\text { of } \mathrm{NH}_{4}\end{array}$ & $\begin{array}{l}\text { Uptake_ } \\
\text { NH4 }\end{array}$ & $R_{1}=\frac{\mu_{\max -N H 4} * C_{N H 4} * X_{N}}{K_{s_{-} N H 4}+C_{N H 4}+\left(C_{N H 4}{ }^{\wedge} 2 / K_{I_{-} N}\right)}$ & $\begin{array}{l}\text { Shareefdeen } \\
\text { and Baltzis., } \\
\text { 1994a; } \\
\text { Baquerizo et al., } \\
2004\end{array}$ \\
\hline $\begin{array}{l}\text { Degradation } \\
\text { of RSC }\end{array}$ & $\begin{array}{l}\text { Uptake } \\
\text { DMDS }\end{array}$ & $R_{2}=\frac{\mu_{\max \_D M D S} * C_{D M D S} * X_{S}}{K_{s_{-} D M D S}+C_{D M D S}}$ & Li et al., 2003 \\
\hline $\begin{array}{l}\text { Degradation } \\
\text { of soluble } \\
\text { substrate }\end{array}$ & Uptake_Hsp & $R_{3}=\frac{\mu_{\max _{-} H} * C_{S P} * X_{H}}{K_{s_{-} S P}+C_{S P}}$ & $\begin{array}{l}\text { Arcangeli and } \\
\text { Arvin, } 1999\end{array}$ \\
\hline $\begin{array}{l}\text { Endogenous } \\
\text { decay of } X_{N}\end{array}$ & Decay_ $X_{N}$ & $R_{4}=K_{d \_N} * X_{N}$ & $\begin{array}{l}\text { Batstone et al., } \\
2002\end{array}$ \\
\hline $\begin{array}{l}\text { Endogenous } \\
\text { decay of } \mathrm{X}_{\mathrm{S}}\end{array}$ & Decay_X $X_{S}$ & $R_{5}=K_{d S} * X_{S}$ & $\begin{array}{l}\text { Batstone et al., } \\
2002\end{array}$ \\
\hline $\begin{array}{l}\text { Endogenous } \\
\text { decay of } \mathrm{X}_{\mathrm{H}}\end{array}$ & Decay_X $X_{H}$ & $R_{6}=K_{d \_H} * X_{H}$ & $\begin{array}{l}\text { Arcangeli and } \\
\text { Arvin, } 1999\end{array}$ \\
\hline $\begin{array}{l}\text { Dissociation } \\
\text { of } \mathrm{NH}_{3}\end{array}$ & dis_NH3 & $R_{7}=K_{A B_{-} N H 3} *\left(C_{-} N H 3 * L i q_{-} H_{i o n}-K a_{-N H 4} * C_{-N H 4}\right)$ & $\begin{array}{l}\text { Batstone et al., } \\
2002\end{array}$ \\
\hline $\begin{array}{l}\text { Dissociation } \\
\text { of } \mathrm{CO}_{2}\end{array}$ & dis_CO2 & $R_{8}=K_{A B_{-} \mathrm{CO}_{2}} *\left(C_{-} \mathrm{HCO}{ }^{*} \mathrm{Liq}{ }_{-} H_{\text {ion }}-\mathrm{Ka}_{-} \mathrm{CO} 2{ }^{*} \mathrm{C}_{-} \mathrm{CO} 2\right)$ & $\begin{array}{l}\text { Batstone et al., } \\
2002\end{array}$ \\
\hline $\begin{array}{l}\text { Hydrolysis } \\
\text { reaction }\end{array}$ & Hydro_sp & $R_{g}=K_{H} * X_{H}$ & $\begin{array}{l}\text { Arcangeli and } \\
\text { Arvin, } 1999\end{array}$ \\
\hline
\end{tabular}


Table 6.2 The model process and stoichiometric matrix

\begin{tabular}{|c|c|c|c|c|c|c|c|c|c|c|c|c|c|c|}
\hline Process & $\begin{array}{l}\mathbf{Z}_{1} \\
u^{\prime}\end{array}$ & $\begin{array}{l}\mathbb{Z}_{u^{\prime}} \\
\underbrace{\prime}\end{array}$ & $\overbrace{1}^{\infty}$ & 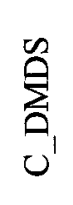 & \begin{tabular}{l} 
ठ \\
\hdashline \\
$U^{\prime}$
\end{tabular} & 宪 & $\begin{array}{l}\tilde{\delta} \\
0^{\prime}\end{array}$ & 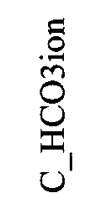 & $\begin{array}{l}z_{1} \\
x_{1}^{\prime} \\
u^{\prime}\end{array}$ & $\begin{array}{l}n_{1} \\
x_{1} \\
u^{\prime}\end{array}$ & $\begin{array}{l}\vec{u}_{1}^{\prime} \\
\dot{x}_{1}^{\prime} \\
u^{\prime}\end{array}$ & $\begin{array}{l}\vec{x} \\
x^{\prime}\end{array}$ & $\begin{array}{l}\dot{n}_{1} \\
x_{1}^{\prime} \\
u_{1}^{\prime}\end{array}$ & ان \\
\hline Uptake_NH4 & & -1 & 1 & & & 0.141 & -0.41 & & Y_N & & & & & \\
\hline Uptake_DMDS & & & & -1 & 3 & 0.0625 & 1.375 & & & $\mathrm{Y}_{-} \mathrm{S}$ & & & & \\
\hline Uptake_Hsp & & & & & & & & & & & $\mathrm{Y} \_\mathrm{H}$ & & & -1 \\
\hline Decay_ $\mathrm{X}_{\mathrm{N}}$ & & & & & & & & & -1 & & & $\mathrm{~b}$ & $1-b$ & \\
\hline Decay_X & & & & & & & & & & -1 & & $\mathrm{~b}$ & $1-b$ & \\
\hline Decay_X $X_{H}$ & & & & & & & & & & & -1 & $\mathrm{~b}$ & $1-b$ & \\
\hline dis_NH3 & -1 & 1 & & & & -0.071 & & & & & & & & \\
\hline dis_CO2 & & & & & & 0.023 & -1 & 1.386 & & & & & & \\
\hline Hydro_sp & & & & & & & & & & & & & -1 & 1 \\
\hline
\end{tabular}

Note:

The units of all the concentrations are $\mathrm{g} / \mathrm{m}^{3}(\mathrm{mg} / \mathrm{l})$

$\mathrm{b}$ is a fraction of inert biomass in total decay biomass

Y_N, Y_S, and Y_H are yield coefficients $((\mathrm{mg}$ biomass $/ \mathrm{l}) /(\mathrm{mg}$ pollutant $/ \mathrm{l}))$ 
$\mathrm{H}^{+}$ion concentration was calculated from the charge balance within the biofilm bulk fluid. Overall charge balance in the bulk fluid is given by Equation 6.3.

$$
\mathrm{H}^{+}+\mathrm{C}_{\mathrm{NH} 4}+\text { other cations }=\mathrm{OH}^{-}+\mathrm{C}_{\mathrm{NO} 3}+2 * \mathrm{C}_{\mathrm{SO}_{4}}+\mathrm{C}_{\mathrm{HCO} 3}+\text { other anions }
$$

Water ionization constant can be represented by Equation 6.4 .

$$
\begin{aligned}
& K_{a_{-} H 2 O}=H^{+} * \mathrm{OH}^{-} \\
& \mathrm{OH}^{-}=\frac{K_{a_{-} H 2 O}}{H^{+}}
\end{aligned}
$$

From Equation 6.3,

$$
H^{+}-\left(\frac{K_{a-K 2 O}}{H^{+}}\right)+M=0
$$

Where,

$\mathrm{M}=\mathrm{C}_{\mathrm{NH} 4}+\mathrm{C}_{\mathrm{M}}-\mathrm{C}_{\mathrm{NO} 3}-2 * \mathrm{C}_{\mathrm{SO} 4}-\mathrm{C}_{\mathrm{HCO} 3}$

$\mathrm{C}_{\mathrm{M}}=$ (cations-anions)

In this study, $C_{M}(\mathrm{mg} / 1)$ represented the resultant concentration of anions and cations other than $\mathrm{NH}_{4}^{+}, \mathrm{NO}_{3}{ }^{-}, \mathrm{SO}_{4}{ }^{2-}$ and $\mathrm{HCO}_{3}{ }^{-}$in the bulk fluid.

Therefore the charge balance equation,

$$
\left(H^{+}\right)^{2}+M^{*} H^{+}-K_{a_{-} H 2 O}=0
$$

By solving Equation 6.6,

$$
H^{+}=-0.5 * M+0.5 *\left(M^{2}+4 * K_{a_{-} H 2 O}\right)^{0.5}
$$

Equation 6.7 was used to calculate the $\mathrm{H}^{+}$ion concentration in the model, subsequently predicting the $\mathrm{pH}$ variation in the bulk fluid. 
A multi-substrate and multi-species biofilm model was developed in this study using the governing equations, process rate equations and additional expressions needed for representing all possible reactions within the biofilter. These set of equations can be solved by integration routines and numerical algorithms implemented in AQUASIM.

\subsection{The dynamic model calibration and sensitivity analysis}

In order to develop the dynamic model, a large number of parameters have been introduced to describe the biofilter process. The parameters (as shown in Table 6.5) could more or less effect the individual variables (gas and aqueous concentrations of the target compounds). The goal of the sensitivity analysis was to identify the most significant parameters in the degradation of gas phase pollutants $\left(\mathrm{NH}_{3}\right.$ and DMDS) and generation of leachate variables $\left(\mathrm{NH}_{3}(\mathrm{aq}), \mathrm{NH}_{4}{ }^{+}, \mathrm{NO}_{3}{ }^{-}, \mathrm{SO}_{4}{ }^{2-}\right.$ and $\left.\mathrm{pH}\right)$.

\subsubsection{Sensitivity analysis}

The sensitivity analysis was employed to identify significant parameters for each variable. Four sensitivity functions are distinguished by AQUASIM. These are absoluteabsolute sensitivity function, relative-absolute sensitivity function, absolute-relative sensitivity function, and relative-relative sensitivity function. The absolute-relative sensitivity function was used in this study to analyze the sensitivity because their units do not depend on the unit of the parameter. This makes quantitative comparisons of the effect of different parameters (p) on a common variable (y) possible. The absoluterelative sensitivity function measures the absolute change in y for a $100 \%$ change in $p$ as described by Equation 6.8 . 


$$
\delta_{y, p}^{a, r}=p \frac{\partial y}{\partial p}
$$

The sensitivity function in AQUASIM was run for the variables in the dynamic model. From the sensitivity results, the most significant parameters were ranked and the five most significant parameters for each variable were identified and tabulated in Table 6.3.

Table 6.3 Sensitivity results and corresponding significant parameters

\begin{tabular}{|c|c|c|c|}
\hline Phase & Variable & Parameter & $\begin{array}{l}\text { Mean } \\
\text { A-R sensitivity }(\mathrm{mg} / \mathrm{l})\end{array}$ \\
\hline \multirow[t]{16}{*}{ Gas } & \multirow{5}{*}{$\mathrm{C}_{\mathrm{CO} 2}$} & $\mathrm{~K}_{\mathrm{La} \mathrm{CO} 2}$ & -6.736 \\
\hline & & $\mathrm{K}_{\mathrm{La}} \mathrm{DMDS}$ & 0.0084 \\
\hline & & $\mathrm{Ks}$ NH4 & 0.0069 \\
\hline & & $\mu_{\max } \mathrm{NH} 4$ & -0.0067 \\
\hline & & $\mathrm{D} \_\mathrm{CO} 2$ & $-2.63 e-005$ \\
\hline & \multirow{6}{*}{$\mathrm{C}_{\mathrm{DMDS}}$} & & 000025 \\
\hline & & $\mathbf{R}_{\text {La }}$ DMDS & -0.00035 \\
\hline & & D_DMDS & $-2.08 \mathrm{e}-00 \mathrm{~s}$ \\
\hline & & $\mu_{\max }$ DMDS & $-5.46 e-007$ \\
\hline & & $\mathrm{Ks}_{\text {DMDS }}$ & $5.42 \mathrm{e}-007$ \\
\hline & & D $\mathrm{SO} 4$ & $6.62 \mathrm{e}-013$ \\
\hline & \multirow{5}{*}{$\mathrm{C}_{\mathrm{NH} 3}$} & $\overline{\mathrm{K}_{\mathrm{LaNH}}}$ & -0.01244 \\
\hline & & $\mu_{\max } \mathrm{NH} 4$ & $-5.22 \mathrm{e}-005$ \\
\hline & & $\mathrm{Ks}_{\mathrm{NH} 4}$ & $2.62 \mathrm{e}-005$ \\
\hline & & $\mathrm{K}_{\mathrm{AB} \mathrm{NH3}}$ & $8.63 \mathrm{e}-008$ \\
\hline & & D_NH3 & $2.25 \mathrm{e}-008$ \\
\hline
\end{tabular}


Table 6.3 Sensitivity results and corresponding significant parameters (continue)

\begin{tabular}{|c|c|c|c|}
\hline Phase & Variable & Parameter & $\begin{array}{l}\text { Mean } \\
\text { A-R sensitivity (mg/1) }\end{array}$ \\
\hline \multirow[t]{25}{*}{ Leachate } & \multirow{5}{*}{$\mathrm{C}_{\mathrm{NH} 3}$} & $\mathrm{~K}_{\mathrm{La} \mathrm{NH} 3}$ & 0.1205 \\
\hline & & D NH3 & -0.0275 \\
\hline & & $\mathrm{K}_{\mathrm{AB} \mathrm{NH} 3}$ & -0.0035 \\
\hline & & $\mathrm{K}_{\mathrm{I} \mathrm{N}}$ & -0.0021 \\
\hline & & $\mu_{\max } \mathrm{NH} 4$ & 0.0021 \\
\hline & \multirow{5}{*}{$\mathrm{C}_{\mathrm{NH} 4}$} & $\mathrm{~K}_{\mathrm{IN}}$ & -0.0203 \\
\hline & & $\mu_{\max } \mathrm{NH} 4$ & -0.0203 \\
\hline & & $\mathrm{K}_{\mathrm{AB} \mathrm{NH} 3}$ & 0.0150 \\
\hline & & $\mathrm{K}_{\mathrm{La} \mathrm{NH}}$ & 0.0124 \\
\hline & & D_NH3 & -0.0026 \\
\hline & \multirow{5}{*}{$\mathrm{C}_{\mathrm{NO} 3}$} & $\mathrm{~K}_{\mathrm{IN}}$ & 0.0285 \\
\hline & & $\mu_{\max } \mathrm{NH} 4$ & 0.0284 \\
\hline & & $\mathrm{K}_{\mathrm{AB} \mathrm{NH3}}$ & -0.00088 \\
\hline & & D NH3 & -0.00087 \\
\hline & & $\overline{\mathrm{La} \mathrm{NH} 3}$ & -0.00072 \\
\hline & \multirow{5}{*}{ C_SO4 } & D DMDS & 0.0949 \\
\hline & & $\overline{\mu_{\max } \mathrm{DMDS}}$ & 0.0938 \\
\hline & & Ks_DMDS & -0.0598 \\
\hline & & $\mathrm{K}_{\mathrm{La}} \mathrm{DMDS}$ & 0.0293 \\
\hline & & D_NH4 & $7.85 \mathrm{e}-006$ \\
\hline & \multirow{5}{*}{ C_Hion } & $\mathrm{K}_{\mathrm{IN}}$ & 0.0035 \\
\hline & & $\mu_{\max \mathrm{NH} 4}$ & 0.0034 \\
\hline & & D DMDS & 0.0017 \\
\hline & & $\mu_{\max } \mathrm{DMDS}$ & 0.0016 \\
\hline & & $\mathrm{K}_{\mathrm{AB} N \mathrm{NH}_{3}}$ & -0.0011 \\
\hline
\end{tabular}

Referring to Table 6.3, it could be seen that the most significant parameters were different for every variable. The most significant parameter for the gas phase variables such as $\mathrm{C}_{\mathrm{CO} 2}, \mathrm{C}_{\mathrm{DMDS}}, \mathrm{C}_{\mathrm{NH} 3}$ was their overall mass transfer coefficients $\left(\mathrm{K}_{\mathrm{La}}\right)$. All other parameters for these variables were much less sensitive for the gas phase removal. 
Within the biofilm compartments, $\mathrm{K}_{\mathrm{La} \_\mathrm{NH} 3}$ was the most sensitive parameter for the $\mathrm{NH}_{3}$ biodegradation, while $\mathrm{D} \_\mathrm{NH}_{3}, \mathrm{~K}_{\mathrm{AB} \_\mathrm{NH} 3}, \mathrm{~K}_{\mathrm{I} \_\mathrm{N}}$ and $\mu_{\max \_\mathrm{NH} 4}$ were also had relatively high sensitivity for the $\mathrm{NH}_{3}$ biodegradation. The nitrification was highly sensitive to $\mathrm{K}_{\mathrm{I} \_\mathrm{N}}$, $\mu_{\mathrm{max} \_\mathrm{NH} 4}, \mathrm{~K}_{\mathrm{AB} \_\mathrm{NH} 3}, \mathrm{D} \_\mathrm{NH} 4$ and $\mathrm{K}_{\mathrm{La} \_\mathrm{NH} 3}$, while the sulfate production was most sensitive

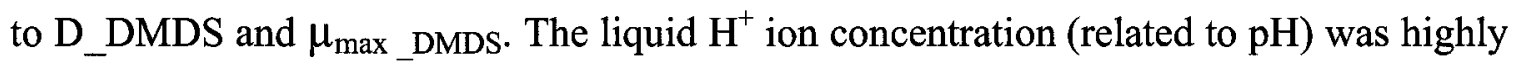
sensitive to $\mathrm{K}_{\mathrm{I}_{-} \mathrm{N}}$ and $\mu_{\max \_\mathrm{NH} 4}$.

The model sensitivity analysis indicated that the $\mathrm{NH}_{3}$ and DMDS biodegradations were independently sensitive to their related parameters. Mass transfer coefficient and biofilm diffusivity had significant effects on the pollutant degradation of $\mathrm{NH}_{3}$ and DMDS with respective constants.

\subsubsection{Dynamic model calibration}

The purpose of model calibration was to adjust the model parameters in order to bring the model output in agreement with observed experiment data. Based on sensitivity analysis, the model parameters were organized to calibrate the model. Before model calibration, the model parameters were estimated from literature reports. Table 6.5 shows the model parameter values and formulae. As shown in Table 6.5, the numerical values were selected from the literature which were related to biofilter studies and/or the values were proposed for the biofilter model study by Baquerizo et al., 2004; Wanner and Morgenroth, 2004; Li et al., 2003; Alonso et al., 2001; Hautakangas et al., 1999. The kinetic constants were reported based on room temperature $\left(298^{\circ} \mathrm{K}\right)$; therefore, 
temperature correction formulae were also given in Table 6.5 (Sander, 2004; Batstone et al., 2002).

As discussed in Section 5.6.2.3, the effect of solubility of $\mathrm{NH}_{3}$ in the presence of $\mathrm{CO}_{2}$ in the aqueous phase was considered in this biofilter model. The model was calibrated accordingly to fit the $\mathrm{NH}_{4}{ }^{+}$and $\mathrm{NO}_{3}{ }^{-}$variations in the leachate. Table $6.5 \mathrm{c}$ shows the dimensionless Henry's coefficient calculation procedure (Sander, 2004). However these traditional formulae did not satisfy the $\mathrm{NH}_{3}$ solubility condition in the aqueous phase when $\mathrm{CO}_{2}$ was present. Therefore, an empirical equation (Equation 6.9) was proposed for Henry's coefficient of $\mathrm{NH}_{3}$ when $\mathrm{CO}_{2}$ concentration varied dynamically in the ATAD off gas. As discussed in Section 5.6.2.3, when $\mathrm{NH}_{3}$ and $\mathrm{CO}_{2}$ concentrations were peaking, the $\mathrm{NH}_{3}$ gas solubility was reduced. Several factors (including chemical and physical) may cause for the solubility reduction. However, for a given condition such as for the biofilter, when $\mathrm{NH}_{3}$ gas solubility was reduced in the aqueous phase, it was believed that it can be explained by the Henry's coefficient variation in the aqueous phase. The model Equation 6.9 satisfied this requirement in the $\mathrm{NH}_{3}-\mathrm{CO}_{2}-\mathrm{H}_{2} \mathrm{O}$ system.

$$
H_{-} N H 3=\frac{\beta^{*}\left(C_{C O 2}(a q)\right)^{2}}{H_{-} N H 3 u n i t * R^{*} \text { Temp }}
$$

As shown in Equation 6.9, in addition to the traditional Henry's coefficient formula for $\mathrm{NH}_{3}$, two additional terms were added in the equation. The first term $\beta$ is a constant and the second term is a square of $\mathrm{CO}_{2}(\mathrm{aq})$ concentration in aqueous phase. The denominator terms are defined in Table 6.5. The $\mathrm{CO}_{2}(\mathrm{aq})$ referred to total $\mathrm{CO}_{2}$ concentration in the 
aqueous phase. As discussed by Hales and Drewes (1979), When $\mathrm{NH}_{3}$ and $\mathrm{CO}_{2}$ were at equilibrium in gas and aqueous phases, the $\mathrm{NH}_{3}(\mathrm{aq})$ concentration depended on $\mathrm{CO}_{2}(\mathrm{aq})$ concentration and reaction rate constants of the formation of intermediate compound. However, in this study, the $\mathrm{NH}_{3}$ and $\mathrm{CO}_{2}$ gas phase concentrations were dynamic and varied significantly through the cycle. Based on the literature (Pazuki et al., 2006; Rumpf et al., 1999; Thomsen and Rasmussen, 1999; Kurz et al., 1995) it was expected that the modified Henry's coefficient would have changed significantly by two orders of magnitude relative to $\mathrm{CO}_{2}(\mathrm{aq})$ concentration. Therefore, as shown in Equation 6.9, the $\mathrm{CO}_{2}(\mathrm{aq})$ concentration was squared to obtain the two orders of magnitude variation of Henry's coefficient to fit the experimental data.

As discussed in Section 6.2, the biofilter height was divided into eight layers. The volume and area of each compartment were calculated based on the packing material data and the biofilm assumptions. A detailed calculation is provided in Appendix E. The dimensions of the reactor in the model for a single layer included: a gas phase mixed reactor volume of $0.01 \mathrm{~m}^{3} /$ compartment; a biofilm bulk volume of $1.375 \times 10^{-4} \mathrm{~m}^{3} /$ compartment; and a biofilm surface area of $1.375 \mathrm{~m}^{2} /$ compartment.

For the model calibration study, initially a single biofilter operating condition was used to calibrate the model. The biofilter conditions include bed temperature of $26^{\circ} \mathrm{C}$, EBRT of $150 \mathrm{~s}$, potable water flow of $21 / \mathrm{min}$ as post-humidification water. Table 6.4 shows the gas phase pollutant loading $\left(\mathrm{C}_{\mathrm{gi}}\right.$ inlet $)$ for the biofilter model study. The parameter's initial values were obtained from the references quoted in the Table 6.5, and then the 
parameter estimation was done based on above biofilter conditions and their corresponding data set. The final parameter values are given in the Table 6.5.

Table 6.4 Biofilter loading for the model calibration

\begin{tabular}{|c|c|c|c|}
\hline Time (hr) & $\mathrm{NH}_{3}$ gas $(\mathrm{mg} \mathrm{N} / 1)$ & Time (hr) & DMDS (mg S/l) \\
\hline 0 & 0.021 & 0 & 0.0027 \\
\hline 1 & 0.024 & 1 & 0.0039 \\
\hline 2 & 0.031 & 2 & 0.0074 \\
\hline 3 & 0.050 & 4 & 0.0119 \\
\hline 4 & 0.058 & 6 & 0.0124 \\
\hline 5 & 0.113 & 8 & 0.0119 \\
\hline 6 & 0.134 & 10 & 0.0108 \\
\hline 7 & 0.166 & 12 & 0.0098 \\
\hline 8 & 0.155 & 14 & 0.0085 \\
\hline 9 & 0.089 & 16 & 0.0074 \\
\hline 10 & 0.050 & 18 & 0.0059 \\
\hline 11 & 0.043 & 20 & 0.0060 \\
\hline 12 & 0.041 & 22 & 0.0048 \\
\hline 13 & 0.038 & 24 & 0.0045 \\
\hline 14 & 0.040 & & \\
\hline 15 & 0.040 & & \\
\hline 16 & 0.046 & & \\
\hline 17 & 0.047 & & \\
\hline 18 & 0.040 & & \\
\hline 19 & 0.040 & & \\
\hline 20 & 0.036 & & \\
\hline 21 & 0.035 & & \\
\hline 22 & 0.033 & & \\
\hline 23 & 0.024 & & \\
\hline 24 & 0.024 & & \\
\hline
\end{tabular}

Due to the complexity of the biofilter model, simultaneous parameter estimation of all parameters was not possible. Instead, the following procedure was used to obtain estimates of the parameters. Similar parameter estimation procedures were used by Arcangeli and Arvin (1999). First the parameters such as diffusion coefficients, Henry's 
coefficients (other than $\mathrm{NH}_{3}$ ), acid-base dissociation constants, kinetic constant for the acid-base reaction, decay constants, initial density of the biomass, and yield coefficient for the biomass growth, were assumed as constant for this study and obtained from the literature. Then, the mass transfer coefficients of the target compounds were estimated by the parameter estimation routine included in AQUASIM. Then the parameters related to biodegradation of target compounds such as inhibition constant, half-saturation concentrations, Henry's coefficient for $\mathrm{NH}_{3}$, maximum uptake rates of the target compounds, were estimated using trial and error approach by visual observation of the model simulation results with experimental data. Finally $\mathrm{C}_{\mathrm{M}}$ was adjusted to fit the $\mathrm{pH}$ prediction with the experimental $\mathrm{pH}$ data.

Initial values for the gas phase parameter $\left(\mathrm{C}_{\mathrm{gi}}\right.$ ini $)$, aqueous phase parameter $\left(\mathrm{C}_{\mathrm{li}}\right.$ ini) and biofilm matrix parameter $\left(\mathrm{C}_{\mathrm{bi}}\right.$ ini) were obtained from preliminary runs of the cyclic loadings. Since ATAD off gas loading are regularly repeating cycle, the last reading of the 24 hours cycle was assumed as an initial value for the following cycle. Therefore, the parameters $\left(\mathrm{C}_{\mathrm{gi}}\right.$ ini, $\mathrm{C}_{\mathrm{li} \_}$ini and $\left.\mathrm{C}_{\mathrm{bi}} \mathrm{ini}_{\mathrm{i}}\right)$ were obtained for every sampling event, based on corresponding biofilter loading conditions $\left(\mathrm{C}_{\mathrm{gi}}\right.$ inlet and $\mathrm{C}_{\mathrm{li}_{-}}$inlet $)$; after the preliminary runs were carried out based on initial values of zero. The $\mathrm{C}_{\mathrm{gi}}$ inlet was the dynamic gas phase loading which was obtained from pilot scale data. The $\mathrm{C}_{\mathrm{li} \_}$inlet was assumed constant as an average concentration of the compound $i$ in feed water. 
Table 6.5a Suggested parameter values for the dynamic biofilter model

\begin{tabular}{|c|c|c|c|c|}
\hline Parameter & Unit & Value & Description & Reference \\
\hline $\mathrm{C}_{\mathrm{M}}$ & $\mathrm{mg} / 1$ & $\begin{array}{l}0.4 \\
(0.1-2.5)\end{array}$ & Represent for anion, and cation in the leachate & $\begin{array}{l}\text { Estimated in } \\
\text { this study }\end{array}$ \\
\hline D_CO2 & $\mathrm{m}^{2} / \mathrm{hr}$ & $2.25 \mathrm{e}-006$ & $\mathrm{CO}_{2}$ diffusion coefficient in the biofilm & \multirow{9}{*}{$\begin{array}{l}\text { Lin and Lee, } \\
2001 ; \\
\text { Coulson and } \\
\text { Richardson, } \\
1996 ; \\
\text { Baquerizo et } \\
\text { al., 2004; } \\
\text { Hao et al., } \\
2002 \text {. }\end{array}$} \\
\hline D_DMDS & $\mathrm{m}^{2} / \mathrm{hr}$ & $1.33 \mathrm{e}-006$ & DMDS diffusion coefficient in the biofilm & \\
\hline D_HCO3ion & $\mathrm{m}^{2} / \mathrm{hr}$ & $1.33 e-006$ & $\mathrm{HCO}_{3}$ ion diffusion coefficient in the biofilm & \\
\hline D_Hion & $\mathrm{m}^{2} / \mathrm{hr}$ & $5.63 e-006$ & Hion diffusion coefficient in the biofilm & \\
\hline D_NH3 & $\mathrm{m}^{2} / \mathrm{hr}$ & $7.20 \mathrm{e}-006$ & $\mathrm{NH}_{3}$ diffusion coefficient in the biofilm & \\
\hline D_NH4 & $\mathrm{m}^{2} / \mathrm{hr}$ & $7.20 \mathrm{e}-006$ & $\mathrm{NH}_{4}$ diffusion coefficient in the biofilm & \\
\hline D_NO3 & $\mathrm{m}^{2} / \mathrm{hr}$ & $6.80 \mathrm{e}-006$ & $\mathrm{NO}_{3}$ diffusion coefficient in the biofilm & \\
\hline D_SO4 & $\mathrm{m}^{2} / \mathrm{hr}$ & $4.00 \mathrm{e}-007$ & $\mathrm{SO}_{4}$ diffusion coefficient in the biofilm & \\
\hline D_sp & $\mathrm{m}^{2} / \mathrm{hr}$ & $5.63 e-006$ & $\begin{array}{l}\text { Soluble substrate diffusion coefficient in the } \\
\text { biofilm }\end{array}$ & \\
\hline $\mathrm{K}_{\mathrm{AB}_{-} \mathrm{CO} 2}$ & $\mathrm{hr}^{-1}$ & 0.01 & $\begin{array}{l}\text { kinetic constant for } \mathrm{CO}_{2}-\mathrm{HCO}_{3} \text { - acid base } \\
\text { reaction }\end{array}$ & \multirow[t]{5}{*}{$\begin{array}{l}\text { Batstone et } \\
\text { al., } 2002\end{array}$} \\
\hline $\mathrm{K}_{\mathrm{AB} \_\mathrm{NH} 3}$ & $\mathrm{hr}^{-1}$ & $1 \mathrm{e}+008$ & $\begin{array}{l}\text { kinetic constant for } \mathrm{NH}_{3}-\mathrm{NH}_{4}^{+} \text {acid base } \\
\text { reaction }\end{array}$ & \\
\hline $\mathrm{K}_{\mathrm{d}_{-} \mathrm{H}}$ & $\mathrm{hr}^{-1}$ & 0.0042 & $\begin{array}{l}\text { Kinetic constant for the heterotrophic-biomass } \\
\text { decay rate }\end{array}$ & \\
\hline $\mathrm{K}_{\mathrm{d}_{-} \mathrm{N}}$ & $\mathrm{hr}^{-1}$ & 0.006 & $\begin{array}{l}\text { Kinetic constant for the nitrifier-biomass } \\
\text { decay rate }\end{array}$ & \\
\hline $\mathrm{K}_{\mathrm{d}_{-} \mathrm{S}}$ & $\mathrm{hr}^{-1}$ & 0.0042 & $\begin{array}{l}\text { Kinetic constant for the sulfur oxidized- } \\
\text { biomass decay rate }\end{array}$ & \\
\hline $\mathrm{K}_{\mathrm{I}_{-} \mathrm{N}}$ & $\mathrm{mg} / 1$ & $\begin{array}{l}12 \\
(2-15)\end{array}$ & Inhibition constant for nitrification & $\begin{array}{l}\text { Baquerizo et } \\
\text { at., } 2004\end{array}$ \\
\hline $\mathrm{K}_{\mathrm{La} / \mathrm{N}_{-} \mathrm{CO} 2}$ & $\mathrm{~m}^{-3} \mathrm{hr}^{-1}$ & $\begin{array}{l}20 \\
(10-200)\end{array}$ & $\begin{array}{l}\text { Volume specific mass transfer coefficient for } \\
\mathrm{CO}_{2}\end{array}$ & $\begin{array}{l}\text { Zhang et al., } \\
2002\end{array}$ \\
\hline $\mathrm{K}_{\mathrm{La} / \mathrm{V}_{-} \mathrm{NH} 3}$ & $\mathrm{~m}^{-3} \mathrm{hr}^{-1}$ & $\begin{array}{l}64 \\
(20-90)\end{array}$ & $\begin{array}{l}\text { Volume specific mass transfer coefficient for } \\
\mathrm{NH}_{3}\end{array}$ & $\begin{array}{l}\text { Baquerizo et } \\
\text { at., } 2004\end{array}$ \\
\hline $\mathrm{K}_{\mathrm{La} / V_{-} \mathrm{DMDS}}$ & $\mathrm{m}^{-3} \mathrm{hr}^{-1}$ & $\begin{array}{l}220 \\
(20-800)\end{array}$ & $\begin{array}{l}\text { Volume specific mass transfer coefficient for } \\
\text { DMDS }\end{array}$ & Li etal., 2003 \\
\hline V_bulk & $\mathrm{m}^{3}$ & $\begin{array}{l}\text { Program } \\
\text { variable }\end{array}$ & $\begin{array}{l}\text { Volume of bulk fluid in the biofilm (vary with } \\
\text { layer and time) }\end{array}$ & $\begin{array}{l}\text { Reichert, } \\
1998 \\
\end{array}$ \\
\hline $\mathrm{K}_{\mathrm{La} \_\mathrm{CO} 2}$ & $h r^{-1}$ & \multicolumn{2}{|c|}{$\begin{array}{l}\text { Overall mass transfer coefficient for } \mathrm{CO}_{2} \\
\mathrm{~K}_{\mathrm{La} / \mathrm{V} \text { CO2 }} * \mathrm{~V} \text { bulk }\end{array}$} & \multirow[t]{3}{*}{$\begin{array}{l}\text { Reichert, } \\
1998\end{array}$} \\
\hline $\mathrm{K}_{\mathrm{La} \_\mathrm{NH} 3}$ & $\mathrm{hr}^{-1}$ & \multicolumn{2}{|c|}{$\begin{array}{l}\text { Overall mass transfer coefficient for } \mathrm{NH}_{3} \\
\mathrm{~K}_{\mathrm{La} \text { V NH3 }} * \mathrm{~V} \text { _bulk }\end{array}$} & \\
\hline $\mathrm{K}_{\mathrm{La}_{\text {_DMDS }}}$ & $\mathrm{hr}^{-1}$ & \multicolumn{2}{|c|}{$\begin{array}{l}\text { Overall mass transfer coefficient for DMDS } \\
\mathrm{K}_{\mathrm{L} a \mathrm{~V} \text { DMDS }} * \mathrm{~V}_{-} \text {bulk }\end{array}$} & \\
\hline
\end{tabular}


Table 6.5b Suggested parameter values for the dynamic biofilter model (continue)

\begin{tabular}{|c|c|c|c|c|}
\hline Parameter & Unit & Value & Description & Reference \\
\hline Ks_NH4 & $\mathrm{mg} / 1$ & $\begin{array}{l}4.8 \\
(0.1-5)\end{array}$ & $\begin{array}{l}\text { Half saturation concentration at biofilm for } \\
\text { nitrification }\end{array}$ & Baquerizo et \\
\hline Ks_DMDS & $\mathrm{mg} / 1$ & $\begin{array}{l}0.05 \\
(0.01-0.5)\end{array}$ & $\begin{array}{l}\text { Half saturation concentration at biofilm for } \\
\text { RSC oxidation }\end{array}$ & $\begin{array}{l}\text { Li et al., } \\
2003\end{array}$ \\
\hline K_H & $\mathrm{hr}^{-1}$ & 0.1 & Kinetic constant for hydrolysis reaction & $\begin{array}{l}\text { Arcangeli } \\
\text { and Arvin, } \\
1999\end{array}$ \\
\hline & & & & \\
\hline$\mu_{\max { }_{-} H}$ & $\mathrm{hr}^{-1}$ & 0.6 & $\begin{array}{l}\text { Maximum growth rate of heterotrophic } \\
\text { biomass }\end{array}$ & $\begin{array}{l}\text { Arcangeli } \\
\text { and Arvin, } \\
1999\end{array}$ \\
\hline$\mu_{\max \_\mathrm{NH} 4}$ & $\mathrm{hr}^{-1}$ & $\begin{array}{l}0.25 \\
(0.01-2)\end{array}$ & Maximum growth rate of nitrifying biomass & $\begin{array}{l}\text { Baquerizo et } \\
\text { at., } 2004\end{array}$ \\
\hline$\mu_{\max \_ \text {DMDS }}$ & $\mathrm{hr}^{-1}$ & $\begin{array}{l}35 \\
(5-80)\end{array}$ & $\begin{array}{l}\text { Maximum growth rate of sulfur oxidizing } \\
\text { biomass }\end{array}$ & $\begin{array}{l}\text { Li et al., } \\
2003\end{array}$ \\
\hline$\cdot$ & & & & \\
\hline rho_H & $\mathrm{mg} / \mathrm{l}$ & 25000 & Initial density of heterotrophic biomass & \multirow{5}{*}{$\begin{array}{l}\text { Baquerizo et } \\
\text { at., } 2004 ; \mathrm{Li} \\
\text { et al., } 2003\end{array}$} \\
\hline rho_i & $\mathrm{mg} / \mathrm{l}$ & 2500 & Initial density of inert biomass & \\
\hline rho_N & $\mathrm{mg} / 1$ & 25000 & Initial density of nitrifying biomass & \\
\hline rho_S & $\mathrm{mg} / 1$ & 25000 & Initial density of sulfur oxidizing biomass & \\
\hline rho_sp & $\mathrm{mg} / \mathrm{l}$ & 2500 & Initial density of soluble biomass & \\
\hline Temp & $\mathbf{K}$ & 299 & & \\
\hline Y_H & - & 0.3 & Yield for growth of $\mathrm{X \_ H}$ in biofilm & $\begin{array}{l}\text { Arcangeli } \\
\text { and Arvin, } \\
1999\end{array}$ \\
\hline Y_N & - & 0.6 & Yield for growth of X_N in biofilm & $\begin{array}{l}\text { Baquerizo et } \\
\text { at., } 2004\end{array}$ \\
\hline Y_S & - & 0.6 & Yield for growth of X_S in biofilm & $\begin{array}{l}\text { Li et al., } \\
2003\end{array}$ \\
\hline
\end{tabular}


Table 6.5c Suggested parameter values for the dynamic biofilter model (continue)

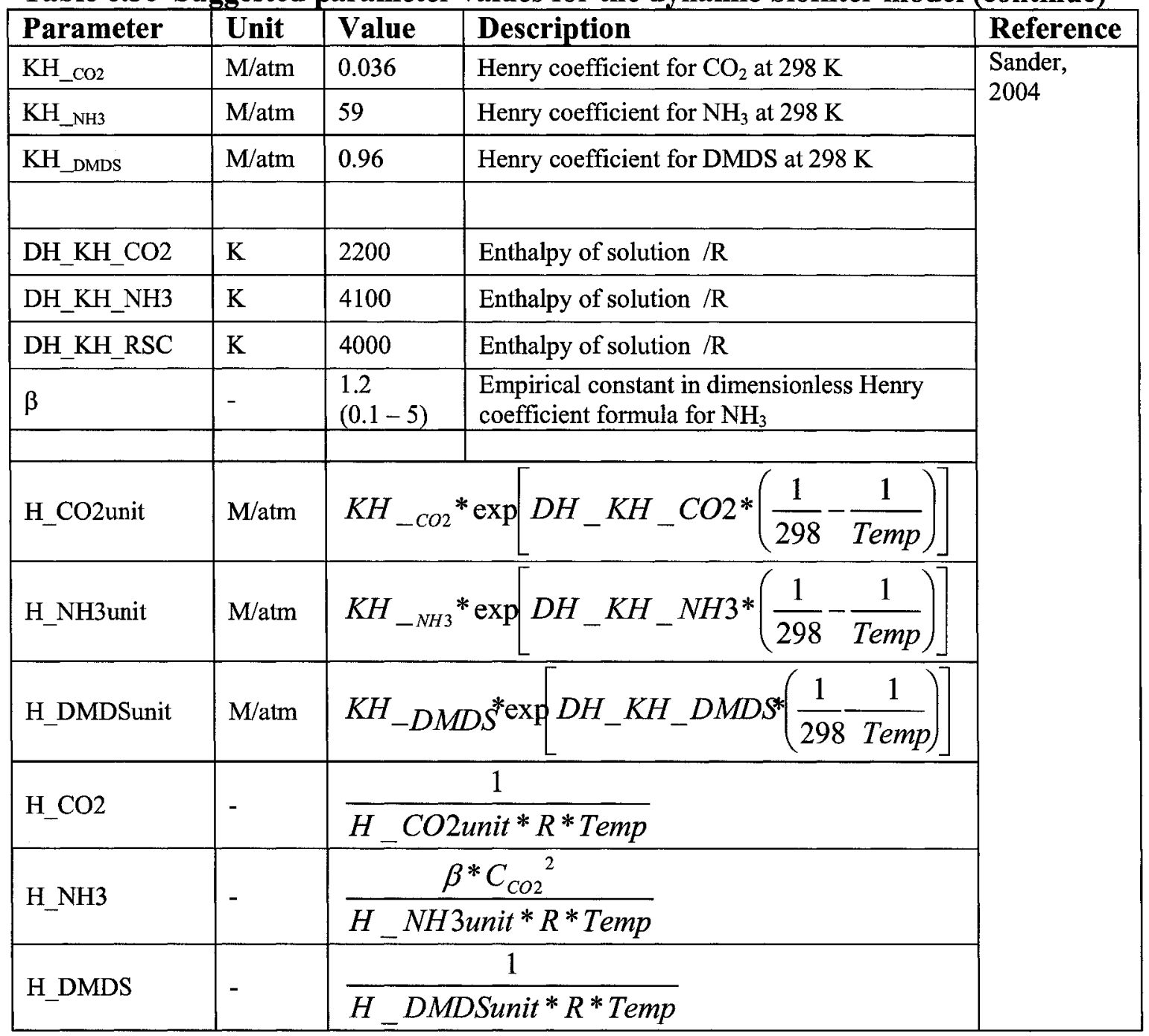

When the biofilter conditions were changed, the model predictions did not match with the corresponding experimental data for a single set of parameter values. It was believed that the parameters (e.g., mass transfer coefficients, maximum growth rates) may depend on the pollutant loading and other physical and chemical conditions, however in this study, these parameters (e.g., mass transfer coefficients and maximum biomass growth rates) were considered as constant variables. Therefore, when biofilter conditions were changed, the model predictions were poor. As discussed earlier, some parameters were 
fixed as the literature values, the remaining parameters were adjusted accordingly to fit with the experimental results of different biofilter conditions. The biofilter conditions corresponding to the sampling events data (E21, E38, E42, E44 and E46 as given in Appendix A) were randomly chosen to accommodate different loading conditions to the model calibration. The adjusted range of parameters values was given within a bracket in Table 6.5.

Table 6.5d Suggested parameter values for the dynamic biofilter model (continue)

\begin{tabular}{|c|c|c|c|c|c|c|}
\hline Parameter & Unit & Value & \multicolumn{3}{|c|}{ Description } & Reference \\
\hline DHo_Ka_CO2 & $\mathrm{J}$ & 7646 & \multicolumn{3}{|c|}{ Enthalpy of $\mathrm{CO}_{2}$ dissociation reaction } & Batstone et \\
\hline DHo_Ka_NH3 & $\mathrm{J}$ & 51965 & \multicolumn{3}{|c|}{ Enthalpy of $\mathrm{NH}_{3}$ dissociation reaction } & \\
\hline DHo_Ka_H2O & $\mathrm{J}$ & 55900 & \multicolumn{3}{|c|}{ Enthalpy of $\mathrm{H}_{2} \mathrm{O}$ dissociation reaction } & \\
\hline pKa_CO2 & - & 6.35 & \multicolumn{3}{|c|}{ Acid dissociation constant for $\mathrm{CO}_{2}$} & \\
\hline pKa_H2O & - & 14 & \multicolumn{3}{|c|}{ Acid dissociation constant for $\mathrm{H}_{2} \mathrm{O}$} & \\
\hline pKa_NH3 & - & 9.25 & \multicolumn{3}{|c|}{ Acid dissociation constant for $\mathrm{NH}_{3}$} & \\
\hline $\mathrm{Ka}$-CO2 & $\mathrm{mol} / \mathrm{I}$ & \multicolumn{2}{|c|}{$10^{\left(-p K a_{-}(C O 2)\right.} * \exp [$} & $\frac{\mathrm{DHo} \mathrm{H}_{-} \mathrm{a}_{-} \mathrm{CO} 2}{R^{*} 100} *\left(\frac{1}{298}\right.$ & $\left.\frac{1}{T e m p}\right)$ & \\
\hline $\mathrm{Ka}_{-} \mathrm{NH} 3$ & $\mathrm{~mol} / \mathrm{l}$ & \multicolumn{2}{|c|}{$10^{\left(-p K a_{-} N H 3\right)} * \exp [$} & $\frac{\mathrm{DHo} \mathrm{H}_{-} \mathrm{Ka} a_{-} \mathrm{NH} 3_{3}}{R^{*} 100} *\left(\frac{1}{298}\right.$ & $\left.\frac{1}{\text { Temp }}\right)$ & \\
\hline Ка_н2о & $\mathrm{mol} / \mathrm{l}$ & \multicolumn{2}{|c|}{$10^{\left(-p K a_{-} H 2 O\right)} * \exp [$} & $\frac{D H o_{-} \mathrm{Ka} a_{-} H 2 O}{R^{*} 100} *\left(\frac{1}{298}\right.$ & $\left.-\frac{1}{T e m p}\right)$ & \\
\hline
\end{tabular}

The model verification was conducted to ensure that the model has been assembled properly and to check for errors in coding in the AQUASIM. The verification was conducted by performing mass balances of $\mathrm{N}$ and $\mathrm{S}$ compounds in and out of the system. Table 6.6 shows the biofilter inlet conditions while Table 6.7 shows the corresponding 
mass balance details. The difference between the biofilter inlet and outlet masses was due to the microbial growth (relative proportion of elements (e.g., $\mathrm{N}$ and $\mathrm{S}$ ) present in microbial cells) and also due to rounding errors on the stoichiometric coefficients (as shown in Table 6.2). The results of the mass balance showed that the processes of the dynamic model were correctly coded in the AQUASIM program.

Table 6.6 Biofilter inlet conditions

\begin{tabular}{|r|r|r|}
\hline Time & $\begin{array}{l}\text { NH } \\
\text { gas } \\
\left(\mathbf{g ~ N}_{\mathbf{m}} \mathbf{3}\right)\end{array}$ & $\begin{array}{l}\text { DMDS gas } \\
\left(\mathbf{g ~ S}_{\mathbf{m}} \mathbf{3}\right)\end{array}$ \\
\hline 0 & 0.054 & 0.0027 \\
\hline 2 & 0.076 & 0.0067 \\
\hline 4 & 0.092 & 0.0282 \\
\hline 6 & 0.236 & 0.0339 \\
\hline 8 & 0.317 & 0.0323 \\
\hline 10 & 0.240 & 0.0210 \\
\hline 12 & 0.201 & 0.0142 \\
\hline 14 & 0.102 & 0.0125 \\
\hline 16 & 0.072 & 0.0092 \\
\hline 18 & 0.065 & 0.0057 \\
\hline 20 & 0.055 & 0.0074 \\
\hline 22 & 0.051 & 0.0059 \\
\hline 24 & 0.046 & 0.0037 \\
\hline
\end{tabular}

\begin{tabular}{|l|l|}
\hline Description & $\begin{array}{l}\text { Initial } \\
\text { values }\end{array}$ \\
\hline Q_gin $\left(\mathrm{m}^{3} / \mathrm{hr}\right)$ & 3.2 \\
\hline Q_lin $\left(\mathrm{m}^{3} / \mathrm{hr}\right)$ & 0.12 \\
\hline
\end{tabular}

Table 6.7 Mass balance details

\begin{tabular}{|c|c|c|c|}
\hline \multicolumn{2}{|l|}{ Compounds } & $\begin{array}{l}\text { Biofilter inlet } \\
\text { g S or N / d }\end{array}$ & $\begin{array}{l}\text { Biofilter outlet } \\
\text { g S or N / d }\end{array}$ \\
\hline \multirow[t]{3}{*}{ S compounds } & DMDS gas & 1.270 & 0.107 \\
\hline & $\operatorname{DMDS}(\mathrm{aq})$ & - & 0.010 \\
\hline & $\mathrm{SO}_{4}{ }^{2-}$ & 0.096 & 1.202 \\
\hline \multicolumn{2}{|l|}{ Total S mass } & 1.366 & 1.319 \\
\hline \multicolumn{2}{|l|}{ Error $(\%)$} & & 3.4 \\
\hline \multicolumn{4}{|l|}{, } \\
\hline \multirow[t]{4}{*}{$\mathrm{N}$ compounds } & $\mathrm{NH}_{3}$ gas & 9.606 & 1.837 \\
\hline & $\mathrm{NH}_{3}(\mathrm{aq})$ & - & 1.860 \\
\hline & $\mathrm{NH}_{4}(\mathrm{aq})$ & 1.659 & 3.137 \\
\hline & $\mathrm{NO}_{3}^{-}$ & 0.012 & 3.369 \\
\hline \multicolumn{2}{|l|}{ Total N mass } & 11.277 & 10.203 \\
\hline \multicolumn{2}{|l|}{ Error (\%) } & & 9.5 \\
\hline
\end{tabular}




\subsection{Results and discussion}

The model was used to simulate the dynamic loading of pollutant. In this case, an experimental data set was used from biofilter conditions similar to those that had been used to calibrate the model. However the pollutant loading were relatively higher than the calibration data sets. The biofilter conditions were air flow rate of $3.2 \mathrm{~m}^{3} / \mathrm{hr}(\mathrm{EBRT}=150$ s); post-humidification water flow rate of $0.12 \mathrm{~m}^{3} / \mathrm{hr}$; bed temperature of $299^{\circ} \mathrm{K}$; and potable water as the source of post-humidification water. The biofilter inlet gas phase concentrations for $\mathrm{NH}_{3}\left(\right.$ as $\left.\mathrm{g} \mathrm{N} / \mathrm{m}^{3}\right)$ and DMDS (as $\mathrm{g} \mathrm{S} / \mathrm{m}^{3}$ ) are shown in Table 6.6.

The dynamic gas phase loading of $\mathrm{N}$ and $\mathrm{S}$ mass was introduced as model input and the output results were obtained from the model simulations. These output result were compared with experiment data obtained in the pilot scale study. Figure 6.3 shows the $\mathrm{NH}_{3}$ gas and DMDS gas experimental results with model predictions. As shown in Figure 6.3, the model output curve was reasonable fit to the experimental data.

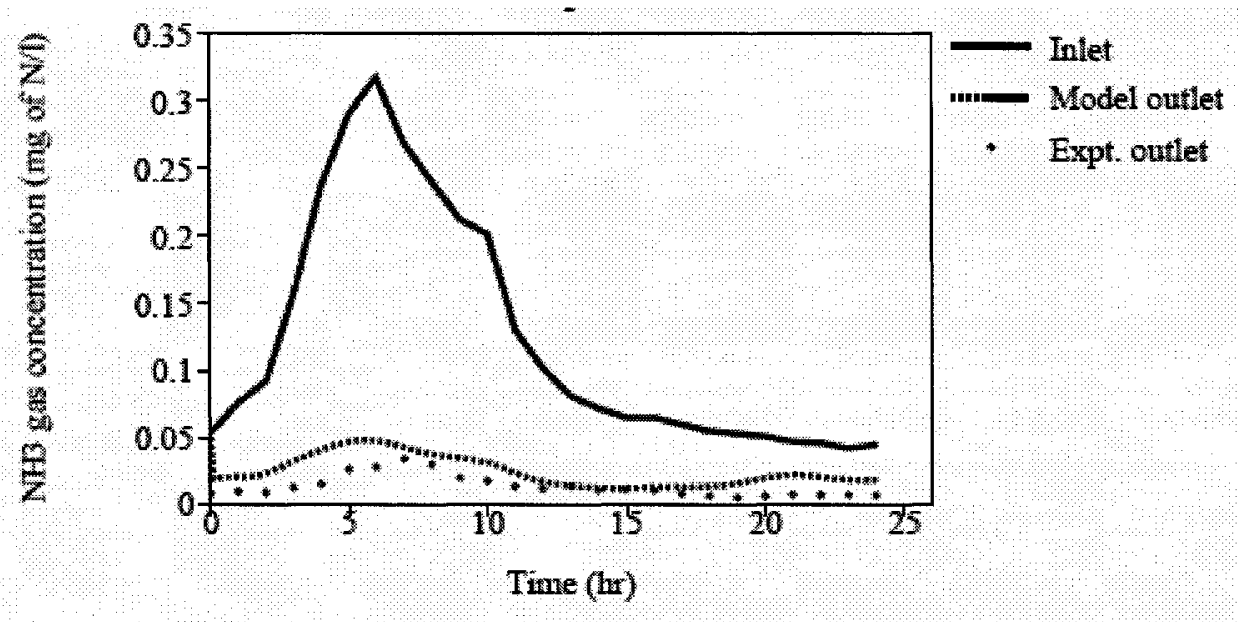

Figure 6.3(a) Gas phase results: experimental data vs. model prediction 


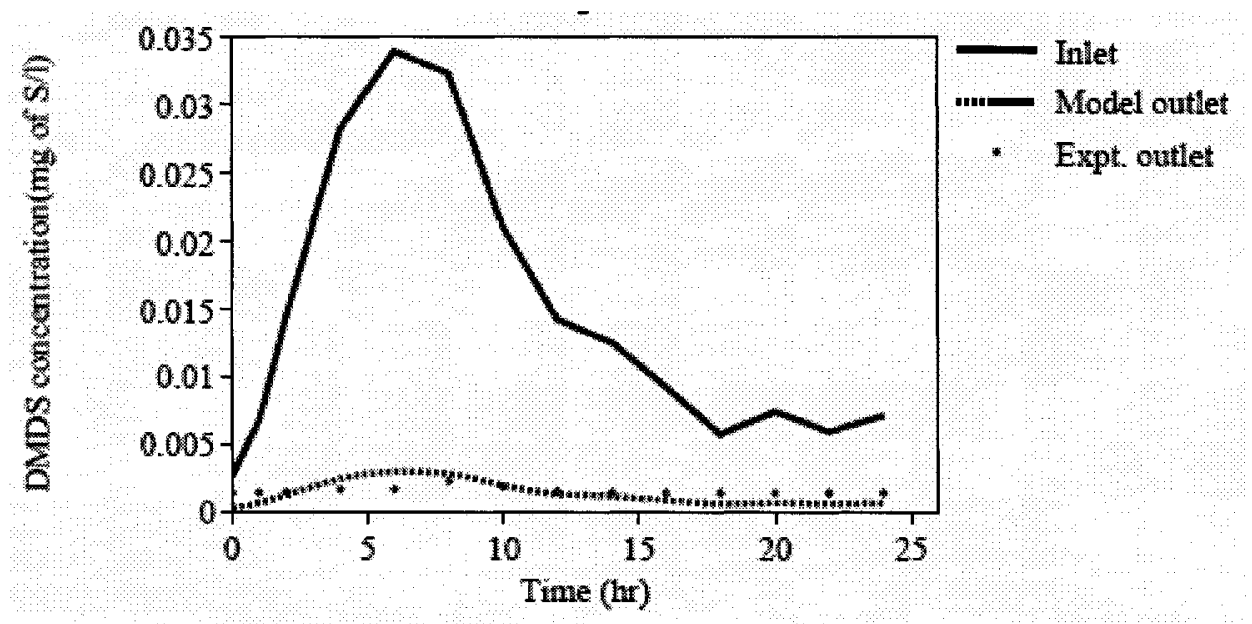

Figure 6.3(b) Gas phase results: experimental data vs. model prediction

TA (mg N/l) was defined as total concentration of $\mathrm{NH}_{3}(\mathrm{aq})$ and $\mathrm{NH}_{4}{ }^{+}$. The TA was selected to compare the experimental data because there was no individual data for $\mathrm{NH}_{3}(\mathrm{aq})$ and $\mathrm{NH}_{4}{ }^{+}$concentrations in the experimental results. Figure 6.4 shows the leachate results versus model predictions for $\mathrm{TA}, \mathrm{NO}_{3}{ }^{-}$and $\mathrm{SO}_{4}{ }^{2-}$. The leachate model output also gave a reasonably fits of the experimental data. Model prediction for TA was relatively higher than experimental data. As discussed in Section 5.6, the mass of $\mathrm{N}$ compounds other than $\mathrm{NH}_{3}$ may contribute for the reduced concentration of TA in the experimental data. The denitrification process was not considered in this model study to reduce model complexity. As reported by Rittmann et al. (2002), the microbiological reactions are affected by other chemical reactions within the system. These close interactions have significant impact on the fate of pollutant. A comprehensive study is needed to understand the interaction between the biological and chemical reactions within a dynamic biofilter system. 
The $\mathrm{NO}_{3}{ }^{-}$concentration variations in the model prediction followed the same trend as the experimental data. The $\mathrm{SO}_{4}{ }^{2-}$ concentration variation in the model prediction was a reasonable fit when $\mathrm{SO}_{4}{ }^{2-}$ was peaking; however in the latter part of the cycle, the experimental data were relatively high. As discussed in Section 5.5, the S mass in the biofilter outlet was relatively higher than the inlet $\mathrm{S}$ mass. The model prediction may suggest that the $\mathrm{SO}_{4}{ }^{2-}$ concentration measurement errors exist in the experimental data.

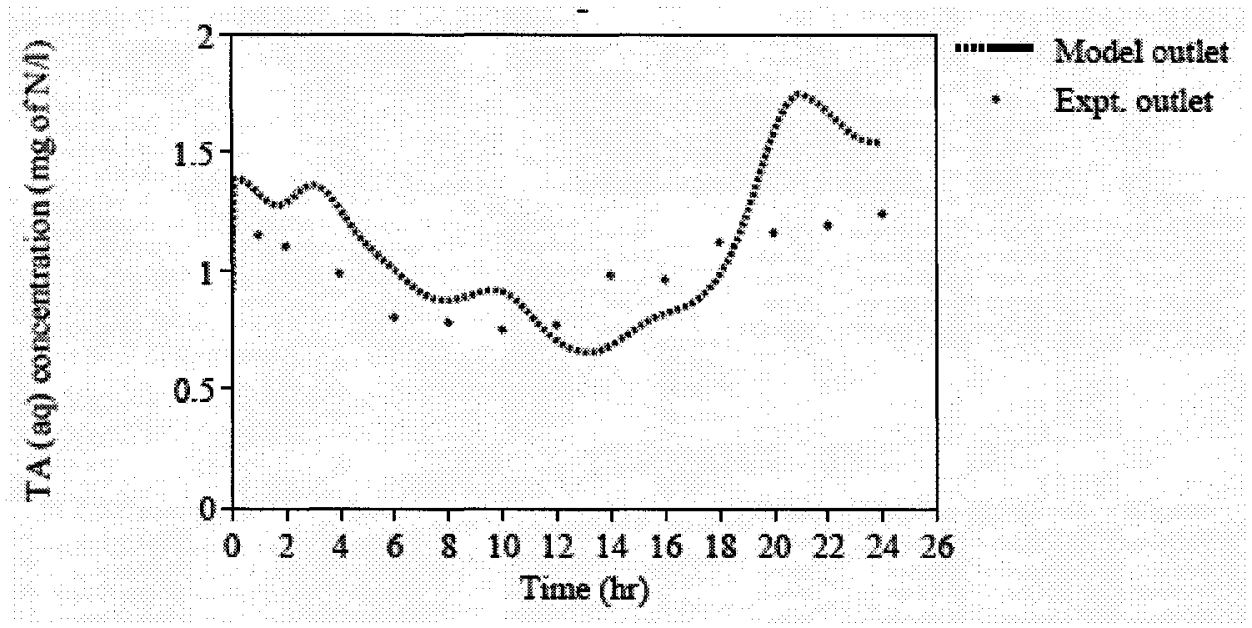

Figure 6.4(a) Leachate TA result: experimental data vs. model prediction

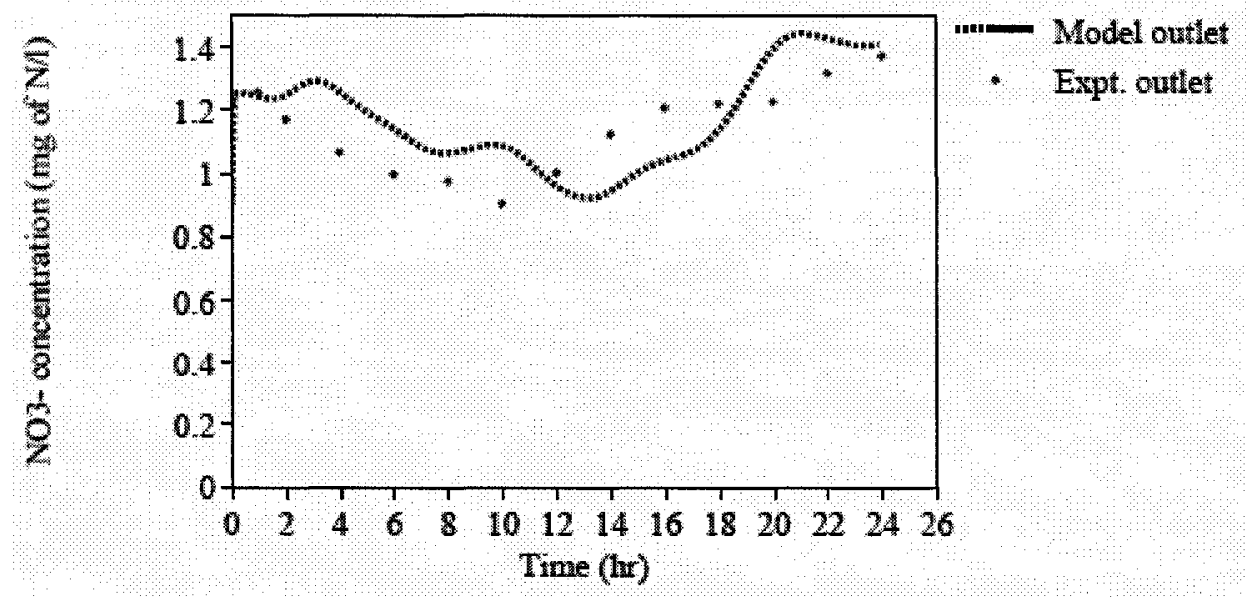

Figure 6.4(b) Leachate $\mathrm{NO}_{3}^{-}$result: experimental data vs. model prediction 


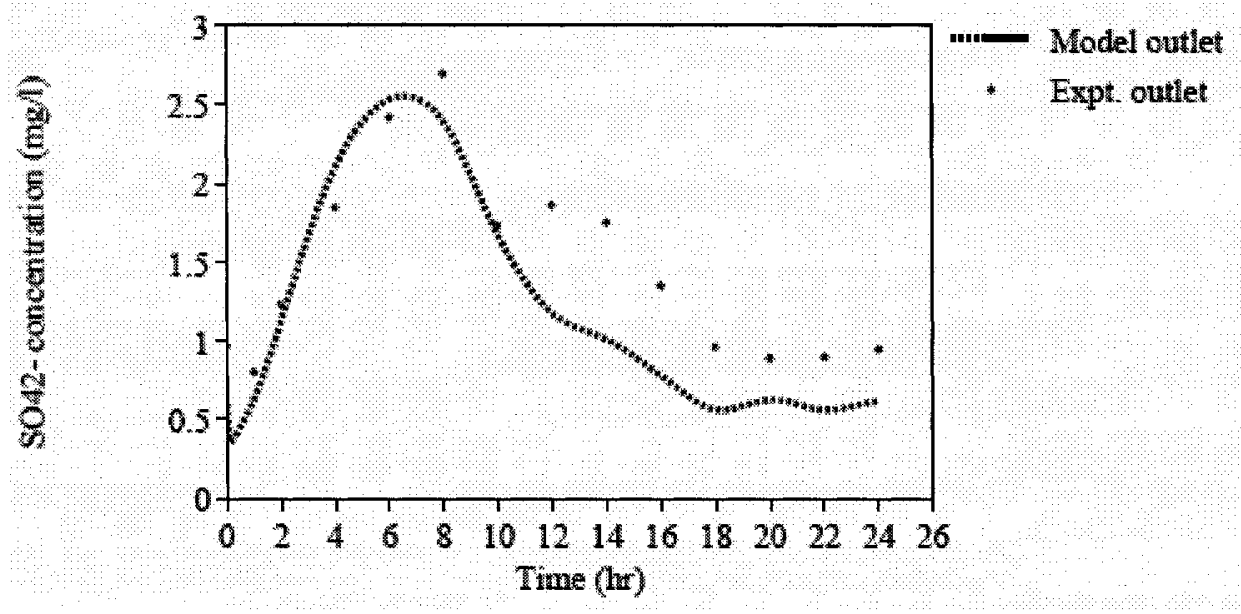

Figure 6.4(c) Leachate $\mathrm{SO}_{4}^{2-}$ result: experimental data vs. model prediction

As $\mathrm{NH}_{3}$ degradation is strongly dependent on $\mathrm{pH}$ and temperature, modeling such cases requires accurate data for the biofilter study to validate the model for the general purpose. Based on this model development, it seems important to have more accurate data for $\mathrm{pH}$, temperature and other variables such as alkalinity of the leachate that varied along the cycle. In this study, the model prediction for the leachate $\mathrm{pH}$ was a relatively good fit with the pilot study data. Figure 6.5 shows the $\mathrm{pH}$ results. The model prediction shows that the $\mathrm{pH}$ decreased at the beginning of the cycle, when the $\mathrm{NH}_{3}$ and DMDS loading increased. Then around the middle of the cycle, the $\mathrm{pH}$ increased to a relatively stable value for the rest of the cycle. Even though the $\mathrm{pH}$ drop in the model prediction was relatively higher than the experimental data, the $\mathrm{pH}$ drop was observed in all the pilot scale and full scale sampling event data, when the $\mathrm{NH}_{3}$ and $\mathrm{RSC}$ gas phase concentrations were peaking. 


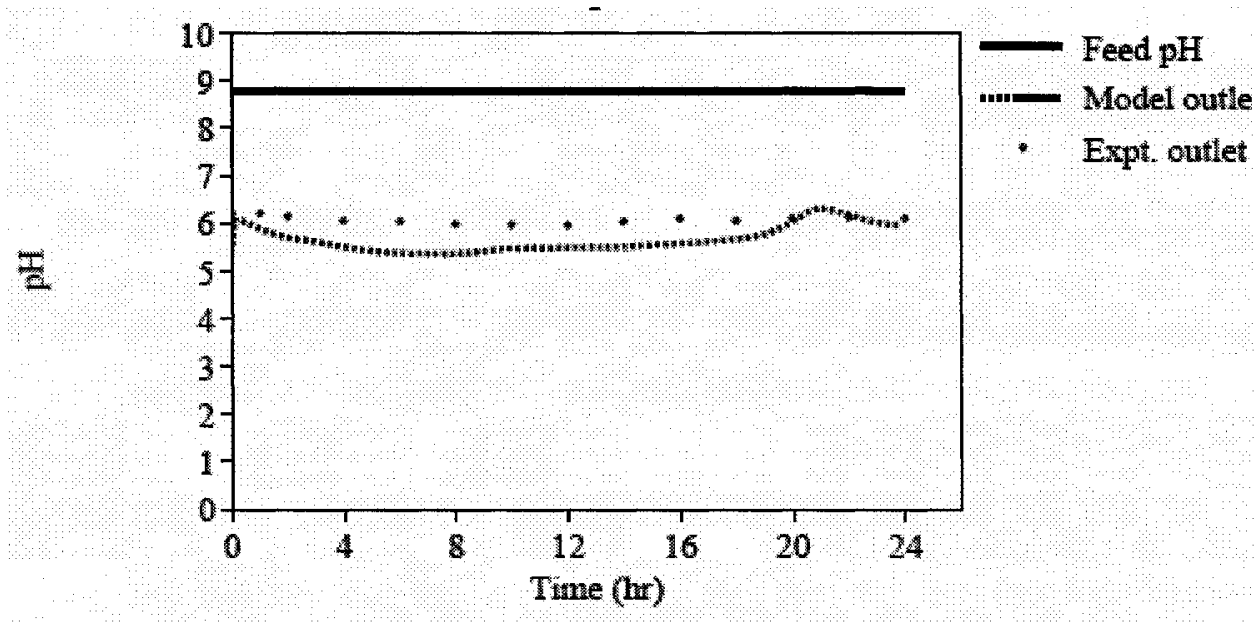

Figure 6.5 Leachate pH: experimental data vs. model prediction

In general, the experimental results and the model results did not match for all cases because of the complexity of the phenomena involved in the biofiltration process. For example, the $\mathrm{pH}$ prediction from a biofilter model was a challenging study. Since the $\mathrm{pH}$ of a natural biological system involved numerous variables and processes, it was very difficult to identify and measure all variables that affect the $\mathrm{pH}$. When the model was used to simulate another experimental data with different biofilter conditions, the results revealed that some of the parameters of the biofilter model needed to be adjusted according to the experimental data. Therefore, model validation studies need to be conducted to use this model for a general case. 


\subsection{Conclusions}

According to the literature, this is the first attempt to develop a dynamic biofilter model for a mixture of two distinct chemical compounds $\left(\mathrm{NH}_{3}\right.$ and $\left.\mathrm{RSC}\right)$. The dynamic biofilter model, which was incorporated into the AQUASIM program, was calibrated with pilot scale biofilter data. The critical observation of $\mathrm{NH}_{4}{ }^{+}$and $\mathrm{NO}_{3}{ }^{-}$concentration variations and the time at which $\mathrm{NH}_{3}$ (gas) concentration peaked along the cycle, was incorporated in the model. The empirical equation (Equation 6.9) was proposed for the Henry's coefficient of $\mathrm{NH}_{3}$ when $\mathrm{CO}_{2}$ concentration varied dynamically in the ATAD off gas.

The model simulation reasonably fit with the actual pilot-scale data, however, the model validation studies need to be conducted to use this model for a general case. The model simulations showed that aqueous phase compounds predictions were relatively high variability along the cycle compared to the gas phase predictions. This model was based on mass balances for the key components in the biofiltration process. The sensitivity of the model variables to the estimated model parameters was investigated. Mass transfer coefficient and biofilm diffusivity had significant effects on the pollutant degradation of $\mathrm{NH}_{3}$ and DMDS.

Further testing of this model using more data would be useful since only a few sampling events (4) were considered in the calibration of the model. Although rate equations and kinetic constants are available in the literature, investigation of certain critical processes such as $\mathrm{NH}_{3}$ solubility in the presence of $\mathrm{CO}_{2}$, is required, before the model can be validated for general usage. 


\section{Chapter \\ Seven}

\section{Overall Conclusions and Recommendations}

\subsection{Conclusions}

The preliminary full-scale study evaluated the effectiveness of the biofilter for the treatment of ATAD off gases. The full-scale wet scrubber removed approximately $85 \%$ of $\mathrm{NH}_{3}$ and $60 \%$ of $\mathrm{H}_{2} \mathrm{~S}$. The biofilter outlet gas concentration for all the compounds were below the detection limit. The biological transformations of RSC and $\mathrm{NH}_{3}$ resulted in the generation of acids. The leachate $\mathrm{pH}$ decreased from 7.7 to 7.2 , when $\mathrm{SO}_{4}{ }^{2-}$ and $\mathrm{NO}_{3}{ }^{-}$concentrations increased in the feed cycle. Almost $88 \%$ of the total $\mathrm{N}$ left the biofilter as $\mathrm{NH}_{4}^{+}-\mathrm{N}$ in the leachate and remaining $12 \%$ of the $\mathrm{N}$ left as nitrification products.

From the pilot-scale study, the ATAD variables such as temperature and ORP values through the feed cycle were evaluated. Immediately after the sludge feeding, the ORP value started to decrease to the lowest value, and then increased to a stable ORP value for the rest of the cycle. The ATAD temperature also slightly decreased immediately after the feeding, and then gradually increased to a stable temperature. The air flow rate into the ATAD controlled the ATAD temperature and ORP values. The lowest air flow rate (30 SLPM) resulted in a temperature that was $15^{\circ} \mathrm{C}$ higher than that observed with the highest air flow rate (150 SLPM). The solid content of digester sludge needed to be within a range of $3-6 \%$. The low sludge loading was not favorable in maintaining the thermophilic temperature while the high sludge loading was also not favorable for sludge 
mixing within the digester. The average TS reduction in the ATAD was $48.3 \%$ while the average VS reduction was $58.4 \%$.

The ATAD off gas consists of mainly $\mathrm{NH}_{3}, \mathrm{H}_{2} \mathrm{~S}$, MM, DMS, $\mathrm{CS}_{2}$, DMDS and DMTS. Due to the sludge-feeding pattern, the ATAD released $\mathrm{NH}_{3}$ and RSCs in a cyclic pattern. The dynamic variations of ATAD off gases were characterized at the scrubber inlet, biofilter inlet and biofilter outlet. The ATAD off gas production was influenced by the air flow rates and the sludge loading rates. When the air flow rate was high (150 SLPM), the gas production increased while the low air flow rate (30 SLPM) reduced the gas production. However, at low air flow rates, relatively high concentrations of pollutants were produced. When the sludge loading was high $(2451 / \mathrm{d})$, the gas production was relatively high and when the sludge loading was low $(150 \mathrm{l} / \mathrm{d})$, the gas production was relatively low.

The wet scrubber removed approximately $80 \%$ of $\mathrm{NH}_{3}$ and around $50 \%$ of RSC. More than $90 \%$ of the remaining RSC was removed within the biofilter in all operating conditions, while the residual $\mathrm{NH}_{3}$ gas removal varied from 50 to $90 \%$ based on operating conditions (e.g., bed temperature). The biofilter outlet RSC concentrations were below the detection limits other than off gas concentration peaking period. The Ncontaining compounds $\left(\mathrm{N}_{2} \mathrm{O}\right.$ and $\left.\mathrm{NOx}\right)$ other than $\mathrm{NH}_{3}$ were detected in the biofilter outlet; however these did not represent a significant quantity of the total outlet $\mathrm{N}$ mass.

The biofilter leachate concentrations were depending on the gas phase pollutant loading. The $\mathrm{SO}_{4}{ }^{2-}$ concentration peaking almost coincided with the $\mathrm{RSC}$ concentration peaking; 
however, the $\mathrm{NH}_{4}^{+}(\mathrm{aq})$ and $\mathrm{NO}_{3}^{-}$concentrations decreased when the $\mathrm{NH}_{3}$ gas concentration was peaking. It may be due to the cooling down of water saturated off gases, the production of other $\mathrm{N}$ containing compounds, or the effects of $\mathrm{NH}_{3}$ solubility in the presence of $\mathrm{CO}_{2}$.

The lack of mass balance closure varied between $+/-30 \%$ of the mass entering the biofilter. The lack of mass balance may be due to the pollutant measurement errors, flow measurement errors or the errors on the technique employed to estimate the mass balance.

The biofilter bed temperature had impact on the biofilter removal efficiency especially on $\mathrm{NH}_{3}$ removal. More than $80 \% \mathrm{NH}_{3}$ removal was observed at the warm bed $\left(26^{\circ} \mathrm{C}\right)$ while around $50 \%$ removal was observed at the cold bed temperature $\left(5^{\circ} \mathrm{C}\right)$. Also high bed temperature $\left(26^{\circ} \mathrm{C}\right)$ increased the nitrification process within the biofilter. The results indicated that the biofilter bed temperature enhanced the nitrification at the same time more contact time (EBRT) was needed to accommodate the nitrification process. The source of post-humidification either plant water or potable water did not stimulate the biofilter performance, once the biofilter had been fully populated with microorganisms. The changes in the bed $\mathrm{pH}$ have little impact on the biofilter removal efficiency. The studied mass loadings of both $\mathrm{S}$ and $\mathrm{N}$ did not affect the removal efficiency significantly. However the high loading of $\mathrm{NH}_{3}$ changed the removal mechanism and may inhibit complete nitrification within the biofilter. 
From this study, it can be concluded that the ATAD off gases can be treated effectively by the woodchip biofilter. The warm bed conditions $\left(-26^{\circ} \mathrm{C}\right)$ and high EBRT $(150 \mathrm{~s})$ enhance the overall removal efficiency of the off gas pollutants. The RSC are removed mainly by $\mathrm{S}$ oxidation to $\mathrm{SO}_{4}{ }^{2-}$, however, the $\mathrm{NH}_{3}$ gas removal mechanisms vary depend on biofilter operating conditions.

A dynamic model was developed to establish a mathematical description of processes (such as physical, chemical and biological) important in the dynamic biofiltration. The dynamic biofilter model, which was incorporated into AQUASIM program, was calibrated with pilot scale biofilter data. The model simulation reasonably fit with the experimental data, however, the model validation studies need to be conducted to use this model for a general case. The model simulations showed that aqueous phase compounds predictions were relatively high variability along the cycle compared to the gas phase predictions.

\subsection{Recommendations}

The research conducted during this study has indicated several areas of research which are worth pursuing. The impact of high loading of $\mathrm{NH}_{3}$ with cyclic dynamic system needs to be studied without other interference (e.g., RSC) to obtain better understanding on the $\mathrm{NH}_{3}$ removal mechanisms in the biofilter. This study may include model analysis with loading, temperature and $\mathrm{pH}$ inhibitions on the $\mathrm{NH}_{3}$ removal characteristics along the cycle. 
The impact on the biofilter packing material along the cycle needs to be investigated to obtain a better understanding of the dynamic removal of pollutants and removal mechanisms. The formation of intermediate compounds along the cycle also needs to be investigated to identify the possible transformation of the components such as $\mathrm{NH}_{3}$ and $\mathrm{CO}_{2}$.

Microbial data would be solid evidence to confirm some of the removal mechanisms, for example denitrification process. Therefore microbial analysis along the cycle may give more information about the removal mechanisms within the biofilter.

Further development on the sampling procedures and analytical technique for all possible trace gases may give better mass balance closure. It may also be helpful to get details about the removal mechanism within the biofilter. 


\section{REFERENCES}

Allen D.G., Kong Z., Fulthorpe R.R., and Farhana L., (2000), Thermophilic biofiltration of volatile organic compounds, Proceedings of the $93^{\text {rd }}$ annual Conference \& Exhibition of the Air \& Waste Management Association, Salt Lake City, Utah.

Alonso C., Zhu X., Suidan M.T., Kim B. R., and Kim B.J., (1998), Dynamic mathematical model for the biodegradation of VOCs in a biofilter: Biomass accumulation study, Environmental Science and Technology, Vol. 32, no. 20, pp. 3118-3123.

Alonso C., Zhu X., Suidan M.T., Kim B. R., and Kim B.J., (2000), Parameter estimation in biofilter systems, Environmental Science and Technology, Vol. 34, no. 11, pp. 23182323.

Alonso C., Zhu X., Suidan M.T., Kim B. R., and Kim B.J., (2001), Mathematical model of biofiltration of VOCs: Effect of nitrate concentration and backwashing, Journal of Environmental Engineering, Vol. 127, no. 7, pp. 655-664.

Alpert J.E., and Boyle M., (2000), Odor modeling and control at a biosolids composting facility, Water Environment Federation, Odors and VOC emissions 2000, Cincinnati, Ohio.

Al-Rayes A.W., Kinney K.A., Seibert A.F., and Corsi R.L., (2001), Load dampening System for vapor phase bioreactors, Journal of Environmental Engineering, Vol.127, no.3, pp.224-232.

Amanullah Md., Farooq S., and Viswanathan S., (1999), Modeling and simulation of a biofilter, Ind. Eng. Chem Res, Vol.38, pp.2765-2774.

Amirhor P., Gould J.D., Arnold.F.D., and Gracia Jr. H.J., (1997), Innovative biofilter controls odors, Biocycle, September 1997, pp.69-76.

Andrew G.F., and Noah K.S., (1995), Design of gas treatment bioreactors, Biotechnology Progress, Vol. 11, pp. 498-509.

Angelidaki I., Ellegaard L., and Ahring B.K., (1993), A mathematical model for dynamic simulation of anaerobic digestion of complex substrates: focusing on ammonia inhibition, Biotechnology and Bioengineering, Vol. 42, pp 159-166.

APHA (1995), Standard Methods for the Examination of Water and Wastewater, edited by Andrew D.E., Lenore S.C., and Arnold E.G., $19^{\text {th }}$ edition, Am. Pub Health. Assoc., Washington D.C. 
Arcangeli J.P., and Arvin E., (1999), Modeling the growth of a methanotrophic biofilm: estimation of parameters and variability, Biodegradation, Vol. 10, pp. 177-191.

Balchunas B.M., Hentz L.H., and Salley W.H., (2000), Odor control considerations for biological treatment systems, Water Environment Federation, Odors and VOC emissions 2000, Cincinnati, Ohio.

Baltzis B.C., Wojdyla.S.M., Zarook S.M., (1997), Modeling biofiltration of VOC mixtures under steady-state conditions, Journal of Environmental Engineering, Vol. 123, No. 6, June 1997.

Baquerizo G., Sakuma T., Deshusses M. A., Gamisans X., Gabriel D., and Lafuente J., (2004), A detailed model of a biofilter for ammonia removal: model parameters analysis and model validation, Proceedings of the USC-CSC-TRG conference on biofiltration for air pollution control - 2004, Redondo beach, CA., pp. 189-200.

Batstone D.J., Keller J., Angelidaki I., Kalyuzhnyi S.V., Pavlostathis S.G., Rozzi A., Sanders W.T.M., Siegrist H., and Vavilin V.A., (2002), The IWA anaerobic digestion model No 1 (ADM1), Water Science and Technology, Vol. 45, no. 10, pp. 65-73.

Becker J.G., North J.M., Seagren E.A., Peot C., and Ramirez M.A., (2003), Reduced sulfur compound production as an indicator of stability in limited biosolids, WEF/AWWA/CWEA Joint Residuals and Biosolids Management Conference and Exhibition 2003, Maryland USA Feb, 19-22, 2003.

Bohn H., and Bohn R., (1988), Soil beds weed out air pollutants, Chemical Engineering, April 25, Vol. 0095, pp. 73-76.

Bohn H.L., (1991), Odour removal by biofiltration: recent developments and practices in odour regulations, controls and technology, Edited by David R. Derenzo and Alex Gnyp, Air \& Waste Management Association, pp.135-147.

Bohn H.L., (1997), Biological treatment of air pollutants, Biotechnology in the Sustainable Environment, Edited by Sayler G.S., Sanseverino J., and Davis K.L., New York: Plenum Press, pp. 139-146.

Bohn H.L., and Bohn K.H., (1999), Moisture in biofilters, Environmental Progress, Vol. 18, No. 3, pp. 156-161.

Booth M.G., and Tramontini E., (1984), Thermophilic sludge digestion using oxygen and air, Book: Sewage sludge stabilization and disinfection, Ed: A.M. Bruce, publisher: Chichester, E.Horwood.

Budwill K., and Coleman R.N., (2000), Removal of dimethyl sulfide vapors in peatsbased biofilters, Proceedings of the $93^{\text {rd }}$ annual Conference \& Exhibition of the Air \& Waste Management Association, Salt Lake City, Utah. 
Cadenhead P. and Sublette K.L., (1990), Oxidation of hydrogen sulfide by Thiobacilli, Biotechnology and Bioengineering, Vol. 35, pp. 1150-1154.

Chitwood D.E., Devinny J.S., and Reynolds F.C., (1999), Evaluation of a two stage biofilter for treatment of POTW waste air, Environmental Progress, Vol. 18, No. 3, pp. 212-221.

Cho K.S., Hirai m., and Shoda M., (1991a), Degradation characteristics of $\mathrm{H}_{2} \mathrm{~S}$, MM, DMS, and DMDS by thiobacillus thioparus DW44 isolated from peat biofilter, Journal of Fermentation and Bioengineering, Vol. 71, No. 6, pp.384-389.

Cho K.S., Hirai m., and Shoda M., (1991b), Removal of DMDS by the peat seeded with night soil sludge, Journal of Fermentation and Bioengineering, Vol. 71, No. 4, pp.289291.

Choi J.H., Kim Y.H., Joo D.J., Choi S.J., Ha T.W., Lee D.H., Park I H., Jeong Y S., (2003), Removal of ammonia by biofilters: a study with flow modified system and kinetics, Journal of the Air and Waste Management Association, Vol.53, pp.92-101.

Chou M.S, and Shiu W.Z, (1997), Bioconversion of methylamine in biofilters, Journal of Air and Waste Management Association, Vol. 47, pp. 58-65.

Chung Y C., and Huang c., (1998), Biotreatment of ammonia in air by an immobilized nitrosomonas europaea biofilter, Environmetal Progress, Vol. 17, No. 2, pp.70-76.

Chung Y.C., Huang C., and Tseng C.P., (2001), Biological elimination of $\mathrm{H}_{2} \mathrm{~S}$ and $\mathrm{NH}_{3}$ from waste gases by biofilter packed with immobilized heterotrophic bacteria, Chemosphere, Vol.43, pp.1043-1050.

Chung Y.C., Huang C., Tseng C.P., and Pan J.R., (2000), Biotreatment of $\mathrm{H}_{2} \mathrm{~S}$ and $\mathrm{NH}_{3}$ containing waste gases by co-immobilized cells biofilter, Chemosphere, Vol.41, pp.329336.

Clemens J., and Cuhls C., (2003), Greenhouse gas emissions from mechanical and biological waste treatment of municipal waste, Environmental Technology, Vol. 24, pp.745-754.

Comas J., Balaguer M., Poch M., and Rigola M., (1999), Pilot plant evaluation for hydrogen sulphide biological treatment: Determination of optimal conditions linking experimental and mathematical modeling, Environmental Technology, Vol. 20, pp.53-59.

Corsi. R.L and Seed L., (1995), Biofiltration of BTEX: media, substrate, and loadings effects, Environmental Progress, Vol.14, No. 3, pp. 151-158.

Cox H.H.J., Iranpour R., Moghaddam O., Schroeder E.D., and Deshusses M.A., (2003), Biological odour control strategies at wastewater treatment plants, WEF/AWWA/CWEA 
Joint Residuals and Biosolids Management Conference and Exhibition 2003, Maryland USA Feb, 19-22, 2003.

Coulson J.M., and Richardson J.F., (1996), Coulson and Richardson's Chemical Engineering, Volume 1: Fluid flow, heat transfer and mass transfer, Fifth edition, Butterworth-Heinemann Ltd, Oxford.

Davies P.R., and Roberts M. W., (1992), Activation of carbon dioxide by ammonia at $\mathrm{Cu}(100)$ and $\mathrm{Zn}(0001)$ surfaces leading to the formation of a surface carbamate, Journal of Chemical Society: Faraday Transactions, Vol. 88, No. 3, pp.361-368.

De Bont J.A.M., Van Dijken J.P., and Harder W., (1981), Dimethyl sulphide as a carbon, sulphur and energy source for growth of Hyphomicrobium S, Journal of General Microbiology, Vol. 127, pp. 315-323.

Dedieu A., Bo C., and Ingold F., (1991), Carbon dioxide organometallic chemistry theoretical developments, metal ligand interactions from atoms to clusters, to surfaces, Edited by Salahub D.R., and Russo N., Kluwer Academic Publishers, The Netherlands.

Demeestere K., Van Langenhove H., Smet E., (2002), Regeneration of a compost biofilter degrading high loads of ammonia by addition of gaseous methanol, Journal of the Air and Waste Management Association, Vol. 52, pp.796-804.

Deshusses M.A., (1997), Treatment behavior of biofilters: start-up, carbon balances, and interactions between pollutants, Journal of Environmental Engineering, Vol.123, No. 6, pp. 563-568.

Deshusses M.A., Hamer G., and Dunn I.J., (1995a), Behavior of biofilters for waste air biotreatment. 1. Dynamic model development, Environmental Science \& Technology, Vol. 29, pp.1048-1058.

Deshusses M.A., Hamer G., and Dunn I.J., (1995b), Behavior of biofilters for waste air biotreatment. 2. Experimental evaluation of dynamic model, Environmental Science \& Technology, Vol. 29, pp.1059-1068.

Devinny J.S., Deshusses M.A., and Webster T.S., (1999), Biofiltration for air pollution control, Lewis publishers.

du Plessis C.A., Kinney K.A., Schroeder E.D., Chang D.P.Y and Scow K.M., (1998), Denitrification and nitric oxide reduction in an aerobic toluene treating biofilter, Biotechnology and Bioengineering, Vol. 58, No.4, pp.408-415.

Emerson K., Russo R.C., Lund R.E., and Thurston R.V., (1975), Aqueous ammonia equilibrium calculations: effect of $\mathrm{pH}$ and temperature, Journal of the Fisheries Research Board of Canada, Vol. 32, No. 12, pp. 2379-2383. 
Epstein E., (2003), Land application of biosolids and residuals: public and worker health issues, WEF/AWWA/CWEA Joint Residuals and Biosolids Management Conference and Exhibition 2003, Maryland USA Feb, 19-22, 2003.

Fan L.S., Leyva-Ramos R., Wisecarver K.D., and Zehner B.J., (1990), Diffusion of phenol through a biofilm grown on activated carbon particles in a draft-tube three-phase fluidized-bed bioreactor, Biotechnology and Bioengineering, Vol. 35, pp.279-286.

Fothergill S., and Mavinic D.S., (2000), VFA production in thermophilic aerobic digestion of municipal sludges, Journal of Environmental Engineering, Vol. 126, no. 5, pp. 389-396.

Gibsion M.J., (2001), Biofiltration of DMDS and $\mathrm{NH}_{3}$ : Investigation of the underlying microbial activities, Ph.D. thesis, The University of Guelph.

Gibson M.J., and Otten L., (1997), Dynamic response of compost biofilters: Laboratory studies using dimethyl disulphide, Air \& Waste Management Association's $90^{\text {th }}$ Annual meeting \& Exhibition, June 8-13, Toronto, Ontario, Canada.

Goldstein N., (1996), Odor control experiences: lessons from the biofilter, Biocycle, April 1996, Vol. 37, No.4, pp.70-74.

Gostelow P., Parsons S.A., and Cobb J., (2001), Development of an odorant emission model for sewage treatment works, Water Science and Technology, Vol.44, No.9, pp.181-188.

Gostelow P., Parsons S.A., and Stuetz R.M., (2001), Odor measurements for sewage treatment works, Water Research, Vol. 35, No.3, pp.579-597.

Hales J.M., and Drewes D.R., (1979), Solubility of ammonia in water at low concentrations, Atmospheric Environment, Vol. 13, pp.113-1147.

Hamer G., (1989), Fundamental aspects of aerobic thermophilic biodegradation, Treatment of sewage sludge: thermophilic aerobic digestion and processing requirements for landfilling / edited by A.M. Bruce, F. Colin, and P.J. Newman, Elsevier applied science London and New York, pp. 2-19.

Hao X., Heijnen J.J., and van Loosdrecht M.C.M., (2002), Sensitivity analysis of a biofilm model describing a one-stage completely autotrophic nitrogen removal (CANON) process, Biotechnology and Bioengineering, Vol. 77, No. 3, pp. 266-277.

Hartikainen T., Ruuskanen J., Vanhatalo M., and Martikainen P.J., (1996), Removal of ammonia from air by peat biofilter, Environmental Technology, Vol. 17, pp.45-53. 
Hartung E., Martinec M., and Jungbluth T., (2001), Biofilters- the influence of different filter materials and different operating conditions on the reduction efficiency, Water Science and Technology, Vol.44, No.9, pp.253-260.

Hautakangas H., Mihelcic J.R., Crittenden J.C., and Oman E.J., (1999), Optimization and modeling of biofiltration for odour control, Water Environment Federation, WETEC'99, New Orleans, Los Angeles

Hentz L.H., and Balchunas B.M., (2000), Chemical and physical processes associated with mass transfer in odor control scrubbers, Water Environment Federation, Odors and VOC emissions 2000, Cincinnati, Ohio.

Hentz L.H., (1997), The chemical, biological and physical origins of biosolids emissions: a review, Post, Buckley, Schuh \& Jemigan Inc., Bowie, Maryland.

Hepner S., Striebig B., and Regan R., (2002), Odor generation and control from the Autothermal Thermophilic Aerobic Digestion (ATAD) process, Water Environment Federation, Odors and Toxic air emissions 2002, Albuquerque, NM

Higgins M.J., Yarosz D.P., Chen Y.C., Murthy S.N., Mass N.A., and Cooney J.R., (2003), Mechanisms of volatile sulfur compound and odour production in digested biosolids, WEF/AWWA/CWEA Joint Residuals and Biosolids Management Conference and Exhibition 2003, Maryland USA, Feb, 19-22, 2003.

Hirai M., Ohtake M., and Shoda M., (1990), Removal kinetics of hydrogen sulfide, methanethiol and dimethyl sulfide by peat biofilters, Journal of Fermentation and Bioengineering, Vol. 70, No. 5, pp.334-339.

Hirano T., Kurosawa H., Nakamura K., and Amano Y., (1996), Simultaneous removal of hydrogen sulfide and trimethylamine by a bacterial deodourant, Journal of Fermentation and Bioengineering, Vol. 81, No. 4, pp. 337-342.

Hodge D.S., and Devinny J.S., (1995), Modeling removal of air contaminants by biofiltration, Journal of Environmental Engineering, Vol. 121, No. 1, pp. 21-32.

Hunt G.T., (2000), Reduced sulfur (TRS) monitoring wastewater/ biosolids process emissions evaluation and selection of methods, Water Environment Federation, Odors and VOC emissions 2000, Cincinnati, Ohio.

Janssen A.J.H., Sleyster R., Kaa C.V.D., Jochemsen A., Bontsema J., and Lettinga G., (1995), Biological Sulphide Oxidation in a Fed-Batch Reactor, Biotechnology and Bioengineering, Vol. 47, pp. 327-333.

Jensen A.B., and Webb C., (1995), Treatment of $\mathrm{H}_{2} \mathrm{~S}$-containing gases: A review of microbiological alternatives, Enzyme and Microbial Technology, Vol.17, pp.2-10. 
Johan W. van Groenestijn and Paul G.M. Hesselink., (1993), Biotechniques for air pollution control, Biodegradation, Vol. 4, No.4, pp. 283-301.

Johnson C.T., and Deshusses M.A., (1997), Quantitative structure activity relationships for VOC biodegration in biofilters, Insitu and on-site bioremediation: papers from the fourth international insitu and on site bioremediation symposium, New Orleans, April 28 - May 1, 1997, Battelle Press, pp. 175-180.

Jones K.D., Martinez A., Maroo K., and Deshpande S., (2004), Kinetic evaluation of $\mathrm{H}_{2} \mathrm{~S}$ and $\mathrm{NH}_{3}$ biofiltration for two media used for wastewater lift station emissions, Journal of the Air and Waste Management Association, Vol. 54, pp. 24-35.

Joshi J.A., Hogan J.A., Cowan R.M., Strom P.F., and Finstein M.S., (2000), Biological removal of gaseous ammonia in biofilters: space travel and earth based applications, Journal of the Air and Waste Management Association, Vol. 50, pp. 1647-1654.

Kampbell D.H., Wilson J.T., Read H.W., and Stocksdale T.T., (1987), Removal of volatile aliphatic hydrocarbons in a soil bioreactor, JAPCA, vol. 37, pp.1236-40.

Kanagawa T., and Kelly D.P., (1986), Breakdown of dimethyl sulphide by mixed cultures and by Thiobacillus thioparus, FEMS Microbiology Letters, Vol. 34, pp.13-19

Kanagawa T., and Mikami E., (1989), Removal of mthanethiol, dimethyl sulfide, dimethyl disulfide, and hydrogen sulfide from contaminated air by thiobacillus thioparus TK-m, Applied and Environmental Microbiology, Vol.55, no.3, pp.555-558.

Karmarkar S., Bahowick T., (2001), Determination of inorganic anions by ion chromatography, QuikChem method 10-510-00-1-A, Lachat instruments division, Milwaukee, WI, USA

Kelly H.G., (1990), Demonstration of an improved digestion process for municipal sludges, Supply and services contract KE405-8-6575/01-SE, UP-D8-010, Dayton and Knight Ltd consulting engineers

Kelly H.G., Melcer H., and Mavinic D.S., (1993), Autothermal thermophilic aerobic digestion of municipal sludges: A one year, full scale demonstration project, Water Environment Research, Vol.65, no. 7, 849-861

Kikuchi R., (2000), Pilot-scale test of a soil filter for treatment of malodorous gas, Soil Use and Management, Vol.16, pp.211-214.

Kim H., Kim Y.J., Chung J.S., and Xie Q., (2002), Long-term operation of biofilter for simultaneous removal of $\mathrm{H}_{2} \mathrm{~S}$ and $\mathrm{NH}_{3}$, Journal of the Air and Waste Management Association, Vol.52, pp.1389-1398. 
Kim N.J., Hirai M., and Shoda M., (2000a), Comparison of organic and inorganic packing materials in the removal of ammonia gas in biofilters, Journal of Hazardous Materials, Vol . B72, pp. 77-90.

Kim N.J., Sugano Y., Hirai M., and Shoda M., (2000b), Removal of a high of ammonia gas by a Marine bacterium: Vibrio alginolyticus, Journal of Bioscience and Bioengineering, Vol. 90, No. 4, pp. 410-415.

Koe L.C.C., and Ng W.J., (1987), Identification of odorous gases originationg from refuse waste, Water, Air and Soil Pollution, Vol. 33, pp.199-204.

Koe L.C.C., and Shanchayan B., (2001), Air pollution control: biofiltration using sand media, Conference proceedings of Engineering beyond 2000, National University of Singapore, Singapore.

Koe L.C.C., and Yang F., (1999), Development of a fixed-film bioscrubber for hydrogen sulfide removal, Water Environment Federation, WETEC'99, New Orleans, Los Angeles, USA.

Kong S., and Allen E.R., (1997), Control of organo-sulphur emissions using biofiltration: dimethyl sulphide, Air \& Waste Management Association's $90^{\text {th }}$ annual meeting \& Exhibition, June 8-13, Toronto, Ontario, Canada.

Kurz F., Rumpf B., and Maurer G., (1995), Vapor-liquid-solid equilibria in the system $\mathrm{NH}_{3}-\mathrm{CO}_{2}-\mathrm{H}_{2} \mathrm{O}$ from around 310 to $470 \mathrm{~K}$ : new experimental data and modeling, Fluid Phase Equilibria, Vol. 104., pp.261-275.

LaPara T.M., and Alleman J.E. (1998), Autothermal thermophilic aerobic waste treatment systems: a state of the art review, Proceedings of the $52^{\text {nd }}$ Purdue industrial waste conference, Purdue University, West Lafayette, Indiana.

Lau A.K., Fast F.E., and Marder D., (1994), Composting odor control using biofilters, Agricultural Institute of Canada annual conference, Canadian Society of Agricultural Engineering, Regina, Saskatchewan, July19-14, 1994.

Lay J.J., Li Y.Y., and Noike T., (1998), Mathematical model for methane production from landfill bioreactor, Journal of Environmental Engineering, Vol.124, no. 8.

Le Cloirec P., Humeau P. and Ramirez-Lopez E.M., (2001), Biotreatments of odours: Control and performances of a biofilter and a bioscrubber, Water Science and Technology, Vol.44, No.9, pp.219-226.

Leson G. and Winer A.M., (1991), Biofiltration: an innovative air pollution control technology for VOC emissions, Journal of Air and Waste Management Association, Vol. 41, No. 8, pp.1045-54. 
Li B., and Bishop P., (2002), Oxidation-reduction potential (ORP) regulation of nutrient removal in activated sludge wastewater treatment plants, Water Science and Technology, Vol. 46, No. 1-2, pp 35-39.

Li H, Crittenden J.C., Mihelcic J.R., and Hautakangas H., (2002a), Optimization of biofiltration for odor control: Model development and parameter sensitivity, Water Environment Research, Vol.74, No.1, pp.5-16.

Li H., Mihelcic J.R., Crittenden J.C., and Anderson K.A., (2002b), Application of a dynamic biofiltration model to a two stage biofilter that treats hydrogen sulfide and organic sulfur compounds, WEFTEC 2002, Water Environment Federation.

Li H., Mihelcic J.R., Crittenden J.C., and Anderson K.A., (2003), Field measurements and modeling of two stage biofilter that treats odorous sulfur air emissions, Journal of Environmental Engineering, Vol. 129, No. 8, pp. 684-692.

Liang Y., Quan X., Chen J., Chung J.S., Sung J.Y., Chen S., Xue D., and Zhao Y., (2000), Long-term results of ammonia removal and transformation by biofiltration, Journal of Hazardous Materials, B80, pp.259-269.

Liberty K., and Taraba J., (2002), Dynamics within a yard waste compost biofilter during ammonia biotransformation, Water Environment Federation, Odors and Toxic Air Emissions 2002, Albuquerque, NM

Lin Y. H., and Lee K.K., (2001), Verification of anaerobic biofilm model for phenol degradation with sulfate reduction, Journal of Environmental Engineering, Vol. 127, No. 2, pp.119-125.

Lith C.V., Leson G., and Michelsen r., (1997), Evaluating design options for biofilters, Journal of Air and Waste Management Association, Vol. 47, pp.37-48.

Lopez T.M., Dreessen W.J., and Schafer P.L., (2000), Identification and measurement of peak odors, Water Environment Federation, Odors and VOC emissions 2000, Cincinnati, Ohio.

Luo J., (2001), A pilot-scale study on biofilters for controlling animal rendering process odours, Water Science and Technology, Vol.44, No.9, pp.277-285.

Malhautier L., Gracian C., Roux J.C., Fanlo J.L., and Cloirec P.L., (2003), Biological treatment process of air loaded with an ammonia and hydrogen sulfide mixture, Chemosphere, Vol. 50., pp.145-153

Martin G., Lemasle M., and Taha S., (1996), The control of gaseous nitrogen pollutant removal in a fixed peat bed reactor, Journal of Biotechnology, Vol 46, pp.15-21. 
Martin R.W., Li H., Mihelcic J.R., Crittenden J.C., Lueking D.R., Hatch C.R., Ball P., (2001), Optimization of biofiltration for odor control: Model calibration, validation, and applications, Water Environment Research, Vol.74, No.1, pp.17-27.

McFarland M.J., (2001), Biosolids Engineering, McGraw Hill, New York.

Moe W.M., and Irvine R.L., (2000), Performance of periodically operated-gas phase biofilters during transient loading conditions, Water Science and Technology, Vol. 41, No. 4-5, pp.441-444.

Morales M., Revah S., and Auria R., (1998), Start-up and the effect of gaseous ammonia additions on a biofilter for the elimination of toluene vapors, John Wiley \& Sons Inc. Biotechnology and Bioengineering Vol. 60, pp.483-491.

Morgan-Sagastume F., Sleep B.E., and Allen D.G., (2001), Effects of biomass growth on gas pressure drop in biofilters, Journal of Environmental Engineering, Vol. 127, No. 5, pp. 388-396.

Murthy S.N., Novak J.T., Holbrook R.D., and Surovik F., (2000), Mesophilic aeration of autothermal thermophilic aerobically digested biosolids to improve plant operations, Water Environment Research, Vol.72, No.4, pp.476-483.

Nave C.R., (2000), Hyper Physics, department of physics and astronomy, Georgia State University, Atlanta, Georgia

Ni J., (1999), Mechanistic models of ammonia release from liquid manure: a review, Journal of Agriculture Engineering Research, Vol. 72, pp.1-17.

Nicolai R.E., and Janni K.A., (2001), Biofilter media mixture ratio of woodchips and compost treating swine odors, Water Science and Technology, Vol.44, No.9, pp.261-267.

Ottengraf S.P.P. and Oever A.H.C.V.D., (1983), Kinetic of organic compound removal from waste gases with a biological filter, Biotechnology and Bioengineering, Vol. 25, pp. 3089-3102.

Ottengraf S.P.P., (1986), Exhaust gas purification, Biotechnology, Vol. 8, Edited by Rehm.H.J., and Reed G., VCH Verlagsgesellschaft, Weinheim, pp. 426-452.

Ottengraf S.P.P., Diks R.M.M., (1991), Process technology of biotechniques: Biotechniques for air pollution abatement and odour control policies, Proceedings of an International Symposium, 27-29, Oct., pp. 17- 31.

Ottengraf S.P.P., Oever A.H.C.V.D., and Kempenaars F.J.C.M., (1984), Waste Gas Purification in a Biological Filter Bed, Innovations in Biotechnology, edited by E.H. Houwink and R.R.van der Mer, Elsevier Science Publishers B.V., Amsterdam, The Netherlands, pp. 157-167. 
Park S.J., Nam S.I., and Choi E.S., (2001), Removal of odour emitted from composting facilities using a porous ceramic biofilter, Water Science and Technology, Vol.44, No.9, pp.301-308.

Pazuki G.R., Pahlevanzadeh H., and Ahooei A.M., (2006), Solubility of $\mathrm{CO}_{2}$ in aqueous ammonia solution at low temperature, Computer Coupling of Phase Diagrams and Thermochemistry, Vol. 30., pp.27-32.

Phae C.G., and Shoda M., (1991), A new fungus which degrades hydrogen sulfide, methanethiol, dimethyl sulfide and dimethyl disulfide, Biotechnology Letters, Vol.13, No.5, pp.375-380.

Phillips V.R., Scolford I.M., White R.P., and Hartstorn R.F., (1995), Minimum cost biofilters for reducing odours and others aerial emissions from livestock buildings: Part 1, basic airflow aspects, Journal of Agriculture Engineering Research, Vol. 62, pp. 203-214.

Pinjing H., Liming S., Zhiwen Y., and Guojian L., (2001), Removal of $\mathrm{H}_{2} \mathrm{~S}$ and MM by a packed tower with immobilized micro-organism beads, Water Science and Technology, Vol.44, No.9, pp.327-333.

Poughon L., Dussap C.G., and Gros J.B., (1998), Dynamic model of a nitrifying fixed bed column: simulation of the biomass distribution of nitrosomonas and nitrobacter and of transient behaviour of the column, Bioprocess Engineering, Vol.20, pp.209-221.

Pride C., (2001), ATADs, odors, and biofilters, Ambio biofiltration Ltd.

Pride C., (2002), ATADs, odors, and biofilters, Florida water resources journal, April 2002, pp. 18-26.

Reichert P., (1994), AQUASIM: a tool for simulation and data analysis of aquatic systems, Water Science and Technology, Vol. 30, no. 2, pp. 22-30.

Reichert P., (1998), AQUASIM 2.1f: user manual, Swiss Federal institute for Environmental Science and Technology (EAWAG), Dubendorf, Switzerland.

Reichert P., and Wanner O., (1997), Movement of solids in biofilms: significance of liquid phase transport, Water Science and Technology, Vol. 36, no.1, pp 321-328.

Ristow N.E, Whittington K., Corbett C., Rose P., and Hansford G.S., (2002), Modeling of a recycling sludge bed reactor using AQUASIM, Water SA (Water Research Commission), Vol.28, No.1, pp.111-120.

Rittmann N.E., Banaszak J.E., VanBriesen J.M., and Reed D.T., (2002), Mathematical modeling of precipitation and dissolution reactions in microbiological systems, Biodegradation, Vol. 13, pp 239-250. 
Rittmann B.E., and McCarty P.L., (1980), Evaluation of steady state biofilm kinetics, Biotechnology and Bioengineering, Vol. 22, PP.2359-2373.

Rittmann B.E., and McCarty P.L., (1980), Model of steady state biofilm kinetics, Biotechnology and Bioengineering, Vol. 22, PP.2343-2357.

Rittmann B.E., and McCarty P.L., (2001), Environmental biotechnology: principles and applications, McGraw-Hill, international edition, Singapore.

Rumpf B., Kamps A. P., Sing R., and Maurer G., (1999), Simultaneous solubility of ammonia and hydrogen sulfide in water at temperatures from $313 \mathrm{~K}$ to $393 \mathrm{~K}$, Fluid Phase Equilibria, Vol. 158-160, pp 923-932.

Sander R., (2004), http://www.mpch-mainz.mpg.de/ sander/res/henry.html

Sawyer C.N., (1978), Chemistry for Environmental Engineering, McGraw-Hill, New York.

Scisson J.P., (2003), ATAD, the next generation: design construction, start-up and operation of the first municipal 2nd generation ATAD, WEF/AWWA/CWEA Joint Residuals and Biosolids Management Conference and Exhibition 2003, Maryland USA, Feb, 19-22, 2003.

Shanchayan B., (2001), A sand biofilter for treatment of odorous air, M.Eng Thesis, National University of Singapore, Singapore.

Shanchayan B., Parker W., and Pride C., (2003), Dynamic analysis of a biofilter treating ATAD offgas, Paper submitted to the $2^{\text {nd }}$ Canadian organic residuals recycling conference, April 24 and 25, 2003.

Shareefdeen $\mathrm{Z}$ and Baltzis B.C., (1994a), Biological removal of hydrophobic solvent vapors from airstreams, Advances in Bioprocess Engineering, Ed: Galindo E., and Ramfrez O.T., Kluwer academic publishers, the Netherlands, pp.397-404.

Shareefdeen Z., and Baltzis B.C., (1994b), Biofiltration of toluene vapor under steadystate and transient conditions: Theory and experimental results, Chemical Engineering Science, vol.49, No.24A, pp.4347-4360.

Shareefdeen Z., Baltzis B.C., Oh Y.S., and Bartha R., (1993), Biofiltration of methanol vapor, Biotechnology and Bioengineering, Vol.41, pp.512-524

Simonelli D., Baldelli S., and Shultz M. J., (1998), Ammonia-water complexes on the surface of aqueous solutions observed with sum frequency generation, Chemical Physics Letters, Vol. 298, pp. 400-404. 
Sincero A.P., and Sincero G.A., (2003), Physical chemical treatment of water and wastewater, IWA publishing, CRC Press, Florida.

Singleton B., and Milligan D., (2000), The evolution of biofiltration and the application of third generation designs, Water Environment Federation, Odors and VOC emissions 2000, Cincinnati, Ohio.

Smet E., Van Langenhove H., and Maes K., (2000), Abatement of high concentrated ammonia loaded waste gases in compost biofilters, Water, Air, and Soil Pollution, Vol.119, pp.177-190.

Smet E., Van Langenhove H., and Verstraete W., (1996a), Long-term stability of a biofilter treating dimethyl sulphide, Applied Microbiology and Biotechnology, Vol. 46, pp.191-196.

Smet E., Van Langenhove H., and Verstraete W., (1996b), the effect of inoculation and the type of carrier material used on the biofiltration of methyl sulphides, Applied Microbiology and Biotechnology, Vol. 45, pp.293-298.

Smith N.A., and Kelly D.P., (1988a, Isolation and physiological characterization of autotrophic sulphur bacteria oxidizing dimethyl disulphide as sole source of energy, Journal of General Microbiology, Vol. 134, pp.1407-17.

Smith N.A., and Kelly D.P., (1998b), Mechanism of oxidation of dimethyl disulphide by Thiobacillus thioparus strain E6, Journal of General Microbiology, Vol.134, pp.30313039.

Staton K.L., Alleman J.E., Pressley R.L., and Eloff J., (2001), $2^{\text {nd }}$ generation autothermal thermophilic aeration digestion: Conceptual issues and process advancements, WEF/AWMA/CWEA joint residuals and biosolids management conference, Feb.2001.

Strauss J. M., du Plessis C.A., and Riedel K.H.J., (2000), Empirical model for biofiltration of toluene, Journal of Environmental Engineering, Vol.126, No.7, pp.644648.

Sun Y., Clanton C.J., Janni K.A., and Malzer G.L., (2000), Sulfur and nitrogen balances in biofilters for odorous gas emission control, American Society of Agricultural Engineers, Vol. 43(6), pp. 1861-1875.

Swanson W.J., and Loehr R.C., (1997), Biofiltration: fundamentals, design and operations principles, and applications, Journal of Environmental Engineering, Vol. 123, No. 6, pp. 538-546.

Tang H.M., Hwang S.J. and Hwang S.C., (1996), Waste gas treatment in biofilters, Journal of the Air and Waste Management Association, Vol. 46, pp. 349-354. 
Taylor B.F and Kiene R.P., (1989), Microbial metabolism of dimethyl sulfide, Biogenic Sulfur in the Environment, American Chemical Society, pp.202-217.

Taylor B.F., (1989), Bacterial transformations of organic sulfur compounds in marine environments, Biogenic Sulfur in the Environment, American Chemical Society, pp.745774.

Tchobanoglous G., Burton F.L., and Stensel H.D., (2003), Wastewater engineering: treatment and reuse, Metcalf $\&$ Eddy, $4^{\text {th }}$ edition, McGraw Hill.

Thomsen K., and Rasmussen P., (1999), Modeling of vapor-liquid-solid equilibrium in gas-aqueous electrolyte systems, Chemical Engineering Science, Vol. 54., pp. 1787-1802.

Togashi I., Suzuki m., Hirai M., Shoda M., and Kubota h., (1986), Removal of $\mathrm{NH}_{3}$ by a peat biofilter without and with nitrifier, Journal of Fermentation Technology, Vol. 64., No. 5., pp.425-432.

Tsipis C. A., and Karipidis P.A., (2005), Mechanistic insights into the bazarov synthesis of urea from $\mathrm{NH}_{3}$ and $\mathrm{CO}_{2}$ using electronic structure calculation methods, Journal of physical Chemistry A, Vol. 109., pp. 8560-8567.

USEPA (United States Environmental Protection Agency), (1990), Autothermal thermophilic aerobic digestion of municipal wastewater sludge, Environmental Regulations and Technology, Office of research and development, Washington, DC 20460.

USEPA (United States Environmental Protection Agency), (1995), AP42, volume1, $5^{\text {th }}$ edition.

VanBriesen J.M., and Rittmann N.E., (2000), Mathematical description of microbiological reactions involving intermediates, Biotechnology and Bioengineering, Vol. 67, No.1, PP.35-52.

Van Groenestijn J.W., van Heiningen W.N.M., and Kraakman N.J.R., (2001), Biofilters based on the action of fungi, Water Science and Technology, Vol.44, No.9, pp.227-232.

Van Langenhove H., Bendinger B., Oberthur R., and Schamp N., (1992), Organic sulfur compounds: persistent odourants in the biologicaltreatment of complex waste gases, Biotechniques for Air Pollution Abatement and Odour Control Policies, Ed: A.J. Dragt and J van Ham, Elsevier Science Publishers B.V., pp. 177-182.

Van Langenhove H., Wuyts E., and Schamp N., (1986), Elimination of hydrogen sulphide from odorous air by a wood bark biofilter, Water Research, Vol.20, pp.14711476. 
Visan M.M., (2003), Mechanisms of odour production in dewatered biosolids, M.A.Sc in Environmental Engineering thesis, Dept. civil and Env. Engineering, Carleton University.

Wani A.H., Branion R.M.R., and Lau A.K., (1998), Effects of periods of starvation and fluctuating hydrogen sulfide concentration on biofilter dynamics and performance, Journal of Hazardous Materials, Vol. 60, pp. 287-303.

Wanner $O$ and Morgenroth E., (2004), Biofilm modeling with AQUASIM, Water Science and Technology, Vol. 49, no. 11-12, pp. 137-144.

Webster T. S., Togna A.P., Guarini W.J., Hooker B., and Tran H., (2000), Operation of a full-scale biotrickling filter reactor to treat off-gas emissions generated from an industrial wastewater treatment plant, Water Environment Federation, Odors and VOC emissions 2000, Cincinnati, Ohio.

WEF (Water Environment Federation), (1995), Odor control in wastewater treatment plants, prepared by a joint task force of the Water Environment Federation and the American Society of Civil Engineers, Alexandria, VA.

Wood P.M., (1986), Nitrification as a bacterial energy source, Nitrification, Ed: J.I. Prosser, published by Society for General Microbiology, IRL press, England.

Wu L., Loo Y.Y., and Koe L.C.C., (2001), A pilot study of a biotrickling filter for the treatment of odorous sewage air, Water Science and Technology, Vol.44, No.9, pp.295299.

Yang Y. and Allen E.R., (1994a), Biofiltration control of hydrogen sulfide 1. Design and operational parameters, Journal of Air and Waste Management Association, pp. 863-868.

Yang Y. and Allen E.R., (1994b), Biofiltration control of hydrogen sulfide 2. Kinetics, biofilter performance and maintenance, Journal of Air and Waste Management Association, pp. 1315-1320.

Yani M., Hirai M., and Shoda M., (1998), Removal kinetics of ammonia by peat biofilter seeded with night soil sludge, Journal of Fermentation and Bioengineering, Vol. 85, No. 5, pp.502-506.

Zhang K., Kurano N., and Miyachi S., (2002), Optimixed aeration by carbondioxide gas for microalgal production and mass transfer characterization in a vertical flat-plate photobioreactor, Bioprocess Biosystems Engineering, Vol.25, No. 2, pp.97-101.

Zhu X., Suidan M.T., Pruden A., Yang C., and Alonso C., (2004), Effect of substrate Henry's constant on biofilter performance, Journal of Air and Waste Management Association, Vol. 54, pp.409-418. 


\section{Appendix A: Experimental schedule and operating conditions}

As discussed in Section 4.2.2, the experimental plan for the pilot study was organized. The experimental schedules and corresponding ATAD and biofilter operating conditions are given in Table A1. In this table, the sampling date referred to the starting date of the sampling and a 24-hour sampling was completed in the following day morning. Within the ATAD conditions, the constant ORP and constant temperature values were referred to the stable ORP and temperature values of latter part of the cycle as discussed in Section 5.2. The sludge (TWAS) feed solids-contents were corresponding to the sampling day feed. However, the ATAD solids-content may influence by feed solids-consistent of few days before the sampling day. The biofilter conditions were given as EBRT, posthumidification flow rate (QL), source of post-humidification water (SW) and bed temperature (BT). The last column of the Table A1 shows the comments on which the water heater usage (W.H.), and addition of limestone on the woodchip packing (lime) were indicated corresponding to the sampling events.

The pilot scale ATAD and biofilter processes were discussed in this dissertation based on the sampling events data given in Table A1. Each section of the discussion was mentioned that, which sampling data sets were used for the analysis. The sampling events data (raw data) was compiled and attached with this dissertation as Microsoft-EXCEL file on a CD-Rom (Appendix F). 


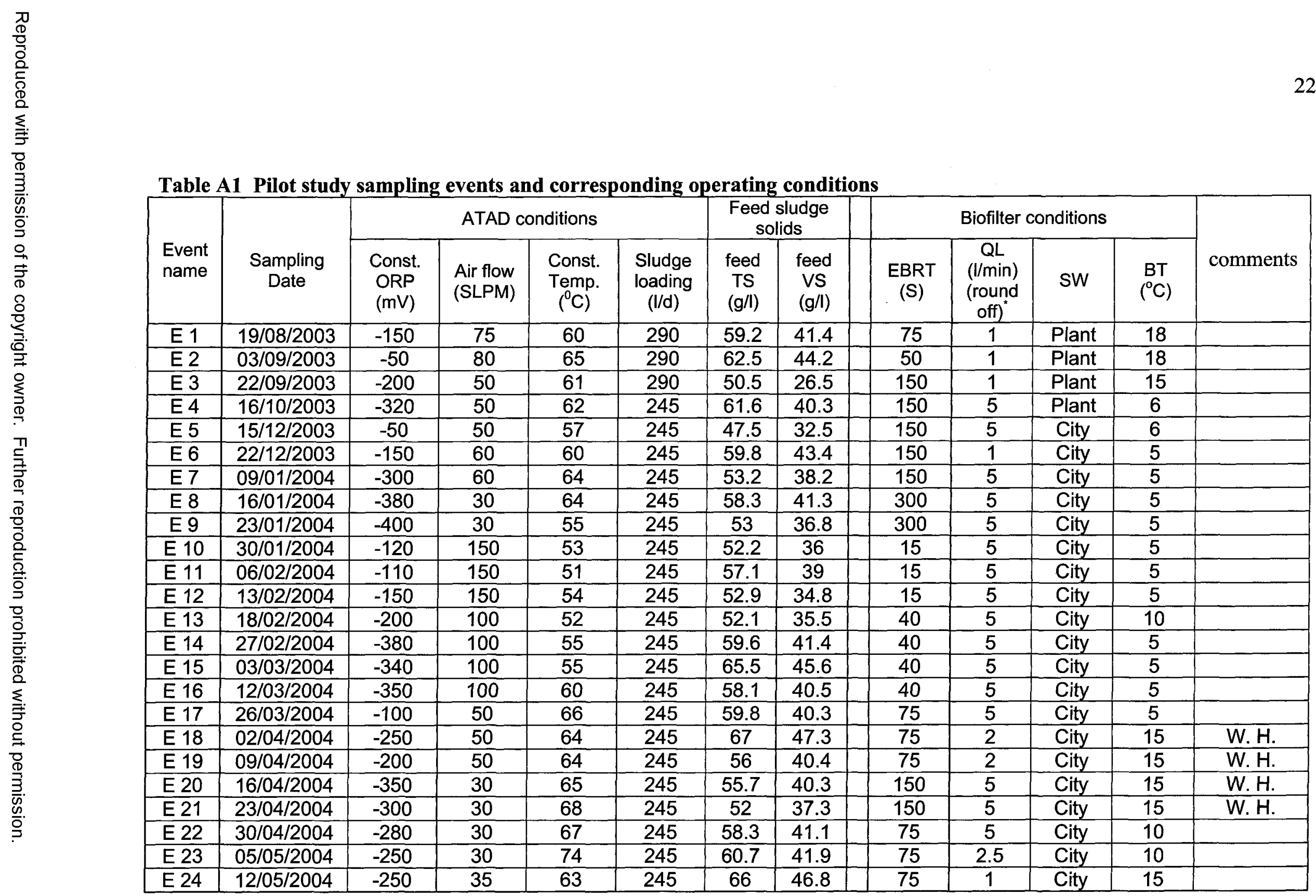


Table A1 Pilot study sampling events and corresponding operating conditions (continue)

\begin{tabular}{|c|c|c|c|c|c|c|c|c|c|c|c|c|}
\hline \multirow[b]{2}{*}{$\begin{array}{l}\text { Event } \\
\text { name }\end{array}$} & \multirow[b]{2}{*}{$\begin{array}{l}\text { Sampling } \\
\text { Date }\end{array}$} & \multicolumn{4}{|c|}{ ATAD conditions } & \multicolumn{2}{|c|}{$\begin{array}{c}\text { Feed sludge } \\
\text { solids }\end{array}$} & \multicolumn{4}{|c|}{ Biofilter conditions } & \multirow[b]{2}{*}{ comments } \\
\hline & & $\begin{array}{l}\text { Const. } \\
\text { ORP } \\
(\mathrm{mV})\end{array}$ & $\begin{array}{c}\text { Air } \\
\text { flow } \\
\text { (SLP } \\
\text { M) } \\
\end{array}$ & $\begin{array}{c}\text { Const. } \\
\text { Temp. } \\
\left({ }^{\circ} \mathrm{C}\right)\end{array}$ & $\begin{array}{l}\text { Sludge } \\
\text { loading } \\
\text { (1/d) }\end{array}$ & $\begin{array}{c}\text { feed } \\
\text { TS } \\
(\mathrm{g} / \mathrm{l})\end{array}$ & $\begin{array}{l}\text { feed } \\
\text { VS } \\
\text { (g/l) }\end{array}$ & $\begin{array}{l}\text { RT } \\
\text { (S) }\end{array}$ & $\begin{array}{c}\mathrm{QL} \\
\text { (l/min) } \\
\text { (round } \\
\text { off) }\end{array}$ & SW & $\begin{array}{c}\mathrm{BT} \\
\left({ }^{\circ} \mathrm{C}\right)\end{array}$ & \\
\hline E 25 & $19 / 05 / 2004$ & -200 & 35 & 63 & 245 & 63.6 & 43.8 & 300 & 1 & City & 15 & \\
\hline E 26 & $26 / 05 / 2004$ & -220 & 50 & 60 & 245 & 78.5 & 55.2 & 40 & 1 & City & 15 & \\
\hline E 27 & $02 / 06 / 2004$ & -250 & 50 & 62 & 245 & 88.3 & 60.1 & 40 & 1 & City & 20 & W.H. \\
\hline E 28 & $09 / 06 / 2004$ & -220 & 100 & 57 & 245 & 69.1 & 42.9 & 40 & 1 & Plant & 20 & W.H. \\
\hline E 29 & $16 / 06 / 2004$ & -320 & 100 & 56 & 245 & 64.8 & 43.5 & 40 & 1 & Plant & 20 & \\
\hline E 30 & $23 / 06 / 2004$ & -250 & 50 & 60 & 245 & 60.8 & 40.7 & 150 & 1 & Plant & 20 & \\
\hline E 31 & $29 / 06 / 2004$ & -300 & 50 & 59 & 245 & 55.5 & 38.4 & 150 & 1 & Plant & 20 & \\
\hline E 32 & $07 / 07 / 2004$ & -150 & 50 & 62 & 245 & 63.6 & 45 & 150 & 1 & Plant & 22 & \\
\hline E 33 & $14 / 07 / 2004$ & -150 & 50 & 65 & 245 & 71.1 & 51.1 & 150 & 1 & Plant & 22 & \\
\hline E 34 & $20 / 07 / 2004$ & -180 & 50 & 64 & 245 & 66 & 47.3 & 150 & 1 & Plant & 22 & \\
\hline E 35 & $29 / 07 / 2004$ & -200 & 50 & 58 & 245 & 63.4 & 45.4 & 150 & 1 & Plant & 22 & \\
\hline E 36 & $04 / 08 / 2004$ & -280 & 50 & 62 & 245 & 66.1 & 47 & 150 & 1 & Plant & 22 & \\
\hline E 37 & $11 / 08 / 2004$ & -250 & 50 & 60 & 245 & 77.2 & 54.4 & 150 & 1 & City & 28 & \\
\hline E 38 & $18 / 08 / 2004$ & -200 & 50 & 64 & 245 & 60.8 & 41.6 & 150 & 1 & City & 28 & \\
\hline E 39 & $25 / 08 / 2004$ & -220 & 50 & 54 & 150 & 64.3 & 44.2 & 300 & 1 & City & 26 & \\
\hline E 40 & $02 / 09 / 2004$ & -200 & 50 & 55 & 150 & 73.6 & 50.2 & 150 & 1 & City & 26 & \\
\hline E 41 & $09 / 09 / 2004$ & -250 & 50 & 56 & 150 & 67.1 & 46.1 & 150 & 1 & City & 26 & \\
\hline E 42 & $21 / 09 / 2004$ & -150 & 50 & 63 & 150 & 73.1 & 49.4 & 40 & 1 & City & 26 & \\
\hline E 43 & $30 / 09 / 2004$ & -240 & 90 & 60 & 245 & 65.4 & 46.6 & 40 & 1 & City & 26 & Lime \\
\hline E 44 & $05 / 10 / 2004$ & -250 & 80 & 62 & 245 & 62 & 44.1 & 150 & 1 & City & 26 & Lime \\
\hline E 45 & $12 / 10 / 2004$ & -150 & 80 & 58 & 245 & 48 & 33.5 & 150 & 2 & Plant & 22 & Lime \\
\hline E 46 & $09 / 11 / 2004$ & -120 & 60 & 60 & 245 & 56.6 & 37.8 & 150 & 1 & City & 18 & Lime \\
\hline E 47 & $11 / 11 / 2004$ & -120 & 60 & 60 & 245 & 62.8 & 42.6 & 150 & 2 & Plant & 18 & Lime \\
\hline E 48 & $16 / 11 / 2004$ & -180 & 60 & 62 & 245 & 72.2 & 51.3 & 150 & 2 & Plant & 18 & Lime \\
\hline
\end{tabular}




\section{Appendix B: \\ ATAD off gas characterization}

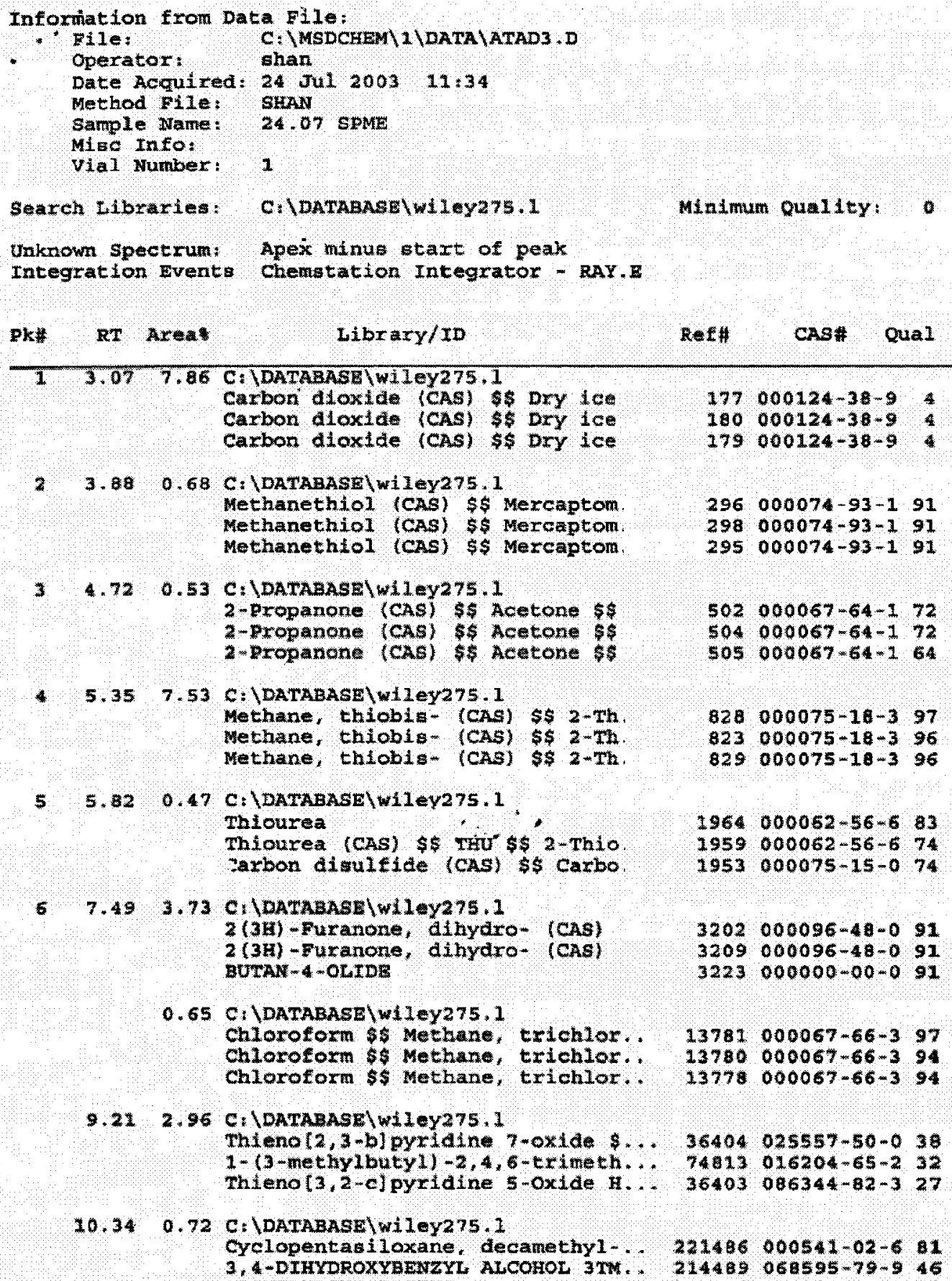


12

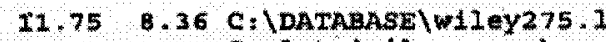

Cyclotrisiloxane, hexamethyl- $(., 0106869000541-05-990$

Cyclotrialloxane, hexamethyl- (.. 106644 000541-05-9 83 $\mathrm{N}$-thyl-1, 3-d1thioivoindoline $4, . \quad 92199 \quad 035373-06-972$

1311.9422 .40 C.DDATABASE $/ w i 1=y 275.1$

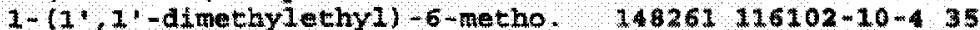
1H-Indole, 5-methyl-2-pheny 1- (. $\quad 92602$ 013228-36-927 14-Indole, 5-nethyl-2-pheny1-1. $92603 \quad 013229-36-927$

$1412,045.76$ C, IDATABASE IW1 1 eY 275,1

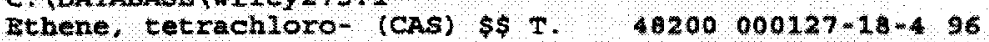
thene, tetrachloro- (CA5) \$\$ T. \&B08 000127-19-495 Ethene, tetrach10to- (CAS) $\$ \$ \mathrm{~T}$, 48206 000127-18-4 95

$15 \quad 12,19 \quad 5,24$ C.NDARABASE W 11 ey275,1

D-TETMETHYLSTLYLACETANILTDE \$\$ $92350017983-73-043$ $4,6,6-T x$ Lmethoxy 1 ndo $1 \mathrm{e}, \$ \$ 1 \mathrm{k}-\mathrm{In}$. 3. 3 D1ethoxy $1,1,1,5,5,5$-hexame

$92280030498-04-543$

$174413000000-00-0 \quad 40$

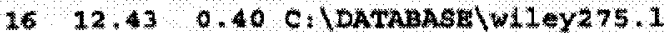

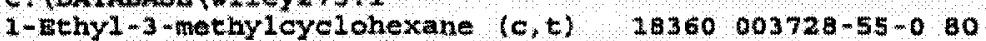
Cyclohexane, 1-ethyl-4-methyl-,., $18296006236-89080$

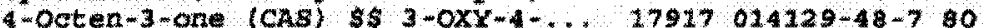

$17 \quad 12.49 \quad 0.75$ C: (DATABASE W 1 IeY 275.1 pyrrolo $[3,2-c]$ dibenzofuran 2 - -utenal, 2 -methyl-(CAs) $\$ \$ 2$ 2-Butenal, 2-methyl-, (E) - (CAS

$92572000000=00 \div 040$ $2709001115-11-27$ $2703000497-03-027$

$3645000127-19-591$ $3642000127-19-591$ $3644000127-19-591$

19

$13,740,59$ C: \DATARASE\W110y275,1

BENZENE, 1,4-BIS (TRIMETHYLSILYL) - 107558 000000-00-0 72 Cyclotrisiloxane, hexamethy1- $\{, \ldots, 106044000541-05-972$ Cyelotrialloxane, hexamathyl- $(* * 206448$ 000541-05-9 64

$20,14,300.45$ C.IDATARASE Jwiley275. 1 - Ipha.-PINWH ALPHA, - PINENE, $(-)-\$ \$$ BICYC10, .alpha.-pipene \$\$, alpha,-pinene

$25392000000-56-891$ $25206000060-56-0 \quad 91$ $25312000080-56-91$

21.14 .470 .77 C. VDATABASElwiley 275,1 Phenol (CAS) \$\$ Izal \$\$ ENT 181 Phenol (CAS) 5 S Izal \$\$ ENT 181 Phenol (CAS) $\$ \$$ Izal $\$$ SNT 181

$22 \quad 14,60 \quad 1.71$ C IDATAEASE W1 LOY275.1 Telsultide, dimethyl (CAs) $\$ \$ 2$ Trisulfide, dimethyl (CAS) \$\$ 2 Trisulelde, dinethy (CAs) \$ 2 .

$4022000108-95-293$ $4821000108-95-2.93$ $4024000108-95-2,90$

$17326003658-80-89$ $17320003658-60-895$ $17323003650 \times 0-7$.

$2314.92 \quad 0,53$ C. (DATABASE wil 1 - 275,1 Cyelopropane, 1 -ethyl-2-hepty1 _,.,53865 076663-86-8 47 5-Dodecene, (z)-(CAs) 1, 1,2,3-tetrame thylcyclohexane, *, 28404,071186-28-2,43

2415,09 5.65 C. VDATARAE W 11 ey275.1

Cyclotetxalloxane, octamethyl , , . 174362 000556-67-2 92 Cyelotetrasiloxane, ootamethyl-, , 174364 000556-67-2 6 cyclotetras loxane, octamethyl-..17363 000556-67-2 83

$2515,34 \quad 0,40$ 0 IDATAaAse w 1 1ey275,1

1-heptadeenol (CAs) $\$ \$$ n-Hepta., 1\$1160 001454-85-9 47 (s) $-3-13,5-$ Dimethyl tet rahydrofu. $\quad 55411004184-43-0.77$ $(\mathrm{s})-3-13,5-\mathrm{Dl}$ methyltetrahydrofu, $\quad 55440,084184-43-047$

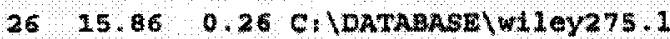

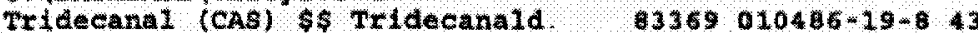


Pentane, 3 -methy $1-$ (Cas) $\$ \$ 3-M$. $3575000096-14-0 \quad 43$

Hexane, $2,2,5,5$-tetramethyl- (C. . $30096001071-61-4 \quad 43$

$27 \quad 15.98 \quad 0.56 \mathrm{C}:$ DATABAsE $\backslash w 11 \mathrm{ey} 275.1$

Decane, 2,2,6-tximethyl- (CAs)

Heptane, $2,2,4,6,6$-pentame thy 1 . .

$69510 \quad 062237-97-272$

Heptane, 4 -ethy $1-2,2,6,6$-tetram.

$55988 \quad 013475-82-6 \quad 64$

$69547062108-31-064$

Thu JuI $2411,54.542003$ 
Area Percent Report

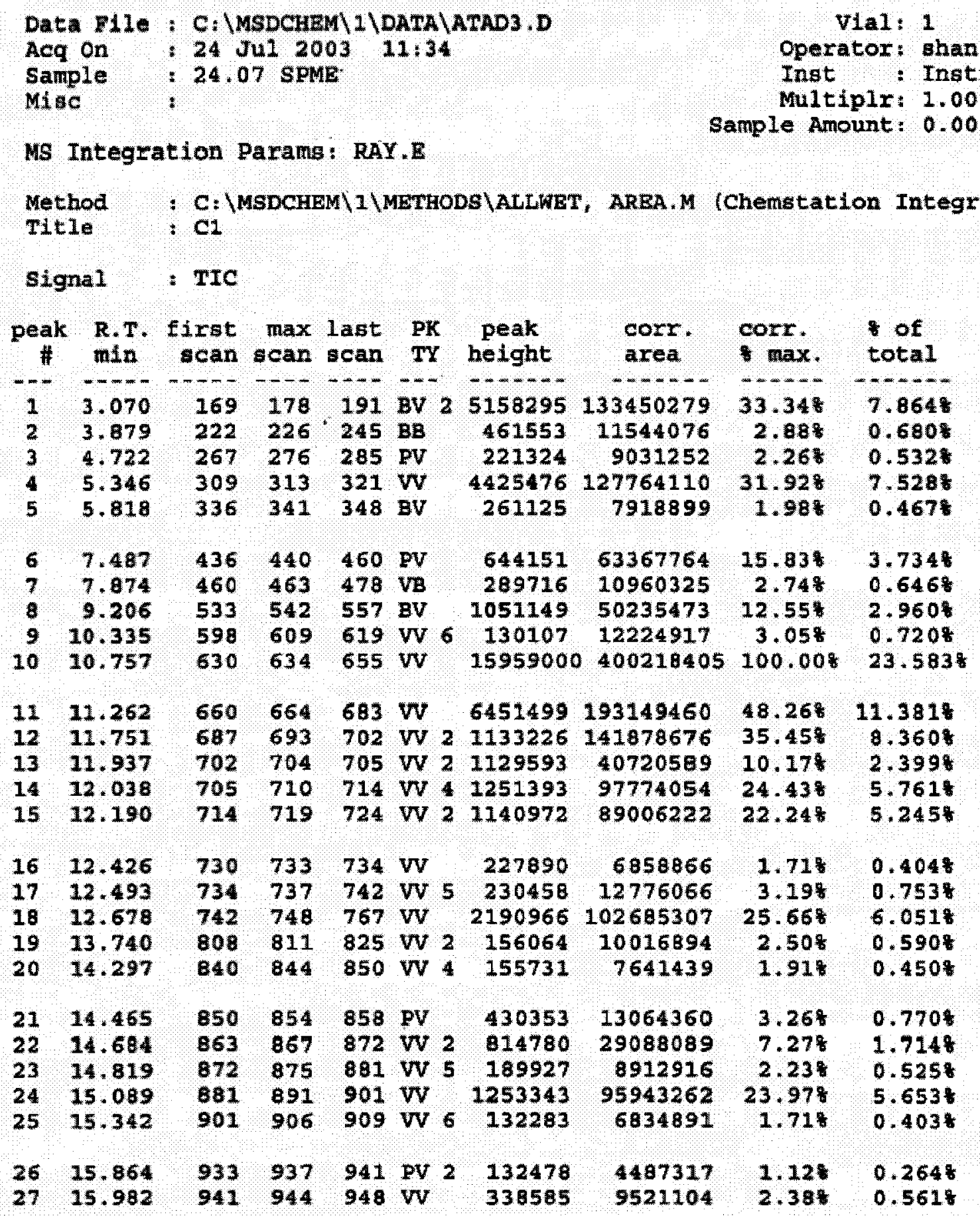

Sum of corrected areas: 1697075013 


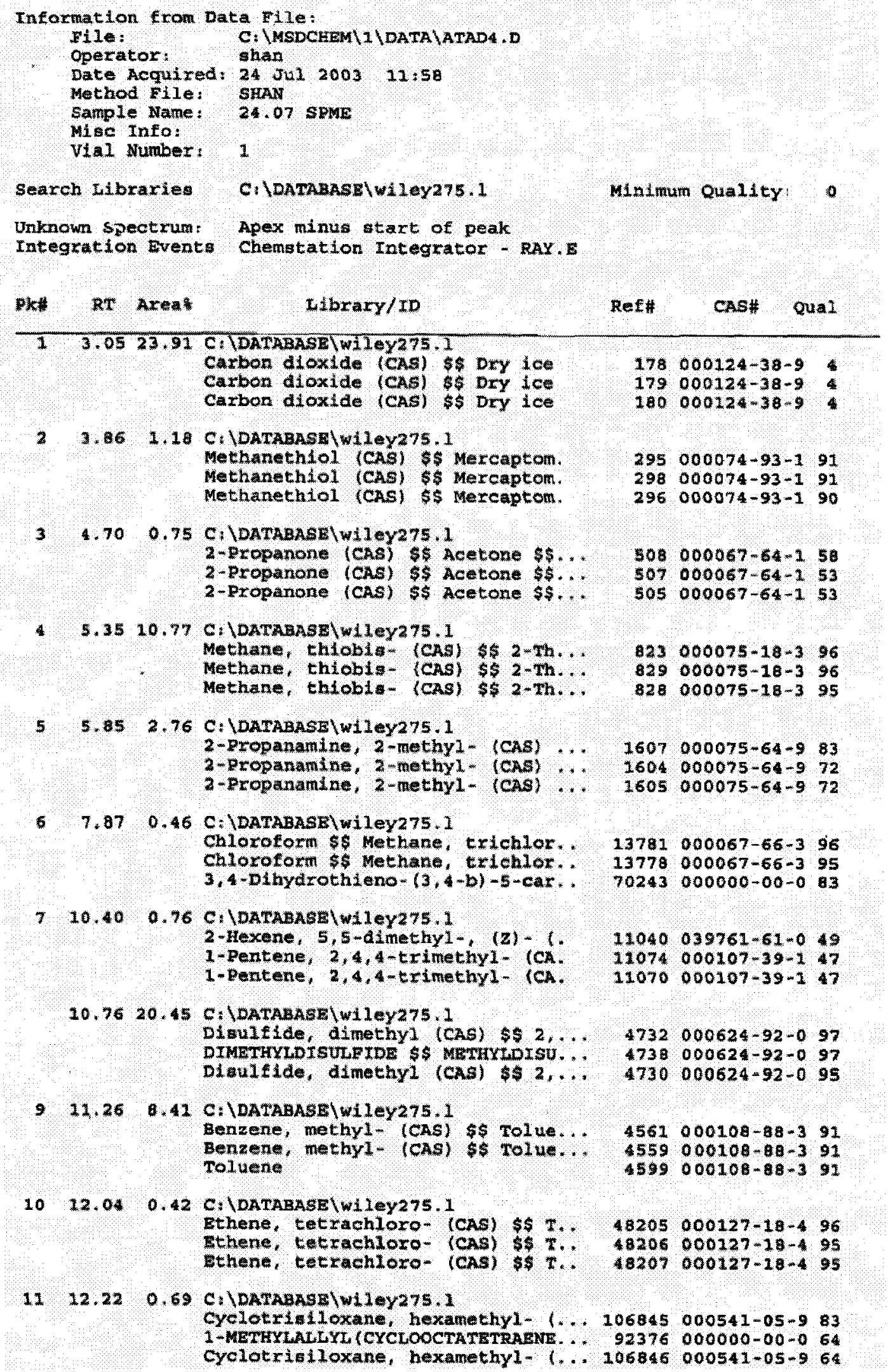


1-Ethy 1-3-methylcyelohexane (c,t) 18360 003728-55-0 80 cyclohexane, 1-ethyl-4-methy1-,.. 18294 006236-88-0 72 4-octen-3-one (CAS) \$\$ 3-OXY-4-... 17917 014129-48-7 72

$13 \quad 12.49 \quad 0.63$ C. IDATARAsE \wiley 275.1

2-Butenal, 2 -methyl- (CAs) $\$ \$ 2, . \quad 2710 \quad 001115-11-347$ cyclobutaneethanol, beta, meth. . 10915 000000-00-0 30 cuanidine, cyano- (CAs) \$\$ Cyan.. 2593 000461-58-5 32

$14.12,68 \quad 3,10$ C: IDATABASElwi1 1 ey 275,1

Acetamide, N,N-dimethyl- (CAs) $\quad 3644$ 000127-19-5 91 Acetamide, N, N-dimethyl- (CAs) 3645 000127-19-5 91 Acetamide, N, N-dimethy1- (CAS) 3643 000127-19-590

$1512,8017.58$ C: (DATABAsE, wiley275.1

Cyclopentasiloxane, decamethyl-.. 221485 000541-02-6 91 Cyclopentasiloxane, decantethy 1-... 221486 000541-02-6 90 3,4-Dihydroxymandelic acid, eth. . 244232 000000-00-0 46

$1613.81 \quad 0.28$ C: DATABASE \w1 1eY275.1

2-pentene, 3-thyl-4,4-dinethyl $18241 \quad 053907-59-849$ Cyclohexane, $1,1,3,5$-tetramethy. $28396 \quad 050876-32-943$ 4-Honene, $2,3,3-\operatorname{trimethy} 1-(z), \quad 53849063830-68-235$

$1714.30 \quad 0.56$ C: IDATABASElwi ley275.1 ALPHA.-PTNENE, (-) - \$\$ Bicyclo... $25205000080-56-894$ Cyclofenchene \$\$ Tricyclo[2.2.1... 25282 000488-97-1 93 cyclohexene, 1-methyl-4-11-meth... 25051 005989-27-5 91

$18 \quad 14.47 \quad 0.51$ C.|DATABAsE $($ W1 1 ey 275.1 Phenol (CAS) \$\$ Izal \$ ENT 181,. 4817 000108-95-2 91 Phenol (CAs) \$\$ rzal \$\$ ENr 161... 4815 000108-95-2 90 Pheno1 (CAS) \$\$ Iza1 \$\$ ENT 181.. 4818 000108-95-2 90

14.701 .31 C: DDATABAsE WIIeY275.1

Trisulfide, dimethyl (CAs) \$\$ 2., 17326 003658-80-8 94 Trisulfide, dimethyl (CAs) $\$ \$ 2, \ldots$ 17320 $003658-80-8 \quad 91$ 161sulfide, dimethyl (CAs) \$\$2,., 17324 003658-80-8 67

$20 \quad 14.80 \quad 0.42$ C: $\mid$ DATABAsE $\backslash$ w1 1 ey275 . 1

$1,1,2,3$-tetramethylcyclohexane **, 28405 $071186-26-2 \quad 53$ 2-octene, 2,6-dimethyl- (CAs) \$..28309 004057-42-5 52 2-octene, 2,6-almethyl- (CAS) \$ .. 28311 004057-42-5 52

$21 \quad 15.11 \quad 3.39$ C: IDATARASE $\backslash$ WILY 275.1

Cyclotetrasiloxane, octamethyl-. \$174362 000556-67-2 91 Cyclotetrasiloxane, octamethyl-, 174364 000556-67-2 86 cyclotetrasiloxane, octamethyl-. 174363 000556-67-2 83

$2215.34 \quad 0.30$ C IDATAEASE 1 w1 1 e 275.1

(z) $-2,2,3,5,5$-pentamethy $1-3$-hexene $40933 \quad 120362-91-647$ silane, [(10-bromodecy 1$)$ oxy]tri... 183031 026306-02-5 47 Gyclopropane, $1,1,2$-trimethy $1-2 \ldots$. 23339 000000-00-0 43

$2315.86 \quad 0.25$ C \DATABASElwiley275.1 Pentane, 3-methyl- (CAs) \$\$ 3-M... 3575 000096-14-0 43 Heptane, 2,2,4,6,6-pentamethy1-... 55988 013475-82-6 38 Urea, N,N'-a1-2-propeny1- (CAS) ... 27575 001801-72-5 35

$2415.98 \quad 0.51$ C: (DATABASElWI ley 275.1 Decane, 2,2,7-trimethyl- (CAs) $69519 \quad 062237-99-4 \quad 72$ octane, 2,2,6-tximethyl- (CAs) $42795 \quad 062016-28-8 \quad 72$ Decane, 2,2,6-trimethy1- (CAs) 69518 062237-97-2 64

Thu Ju1 24 12:42:08 2003 
Area Percent Report

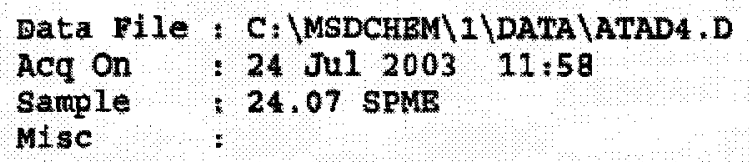


Appendix C:

\section{Gas phase RSC calibration data}

(a) $\mathrm{H}_{2} \mathrm{~S}$

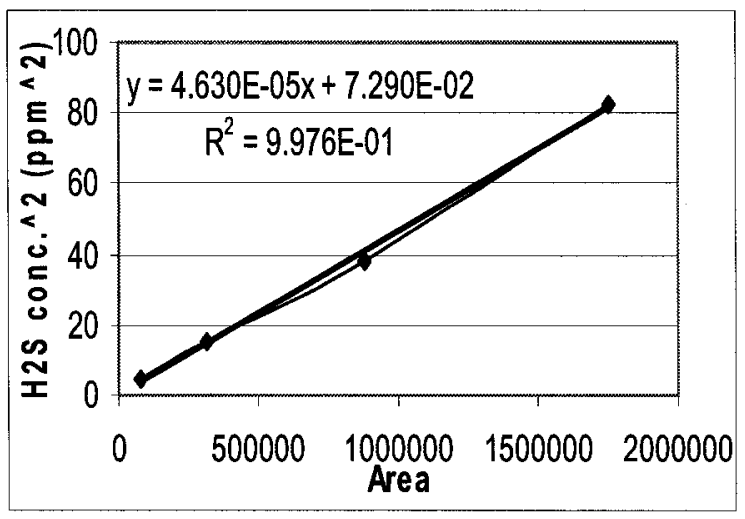

(c) DMS

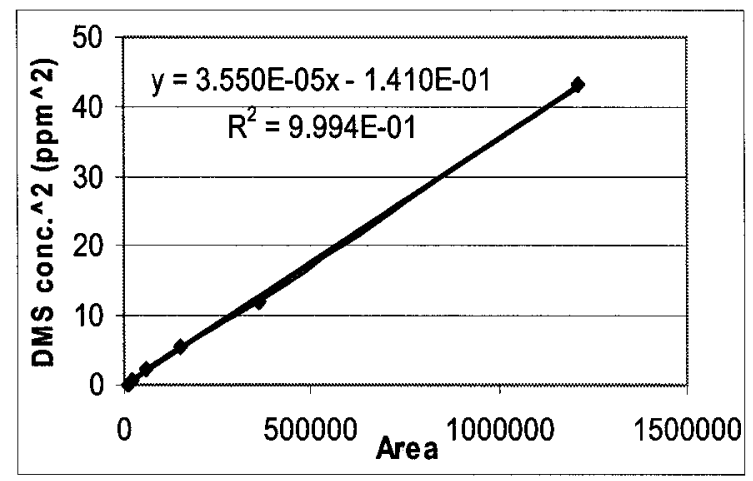

(e) DMDS

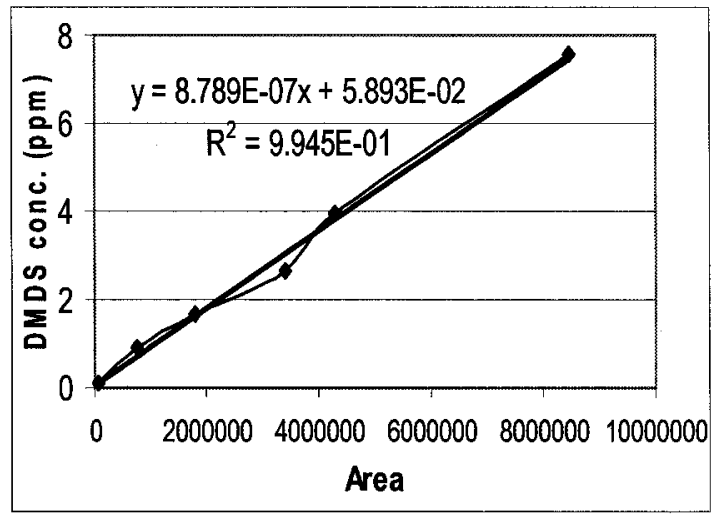

(b) MM

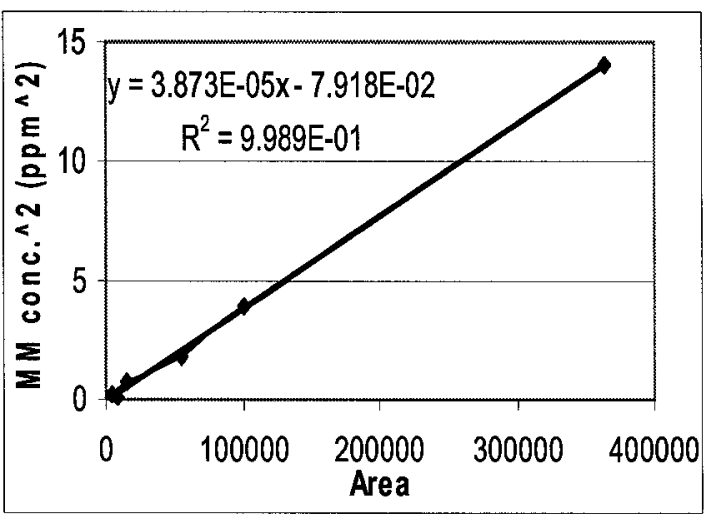

(d) $\mathrm{CS}_{2}$

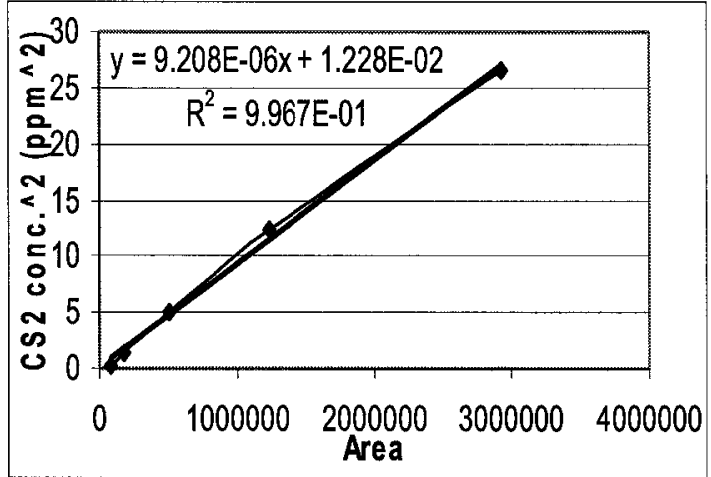

(f) DMTS

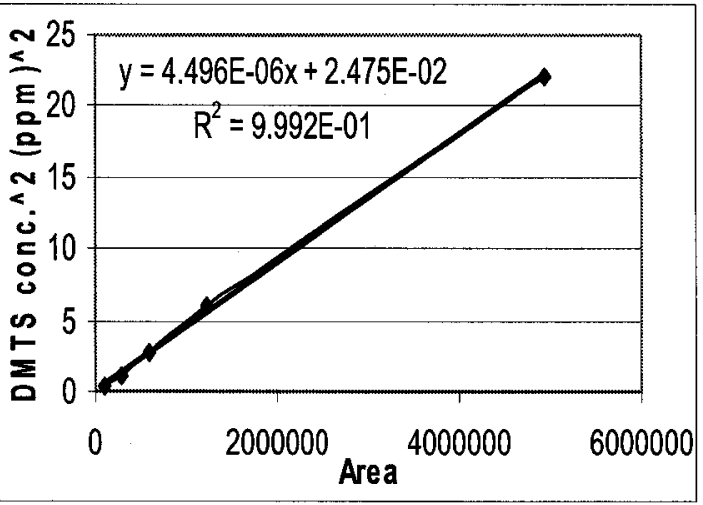




\section{Appendix D:}

\section{Aqueous sample calibration data}

(a) $\mathrm{NH}_{4}{ }^{+}(\mathrm{aq})$

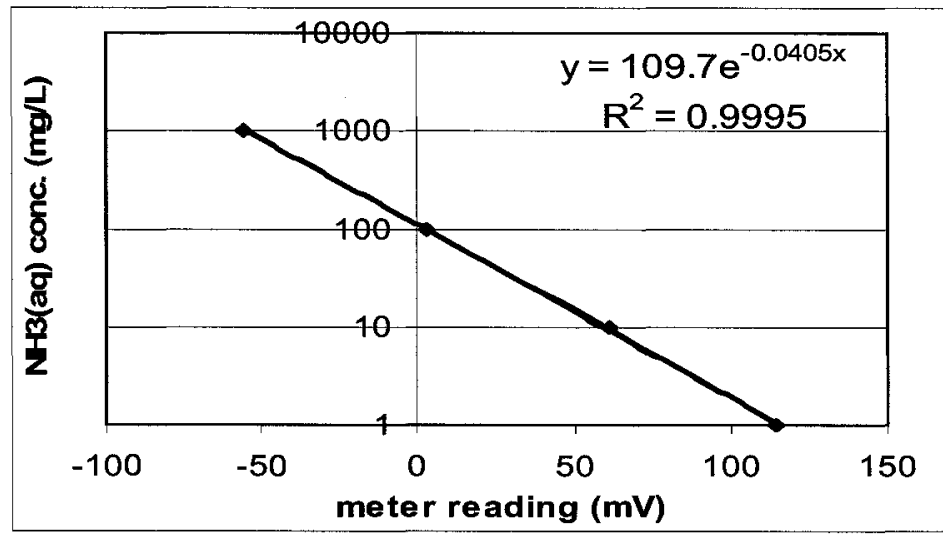

(b) Nitrite- $\mathrm{N}\left(\mathrm{NO}_{2}{ }^{-} \mathrm{N}\right)$

(c) Nitrate- $\mathrm{N}\left(\mathrm{NO}_{3}-\mathrm{N}\right)$
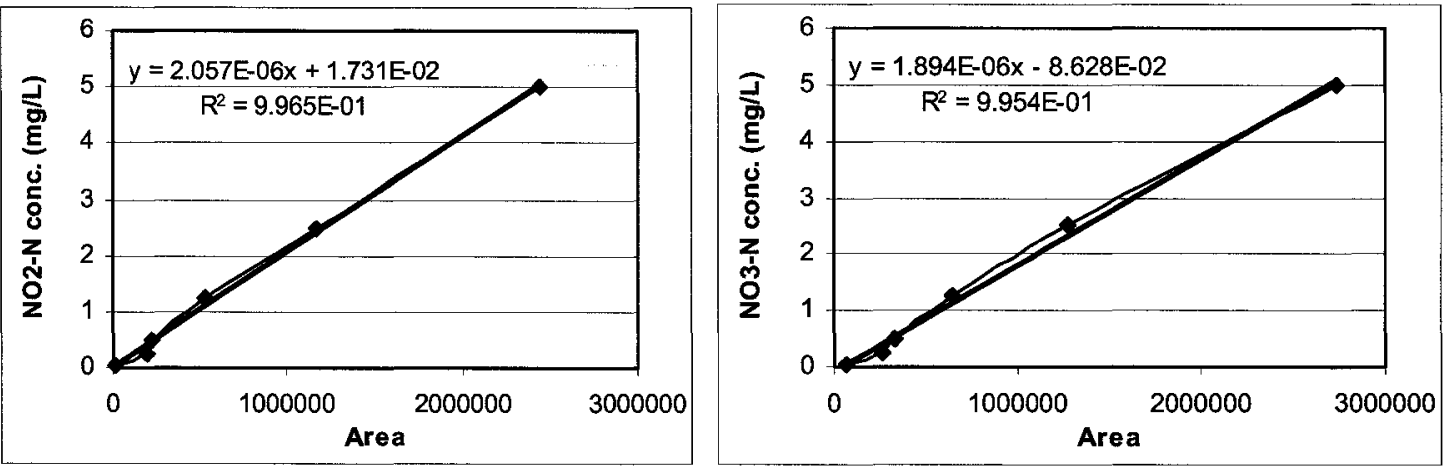

(d) Sulfate $\left(\mathrm{SO}_{4}^{-}\right)$

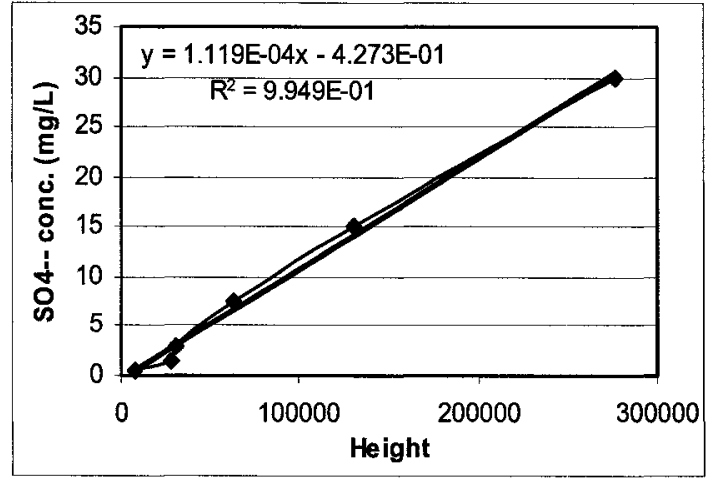




\section{Appendix E: Estimation of reactor dimensions in the model development}

The model reactor dimensions were determined based on the pilot scale biofilter media analysis (the bed porosity and woodchip moisture content) and assumption made based on the literature values (specific surface area of the woodchip media and biofilm thickness). As discussed in section 6.2, the biofilter height was divided into eight layers. The final volume and area calculations were based on the compartments of each layer.

$\begin{array}{ll}\text { The bed porosity from media analysis } & =0.6\end{array}$

Average moisture content of the woodchips from media analysis $(\mathrm{m} / \mathrm{m}) \quad=34 \%$

Total volume of the biofilter $(0.6 \mathrm{~m} \mathrm{x} 0.3 \mathrm{~m} \mathrm{x} 0.75 \mathrm{~m}) \quad=0.135 \mathrm{~m}^{3}$

Therefore total volume of air within the reactor $\left(0.6 * 0.135 \mathrm{~m}^{3}\right) \quad=0.08 \mathrm{~m}^{3}$

Gas phase mixed reactor volume for a single layer $\left(\mathrm{m}^{3} /\right.$ layer $) \quad=0.01$

The woodchip density from the literature $=1156 \mathrm{~kg} / \mathrm{m}^{3}$

Total volume of packing in the reactor $\left(0.135 \mathrm{~m}^{3}-0.08 \mathrm{~m}^{3}\right) \quad=0.055 \mathrm{~m}^{3}$ Specific surface area of the woodchip packing $\quad=200 \mathrm{~m}^{2} / \mathrm{m}^{3}$ (Assumed based on Phillips et al., 1995; Shareefdeen et al., 1994; Deshusses et al., 1995) Therefore, total surface area of the packing $\left(200 * 0.055 \mathrm{~m}^{2}\right) \quad=11 \mathrm{~m}^{2}$ Biofilm surface area for a single layer $\left(\mathrm{m}^{2} /\right.$ compartment $) \quad=1.375$

Average biofilm thickness $=100 \mu \mathrm{m}$ (Assumed based on Deshusses et al., 1995; Baquerizo et al., 2004) 
Based on total surface area of the packing and the biofilm thickness, the bulk volume of biofilm was determined.

Total bulk fluid volume of the biofilm $=11 * 100 * 10^{-6} \mathrm{~m}^{3}$ $=0.0011 \mathrm{~m}^{3}$

Biofilm bulk volume for a single layer $\left(\mathrm{m}^{3} /\right.$ compartment) $=0.0001375$

(c)

The values (a), (b) and (c) were incorporated into the model development. 